\title{
SEEING AND ENVISIONING: CAMERA-BASED PRACTICE, DEMOCRATIC PRAXIS, AND SOCIALLY ENGAGED ARTS IN TORONTO
}

\author{
by \\ Kris Erickson \\ Bachelor of Fine Arts, Ryerson University, Toronto, Ontario, Canada, 2003 \\ Master of Arts, Ryerson University and York University, Toronto, Ontario, Canada, 2006
}

A dissertation presented to

Ryerson University and York University

in partial fulfillment of the

requirements for the degree of

Doctor of Philosophy

in the Joint Program in

Communication and Culture

Toronto, Ontario, Canada, 2015

(C) Kris Erickson 2015 


\section{AUTHOR'S DECLARATION}

I hereby declare that I am the sole author of this dissertation. This is a true copy of the dissertation, including any required final revisions, as accepted by my examiners.

I authorize Ryerson University to lend this dissertation to other institutions or individuals for the purpose of scholarly research.

I further authorize Ryerson University to reproduce this dissertation by photocopying or by other means, in total or in part, at the request of other institutions or individuals for the purpose of scholarly research.

I understand that my dissertation may be made electronically available to the public. 
Seeing and Envisioning: Camera-Based Practice, Democratic Praxis, and Socially Engaged Arts in Toronto

Kris Erickson

Doctor of Philosophy in Communication and Culture, 2015

Ryerson University and York University

\begin{abstract}
This project explores the varied ways cameras have become integrated into contemporary socially engaged arts practices. The emergent, participatory, and inclusive characteristics of these diverse practices are increasingly common in contemporary art and culture, with cooperative processes, community activism, formal experimentation, and public involvement being regarded, now more than ever, as legitimate strategies for developing artistic form and content. This project considers the innovative uses of cameras in these practices, arguing that such uses are not simply convenient or instrumental, but are often critical mediations between visual realism and cultural expressivity. The dissertation begins to address a gap in research on material practices in the cultural production of art by elaborating a theory of socially engaged camera arts. Drawn from ethnographic research in the Toronto community arts/socially engaged arts ecology, this theory begins to describe how camera practices seem to be moving beyond traditional image production practices in order to support and even help envision broader repertoires of practice in processes of social and cultural action. The dissertation develops three interrelated theoretical frames - expansion, organization, and pedagogy - to insist on the key place of socially engaged camera arts, and camera arts in general, in the iterative, activist-led revitalization of community cultural infrastructures.
\end{abstract}




\section{ACKNOWLEDGEMENTS}

I would first like to acknowledge the people on whose land this dissertation was wholly conceived, researched, and written: the Mississaugas, currently of the New Credit First Nation; but also the Haudenosaunee before them, the Huron-Wendat before them, and the many other peoples and cultures whose names we have lost, but whose lives nevertheless also shaped the Toronto we now know and call home.

I am incredibly appreciative to the people who allowed me the space and time to interview and observe them, both the practitioners I write about here, but also the others I worked alongside, as well as the many participants who welcomed me into their communities and amplified, extended, and challenged the image of the community that practitioners sought to help me recognize.

I am grateful for the generous guidance of my dissertation committee: Deborah Barndt, Blake Fitzpatrick, and my chair, Alan Sears, all of whom I count as friends, colleagues, and mentors.

I am indebted to my cohort, fellow students and now graduates, who supported and challenged my thinking in classes and over countless cups of coffee. I am particularly grateful to Marta Berbes, Andrew Bieler, Paul Couillard, Matt Feagan, Chrisa Hoicka, Sara Martel, and Michael Thorn for the time and interest they brought to my writing in various stages of development.

Finally, I would like to thank Dr. Kristen Jewell, as well as the cancer specialists at Princess Margaret and Mount Sinai Hospitals and the Zane Cohen Centre: Dr. Carol Swallow, Dr. Eric Chen, Dr. Bernard Cummings, and the many nurses, technicians, residents, volunteers, and others for helping myself and my family pull through a very sudden and strange illness. 


\section{DEDICATION}

I dedicate this work to my children, Midori and Hollis, to my wife, Hien, and to the many families I have been honoured to be part of: both those I have known, and those I will never meet, scattered across the globe. 


\section{TABLE OF CONTENTS}

AUTHOR'S DECLARATION ii

ABSTRACT

ACKNOWLEDGEMENTS iv

DEDICATION

TABLE OF CONTENTS vi

LIST OF PLATES

$\begin{array}{ll}\text { 1. INTRODUCTION } & 1\end{array}$

$\begin{array}{ll}\text { 1.1. Framing Concepts } & 3\end{array}$

Socially Engaged Arts: Terms and Working Definitions $\quad 6$

Towards Socially Engaged Camera Arts 16

1.2. The Research: Strategies, Methods, Methodologies $\quad 18$

Research Questions $\quad 19$

Mixed Methods: A Naturalistic Approach 20

Ethnographies: Critical, Public, and Feminist 22

Into the Field: Personal Beliefs and Experiences $\quad 26$

About the Sites $\quad 32$

Challenges and Contradictions 39

1.3. Outline of the Thesis $\quad 44$

2. THEORETICAL GROUNDING: SOCIALLY ENGAGED ARTS 47

$\begin{array}{ll}\text { 2.1. Early Roots: To the 1920s } & 47\end{array}$

$\begin{array}{ll}\text { The Late 19th Century } & 47\end{array}$

2.2. Worker Film and Photography

The Interwar Years to the Cold War Consensus

2.3. Arts and Social Welfare: The Emergence of "Community Arts" 61

2.4. To the Present: Cameras and Democratic Arts $\quad 64$

3. FINDINGS, I: STRATEGIES OF EXPANSION

3.1. Expanding Engagement: "Who else might participate in art?"

$\begin{array}{ll}\text { Engagement as Inclusion } & 73\end{array}$

Community Leaders: Engaging Responsibility $\quad 84$

Engagement and Re-engagement: Revitalizing Life Practices 87

Engaging the Everyday: Politics Meets Aesthetics $\quad 89$ 
3.2. Expanding Form: "How else might art be done?" 92

Legitimate Practice $\quad 92$

Process and Relationship $\quad 96$

Democracy and Participation $\quad 102$

Technique and Form in Socially Engaged Arts 103

Method and Form in Socially Engaged Arts 106

Form and Engagement 109

3.3. Expanding Territory: "Where else might art be done?" 112

Space and Socially Engaged Arts 112

$\begin{array}{ll}\text { A Fluid Art } & 117\end{array}$

4. FINDINGS, II: CAMERAS AND STRATEGIES OF EXPANSION 121

$\begin{array}{ll}\text { 4.1. Expanding the Vernacular } & 122\end{array}$

Vernacular's connotations $\quad 123$

Shared Vernaculars? 134

$\begin{array}{ll}\text { Vernacular's Techniques } & 135\end{array}$

Limitations of the Vernacular 137

4.2. Expanding What's Visible 139

Making Visible 140

Techniques of Making Visible: Images and Beyond 143

Infrastructures of Making Visible 149

4.3. Expanding the Performative $\quad 151$

Contradictions of Visuality and Performativity 155

A Propositional Art 162

4.4. Across and Beyond Genres 165

5. SYNTHESIS, I: ORGANIZING EXPANSION 169

5.1. Structure and Labour in Socially Engaged Arts 169

5.2. Within: Intraorganizational Relations 173

Too Much Autonomy? 178

$\begin{array}{ll}\text { Volunteerism } & 181\end{array}$

Between Ideals and Practices 183

5.3. Beyond: Extraorganizational Relations 189

Arts Councils' Support 193

$\begin{array}{ll}\text { Outcomes-based Funding } & 195\end{array}$ 
5.4. Between and Amongst: Interorganizational Relations 197

Arts Amongst Community Organizations 205

$\begin{array}{ll}\text { Spaces of Experimentation } & 206\end{array}$

6. SYNTHESIS, II: IMAGINATIVE SOCIALLY ENGAGED PEDAGOGIES 211

$\begin{array}{lr}\text { 6.1. Contention and Alternative } & 212\end{array}$

$\begin{array}{ll}\text { Contention } & 213\end{array}$

$\begin{array}{ll}\text { Alternative } & 216\end{array}$

Exchange and Gift Economies $\quad 217$

$\begin{array}{ll}\text { Subjectus and Subjectum } & 218\end{array}$

Towards an Imaginative Socially Engaged Pedagogy 219

6.2. Exploring Where Aesthetics Meets Popular Education 222

$\begin{array}{ll}\text { 6.3. The Workshop } & 223\end{array}$

Workshops at MABELLEarts $\quad 228$

$\begin{array}{ll}\text { 6.4. The Project } & 234\end{array}$

Digital Story as Project Work 238

$\begin{array}{ll}\text { 6.5. The Laboratory } & 248\end{array}$

CONCLUSIONS: TOWARDS IMAGINATIVE SOCIALLY ENGAGED PEDAGOGIES 261

Cameras and Socially Engaged Art 264

$\begin{array}{ll}\text { Organizational Challenges } & 267\end{array}$

$\begin{array}{ll}\text { Strategies of Expansion } & 270\end{array}$

Moving Forward: Questions and Further Research 273

$\begin{array}{ll}\text { APPENDIX: PROFILES } & 277\end{array}$

$\begin{array}{ll}\text { Artist-Practitioner Profiles } & 277\end{array}$

$\begin{array}{ll}\text { Organizational Site Profiles } & 280\end{array}$

$\begin{array}{ll}\text { REFERENCES } & 283\end{array}$ 


\section{LIST OF PLATES}

Plate 1 Riis, Jacob. 1890. Children sleeping in Mulberry Street. Published in:

How the other half lives: studies among the tenements of New York.

New York: Charles Scribner's Sons.

https://commons.wikimedia.org/wiki/File:Riischildren.jpg

Plate 2 Atget, Eugene. 1925. Men's Fashions / Magasin, Avenue Des Gobelins.

Rochester: George Eastman House.

http://www.geh.org/fm/ATGET/HTMLSRC/m197601090003_ful.html.

Plate 3 Weston, Edward. 1925. Excusado. Rochester: George Eastman House. http://www.geh.org/taschen/htmlsrc8/m197400610064_ful.html.

Plate 4 Curtis, Edward S. 1905. An Acoma Woman. Published in: The North

American Indian. [Seattle] : Edward S. Curtis, 1907-30, Suppl. v. 16, pl. 572.

https://commons.wikimedia.org/wiki/File:Acoma_woman_by_Edward_ S._Curtis,_1905.jpg.

Plate 5 Photographer(s) unknown. 2015. Panorama of the Sketch studio space during a workshop on Art and Public Health. https://instagram.com/p/yZ1I4wF9iM/?taken-by=sketchtoronto

Plates 6-8 Stricke, Mindy, et al. 2010. You Are Not Where You Were. http://www.mindystricke.com/\#/youarenotwhereyouwere/

Plate 9 Stricke, Mindy, and Nina Laubach. 2011. Screenshot from At the Table: Mothers Sharing Stories Through Art. Directed by Brijetta Hall Waller. Madison: Metta Productions.

https://www.youtube.com/watch?v=YW6ey1gSa8Q

Plates 10-11 Stricke, Mindy, et al. 2010. Good Eater. Eagle Heights Community

Gardens, Madison. http://www.mindystricke.com/\#/goodeater/

Plates 12-13 2014. Screen shot of the Sketch Toronto Instagram account.

https://instagram.com/p/q4HbYOF9rP/?taken-by=sketchtoronto

Plate 14 Lamin and journeystohealth. 2013. Still from Lamin/Last King. Toronto: Four Villages Community Health Centre.

https://www.youtube.com/watch?v=eKPiN0Pj2XE

Plates 15-17 Photographer(s) unknown; rephotographed by the author. 2011. From the Inside Out Project. Regent Park, Toronto. http://mnfsto.com/projects/inside-out-project/ 
Plate 18 Photographer unknown. 2014. Mabelle Park Bread Oven. Etobicoke:

MABELLEarts. http://mabellearts.ca/projects/

Plate 19 Photographer unknown. 2011. From A Light in Midwinter. Etobicoke:

MABELLEarts.

https://www.flickr.com/photos/mabellearts/5442052533/

Plate 20 Photographer unknown. 2011. Regent Park, Toronto.

Plates 21-24 Kayondra and journeystohealth. 2013. Stills from Kayondra/A Moment in Life. Toronto: Four Villages Community Health Centre. https://www.youtube.com/watch?v=m3eyTZ-g0hM

Plates 25-26 Kayondra and journeystohealth. 2013. Stills from Kayondra/A Moment in Life. Toronto: Four Villages Community Health Centre.

https://www.youtube.com/watch?v=m3eyTZ-g0hM

Plate 27 Photographer unknown. 2011. From Portraits of Silence. Parkdale, Toronto: Making Room. http://making-room.org/2011/08/25/healthand-wholeness-in-parkdale/

Plate 28 Photographer unknown; rephotographed by the author. 2012. From Portraits of Silence. Parkdale, Toronto: Making Room.

Plate 29 Photographer unknown; rephotographed by the author. 2012. From Portraits of Silence. Parkdale, Toronto: Making Room.

Plate $30 \quad$ Photographer(s) unknown. 2011. From Sparks that Fly. Parkdale, Toronto: Making Room. http://making-room.org/our-history/

Plate $31 \quad$ Fleitas, Katherine. 2012. The Ocean, from A Light in Midwinter. Etobicoke: MABELLEarts. https://www.flickr.com/photos/mabellearts/6976346039/

Plate 32 Houston, Leah. 2010. Sasha and Metha. Etobicoke: MABELLEarts. https://www.flickr.com/photos/mabellearts/8748607691/

Plates 33-40 Quennisha and Omar. 2012. Untitled stop-motion animation. Etobicoke: 233 MABELLEarts. 


\section{INTRODUCTION}

This dissertation is an exploration of the role cameras play in socially engaged arts practices in the Toronto area. As with other technologies, cameras are both a tool with which people can exert some control and agency over the conditions of their lives and, at the same time, a means by which dominant social forces may attempt to objectify, colonize, and exploit the intrinsic value of their being. Like other visual media, cameras variously enable and stymie complex understandings of the visible world. Moreover, their inherent quality of pairing realism and artifice - of representing visible appearances "as they are" while simultaneously highlighting the agency inherent in the processes whereby only some appearances get selectively represented - allow people using cameras to participate in such knowledge production in a variety of ways. Treated simplistically, people use cameras as image-making tools that help to convey the apparent reality of a found or fabricated scene. However, when considered more fully, or perhaps more artfully, people use cameras to enact strategies for envisioning - that is, for seeing the depth and complexity of the perceivable world, as well as through and beyond it - in order to render distinct perceptions (including, but not merely, visual ones) and unique experiences in a variety of representational and expressive forms. It may be an oversimplification to boil this down to a distinction between taking pictures and making images; yet, to an important degree, dominant social forces seem to pressure the average person away from the latter and toward the former course of action. Asserting a parallel between sociocultural and political action - between how we choose to represent ourselves aesthetically, and how we demand to be represented politically - seems useful, if not imperative, for the health and vibrancy of our cultural identity.

Socially engaged arts, through its variety of artistic, activist, and pedagogical strategies, also aims squarely at this twin goal of an aestheticized politics and a politicized art. For those 
practitioners who bring cameras into their socially engaged activities, these goals are no different. Yet despite a strong mandate to create art in aesthetically and politically innovative ways, the general pressures of habit and convention persist. The fundamental design of contemporary cameras and the digital systems we use to store and distribute digital images invariably impacts upon the work of socially engaged arts practitioners and organizations (namely, that cohort of people working at or near the intersection of art, social justice, and community development). How do such practitioners and organizations variously adopt and resist conventionality in camera arts practices - and in socially engaged practices more generally? What parallels and overlaps exist amongst these forms and modes? What challenges do practitioners and organizations remain faced with in either case?

The sheer diversity and novelty of sophisticated camera practices in socially engaged arts is quite remarkable: in Toronto alone one can readily glimpse the empowerment aims of photovoice, the experiential strategies of digital storytelling, the richness of the documentary genre, and the new formal possibilities that digital storage, distribution, and production technologies offer to practitioners.

Nevertheless, the increasingly commonplace uses to which cameras are often put elsewhere - that is, in other spheres of experience but also in those that intersect with or are appropriated by socially engaged arts - continually threatens to circumscribe and diminish the impact of these efforts: for example, in the constrained performativity of the "selfie," the repetitive decontextualization of the internet "meme," the normalization of selective surveillance to protect property rather than people, the continued exoticization and representational exploitation of countless ethnic groups and intersectional sub-groups, and so on. In short, just as 
the sociopolitical and socioeconomic contexts within which socially engaged arts occurs are shifting, so too are the aesthetic strategies deployed to make art that meets the criteria of being "socially engaged."

The project of this dissertation is to explore what an imaginative, visionary, aesthetically critical, politically active, and democratically cooperative camera arts - what I will soon elaborate as a socially engaged camera arts - might look like in practice. By looking to the field of practice most likely to foster its development (namely, community arts and socially engaged arts) and attending to the experiences and opinions of a number of practitioners from this field who seem committed to what is at stake in such art, this project will outline key features, core contradictions (such as its inaccessible emphasis on the visual), and immediate outcomes of these types of aesthetic interventions. It will draw on the aesthetic and pedagogical innovations at the heart of community and socially engaged arts to point to both past successes and challenges to future possibilities. Finally, this thesis will address both the general lack of attention paid to socially engaged arts as a vital cultural phenemonon, and assert the key role of cameras in developing and expanding this vital field of activist cultural production.

\subsection{Framing Concepts}

The key theoretical contribution I seek to make in this thesis is to begin elaborating a theory of praxis around what I am calling socially engaged camera arts. This hybrid term is meant to elaborate the unique contributions camera-based practices make to the broader efforts of the socially engaged arts of which they are a part, and to draw together common theoretical features amongst a diverse set of practices. I have chosen to explore this praxis in terms of three key frames - strategy, organization, and pedagogy - which seem to me highly useful ways to 
begin to understand the complex interplay of cultural phenomena and social forces at the heart of this field of activity.

"Socially engaged arts," like "camera-based practices," is an umbrella term in common use in contemporary artistic discourse. The term signifies a range of artistic practices in which minority and marginalized individuals and social groups are engaged by practitioners in artistic and media production activities. I am using it in preference to a number of other related terms, a decision I will discuss in more detail below. For the moment, however, I will simply suggest that a socially engaged artistic practice maintains, at a minimum, the following three commitments. First, it (or, specifically, those who practice it) develops and deploys art-making activities specifically geared to engaging participants and audiences who are neither formally trained as artists nor experienced as patrons. This often implies interventions which are designed to engage with those individuals and communities deemed to be "at the margins." Secondly, it adopts artistic processes and focuses on aesthetic experiences that best support maintaining and growing such engagement with individuals and communities. A third commitment that socially engaged art makes is to bringing art into spaces and situations not traditionally associated with an engaged artistic practice, nor sometimes with artistic practice in general. While these commitments are often meant to imply a political dimension to the cultural work of socially engaged arts, perhaps even a radical democratic one, I want to insist that they do not necessarily or explicitly do so. Just as socially engaged arts stands for a range of practices, it maintains a range of contradictions as well.

In this dissertation I am using the term camera-based arts (and, occasionally and interchangeably, camera-based practices) in an inclusive way similar to how I use socially 
engaged arts. By camera-based arts I mean to imply two key distinctions: the first is a principally technical one, simply meant to suggest a range of technologies that includes both particular media like photography, filmmaking, videography, and the like, but also the range of techniques that a concern with such media implies - namely, those intertwined properties inherent in all verisimilitudinous representation: their simultaneous and contradictory capacity to render objective appearances and subjective expression. Thus although by camera-based arts I literally mean uses of camera technologies, particularly in socially engaged arts, I also want to include those practices in which cameras are deployed less obviously or more diffusely: that is, where cameras figure into activities in less clear cut or decisive ways, yet where matters like documentation or personal expression exist as key goals.

A second distinction I want to highlight by using the term camera-based arts relates to the shifting notions of authorship that such a term implies. By placing an emphasis on a processual use of cameras instead of simply the images they might produce, I mean to highlight the importance in socially engaged arts on processes of image-making rather than exclusively on image-production. One implication of this is to point out that the experiential outcomes of camera arts in these practices become at least as important as the images that get produced: because camera-based practices are put to a range of educational, recreational, expressive, and performative ends, images sometimes become only incidental to broader artistic activity. This emphasis on process also raises the possibility of multiple authorship - something conducive to the participatory and cooperative strategies commonly deployed in other socially engaged arts efforts, and amenable to camera arts as well.

As with the above preliminary definition of socially engaged arts, so with this definition 
of camera-based arts: that is, while it aspires to technologically sophisticated, aesthetically innovative, and socially activist forms and practices, camera-based arts invariably maintains a number of contradictions to which more mainstream uses of cameras - historical and contemporary - are prone. Indeed, this is the main risk inherent in utilizing these terms, as well as the hybrid one of socially engaged camera arts: namely, idealizing practices that may maintain a number of materially consequential and possibly deleterious contradictions. I admit that this is certainly possible; however, I believe a degree of self-reflexivity can be identified throughout the text, and that this and a theoretical turn to pedagogy may be worth such a risk.

\section{Socially Engaged Arts: Terms and Working Definitions}

There are, of course, no unequivocal signifiers, just as there is no art practice that avoids all forms of co-option, compromise, or complicity. It seems wiser to openly acknowledge this impurity than to assume that it can somehow be defeated at the level of terminology. (Kester 2011,2)

Because this project is concerned with a rather unconventional variety of camera-based practices - namely, that of arts done in and with communities - I will explore in this section some of the more salient aspects of this elusive field of social and aesthetic practice. I begin by looking at recent critiques of relational art and aesthetics, since this discourse seems to frame some of the core aspects of this practice relevant to this dissertation - namely, its relation to social justice, political activism, the professionalization of art, and the role of cultural production in the broader context of North American culture.

Claire Bishop's (2012) recent enumeration of terms referring to the "expanded field of post-studio practices" provides a useful point of departure, since it begins to outline at least the 
formal diversity of techniques inherent in socially engaged practices. Her list includes

“community-based art, experimental communities, dialogic art, littoral art, interventionist art, participatory art, collaborative art, contextual art and (most recently) social practice" $(2012,1)$. In part, this list implies a critique of Nicolas Bourriaud's "relational aesthetics" (see Bourriaud 2002) a concept that has become paradigmatic in contemporary art world discourse, at least in much of the northern hemisphere, but which differs from socially engaged practice in key ways. "[E]ven though," Bishop argues, "the rhetoric around [relational aesthetics] appears, on a theoretical level at least, to be somewhat similar" to the socially engaged art concerning her (what she subsequently prefers to call 'participatory art'), relational aesthetics has largely served to "render discursive and dialogic projects more amenable to museums and galleries" rather than to pursue the "creative rewards" of a "politicised working process" $(2012,2)$.

Grant Kester (2011) is similarly critical of Bourriaud and the selective politicization of his relational aesthetics. In The One and the Many: Contemporary Collaborative Art in a Global Context Kester argues: "While Bourriaud's writing is compelling, it is also highly schematic.... $[\mathrm{H}]$ e provides few substantive readings of specific projects. As a result, it is difficult to determine what, precisely, constitutes the aesthetic content of a given relational work" (2011, 30). More incisively, Kester argues that "traditions of performance art and socially engaged collaborative practice that extend back to the 1960s" are absent from and unacknowledged in Bourriaud's account. Listing some of his omissions, Kester writes:

From the work of Conrad Atkinson, Grupo de Artistas Argentinos de Vanguardia, David Harding, and Helen and Newton Harrison, through Suzanne Lacy, Peter Dunn and Loraine Leeson, Carole Condé and Karl Beveridge, Group Material, and Welfare State, 
and up to groups such as Ala Plastica, Huit Facettes Interaction, Grupo Etcetera, Platform, Littoral, Park Fiction, Ultra Red, and many others, we find a diverse range of artists and collectives working in collaboration with environmentalists, AIDS activists, trade unions, anti-globalization protestors, and many others.

Although he seems to leave it unstated, Kester's inclusion of groups on the cultural and political left aim to critique not only the normative but the broadly conservative and possibly neoliberal sympathies at the heart of Bourriaud's aesthetics. All but naming this political orientation, Kester continues his critique:

This tradition is not only absent from Bourriaud's account, it is openly disparaged as naive and even reactionary. "Any stance that is 'directly' critical of society," as Bourriaud writes, "is futile." Bourriaud offers an ominous description of socially engaged art practice marching in lock-step conformity with a vaguely Stalinist political program ("It is clear that the age of the New Man, future-oriented manifestos, and calls for a better world all ready to be walked into and lived in is well and truly over”) (Kester 2011).

Common to both Kester's and Bishop's critiques of Bourriaud's relational aesthetics are two key points. First, both share a belief in a truly politicized aesthetics (and, conversely, an aestheticized politics), a practice rooted pragmatically in the "real world" - that is, actualized social contexts contingent on material social conditions - rather than speculatively in the specialized art world contexts with which Bourriaud seems principally concerned. Secondly, and perhaps more fundamentally, Bishop and Kester share a belief in an engaged, collaborative, or participatory aesthetics. An aesthetics, that is, that is capable of radically reconfiguring and demystifying the core relation between art and audiences. 
In order to understand why Bishop and Kester feel compelled to challenge the apparent art world hegemony of Bourriaud's relational aesthetic, it is worth the risk of expanding their rather extensive lists even further in order to explore what's at stake in opening art up to previously non-art world processes, audiences, and makers. Such an all-in approach may seem prone to trading such properties as skill and quality for difference, experience for participation, value for plurality, or art for politics. However, understanding real world art through such binary oppositions as aesthetic or propagandistic fundamentally misconstrues the actual history of artistic development. In this sense, the 1960s roots of contemporary practices to which Kester alludes might be traced back even further, certainly to before the interwar period, and perhaps even before the turn of the last century to the very beginning of modern Western industrial society (for a rare account of such art in the early to mid-twentieth century U.S., see Graves 2005; for a compelling look at the role of nineteenth century artist and designer William Morris on contemporary maker culture, see Gauntlett 2011; and for a rigorous and sophisticated study of the role of early photography at the intersection of industry and aesthetics, see Edwards 2006a).

I will explore some of this history in Chapter 2. For now, let's return to the challenge of categorizing and enumerating this subset of contemporary artistic practices. By now it should be clear that the field is both broadly inclusive, but also somewhat selective and fluid. Attending to such a seemingly mundane topic as naming might, I argue, actually speak volumes about the shifting material goals and structural challenges facing practices and organizations. Tom Finkelpearl (2013), for example, has opted for the term "cooperative art" or "social collaboration" in an attempt to reintroduce the pragmatist philosophy of John Dewey to practices similar to those described by Bishop and Kester. Cooperative works, Finkelpearl argues, "examine or enact the social dimension of the cooperative venture, blurring issues of authorship, 
crossing social boundaries, and engaging participants for durations that stretch from days to months to years" $(2013,6)$.

Another term, "neighbourhood arts," is used locally in Toronto (at least by the municipal Toronto Arts Council which coined the term) as a banner beneath which a variety of similar practices might be united. While the term "neighbourhood" invokes similar concerns in place of terms like "socially engaged" or "community," it may also suggest distinct possibilities. For example, neighbourhood arts may imply both the publicness and presumed openness of the works and processes (in many ways for, by, or about local communities), or the idea that communities - defined by a wider range of identity markers rather than simply place - invariably locate themselves and define their individual members as a felt presence within a wider urban geography. A relatively recent term, however, and one coined by the municipal funding body, the Toronto Arts Council, neighbourhood arts may be inadvertently steering these arts into the realm of municipal politics, where neighbourhood designations more strongly overlap with ward boundaries, with real estate jargon, and even with the lingo of "districts" common to urban renewal discourse (for example, see McLean 2014).

In the American context, Arlene Goldbard has deployed a variety of terms across a number of writings to signal similar, but subtly shifting practices. These include "the movement for cultural democracy" (Goldbard 2003, 183-184) and "community cultural development" (Goldbard 2006) which, despite dropping the term "art," nevertheless have the advantage of explicitly pointing to the politics of these processes and the obvious but often unspoken connections they have with the broader field of culture. It is likely that the title of James Bau Graves' (2005) monograph, Cultural Democracy: The Arts, Community, and the Public Purpose, 
was influenced by Goldbard, or at least the work of the now defunct, US-based, Community Arts Network (CAN; for example, see Burnham, Durland, and Ewell 2004) to which Goldbard and Graves both belonged. In these and other cases, the terms seem to emphasize a belief in the practice of art, and of culture more generally, as a pragmatic force for materializing structural change, and not merely endeavours for facilitating aesthetic experiences in the abstract. Aesthetic and cultural work is in the public realm, in other words, instead of consisting of simply private exchanges. Moreover, such practices imply more than a simple instrumentalization: that is, more than art fostering aesthetic experience, or more than art subordinated to political interests. Rather, these practices (and their authors) envision art as action, both political and aesthetic, form meeting content in the everyday contexts of their varied makers.

At this point it should be clear that the wide variety of terms in play makes analysis difficult. From this point forward, I will use the term socially engaged art to imply social cooperation, participatory art, collaborative or dialogic art, social practice (see Jackson 2011), and cultural democracy, among the others raised above. Occasionally I may use the term community art, which is one commonly used by a number of practitioners with whom I spoke. Like the others mentioned above, community arts has its own lineage, and a history spanning decades. (More accurately, it has several histories, manifesting with key differences on at least two continents. For example, see Braden 1978; Kelly 1984) However, for the sake of simplicity, and at the risk of being confusing, readers should understand community art as a particular variety of practice falling under the broader umbrella of socially engaged art. With regards to this simplification, I share Goldbard's concerns about the risks of asserting a movement where no coherent narrative, and only seemingly simpatico practices, exist (see Goldbard 2003): such risks are great. I also accept Grant Kester's truism, there are no "unequivocal signifiers.” For the 
purposes of my analysis, though, it is necessary to adopt such an umbrella term as socially engaged arts, even if to some minds another sounds better or rings truer. I only hope the profound diversity implied by the one I favour will be kept continuously in mind by my readers.

Neither can I claim to have coined the term socially engaged camera arts. The term derives from socially engaged arts, of course, which has a decades old history. Pablo Helguera (2011) prefers the term because of how it implies, in part, an inclusive framework by which to meaningfully unify many of the above practices while continuing to remain open to emergent ones (see also Thompson 2011). As Helguera suggests in his Education for Socially Engaged Art: A Materials and Techniques Handbook, the term has been around since the mid-1970s in an American context (Helguera 2011, 5). Helguera acknowledges that "as a category of practice, [socially engaged art] is still a working construct," but adds:

In many descriptions $[\ldots]$ it encompasses a genealogy that goes back to the avant-garde and expands significantly during the emergence of Post-Minimalism. The social movements of the 1960s led to greater social engagement in art and the emergence of performance art and installation art, centering on process and site-specificity, which all influence socially engaged art practice today (Helguera 2011,2).

In a kind of defense of the term, Helguera suggests that the variety of other, competing descriptors are often attempts to "draw lines between generations and unload historical baggage." (Why socially engaged arts is exempt from this process Helguera doesn't seem to say.) Indeed, recent terms like "social practice" or Bourriaud's "relational aesthetics" exclude, consciously or otherwise, reference to art-making. This, he argues, has a detrimental effect: 
The exclusion of "art" coincides with a growing general discomfort with the connotations of the term. "Social practice" avoids evocations of both the modern role of the artist (as an illuminated visionary) and the postmodern version of the artist (as a self-conscious critical being). Instead the term democratizes the construct, making the artist into an individual whose specialty includes working with society in a professional capacity (Helguera 2011,3).

For better or worse, such democratization of artistic practice implied by terms like social practice risks demoting the artist, having her become an amateur or dilettante. ("Amateur" is often, though not always, a pejorative in artistic practice; for a brief but compelling discussion, see Roberts 2008) Just as importantly, such a process of levelling raises, as Helguera suggests, "the question of whether such activity belongs to the field of art at all" - both, as we shall see, matters of central concern to many of the practitioners with whom I spoke. Art students, he continues, "attracted to this form of art-making often find themselves wondering whether it would be more useful to abandon art altogether and instead become professional community organizers, activists, politicians, ethnographers, or sociologists." This is a crucial matter impacting on the identity-formation of young artists, but also, I will argue, on how veteran practitioners conceive of their practice as something in continuity with or distinction from previous historical genres, or from the field of arts altogether.

For instance, if practitioners of whatever age or experience imagine what they do as related to, but not fundamentally as art, their conception of the labour of their associates and themselves (i.e., how it is organized, what goals it strives for, from what sources its financing is secured, how it remunerates its practitioners, and so on) will undoubtedly differ from the 
conceptions of their counterparts. Rather pragmatically, Helguera insists that socially engaged artists "can and should challenge the art market in attempts to redefine the notion of authorship, but to do so they must accept their existence in the realm of art, as artists" (Helguera 2011,4). Further,

$[\mathrm{T}]$ he artist as social practitioner must also make peace with the common accusation that he or she is not an artist but an "amateur" anthropologist, sociologist, etc. Socially engaged art functions by attaching itself to subjects and problems that normally belong to other disciplines, moving them temporarily into a space of ambiguity. It is this temporary snatching away of subjects into the realm of art-making that brings new insights to a particular problem or condition and in turn makes it visible to other disciplines (Helguera 2011, 5).

Within the context of a practice that often emphasizes its social dimensions - that is, the engagement of a variety of participants in artistic production processes - Helguera's emphasis on the role of the artist as an emergent rather than a fixed subjectivity is important. Even more important, however, is his insistence on the artist as a key figure, a key author in such practices. While this may seem contradictory to the purportedly democratic aims of such practices, it should simply be pointed out that authority neither implies authoritarianism, nor does it deny agency. Authorship - even in the case of images - can be multiply inscribed. In any event, this is a key matter that I will address in subsequent chapters.

One final point about socially engaged arts as Helguera frames it. I take issue with his suggestion, made in the previous long quote, that socially engaged art's actions be "temporary." I believe this is an unfortunate choice of words since, while particular actions and aesthetic 
experiences might feature impermanent spaces and unfixed durations, such art might also be envisioned as permanent, infrastructural commitments featuring aesthetic social action and activist modes of artistic making that will radically impact present and future socioeconomic and sociopolitical structures. Socially engaged arts, in short, might experiment with limited duration and ambulatory forms, but residency - as a kind of rootedness in a cultural context or physical geography, or both - may best string together these interventions into a laboratory of practice.

In any case, I am drawn to the implications of Helguera's overall argument - namely, that contemporary artists (and artist-amateurs) must self-reflexively acknowledge the conditions of their labour. As a key component of what Gregory Sholette refers to as the "dark matter" of the art world - or more generally as the "creative dark matter" of our "post-industrial society" (Sholette 2011, 1; emphasis in original), this alienated creative labour constitutes some of the most socially necessary political and economic action inherent in neoliberal society, a matter I will return to throughout.

Accordingly, socially engaged art is not simply a vehicle by which makers and participants engage in a different kind of creative praxis. Moreover, it is not simply about telling stories, singing, putting on plays, and making pictures with people who normally don't do these things. Socially engaged arts demands we ask what is most worth doing, which ways are best worth being, what traditions are best kept, which changes most needed, and what roles we might each play in doing this together. By emphasizing art, and by refusing to normalize an (possibly disingenuous) equality or democracy of practice, socially engaged art strives to develop a more refined critical and political edge: maintaining the skilled and experiential diversity of its participants and their typically non-mainstream communities and cultures while challenging 
(rather than discarding) the issues that artistic practice raises, such as authorship, expertise, form, and so on.

\section{Towards Socially Engaged Camera Arts}

Although my focus will now turn to camera arts, I have discussed socially engaged arts at some length because these practices provide a useful frame through which to understand those practices that deploy critical, self-reflexive and materially productive social engagement strategies predominantly using the camera-based arts. My point now is to suggest that camera arts may, in our contemporary world, be a key means through which the radically inclusive goals of socially engaged arts can be achieved. That is, while camera arts are being developed as particular forms of socially engaged arts, a number of the medium's inherent qualities may also play a transformative role in those practices within which they do not normally play an obvious or significant part.

The unique role that camera practices might play in socially engaged arts, I argue, is due in part to the ubiquity and global reach of those practices. In the Introduction to Visions of Modernity: Representation, Memory, Time and Space in the Age of the Camera, Scott McQuire (1998) argues, "camera technologies have profoundly transformed the world we inhabit. [...] The shift to secular, urban-industrial, bureaucratic societies, which has forged the distinct horizons of modernity, is not only unimaginable but practically inoperable in the camera's absence" (1). McQuire goes on to align camera practices with national and transnational processes of migration, suggesting that it is no coincidence that the "modern desire to transcend time and space" (6) can be located in both the development of the medium and of the emergence of the nation-state under capitalist social relations. He proposes: 
If modern migration has been driven by the development of a global economy and the consolidation of a global division of labour, these processes have been inseparable from the emergence of transnational cultural flows. Rapid circulation of people and products is today counterpointed by the rapid circulation of images and representations. (6)

The effect, he suggests, is double-edged, leading both to "possibilities of cultural and political reinvention," on the one hand, and "social dislocation and cultural dispossession" (6) on the other:

If the camera has opened new horizons to the gaze of colonizer and tourist, it has also offered the diasporic and displaced a powerful means to overcome distance and absence, to sew together the poles which life has split asunder. As much as the photograph marks a site of irreducible absence, it is frequently the talisman signalling the possibility of return. (McQuire 1998, 7)

It is to such holistic, convivial, culturally enriching, and healing practices that a theory of socially engaged camera arts must necessarily attend. As I will discuss in the next chapter, I am principally concerned with three historical moments where questions of labour, popular culture, and political activism meet. Namely: first, the worker film and photography movements that emerged mainly in Europe and North America during the interwar years (the 1920s and 1930s); secondly, the UK community arts movement that developed out of a variety of concerns (though principally feminist and working-class) associated with cultural democracy in the postwar social welfare state; and, finally, the present and recent past where the ubiquity of digital camera technologies has spawned less a movement than a cluster of socially engaged artistic methodologies (such as digital storytelling and photovoice, among other collaborative and 
participatory methods; for example, see Bromley 2010; Lambert 2009; Wang 1999; Wang and Burris 1997; Ewald 2002).

In that chapter I will begin to argue that, while it is clear that no direct lineage of practice persists, the continuity and re-emergence of thematically and formally similar practices in distinct geographies, situations, times, and sociopolitical ecologies suggests that a common - or at least complementary - set of strategies may be identified and enumerated. Commensurate with the goals of any socially engaged art, then, socially engaged camera arts can and should be seen as a body of methods (ethical, pragmatic, pedagogical, organizational, and theoretical) for aesthetically engaging and politically intervening in both the local and overarching conditions of modernity and capitalism that have so thoroughly attempted to structure lived experience across the globe.

\subsection{The Research: Strategies, Methods, Methodologies}

For the moment, however, I will turn to a more descriptive account of the project, its methodological underpinnings, the particular research strategies I deployed during the course of my inquiry, and some of the key contradictions that have been raised. This project adopts a qualitative, mixed method ethnographic approach informed to varying degrees by theories of activist art, democratic political praxis, feminist praxis, and popular pedagogy. It does this in order to inquire into the contemporary practice of socially engaged camera arts in Toronto by relying on artist-practitioners and artist-participants as guides to the field. It aspires to contribute not simply to academic discourse, but to the on-going project of community art, socially engaged art, and socially engaged camera arts praxis.

The two major components to the methodology were participant observation and semi- 
structured interviewing, followed by an inductive analysis of field notes and transcripts of interviews by artist-participants. I formally interviewed 16 artist-practitioners (a term I will define in detail below), asking them about their work, whether as an independent artist or as a practitioner supporting a broader artistic and organizational practice, and about the value they saw in working the way they did, and particularly with cameras. Four discrete sites (as well as, briefly and unexpectedly, a fifth) materialized for my research as a participant observer, allowing me to spend more than 100 hours attending to the interactions between and amongst participants and practitioners in order to understand some of the context within which they engaged.

\section{Research Questions}

There have been three key areas of inquiry for me in this project: first, exploring what actions, objects, and events constitute socially engaged camera arts, whether as aspects of socially engaged art or of some other form of praxis. Secondly, understanding the role(s) played by cameras within the broader context of socially engaged arts practices, particularly in terms of how well or poorly they integrate into these practices. And thirdly, exploring the meaning and value of these artistic practices to the lives of those involved; specifically, in order to understand the ways these practices do or do not contribute to collective (rather than individual) notions of community and identity.

These interests can be reframed in terms of the following research questions:

- Materially speaking, what goes into making socially engaged camera arts what they collectively are? Who - including which individuals and what organizations - are involved in their practices? What are the terms of that labour? What kinds of events are mobilized (pedagogical or performative)? What kinds of images are produced? What 
kinds of relations and processes are instantiated?

- What role(s) do cameras play in socially engaged arts? By whom are they typically used - namely artist-practitioners or artist-participants? In what contexts are they typically present? For what ends are their images made?

- In what ways are socially engaged camera arts practices seen as important? What values are attributed to them by various actors (especially artist-practitioners and participants)? How does such valuation relate to camera arts being central or peripheral to a socially engaged artistic practice as a whole?

\section{Mixed Methods: A Naturalistic Approach}

In order to address the above research questions, and to develop a theory of the political aesthetics that is, I argue, at the heart of socially engaged camera practices, it seemed most appropriate to both speak to people involved in practices that deployed socially engaged camera arts and to observe those practices in action. This seemed best accomplished with a mixed method qualitative ethnographic study consisting primarily of interviews and on-site participant observation, and broadly informed by what Yvonna S. Lincoln and Egon G. Guba (1985) have called "naturalistic inquiry."

According to Lincoln and Guba, naturalistic inquiry is best understood as a postpositivist research paradigm implying a series of ontological and epistemological beliefs about scientific research that challenge not only positivist models of inquiry, but prepositivist ones as well (189). (Stanley and Wise (1993) render the contrast succinctly, describing the naturalist model as "one in which 'theory' comes out of research rather than preceding it" (151).) Attending to what Lincoln and Guba say about the paradigm is useful because they elaborate a framework where 
the affinities of recent and emerging methods - such as feminist, social movement, decolonizing, or arts-based approaches - might be drawn together, taking into account their distinct origins and emphases, but also trusting in their complementary ontological and epistemological assumptions and often simpatico ethical and political commitments.

In their analysis, Lincoln and Guba cite several critiques of the paradigm, drawing from these a general conclusion that positivism "can be reshaped, apparently, to suit the [researcher's] purpose" leading to "some inconsistencies and some idiosyncracies" emerging in positivist practice (24). They suggest that, despite this arbitrariness, positivism nevertheless makes several key, salient assumptions that postpositivist paradigms can and often do seek to directly challenge. In what seems an attempt to prevent postpositivist inquiry from itself slipping into inconsistent and idiosyncratic practice, Lincoln and Guba identify what they feel to be the five most pertinent positivist axioms in order to then develop corresponding naturalist axioms as a means of preliminary critique (see 37). Since most of the rest of their book is spent unpacking these axioms, I can only deal superficially with them here; nevertheless, they concern:

1. The nature of reality (ontology): realities are multiple, constructed, and holistic.

2. The relationship of knower to known (epistemology): knower and known are interactive, inseparable.

3. The possibility of generalization: only time- and context-bound working hypotheses are possible.

4. The possibility of causal linkages: all entities are in a state of mutual simultaneous shaping, so that it is impossible to determine causes from effects.

5. The role of values (axiology): inquiry is value-bound. 
Although these axioms remain somewhat schematic, and although Lincoln and Guba remain a little ambiguous on certain matters (such as the relation of academic research to broader sociopolitical praxis, or on matters like globalization and the lingering effects of colonialism on scientific research), their account of naturalism provided me at least a preliminary way of anchoring the humanist, inductive, and emergent research I anticipated in my own plans to speak, observe, and work with those involved in socially engaged arts organization and practice. Certainly the ideas of plurality and holism, interactivity and reversibility seemed well-suited to approach the particular object of this study. Yet these ontological and epistemological values also echoed my own convictions about the mutually-constructed and emergent character of research into social realities.

\section{Ethnographies: Critical, Public, and Feminist}

In more practical terms, I drew broadly on ethnographic methods and theories to both organize my fieldwork and later help frame an analysis of my interview and observational data. The fit here with a naturalistic approach seemed appropriate. By pairing semi-structured interviewing with participant observation, a key goal was to draw on the strengths of these anthropological techniques - while trying to minimize their sometimes problematic limitations in order to explore a complex set of cultural practices.

As an interpretive social scientific framework, ethnography has historically claimed that the phenomena of cultures - both their relations and the artefacts they produce - can be communicated about (typically written about or, at least, discursively constructed; see Lindlof and Taylor 2011). Normative variations of ethnography have further asserted that such accounts can be considered objective in the representative portrayal of their material phenomena and 
human subjects (rather than being, say, a subjective and selective framing filtered through social structures and power relations. See Smith 1999 particularly Chapter 3, "Colonizing Knowledges," for an important critique of this tradition in ethnography.)

By contrast, decolonizing and feminist approaches to ethnography challenge several aspects of these claims. Feminist ethnography, for example, insists that objectification risks an "othering" process, wherein hierarchies of authenticity and legitimation are masked and effaced, so that accounts of social phenomena are passed off as true rather than subject to interpretation (and re-interpretation), or as autonomous rather than tacitly affected by dominant social forces (capitalism, patriarchy, white supremacy, heteronormativity, and so on). Recent feminist ethnography in particular seems to encourage a critical self-reflexivity on the part of the researcher capable of resisting any impulse to legitimize these forces, their agents, or their claims. As Borland (2007) argues, this self-reflexivity continues to extend to feminism itself, supporting the empathetic and egalitarian work of exploring women's experiences while nevertheless critically engaging critiques of normativity within feminism, such as white feminism.

In short, the open-ended, inductive, and emergent characteristics of more recent and critical ethnographic methods seemed well suited to inquiring into the character of cultural change and practice at the heart of socially engaged arts. While other methodologies might have also been useful complements to this study, particularly those related to organizational knowledge and practice (for example, see Argyris and Schön 1978; van Maanen 2009), I have consciously prioritized those that imply a more engaged and ethical relation with research participants - and, in this case, their communities of practice. In other words, I have tried to take 
an activist approach.

In order to pursue such an activist stance, I have drawn on several other methodological approaches. Public ethnography, for example, claims to privilege both a participant's knowledge, similar to other recent ethnographic practices, but it also claims to attend to her ethical commitments in and beyond the research frame. This seems important to an account of socially engaged arts, since the nature of such arts often leads to appearance and performance in public spaces, as well as in other pseudo-public contexts (such as on the internet).

However, socially engaged arts may itself enact a kind of public ethnographic research as it mediates between inquiring into the everyday lives of participants and representing the "findings" of such study in a variety of aesthetic forms. As Kenneth Plummer (1999) argues, "public ethnography ... is no longer simply the domain of the expert social scientist," but rather represents a "new sphere" of activity that advocates for and contributes to "a public debate about the moral and political life of a society" (642). A researcher's sensitivity to the challenges that this duality raises - that is, that public ethnography is both a methodology to deploy, but also one that may be found in practice - seems both ethically and substantively important. Carol Bailey (2008) provides a useful summary of what seems core to the methodology:

(1) its primary means of collecting data is in-depth field research, (2) it is motivated by a desire to reduce social injustice, (3) it critiques the structures and social processes that promote inequality, (4) it includes active participation of the scholar in the fight against repressive conditions, and (5) its desired audience extends beyond academic circles to include some facet of the public at large (266). 
Certainly its social justice and activist principles seem to align with the factors motivating socially engaged arts. However, as Plummer suggests, "we have to be careful," since as the circle of what seems worth telling about people's everyday lives expands, so do definitions over what is morally justifiable about the telling. While I agree with Plummer's suggestion that there is a need for an "ethically skilled public ethnographer whose work should be held accountable on a number of dimensions" (644), I also recall Linda Tuhiwai Smith's (1999) skepticism of the assumed good of scientific research - and, by extension, the default benevolence of the researcher. In my opinion, the worth of public ethnography is in the opportunity it provides to maintain the complexity of these two positions: to assert that rigorous scientific research can be beneficial but that, in order for it to be so, it must also be done ethically.

To this end, I am also indebted to decolonizing, transgressive, and emancipatory research methodologies (including Indigenous methodologies) for several reasons. First, for how such methodologies insist on research not simply on those from the margins, but also with them though preferably by them as well. While I have no grounds to claim affinity with those who have experienced inequality, injustice, or exploitation, I have nevertheless tried to "create space," as Brown and Strega have suggested (Brown and Strega 2005), by asserting the legitimacy of socially engaged arts (and, by extension, of their participants and practitioners) as a burgeoning practical and theoretical field of cultural production.

Secondly, these methodologies have served to continuously remind me of the limitations of what I might accomplish with this dissertation. That is, despite all attempts to speak to as wide as possible a range of experiences, and on behalf of as diverse a range of practitioners as exists in 
the contemporary context, I wholly acknowledge the limitations of my interventions, and recognize the vast amount of cultural knowledge that remains guarded and inaccessible to me. I can only hope that this project provides future researchers and practitioners a useful point of departure, though I would be perfectly satisfied if it served better as a substantial target of critique.

In addition to these methodologies, I am also interested in those deployed in social movement research. In particular, I appreciate the interdisciplinary frame that can be applied to the study of what artists, activists, and social scientists do as inquiries into collective action. Applied to socially engaged arts, such methodologies recognize the political implications of aesthetic activity done in collaborative and community-based contexts. This is crucial, since the actions of specific practices, organizations, and practitioners in socially engaged arts is often ambiguous and ambivalent, rather than uniformly radical, egalitarian or democratic. Scholars like Polletta (see Polletta 2001; Polletta 2002; Polletta 2006) and Tilly (see Tilly 1977; McAdam, Tarrow, and Tilly 2001; Tilly 2008) have elaborated meaningful, cross-cutting theoretical concepts that have helped in my interpretation of the various actions I came across during my field work within this rather non-traditional field of practice. (In Chapter 6, for example, I draw on theories of contention to explore how socially engaged arts are, and are not, politically resistant sociocultural practices - collective practices that differ in dramatic ways from more traditional forms of protest.)

\section{Into the Field: Personal Beliefs and Experiences}

In order to better understand the challenges that those in socially engaged arts face, and to observe the solutions they collaboratively and cooperatively develop, I conducted a series of 
interviews with practitioners at several Toronto-area sites where camera-based arts seemed an important, if not vital, component of their aesthetic and organizational goals. These interviews were mostly done with artists but also with activists and volunteers associated with the practices who demonstrated an interest in the place of cameras in their work. I also volunteered extensively at several sites - sometimes intensively for several days, sometimes periodically for several months - to actively observe the ways art and artistic labour was organized and deployed to specific activities and projects, and to develop some degree of understanding - however limited - of the roles played by participants in such work. Across these and other sites, I encountered a diversity of practices appealing to a variety of audiences and participants, and witnessed both successes and failures in terms of art and politics. While results were often mixed, sometimes practices were successful at making both art and politics; occasionally they failed to accomplish either.

Throughout my intermittent participation, since 2004, in Toronto-area community arts, I have been interested in the factors that bring people to engage in the practice of community arts. For me, these practices, and the people they seemed to attract (participants and practitioners alike), were exciting, cross-disciplinary, and often unpredictably raw, combining a diversity of processes and forms with a range of people, many of whom have traditionally been excluded from artistic practice. It felt, too, that I was not alone in my enthusiasm: increasingly, it seemed community-engaged projects and processes were behind all sorts of public murals, street performances, and community activities - more so than I experienced (or perhaps noticed) in my first five years living in the city.

Yet something of these forms and practices also felt tenuous, as if the forms and images 
papered over a much more complex context, where the pieces were being held together tenuously, tenderly but also delicately, as if by wire and string rather than by more durable cultural infrastructure. I wondered where the people who made these things were; what they did at other times of the year. I wondered how artists and organizations could sustain practices so clearly indebted to the unpaid labour of community members and volunteers. I wondered whether the kind of energy I felt in community arts - that is to say, a feeling as if such arts manifested and enacted possibilities for making social change through cultural as well as political action - I wondered whether these feelings were common, and whether such change, through such means, was really possible.

Thus this dissertation began as an impulse to better understand how and why people in community arts - both artist-participants and artist-practitioners - did what they did, often voluntarily or for low pay, and why they thought doing this was valuable, often despite being financially unprofitable and physically exhausting. The questions evolved, in other words, from a desire to understand, paraphrasing Richard Chalfen (1987), what all the "fuss" was about in the field of community arts cultural production in Toronto.

As I mentioned earlier, it became quickly apparent that "community arts" was somewhat of a contested term, particularly for artist-practitioners. It seemed a term which might sometimes mask important alignments and contradictions with other artistic and social practices. As I argued in the previous section, some practitioners actively appropriate this term while others use different ones to lend a distinct, albeit related, emphasis to their endeavours. As I have also already argued, my deployment in this dissertation of socially engaged camera arts - and socially engaged art more generally - is an attempt to include community arts as one among a 
number of community-engaged aesthetic and political practices, such as community media, community theatre, spectacle arts, digital storytelling, activist art, public art, social practice, and more. Further, it is an attempt to analytically foreground both the political ("socially engaged") and aesthetic ("arts") aspects of such integrated practices - or, occasionally, to highlight the apparent lack of one or both of these facets.

While the practices I observed and the artist-practitioners with whom I spoke generally had very clear and transformative political commitments, these commitments emphasized distinct values, and hinted at a field made up of quite diverse political viewpoints. As I will detail in subsequent chapters, it is my contention that, in general, the field of community arts is not uniformly so radical and, indeed, at times may even hold quite conservative views. Although the term "social" is just as political and is just as ambiguous and ambivalent as the term “community" (for example, see Arendt 1998; Bauman 2001; Latour 2005; Tuer 2005a), the term "engagement" is meant to insist on a more overt attention to praxis than community alone implies, even if in doing so this insistence fails to resolve the potential homogeneity and heteronomy that the term "social," like "community," risks insinuating. In short, socially engaged camera arts is intended to function as a more analytical term than the largely descriptive community arts. It is not, however, meant to act as a replacement.

My research began after I attempted to contact a number of artists and cultural workers through phone and email, I ended up working directly with several dozen people across ten distinct sites. In many cases I began by contacting media arts centres to inquire about volunteering within the context of my research project. In some cases, I was referred by one practitioner to another based on the rather vague criteria I had set out (generally speaking, "who 
is doing interesting things with cameras in socially engaged or community arts?”).

In all, I formally interviewed 16 artist-practitioners, asking them about their work, whether as an independent artist or as a practitioner supporting a broader artistic and organizational practice, and about the value they saw in working the way they did, and particularly with cameras. I transcribed the majority of the interviews in full, a few only partially, and shared each transcript with its practitioner-interviewee.

In the context of this project, interviewing permitted me interaction and engagement with persons who were more or less central, more or less peripheral, to a socially engaged arts site (such as, on the one hand, artistic directors, leaders, mentors, and resident artists and, on the other hand, commissioned artists, audience members to performances, volunteers, and other guests). These kinds of interviews allowed me to contextualize what I learned from my experiences as a participant observer, and gave me opportunities to rethink assumptions I may have had going into particular sites.

However, interviews also allowed me to engage in practices in which more timeintensive or context-sensitive participant observation would have been prohibitive, inappropriate, or impossible. For example, it may have been both difficult and inappropriate for me to enter safe spaces to observe group work with racialized queer spectrum youth (LGBTQ+ or LGBTTQQ2SA). Interviews with those practitioners who habitually work with queer spectrum participants allowed me a glimpse into the work involved in realms of cultural production to which I have limited access. At the same time, such interviews humbly remind me that there are certain accounts I cannot ethically purport to know, and for which even my most hesitant and cautious claims are inadequate, and possibly flat out wrong. Moreover, even with interviews 
such as these, there are many accounts I will have altogether missed, since the structural constraints placed upon those working in Toronto's socially engaged arts ecology means that many marginalized practitioners may have little interest and fewer resources to number among the most visible and prominent of practitioners - that is, those for whom granting an interview to a white, male doctoral student seems like a good use of their time.

In short then, interviews were done with artist-practitioners from the sites at which I served as participant observer (see below), but also with artist-practitioners from sites more indirectly related to the Toronto socially engaged arts ecology. In part this was an attempt to cautiously address the limited degree of diversity in the account I sought to develop. However, it was also an attempt to connect practice and context in an otherwise diverse field.

In beginning to analyze the text of these interviews, I adopted no formal coding method, though I drew on what Lindlof and Taylor (2011) had to say about inductive and, particularly, what they call abductive or interpretive analysis (243) in beginning to make inferences about, and interpretations of, the issues and concerns raised by practitioners. Typically in this analysis I would highlight several passages from a transcript (usually two dozen or so of varying lengths) and then, iteratively shuttling between writing and positioning these snippets in a word processor document, I would work to draw together ideas from across the interviews that seemed to be thematically interrelated (moreover, without any intentional but merely intuitive sense of what such themes might be). Occasionally I would position a snippet in more than one location as I worked out what the analytical boundaries amongst different themes might be.

In general throughout this process I tried my best to maintain the voices of the practitioners, working from what they seemed to be saying rather than from some imposed 
framework of what I expected to hear. This has meant, at times, maintaining some of a practitioner's thought process by using direct, minimally edited quotes whenever it seemed appropriate to represent their efforts at grappling with or developing an idea. In the places where I paraphrased, there was a more concerted effort to minimize the quirks of spoken language by editing out certain words or inserting ellipses. In either case, however, I attempted to remain faithful to the particular argument I perceived them to be making at that moment.

\section{About the Sites}

As part of my research I also engaged in focused observation at four distinct sites for more than 100 hours in total, primarily attending to the interactions practitioners and participants had, but also in order to understand some of the context underlying practitioners and participants working together. The particular sites in which I acted as a participant observer included:

MABELLEarts in Etobicoke, Regent Park Focus Youth Media Arts Centre, Making Room in Parkdale, and a youth digital story project held in the west end and sponsored by North York Community House and Four Villages Community Health Centre. (In addition to providing descriptions here, briefer Organizational Site Profiles may also be found in the Appendix, alongside Artist-Practitioner Profiles of practitioners at these and other sites.)

Several other, far briefer, volunteer situations allowed me additional participant observation experience when I was asked by practitioners whom I had interviewed to lend a hand in their own work. For example, I took photos for El Whidden in the development of her Department of Public Memory project (with Maggie Hutcheson), and coordinated an informal camera workshop at the request of Michael Burtt for participants at Making Room. Although I have preferred to focus on the more extensive and longer term participant observation 
experiences in this thesis, I want to mention these others because they nevertheless impacted my research.

Due to the fluid ways in which community arts and socially engaged arts cohere as fields of practice, traditional arts practices and traditional artists can, at times and quite legitimately, claim to be community-oriented or socially-engaged, or insist that a dimension of their practice be described as such. For the purposes of this project, I have assumed an inclusive, but slightly more restrictive definition than this which I used to determine possible sites for fieldwork. Indeed, I have conducted research at sites where the primary purpose is either explicitly described as "community arts" or "community media" - stated, for example, in their promotional material or on their website - or, alternatively, where a more implicit connection to the field exists. In the latter case, I have drawn on recent funding allocation reports from the Ontario and Toronto Arts Councils, as well as on anecdotal conversations with several TAC employees to differentiate so-called community arts groups from artists and groups periodically engaged in socially engaged arts.

This differentiation may seem pedantic; perhaps an example will help articulate why it is not. Galleries and museums and even artist-run centres may have a wholly relevant community or "outreach" focus that functionally or literally produces forms and practices that might be called "community art." My interest is in those organizations that make this focus a central and on-going part of their activities. In short, I sought organizations for my research where artists and cultural workers (what I will from now on be calling artist-practitioners or simply practitioners) worked in some collaborative, reciprocal fashion with community members (what I will call artist-participants or participants), and where this cooperative collaboration was a core activity 
of the organization.

As this general criterion leaves several dozen possible sites in the Greater Toronto Area, from community theatre troupes to spectacle arts companies, I developed some additional criteria by which to determine a reduced set of candidates that could furnish a generally representative analysis, but render it more practically feasible for a solo researcher. First, I sought organizations that had some extended history of doing community or socially engaged arts: at a minimum, this implied a practice that had been around for at least five years. This was meant neither to be exclusionary or derisive of new artists or practices peripheral to these ones, nor to disregard the rather incipient problems of attrition and instability, particularly as this affects youth artists, artists of colour, queer artists, and practitioners from other marginalized groups. Rather, with the threshold of a minimum organizational age I assumed that working conditions and organizational histories might attract a wider range of both artist-practitioners and artist-participants than did newer or less directly community arts-based or socially engaged practices. Accordingly, with that wider range, I assumed a greater store of self-reflexive experience upon which practitioners might draw during interviews.

Secondly, I sought organizations that were actively engaged in camera based practice, including digital or photochemical photography or video production. While this implied, at the very least, organizations that were active in documenting their collaborative artistic endeavours, it was more about practices where camera-based methods were more central to, if not primarily about, the work of artist-practitioners and artist-participants. In other words, I was drawn to those community arts practices that were making photographs and videos as or amongst their primary artistic activities. As I have said earlier, there are many community arts organizations that focus 
on theatre, music, mural work, and a whole host of other forms instead of or alongside camerabased work.

Thirdly, and finally, I sought organizations that worked with a wide range of artistparticipants. While many organizations in the fields of community arts and socially engaged arts invariably engage with youth, I purposely sought those who aimed to work with a broader range of community agents. I wanted to know whether the pedagogies used with some artistparticipants differed from the "andragogies" (see Knowles, Holton, and Swanson 2005) used with others; or, rather, what effects, if any, different cohorts had on the ways artist-practitioners and organizations chose to engage with these varying types of artist-participants. I assumed that a wider mixing of participants might result in distinct techniques for artistic learning and production compared with more homogeneous groups, and I wanted to explore this assumption.

These criteria led me to consider a number of sites and practitioners. However, of the number of people I contacted and followed up with (sometimes multiple times), four discrete sites (as well as, briefly, a fifth) materialized for my research.

First, MABELLEarts, a Toronto Community Housing (TCHC) hosted, Toronto Arts Council (TAC) and Ontario Arts Council (OAC) funded community arts organization working out of Mabelle Park in Central Etobicoke. In the more than seven years of its existence, MABELLEarts has developed a significant historical practice of creative camera-based practice, incorporating both film and photography, as art and documentary, in their seasonal outdoor events, electing to position artist-participants both in front of and behind the camera.

MABELLEarts's ongoing association with Jumblies Theatre is also of note: the company began as a more permanent continuation of Jumblies Theatre's production of Bridge of One Hair 
(2007), the result of a multi-year residency begun at Mabelle Park in 2004 (The VIVA! Project 2009). During my time there as a participant observer, I helped a commissioned artist deliver a pinhole camera workshop, in addition to recording a timelapse film. In the process, I observed a range of actions and interactions, by artist-practitioners and artist-participants, prior to, during, and following the workshop sessions. I also observed and participated in some of the recurring events of MABELLEarts, such as A Light in Midwinter.

My second site was Regent Park Focus Youth Media Arts Centre (hereafter Regent Park focus or, simply, Focus), which is also funded in part by TAC and OAC grants, but also historically through other non-arts funding sources, such as the Ontario Trillium Foundation, and the long defunct Ontario Anti-Drug Secretariat. Regent Park Focus was formerly located in TCHC-hosted space; in their new facilities, Focus continues to offer multi-disciplinary, mediacentered artistic opportunities to a predominantly youth-based cohort of artist-participants. Like the other sites and practices I observed, Focus is integrated with other community arts and community development organizations, both from the adjacent community (Regent Park) and from the Greater Toronto Area more broadly. A particularly significant partner is Pathways to Education ("The Pathways Model” 2013), a program that aims to curb high school drop out rates amongst youth from low-income families using a variety of strategies and incentives, and for which Focus workshop participants receive "credit". My observations at Focus consisted of working with a volunteer photojournalist to support his multi-week introductory tutorial to photographic practice, a tutorial that was one of these credit programs, and which was almost entirely made up of youth/students enrolled in the Pathways program.

My third set of observations took place at Making Room, a TAC and OAC funded multi- 
disciplinary community arts practice operating out of the Parkdale Activity and Recreation Centre (PARC), a self-advocacy centre for consumer survivors of the psychiatric system or people dealing with mental health issues, which is located at the heart of Toronto's Parkdale neighbourhood. Begun, and often still referred to, as Sand in Water, Making Room is similarly interconnected with a variety of community arts and community development organizations: at the time of my participation, affiliations included those with the artist-run Whippersnapper Gallery, with other arts organizations and social services both at PARC and the Queen West and Parkdale neighbourhoods, and with Jumblies Theatre, among others. However, unlike Regent Park Focus or MABELLEarts, the artist-participant cohort of Making Room has typically been adult, consisting of adults and seniors, many of whom are low-income and from the immediately surrounding area. My observations were made over the course of several of their weekly workshops, during a walking photography trip to the nearby lakeshore, and during several other special events, notably the June 23, 2012, Join the Adventure Boat Launch and Pageant.

A fourth set of observations took place during a digital storytelling workshop coordinated by Jennifer Lafontaine and Emmy Pantin, formerly of the Centre for Digital Storytelling Toronto. The four day, approximately 24 hour workshop took place in a TCHC complex with a dozen middle school-aged youth. (Interestingly, this cohort was among the youngest Lafontaine and Pantin had worked with in their experiences facilitating digital story workshops across Ontario and Canada: the pair typically work with adults or much older youth.) These young artist-participants had had a little contact with Lafontaine and Pantin prior to the workshop, but were familiar with one another through both school, their neighbourhood, and a weekly youth group facilitated by Four Villages Community Health Centre. The artist-practitioners were supported by Four Villages, and specifically by an OAC pilot grant that sought to fund artist 
residencies in health care settings. My participation included supporting the production of the artist-participants by helping them take photographs and video footage to incorporate into their digital story compositions, as well as subsequently editing such videos.

My final experience as a participant observer was in support of an afternoon drop-in workshop coordinated by community artist and photographer Mindy Stricke as part of a recent phase of her multi-year, multi-site Greetings From Motherland project. The project, recently funded by TAC and the Canada Council for the Arts, has consisted of a series of collaborative, multi-disciplinary art projects exploring issues of motherhood and gender, with artist-participants from Minneapolis and Toronto (Stricke 2010; Stricke 2013). My role at the drop-in workshop which took place at the Harbourfront Community Centre - consisted of helping Motherland's Artistic Director, Mindy Stricke, engage non-participant mothers and caregivers in a series of low-intensity artistic activities, such as collaging, printmaking, and free writing. Although the experience here was invaluable, it was certainly anomalous; indeed, in two senses. In the first place, the workshop was a very brief encounter with Stricke's practice (it was, however, paired with an interview I conducted with her). Additionally, this weekday drop-in was not usual for Stricke, who had organized a series of sessions on the weekend for which participants had to sign up to attend. As such, the drop-in session was more an attempt to expand the audience of the weekend workshops (which hadn't yet begun), and meet other mothers and caregivers who either might not be able to attend those sessions, or who might not have heard about them.

In any event, these experiences allowed me to better understand the contexts within which artist-practitioners and artist-participants work together. Certainly the diversity of the experiences - in all aspects from geographic location, the gender and ethnic makeup of artist- 
participants (and, for that matter, of artist-practitioners), the types of artistic activity, and the structure of engagement related to such activities - might seem to imply that little generalization may be possible, of either socially engaged art or socially engaged camera arts specifically. For now, let me simply say that the interviews I conducted contemporaneously with my observations did much to both broaden and deepen my understanding of these contexts, and of the diversity of practice that characterizes the current Toronto community arts and socially engaged arts ecology.

\section{Challenges and Contradictions}

Aside from the general challenges which attend an academic research project which is dependent on fieldwork, there are several aspects of this research which I am simply incapable of adequately addressing. These limits are non-trivial, and mark important boundaries beyond which my research is simply inapplicable. The first concerns the privileging of the visual that camera-based practices demand, and the inaccessibility and exclusivity this implies. The second concerns my social status, while the third concerns the social status of the majority of artistpractitioners with whom I spoke. These latter two relate to the perpetuation of a variety of forms of discrimination and social inequality from which I and the artist-practitioners I interviewed have almost certainly benefited from; in this context in particular this implies what is often referred to as white privilege.

\section{Ocularcentrism}

My concern with camera arts is invariably a concern with visual aspects of knowledge and experience. As such, in this dissertation I have paid scant attention to the experience of people with visual impairments in camera arts practices; this includes people with varying degrees of blindness, of course, but also those who may experience colour vision deficiency or 
other ocular disorders (whether biological, psychosocial, and so on). While I believe the cooperative and process-based qualities of socially engaged arts have done much to reorganize the specific bodily and sensory appeals of various forms and media, including camera based arts, as part of constructing broader access to a wider cohort of potential participants, I admit I have not fully considered the matter in the text of this thesis. The more general matter of ensuring accessibility to socially engaged arts activities, by continuing to develop relevant accommodations and eliminating physical and social barriers, is a concern demanding further theoretical consideration.

\section{My Own Privilege}

Another concern relates to my perceived status and identity as a temporary researcher in field work contexts in which I was perceived to be simultaneously in the minority and of the dominant strata of society. I made particular efforts to remain conscious of the multiple personae I was seen and presumed to embody in my presence as a participant observer at various sites, expecting that people from these communities would see me from many different and contradictory perspectives. I tried to remain conscious of how practitioners and participants may perceive me as academic researcher, outsider to the community, cisgendered and heterosexual male, white and (upper) middle-class, bodily and cognitively "abled," adult, and generally socioeconomically privileged. Although I was keen to observe both similarities and differences from within and across sites, I tried to remain open to the ways these characteristics may have marked me, from the perspectives of both practitioners and participants, as different. I made efforts to identify the potential impacts that these and other identity markers might have on the people with whom I interacted, and I strove to be self-reflexive about the invariable impact on my own thinking that such acculturated characteristics might have during the analyses I subsequently 
made of people's words and actions. I feel cautiously optimistic that I have presented some meaningful understanding of the work in which these agents were and are involved in, and have done so in a way that balances a fidelity to their commitments with the assertion of my own. However, I am well aware of my many failings and shortcomings that remain.

For example, there are certainly limits to what I, as a male author, can accomplish with a feminist epistemology - regardless of my sympathies. For example, maintaining the authorial "voices" of practitioners in socially engaged arts, as I have tried to do throughout this text, is meant as an attempt to legitimize and value the work they do, and hint at the complex experiences of the participants with whom they collaborated. Their endeavours and legacies are, I feel, important to broadcast as widely as possible to an audience of sympathetic and empathetic artists, activists, practitioners, policy-makers, and scholars. Yet I also recognize that naming the sources of these words and thoughts also risks, however unintentionally, appropriating and perhaps even exploiting them, and perhaps even the community members with whom they have partnered.

Indeed, the possibility of this potential effect weighed heavily in my decision not to interview participants but to focus instead on practitioners, just as it led me to anonymize certain passages from these interviews that I felt might lead to potential repercussions for individuals from the communities about which they speak. My decision to publish only a select few on-site photographs stems from the same concern: although the practitioners I interviewed gave informed oral and written consent, the active participants I observed gave no similar consent; moreover, their interactions with me were framed more organically by particular experiences in and with their communities rather than in relation to some external academic framework, 
however ethically conceived. Graciously, for the times I was there and the times I have returned, I was and continue to be part of that community. However, it remains invariable that that membership, and the associated privileges and responsibilities that come with it, changes the moment I attempt to redefine or broaden that community. To my mind, matters of consent necessarily change as a result, and must be continually renegotiated.

Ultimately, I may have gotten it wrong: although I chose to variously anonymize and paraphrase participant voice (my on-site observations, of course, since no interviews were conducted), my blanket decision not to interview them may skew the account a reader may form in her mind of them, their communities, and their broad motivations. Similarly, selectively giving pseudonyms to the words of practitioners carries the risk of distorting the statements that remain identifiable, and similarly mischaracterizing identity, intention, and motivation. I can see no way of avoiding this situation, and only hope that my ethical decisions, which always took priority over the editorial ones relating to my thesis, were also the most beneficial (or least exploitative) ones.

\section{Privilege and the Shape of the Field}

Perhaps the most significant factors affecting my research relate to the diffuse but clearly salient social inequities currently underpinning contemporary culture. Just as my own status and social position has benefitted from such injustices in various tacit and explicit ways, so has the ecology of the field been fundamentally shaped by the same. White privilege or white supremacy, for example, continues to affect socially engaged and community arts practitioners indeed, acutely so for those facing additional social inequalities (see Crenshaw 1991). Thus, although many of the sites work with largely non-white populations, and thus have significant 
diversity amongst their artist-participants, artist-practitioners at these and other sites are generally from a less diverse background, tending to be university-educated and caucasian. While this may be slowly changing in certain contexts, practitioners of colour face distinct barriers to equal participation in the field. This underrepresentation of marginalized and minority practitioners has important ramifications that includes but also goes beyond concerns about who is and isn't in positions of power and authority.

These and other structural inequalities are clearly reflected in my own research, since it is with organizations and practitioners which possess a certain degree of privilege that I have been most successful at connecting. Thus while I believe it is instructive to engage with the rich collective experience that these practitioners maintain, I also acknowledge the idiosyncrasy and potential bias inherent in such experience, as well as how such bias (including my own) impacts the claims I might make.

I made some effort in my interviewing to contact active and experienced socially engaged artists in an attempt to correct for this and other distortions. Ultimately, however, there are limits to what such attempts to attain representativeness can accomplish. Indeed, in an ecology marked by such distinctive, incomparable, and even idiosyncratic practices, taking an artist-practitioner as representative of the aesthetics and politics for which they stand is readily prone to tokenizing and stereotyping. I have taken great pains in this dissertation to avoid such spurious claims.

That said, I have sought some input from people who take up interesting positions within the community arts and socially engaged arts ecology of current practices in Toronto. In addition to attempting to speak to practitioners from diverse ethnic, racial, and cultural backgrounds, I sought to speak with volunteers, for example, who contribute a significant amount of labour to 
the field. Likewise, I wanted to speak to emerging artists, and representatives of arts organizations conducting community outreach, both of whom may hold important insights on community arts from more conventional art school and studio based practices.

As I indicated above, I particularly wanted to speak to veterans of community arts and socially engaged arts in Toronto, as well as veteran activists or community developers, who have stayed with or come to the arts, respectively, because of the intrinsic value they have to complement, not simply support, political concerns. Finally, I should be clear that there were many people with whom I sought to speak but, due to time limits and even incorrect contact information, who I failed to connect with. I look forward to meeting them, and reencountering those I did speak with, in the future.

\subsection{Outline of the Thesis}

In Chapter 2, I will develop a preliminary genealogical history of socially engaged camera arts which traces its roots to the twin struggles over visual representation that has trailed the development of cameras since the eighteenth century, and political representation which has impacted aesthetics since at least the age of Enlightenment.

In Chapter 3, I will begin to unpack what I discovered during the course of my fieldwork. I will elaborate on what I am calling strategies of expansion that, despite specific and distinct manifestations of practice, seemed common amongst socially engaged arts. I will argue that many of the practices I explored have found success because they actively pursue these expansive strategies - namely in terms of engagement, form, and territory. Respectively, these clusters of strategic action support the development of participation and cooperation, of products and processes, and of spaces and situations in socially engaged arts, and socially engaged camera 
arts practices. Taken in sum, such strategies attempt to foster an inclusive and emergent approach to artistic work.

In Chapter 4, I will consider several ways these strategies of expansion are broadened and deepened through the use of camera arts. Continuing to explore the results of my field work, I will argue that the specific relations of camera-based representation to both the visual world and non-verbal communication support practice that expands upon what I am calling the vernacular, visible, and performative aspects of socially engaged arts.

Chapter 5 will shift focus on what practitioners had to say about the organizational context within which they, as socially engaged artists, seem to operate. In this chapter I will step back from specific considerations of particular camera-based practices in order to explore the broader conditions that support and constrain socially engaged arts in general (and socially engaged camera arts in particular).

Chapter 6 will continue in this vein, arguing that a praxis of learning mediates between artistic and organizational challenges in socially engaged arts and camera arts. I will look to existing pedagogical strategies - namely, workshops, projects, and laboratories - and explore how camera-based practices might best support and integrate into these strategies for addressing aesthetic and organizational challenges.

I will conclude by summarizing some key findings, and outlining possibilities for further research and praxis. 


\section{THEORETICAL GROUNDING: SOCIALLY ENGAGED ARTS}

\subsection{Early Roots: To the $1920 \mathrm{~s}$}

\section{The Late 19th Century}

Because of the logistics of obtaining a local photographer, occasionally a well-fed child would be put back in rags for a picture that should have been taken months or years ago. (Osman and Englander 1981, 111)

The interconnections

between and amongst socially

engaged practices and

camera-based arts can be seen

to exist, in various forms, at

least as far back as the social

reform work from the late

nineteenth century. While

some of these practices

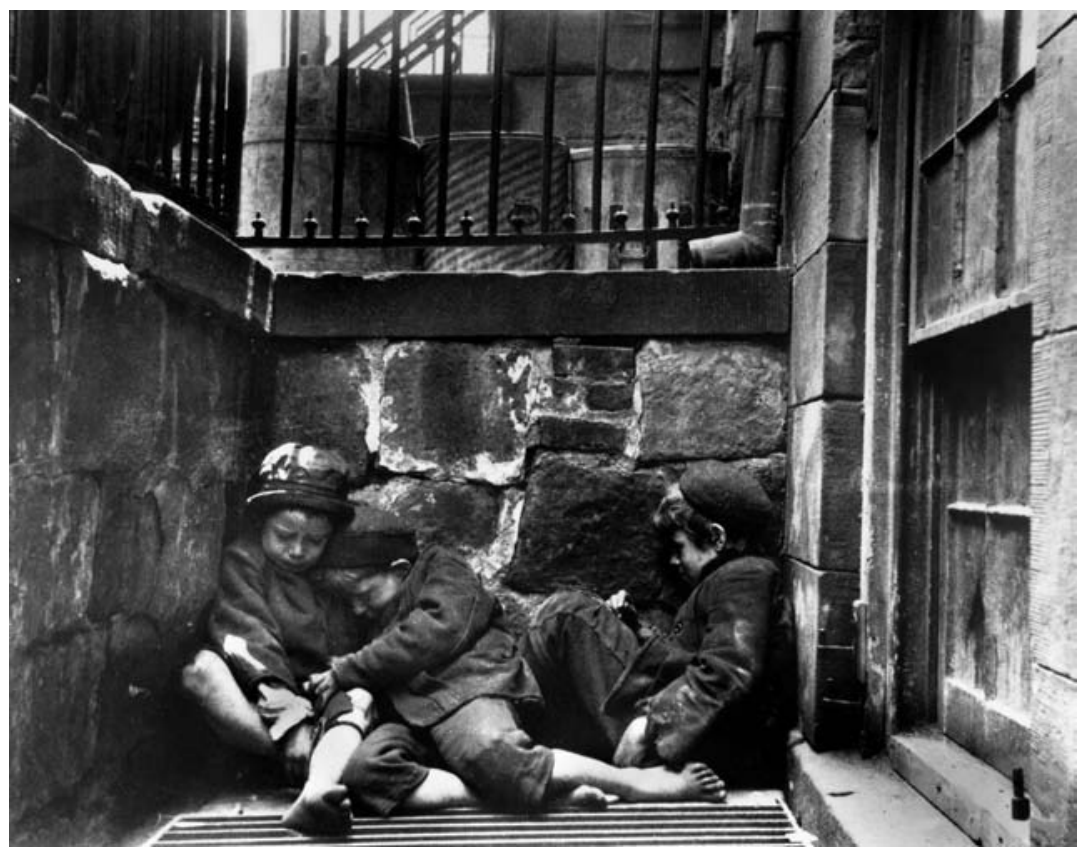

emphasized aesthetics, many

Plate 1 - Jacob Riis. 1890. Children sleeping in Mulberry Street.

deployed the medium far more instrumentally, such as in the work of Dr. Thomas John Barnardo (see Koven 1997) or Jacob Riis (see Braden 1983; Rosler 2004). Indeed, the title of Riis' most famous work, How the Other Half Lives, implies an unproblematic or naive realism informing the construction and presentation of the images, as if they were mere windows onto the worlds of his subjects and their communities, rather than formally structured and subjective images expressing certain opinions about poverty and morality, and implying certain assumptions about these and other matters. Taken so objectively, such work normalizes a seemingly reified and 
insurmountable stratification, a division that implies one group's supposed superiority over the other. Cameras were often deployed charitably in these strategies to objectively portray the destitution of the subordinate group (e.g., the urban "poor," the "noble savage" of early anthropology) by those purportedly in a more privileged position (socioeconomic, moral, and so on) to fashion such images. The matter of who can legitimately represent - or, rather, who can best make a legitimate representation - of another, which is a key thread that winds its way through this history of socially engaged camera arts, finds its roots in these early camera practices.

Interpreted broadly, aspirations for social engagement using cameras extend to photography's conception. For example, the esteemed nineteenth century French scientist, François Arago, championed Louis Jacques Mande Daguerre's early photographic process before the French Academy as being of immense public benefit. As John Tresch (2007) has argued, Arago imagined the socially transformative possibilities of the medium with such concerns as workers' labour, the dissemination of scientific knowledge, and universal suffrage. Arago was not merely sympathetic to workers' concerns. As Tresch argues, Arago's political and scientific commitments might be harmonized in what the former terms a labor theory of knowledge: “most striking,” Tresch writes, “is Arago’s insistence on the epistemological contribution of worker-inventors: the doing and making of the laborer is also a knowing" (2007, 462; emphasis in original).

Such utopian aspirations seemed uncommon at the time, however, and for at least the next three decades the use of cameras and the circulation of images was strongly tied to social stratification, particularly along the lines of income, but also in terms of gender, sexuality, and 
race. Effectively, the medium was available only to those who could afford it, due in part to the financial capital needed to secure equipment and the daylight hours needed for crafting early photographic prints - money and time that urban working classes, rural peasants, colonized populations, and others were systematically denied. Access to camera-derived imagery was also due in part to the generally singular nature of photographic images of the time. Although photographic technologies contributed to both the development of mass production lithographic techniques and the mechanical representation of motion during the nineteenth century, neither such printing technologies nor "motion pictures" were in wide enough use to make materials and technologies available until several decades into the twentieth (for example, see Bicket and Packer 2004; Charney and Schwartz 1995).

In addition, celluloid film for use in cameras was invented subsequent to photography’s inception. For at least half a century following Arago's announcement in 1839, the duplicability we now associate with camera-based images was simply not the reality, with fragile glass or paper negatives, or direct positives (as in tintype or daguerreotype) being most prevalent (the former were seldom used to make more than a handful of copies and the latter were entirely unique; for the curious, an extensive list of 19th century positive methods can be found in Hannavy 2008, 1158-61). In short, not only was access to camera technologies determined by social class standing, but so was access to their products, photographic images. The effect was that social class divisions structured access to the medium as both a process and a product for a significant portion of its early history. Such limited access worked to produce particular narratives of what the medium was able to communicate - overwhelmingly bourgeois, capitalist, and liberal - and these narratives tended to dismiss the complexity and ambiguity of camerabased forms and the labour their manufacture demanded (see Edwards 1996; Edwards 2006a). 
It is worth briefly attending to this period, I argue, because it sets the tone that subsequent imaging will take. Specifically, it is during this time that the neutrality and directness of photography was being asserted, the evidentiary realism that remains so crucial to a variety of trends in social documentary even to this day. Steve Edwards (2006b) has suggested that this assertion coincided with another, perhaps more historically prominent one related to the development of photography as an artistic medium. These two "chattering ghosts" of art and documentary, to borrow from the late Allan Sekula $(1981,15)$, worked to position photographic practice as variously image or document; or, following Edwards' argument, as either the "pristine object of art" or "lowly workaday carriers of information" (2006b, 12-13), respectively. Like Sekula, Edwards asserts that these uses of the medium are actually paired and intertwined. He uses the term "allotropic," a transposed technical scientific term, to suggest a type of material that presents, under varying circumstances, wildly

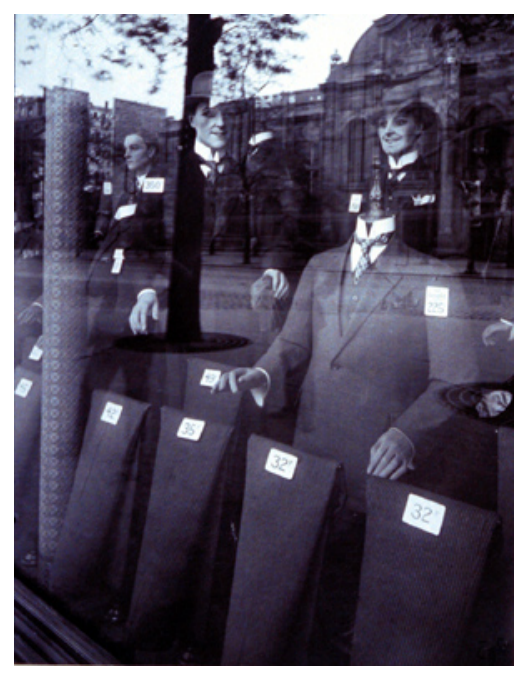

Plate 2 - Eugene Atget. 1925. Men's Fashions / Magasin, Avenue Des Gobelins.

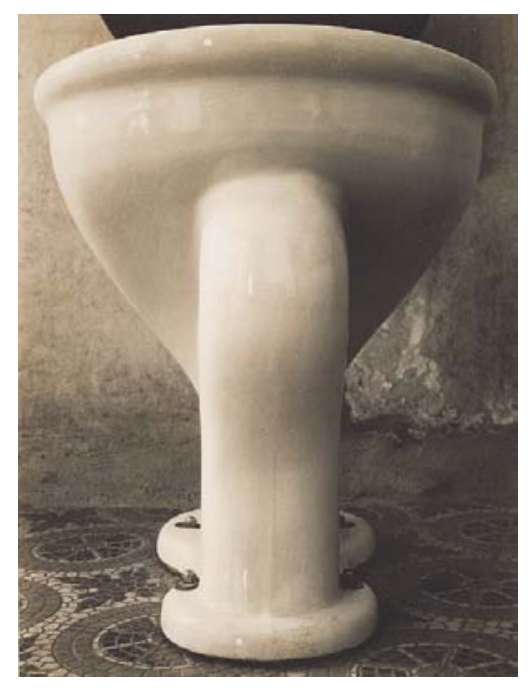

Plate 3 - Edward Weston. 1925. Excusado. distinct physical properties (also see Edwards 1996, 38). Carbon is the classic example of an allotropic material, with coal and diamond as two of its most widely differing forms. Applying the term to photography, Edwards' allotropy suggests a medium that can be put to a variety of seemingly distinct uses, each having at their core interrelated epistemological effects. (One need only think of the "art" inherent in Eugene Atget's records of turn of the century Paris, or the 
tangibility of Edward Weston's peppers or other objects; however, Edwards suggest this ceaseless "turning" from one to the other, art to document and vice versa, is fundamentally inherent in any and every photograph.) More importantly, he states:

The point I want to make about this allotropic form is not simply that photography is both art and document - the one figured by the "objective reality" in front of the camera, and the other by the "genius" who directs the apparatus - but that these elements exist as the fragments of an allegory of labor. (13-14)

Edwards' attention to labour is crucial, as it implies matters of autonomy and agency, and attends to the question of who has the material capacity - distinct from the moral right - to control a tool of representation (or, more generally, a means of production). The early days of photographic practice were marked by a strong tendency to position some people behind the lens, and others before it. This division between image-makers and subjects - overwhelmingly gendered, racialized, and class-based - invariably reflected and even asserted more general forms of social stratification. While this has changed somewhat in the intervening century, and certainly in the counterhegemonic camera arts strategies I will outline below, normative camera practices typically continue to assert such stratification. This poses a challenge for socially engaged arts.

Complicating matters is the attempt made on the part of some photographers to challenge the effects of such stratification in their practices. Su Braden's (1983) Committing Photography is one of the earliest texts to critique the normalized history of bourgeois photography from a feminist and pro-labour perspective. In it, she criticizes nineteenth century social reform photographer Jacob Riis, arguing: 
For all his humanity and in spite of his success in getting a certain number of rehousing schemes established after the publication of his book How the Other Half Lives (1901), Riis's attitude towards the poor was fundamentally based on pity and it appealed to the sentiment of pity in others. He was not concerned to reveal causes to the poor themselves to enable them to fight their own case. His intention was to use his photographs to reform the existing order but not to tamper with its established hierarchy (2).

Though he was one of the first, Riis was not unique: he was part of a tradition of social documentary that featured photographers and later filmmakers from across the world (the developed world, at least) who found in the emerging aesthetic of photography a means moreover, a strategy - with which to mobilize a particular, largely liberal version of political and economic reform, one which offered help from above, but crucially not tools from below. Martha Rosler (2004) argues that this strategy of reform was effectively charity, a practice through which inequalities are maintained:

Reformers like Riis and Margaret Sanger strongly appealed to the worry that the ravages of poverty - crime, immorality, prostitution, disease, radicalism - would threaten the health and security of polite society as well as to sympathy for the poor, and their appeals were often meant to awaken the self-interest of the privileged. The notion of charity fiercely argued for far outweighs any call for self-help. Charity is an argument for the preservation of wealth, and reformist documentary (like the appeal for free and compulsory education) represented an argument within a class about the need to give a little in order to mollify the dangerous classes below, an argument embedded in a matrix of Christian ethics (177). 
The work of Riis and others tacitly and compellingly suggests that alternate forms of representation had become necessary because they could, and did, bring attention to matters of social stratification in profoundly original ways. While their images can be seen as partial precursors to the socially engaged camera practices that only really began to develop in the 1920s, it's clear that their processes were deeply flawed. While the content seemed to portray a subject matter that was largely unspoken and invisible, the means by which such content was rendered was profoundly objectifying and ethically objectionable.

\section{Related motivations influenced the}

subsequent, early twentieth century photographs by Lewis Hine of workers in the southern US, and by Edward S. Curtis of native North Americans. Although sympathetic to his subjects and their communities, Curtis nonetheless simplified his subjects by declaring his images to be documents of a "vanishing race" (see Curtis 1972; Curtis 2007). To borrow from Jay Ruby’s (2000a) insightful reading of tendencies in the history of ethnographic film, Curtis's images represent less an objective view of a shrinking indigenous North American population, but rather an instance of privileged authors speaking "for" or "about" their (purportedly abject and mute) subjects, with all the

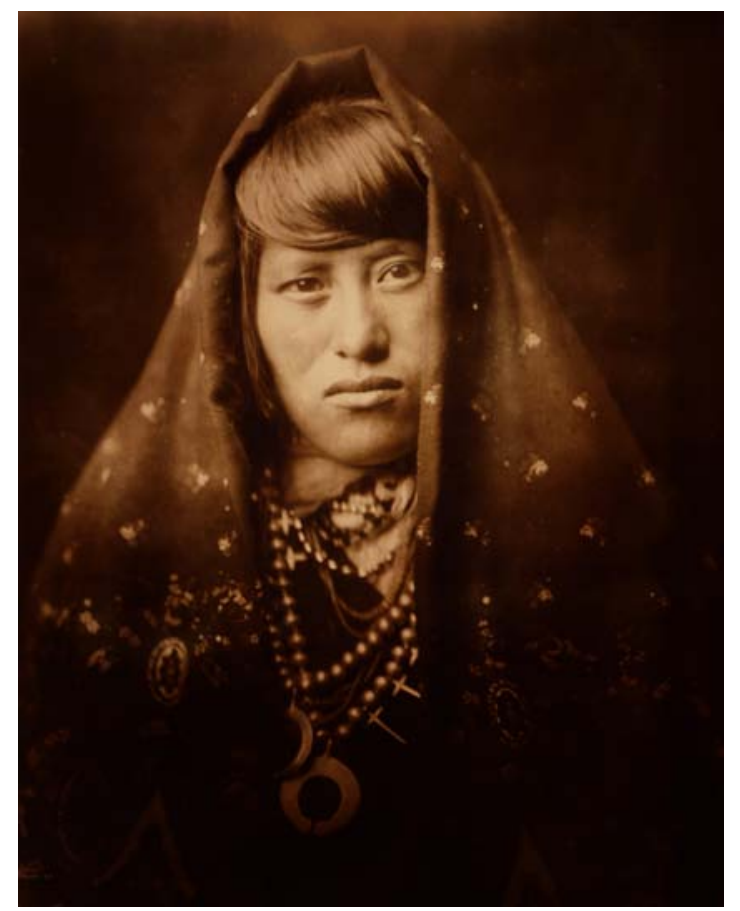

Plate 4 -Edward S. Curtis. 1905. An Acoma Woman.

Although critiques of naïve realism (as in the work of Curtis and Riis) in historical accounts of camera practices are now common, canon continues to cast a long shadow. As Ribalta, Tsinhnahjinnie, Wolf, and others have more recently argued, the work of historical contemporaries who were critical then of more mainstream methods and representations is a project that demands further consideration. 
misrepresentations, stereotyping, and even fabrications that might be associated with narrating cultural identity based on minimal involvement "with" (or in the absence of co-production “alongside") those being represented. Hulleah J. Tsinhnahjinnie (2003), a

Dine/Seminole/Muscogee photographer and artist, addresses the complexity of such representation, a complexity to which Curtis would have been blind. Critiquing his image of an Acoma woman, Tsinhnahjinnie writes:

\begin{abstract}
Aboriginal beauty. Curtis photographed a beautiful Acoma Pueblo woman staring into the lens. It is an intense moment, not exactly an endearing stare. Curtis was the voyeur photographer aware of the physical. What of her mind? Her thoughts of yesterday, today, and tomorrow? I can relate to the energy that she emits. It reminds me of the summers when my father, a painter, would travel to Monument Valley or Canyon de Chelly to paint the landscape and sell the paintings to the tourists who were watching him paint. My brother, sister, and I would play nearby, climbing the red rocks, playing in the sand. The tourists would call us over and take our picture, sometimes giving us a quarter, the look I perfected was the look that the Acoma woman is giving Curtis: "Take your photograph and...." I like this image: perhaps I am projecting, but isn't this what it's all about? (Tsinhnahjinnie 2003, 48)
\end{abstract}

Tsinhnahjinnie's meditation hints at a profound depth of cultural experience to which Curtis, and many of his viewers since, would have remained oblivious. It is important to remember, however, that this is not an inherent characteristic of the medium, but of the normative practices developed around it. Certainly, examples exist that counter the dominance of this "speaking about" tradition in camera based practice. Tsinhnahjinnie, for example, refers to 
the work of Jennie Ross Cobb (Aniyunwiya; see Tsinhnahjinnie 2003, 48-49), a nearcontemporary of Curtis. However, it is not until the end of the first World War and emergence of cooperative camera organizations that the dichotomous and objectifying relation between author and represented subject gets challenged, and the first tentative steps toward socially engaged camera arts are made. Even so, instances of conscious and critical engagement of image-makers with their participant-subjects, where photographers and filmmakers actively sought to "speak alongside" rather than "for" or "about," remained episodic for at least another century. Nevertheless, there were antecedents.

\subsection{Worker Film and Photography}

\section{The Interwar Years to the Cold War Consensus}

Riis published How the Other Half Lives at approximately the same moment that George Eastman, founder of Kodak, invented his famous Brownie camera (1890). The most financially and technically accessible photographic technology of its time, the Brownie is frequently cited as the single technological development that precipitated the shift of photography away from the dedicated amateur practice that preceded it, and the more casual but ubiquitous popular photography that followed (for example, see Freund 1980; Braden 1983; Ford and Steinorth 1988; Brayer 1996). The Brownie, containing both a simplified optics and shutter system and dry-plate photo-chemistry affixed to a flexible celluloid material, was designed to engage a broader and, importantly, consumer audience.

Implied in the shift toward ease of use is the argument that the Brownie contributed to organizing photographic, and eventually all camera-based labour, in key ways. To facilitate ease of use, crucial mechanisms were simplified, reducing the chance for end users to make mistakes, 
but also limiting their ability to make technical interventions. In turn, to determine preferred settings for such mechanisms, standards were established that created fixed relationships between and amongst certain properties. Many of these standards persist to this day - for example, "ISO," a measure related to photochemical film sensitivity, remains on digital cameras, and "F-stop" remains the nomenclature for aperture settings. However, many of these standards were established with "ideal conditions" in mind - typically bright, cloudless, sunny days, moments when many people were at work, whether domestically or in the labour force, and certainly in the temperate climates of Western Europe and North America. As Su Braden (1983) argues:

Life as it was being lived by working-class people in the 1880 s was very tough, but the design of Eastman's camera did not make it possible for them to photograph crucial elements of their histories such as working conditions in the factories or the insides of their homes. Even very much later, [...] there are few photographic records of the interiors of working-class homes (19-20).

The technical limitations of recording scenes in low light were coupled with a functional simplicity that made recording scenes in brighter, sunnier conditions almost a necessity for a good portion of the history of consumer photography. Braden's argument is that the technological limitations of the medium affected, if not determined, the social conditions of its subsequent use. Later she adds:

Technical access to photography and, by implication, to the publication of images has been largely determined by the natural profit motives of the manufacturers of cameras and processing materials. The fact that photographic skills are generally thought of as 
being instantly accessible is due to the decision of the manufacturers to concentrate from the very beginning on simplification rather than on a complete system of training, to make photography accessible to as wide a buying public as possible. In doing so, they have not only imposed many restrictions on the type and quality of photographs that most people produce, but also on the way the majority of us view the use and distribution of photographic images (20).

Writing in the early 1980s about developments nearly a century prior, Braden's argument raised profound questions about the ambivalent relationship between camera-based technologies and the techniques of capitalism. It is no coincidence that her argument emerged during the decline of the welfare state in Britain and simultaneous rise of Thatcherism (social and economic conservativism). Indeed, the parallels Braden sought to make between community arts and photography and the emergent critical photographic practices of the past continue to be relevant today as new modes of visualization (based upon digital technologies and networked social media) are made to interact with familiar modes of political economic practice (late capitalist and representative democratic regimes that bore more than a passing resemblance to authoritarian regimes of the past).

A crucial part of Braden's argument involves the development of worker-photography, an international movement that roughly began just prior to the First World War and ended near the beginning of the Cold War (signalled, arguably, by the closure of the NY Photo League in 1951; see Tucker 1983; Klein and Evans 2011; Tucker 2011). At times, this movement recognized the work of less politically-committed and less renowned amateur photographers - and, later, filmmakers - who strove to document everyday home and work life (see Erika Wolf's discussion 
of proletarian photography and fotoliubiteli, Wolf 2011). As Michael Denning (2011) has argued of the US cultural front during the 1930s, a significant portion of those attached to the movement are "fellow travellers" with only informal affiliations to political parties or organizations of the era. To exclude this sizable group from analysis may afford a more strategic view of the worker film and photo movements proper, but at the cost of a consideration of the effect, particularly in the US, where the left was far more dispersed and disparate. At the very least, I believe, a history concerned with socially engaged camera arts should not discard such amateur or vernacular image-making so hastily, however complex it makes the task of analysis.

Nevertheless, the formal worker-photography movements remain better documented and studied. It is generally agreed that it initially began in the newly formed Soviet Union in the early 1920s (see Wolf 2011), but similar practices emerged in Germany, the US, and other European countries by the end of the decade. Although national, and even local, worker film and photo organizations developed relatively autonomously from one another, they contributed to systems of publication, exhibition, and distribution that circulated photographs and toured films internationally. Several histories now exist about the various movements and their members (the most recent being the catalog to Jorge Ribalta's curated exhibit A Hard, Merciless Light: Worker Photography, 1926-1939 at the Museo Reina Sofia, Madrid, as well as Mason Klein and Catherine Evans' The Radical Camera: New York's Photo League, 1936-1951. See Museo Reina Sofia 2011; Klein and Evans 2011). Rather than reproduce these complex histories in any detail, let me draw out a few key themes that point to this being a significant moment in the history of socially engaged camera arts.

First, the emergence of worker photography coincided with the technical development of 
a popular press capable of producing print runs of specifically visual materials to thousands and even millions of readers (see Bicket and Packer 2004; Ribalta 2011). Although technical innovations to film and camera technologies had advanced in the years since the emergence of dry plate negatives (the Brownie) during the 1880s and 1890s, it wasn't until affordable halftone lithographic printing presses became widely available that photographs could be widely duplicated and distributed. Further, it was with an emerging political ethos that a novel symbolic form and content (such as that offered by nascent photojournalism and photo collage as well as professional encouragement of amateur production and publication) could find an audience. Also of importance is the development of affordable motion picture film-making, duplicating, and projecting equipment. Although this period witnessed the rise of early documentary auteurs (such as Dziga Vertov and Robert Flaherty, among others), new, non-bourgeois aesthetics were being developed, and attempts at cooperative and collaborative authorship also began to emerge. During the 1930s in particular, many of the worker organizations were redefined as film and photo leagues, with the effect being that both resources and expertise related to these media were pooled. Worker photographers collaborated on films, filmmakers shared space and equipment with photographers, both participated in or coordinated workshops and contributed to common print publications (such as newsletters), and film screenings were often paired with photography exhibitions in shared or adjacent spaces (see Rosenblum and Osman 1983).

A second theme is that the development of worker-centered practices coincided with the major political concerns of the era: namely, the establishment of the Soviet Union, the sociopolitical upheaval fostered by the Great Depression, and the fight against fascism in Germany and Spain. Indeed, "coincided” makes the relationship between cultural production and politics seem spurious: in many cases, filmmaking and photography not only responded to the 
era's political changes, but contributed to inspiring them. This, however, is a contentious issue: the role of culture and cultural production in political action was highly disputed at the time (for example, see Sochor 1988); and the creative output of the era was subsequently dismissed by many for its seemingly overt political and propagandistic leanings (and not only in filmic and photographic production). Unfortunately, such denigration has effectively ignored the radical novelty of such production: the kinds of collectivization and collaboration - of material resources, not simply political ideas - needed to maintain both local facilities, equipment, and expertise as well as international networks of circulation and distribution have been, unfortunately and unfairly, relatively ignored. With the emergence of participatory and collaborative practices as the vanguard of contemporary artistic practice, this early iteration of collectivized labour has, until recently, been too readily dismissed.

A third theme is that the development of worker-centered practices was often reciprocally informed by aesthetic practices of professionals in film and photography. In many circumstances, of course, the presence of professionals had a chilling effect on amateur camera arts practices (such as in the emerging Soviet Union, where representational practices came increasingly under state control; see Wolf 2011). However, this was not universal. In certain notable examples - from the open submission calls of the Soviet journal Sovetskoe foto or the German journal Arbeiter-Illustrierte Zeitung (AIZ) specifically directed towards amateur imagemakers, to the mentorship practices of the Workers Film and Photo League or Nykino in the US (Ribalta 2011; Wolf 2011; Tucker 1983; Tucker 2011) - the intermingling of professional and amateur image-making offered spaces for rich cultural exchange.

Although the actual impact, national or international, of the worker film and photography 
movements has been criticized (for example, see Forbes 2011), the work came to influence a broad range of practice, most notably that done in the UK at the beginning of the 1970s called "community photography."

\subsection{Arts and Social Welfare: The Emergence of "Community Arts"}

As I suggested above, perhaps the most important account of the community photography movement emerging in the UK during the 1970s is Su Braden's Committing Photography (1983; see also Braden 1978). Written at the tail end of that movement, Braden's critical history weaves together portraits of groups and individuals at its forefront during the 1970s and 1980s (such as Jo Spence and the Hackney Flashers Collective, Half Moon Gallery and the journal Camerawork, or Bootle Art in Action) with the work of social documentarists like W. Eugene and Eileen Smith and Philip Jones Griffiths, and critical thinkers like Walter Benjamin, Hans Magnus Enzensberger, and Paulo Freire. Indeed, and particularly when coupled with the essays found in the two volumes of Photography/Politics (Dennett and Spence 1979; Holland, Spence, and Watney 1986), Braden's account provides an important theoretical bridge: on the one hand, linking the emergence of UK-based community arts practice to the strongly class-based politics of the worker arts movements; and, on the other hand, articulating interconnections between and amongst the strongly identity-based politics of contemporary poststructuralist, feminist, and postcolonial art and cultural practices. Braden's monograph is all the more important for arriving at a time (a nascent postmodernism) when the social functions of art in general, and the realist claims of film and photography in particular, were heavily criticized and increasingly denigrated by a deracinated mainstream art historical discourse (see Roberts 1998; Van Gelder and Baetens 2010). 
Also at this moment, film and photography were becoming increasingly institutionalized in the spaces of art world exhibitions, galleries, and museum collections (for an excellent critical review of the literature on this tendency, see Ribalta 2008). Such an institutionalization signaled a number of cultural and political shifts - what Michael W. Apple (2000) has called a "conservative restoration," characterized by a broad shift away from agential democratic participation and toward less critical "consumptive practices". In short, a weakening of the state (particularly the welfare state), the strengthening of corporate control, and the normalization of the broad logic by which these practices seem to become "common-sense" in discourse and practice (much of which can be captured, albeit simplistically, under the concept of neoliberalism; however, Apple's own concept of "conservative modernization" is arguably more robust. See Apple 2000; Apple 2004).

Most germane to this study, an institutionalization of particular art forms implied that camera arts were no longer as attached to the avant-garde as they once might have been. Indeed, and in general, the shift away from avant-garde camera practices had already happened much earlier, so that even by the 1960s, much of what had become the avant-garde tended to favour the formalist and embodied practices of minimalist, conceptual, and performance arts over the more seemingly ocular-centric expressivity of representational film and photography. The influence of Frankfurt School "culture industry" and structuralist "semiological" critiques of mass culture contributed to a tendency for critical camera practices to emphasize deconstructive critiques of popular mass media practices, and shy away from developing the realist aesthetics and cooperative and collaborative aims of their antecedents.

Guy Debord's thesis about the "society of the spectacle" (2006), for example, did much 
to dampen the critical thrust of the realism that documentary film and photography seemed aligned with. Debord's thesis focused on the ideological and illusionistic dimensions of contemporary society, effectively (if implicitly) accusing all camera-based practices of objectifying the world and superficially portraying appearances as if they were contiguous with reality (for a rather devastating critique of Debord, see Berman, Pan, and Piccone 1990). In short, photorealism in moving and still images was treated as suspect by those on the left, even though socialist publications continued to use such images and, indeed, even model their images on mainstream pictorial conventions:

There are, of course, important differences in the photographic subject matter between the commercial and left press. The left are less likely to use sexist photographs of women, sentimental pictures of royalty, animals and children, car or aircraft disasters and so on - the mainstay of the commercial papers. Instead they concentrate on pictures of demonstrations, pickets, left party and union officials, conferences and celebrations, such as festivals or ideologically correct rock concerts. The purpose of the photographs is seen as a boost to morale, showing fellow workers dissenting, active and organised (Braden 1983, 36).

Contradictions arising from this distrust of images coinciding with the tacit recognition of their continuing power resulted, Braden argues, in a fairly pedestrian use by the left: "The positive image the left press tries to give to militant workers is the absolute minimum that can be done to communicate a socialist perspective" (Braden 1983, 36). David Trend (1992a) goes even further, stating in a different context:

All too often, Left culture has consigned itself to a reactionary posture in which the very 
terms of its struggles are defined by the opposition. This locks progressive activists into a one-dimensional paradigm of response, casting them as the voice of a marginalized and subordinate Other. Such an attitude precludes the articulation of a positive agenda that might define the terms of an argument. (26)

Braden prefigures this sentiment, arguing, "The reluctance of the left in Britain to take a positive attitude towards the creation of a visual language expressive of its views amounts to what is virtually a philosophy of iconoclasm" (54). She goes on to suggest that left-leaning community organizations that remained at some distance from the core of the political party were most successful at instantiating critical and collectivized practices. At the same time, as such organizations and artists sought to deploy the rhetorical strategies of the visual materials of the earlier era (including print journals, posters, exhibitions and so on), they attempted to do so in ways that challenged the inequalities - whether assumed or actual, such as patriarchy, singular authorship, professionalism, or formalism - inherent in the practices of their predecessors.

Collections like the already mentioned Photography/Politics: One (Dennett and Spence 1979) and Photography/Politics: Two (Holland, Spence, and Watney 1986), as well as Stevie Bezencenet and Philip Corrigan's Photographic Practices: Towards a Different Image (1986), and the journals Camerawork (see J. Evans 1997), Screen Education (see Alvarado, Buscombe, and Collins 2001), and Ten.8 (see Dewdney 2011), did much to enrich such cultural production praxis with a range of critical thought that actively sought to enlarge the scope of discourse and praxis beyond Marxist, class-based critique.

\subsection{To the Present: Cameras and Democratic Arts}

It is tempting, at this point, to suggest that socially engaged camera practices went into a 
period of dormancy beginning in the mid- to late 1980s. It can certainly be argued that the effects of Thatcherism in the UK, and the so-called "culture wars" in the US during the 1980s played a role in chilling the artistic experimentalism of the previous two decades and state-sponsored patronage of cultural production of all kinds. Thus while cuts to funding were a significant part of the challenge, postmodern discourses that were openly hostile to camera-based realism (as if it were synonymous with scientific positivism) achieved the dominance during the same period (see Jay 1994 especially chapter 10, "The Ethics of Blindness and the Postmodern Sublime"). Simultaneously, concerns with labour and (radical) Left politics in relation to art were denigrated; Gail Day (2010) has referred to this drought in the history of critical art theory and practice as the "long nineteen-eighties" (23; quoted in Edwards 2012,2). On a more practical, policy-oriented level, David Trend (1992b) has argued that the demise of nascent programs, like the NEA's (National Endowment for the Arts) artists-in-schools program, threatened to undermine the attention to labour that critical amateur production in the arts had begun to foster (especially chapter 2, "Living in the Material World;" see also Bolton 1992). Finally, important critical journals of the era, such as Ten.8 and Camerawork, folded by the early 1990s, significantly altering the terrain upon which international discourses rooted in critical camerabased practices could be carried out. (A few, however, such as Afterimage, continue to be published. For an anthology of Camerawork essays, see J. Evans 1997; for an anthology of the journal Screen Education, see Alvarado, Buscombe, and Collins 2001)

However, it is perhaps more accurate to say that antecedents to socially engaged camera practices during this time began to develop across a wider range of contexts than before. Anthropologists like Sol Worth and Jay Ruby, for example, worked to develop disciplinary and cross-disciplinary academic practices that aimed to consider vernacular, amateur-produced, or 
"home mode" (Chalfen 1987) visual communications as rich fields of sociocultural analysis (see, for example, Worth and Adair 1997; Worth 1981; Ruby 2000b). Their efforts, along with those of colleagues like Howard S. Becker, Richard Chalfen, Larry Gross, Doug Harper, Jon Wagner, and others directly contributed to the development of journals like Studies in the Anthropology of Visual Communication (SAVCOM) and Visual Sociology (now Visual Studies) and professional academic organizations like the International Visual Sociology Association (IVSA) and the Society for Visual Anthropology (SVA).

While these practices demonstrate a sophisticated blend of praxis and theory, there is more work to be done in assessing whether or to what extent their alignment with academic and other institutional structures impacts upon the radical critique and cooperative tendencies (rather than stratified disciplinary organization) launched by their predecessors.

Indeed, even if community photography largely ceased as a spatially and temporally bound entity, ending in the UK in the early 1990s, its goals may have migrated, directly or coincidentally, to the praxis of using visual communicative tools and strategies in and with a range of communities and non-governmental, non-corporate organizations. For example, the work of Deborah Barndt (Barndt 1980; Barndt, Cristall, and Marino 1982; Barndt 1991; Barndt 2011) has demonstrated the important role of critical and participatory documentary in supporting popular education practices in the global south. Locally, Barndt was also instrumental in developing The Moment Project of the Jesuit Centre for Social Faith and Justice. With artist Amy Gottlieb, Barndt co-taught "Community Photography for Social Change," a year-long course for community workers. The project resulted in the collaborative production of a number of community photo-stories on social issues that were subsequently published quarterly in the 
Jesuit Centre publication, The Moment. Barndt's images, including those collaboratively produced, serve to do more than simply depict key figures and events from the flux of social movements: instead, they balance the contingency inherent in such labour with the archival and testimonial characteristics of the medium, and provide both an objective and affective basis upon which to engage with a movement as it was from the position of social movement building as it continues to be. (As co-founder of the Community Arts Project at York University, Toronto, and general champion of the city's community arts ecology, Barndt's on-going presence in the field see Charlton et al. 2013- demonstrates a practical, not merely theoretical, commitment to linking past and present.)

Other artists from Canada and the First Nations were notable in embracing cooperative and collaborative methodologies, with the labour-oriented photographic work of Carole Condé and Karl Beveridge (see Tuer 2005b; Condé, Beveridge, and Barber 2008), and the incorporation, in 1985, of the Native Indian/Inuit Photographers' Association (NIIPA; Native Indian/Inuit Photographers' Association 1996), followed a year later by the Mayworks Festival of Working People and the Arts (in 1986; Mayworks Festival of Working People and the Arts 2012). Mayworks, in particular, asserts an explicit concern with the kinds of labour-oriented, identity politics infused, and participatory in its objectives. From their website:

Mayworks' artistic vision is specifically guided by our equity policy that recognizes the systemic discrimination and injustices faced by equity-seeking groups, and designates women, First Nations people, people of colour and queer-identified people as being disadvantaged in our society. To that end, our artistic vision actively seeks to allow for representation of these designated groups both as audiences and artists, and in the type of 
programming we do. We are also guided by a desire to provide programming that will engage new, non-arts audiences, and that will challenge euro-centric notions of art (Mayworks Festival of Working People and the Arts 2012).

A number of artist-run centres (ARCs) concerned with contemporary arts and camerabased practices have also supported such cooperative and collaborative programming and project work. Here in Toronto, Gallery 44, an artist run centre that maintains exhibition space, darkroom facilities, and an outreach program was established in 1979 (Gallery 44 2014), as was A Space Gallery (founded in 1971) - a multi-disciplinary artist-run space which, in 2000, hosted the Community Art Biennale, helping foster the critical volume it subsequently published (see FordSmith and Methot 2001). The more recently established Whippersnapper Gallery is actively supporting community arts among other practices, with a dedicated focus on emerging artists and visual practices (see Whippersnapper Gallery 2015). (The ArtBridges/ToileDesArts project maintains a comprehensive listing of contemporary socially engaged arts practices from across all of Canada, including Toronto. See ArtBridges - ToileDesArtes 2015.)

It is clear, in short, that there is a great deal of diversity in what seems to be a burgeoning contemporary practice. Recent methodological and practical innovations, like photovoice (for example, see Wang et al. 2004; Wang and Redwood-Jones 2001; Wang and Burris 1997; Wilson et al. 2007) or digital storytelling (see Bromley 2010; Lambert 2012), have entered the repertoire of many organizations, alongside legacy and inherited practices (often innovations themselves). Even many non-arts organizations, particularly those in health promotion and social services and which have long supported socially engaged arts efforts, have shifted their mandates to make art a more central component of their activities. 
This is all accomplished, of course, with varying degrees of success. It need hardly be said that diverse practices do not necessarily guarantee diverse and equitable participation. In fact, as policy discourses like "creative cities" become increasingly mainstream, profound contradictions emerge as some interpretations of what art is and what it should be doing begin to take precedence over others. All this is happening within a broader social context: where neoliberal economic policy still seems to be dogma; where a conservative - and often also xenophobic, racist, heterosexist, patriarchal, transphobic, ageist ... (should I go on?) - social policy seems to be met with an ever weakening opposition; where the financial impoverishment of artists - even those with training or experience in other fields - seems only to be deepening. What is going on?

It's unfair and absurd to lay society's current problems at the feet of socially engaged artists, just as it would have been ludicrous for their predecessors to be blamed for past problems. Nevertheless, if we leave artists blameless (as perhaps we should) we must focus the critique on art itself, which has a key role to play in making change. This is not necessarily in terms of ameliorating social problems and fixing cultural crises, but in terms of envisioning or rehearsing new cultural forms and novel aesthetic practices, particularly at a structural level. In this sense, something is failing: these forms, or at least their implications, remain largely unperceived; these experiences largely inaccessible. Socially engaged arts may - and do - foment profound change on a local level, but couldn't they go farther? As I will argue throughout the rest of the dissertation, I believe that socially engaged camera arts - and socially engaged arts in general are positioned to help take on this challenge, particularly in how they might contribute to imagining and envisioning the kind of world we wish to see precisely by offering us the means of taking a hard, empathetic, and ultimately interventionist look into the one we already have. 


\section{FINDINGS, I: STRATEGIES OF EXPANSION}

This chapter will explore the conversations I had with practitioners of socially engaged arts and socially engaged camera arts in Toronto, and consider some of the experiences I had participating in events and activities they helped coordinate. While it is true that these and similar practices may bear little overt resemblance to one another, and while practitioners may hold quite distinct opinions of what matters most to a successful socially engaged art practice, commonalities exist nevertheless. In the next chapter I will explore several key roles that cameras seem to most often play in materializing this art in its contemporary forms and practices. In this chapter, I will explore what I perceived to be the dissatisfaction with and active resistance to dominant notions of art in general - whether perceived or actual - that practitioners hold in common.

To this end, I am suggesting that socially engaged arts organizations are concerned with addressing - practically, artistically - three key concerns. These concerns relate to the distinct concepts of engagement, form, and space. In order to appreciate the import of these concerns, I will reframe them as questions, namely: "Who might participate in art?" "What forms might this art take?" and "Where might art take place?" Indeed, given the critical and political edge to much of this work, the questions may be better put as "Who else might participate in art?" "What other forms might art take?" and "Where else might art take place?" These questions represent what I am claiming to be three key strategies of expansion that are common to distinct instances of socially engaged art. They also serve as a way of organizing the common threads that link practitioners working in the field who have hailed from distinct social, cultural, political, economic, artistic, and educational backgrounds. 
I am using the term strategies of expansion to characterize the labour involved in realizing the particular approach to artistic practice that socially engaged art offers. This is because practitioners' understandings of art are generally embedded in their praxis rather than in some explicitly defined philosophy of what art is or should be. For practitioners, in short, socially engaged art resides at least as much in the strategies they use to realize their visions as in the forms such art might eventually take.

For many of the practitioners with whom I spoke, this particular cluster of pragmatic concerns (namely over how art is done, with whom, and in what spaces and situations) have become foundational to their artistic practice. For Leah Houston, for example, cooperation and collaboration are imperative on a personal level:

In terms of my own life, community arts is what excited me as an artist. I always found myself being drawn to art and wanting to do art from the time I was a little kid, but it never landed for me until I found a way to do it with other people. In a sense, it's not even a choice that I'm responsive, it's actually who I am artistically - what I actually need to make art is that input of a neighborhood.

Yet, although personal, Houston's concerns are not meant to result in a wholly individualistic art but are rather expansive, intending to draw participants and practitioners - and, indeed, communities - into a mutually informing and reciprocal creative praxis. As we will see, personal creation is not necessarily abolished in socially engaged arts. Rather, the intention is to actively reframe and strategically incorporate it into work done with others. Moreover, the division of labour that such socially engaged arts strategies imply is radically redefined, potentially leading to not only new creative forms and practices, but those in other fields of 
social and cultural endeavour as well.

This chapter explores, in turn, these three broad strategies to which socially engaged artists appears committed. By declaring each concern a strategy of expansion, I am suggesting that each signals an attempt to steer the broader field of art toward greater inclusion: first, by expanding engagement in order to reconceive who can legitimately participate in artistic activity; secondly, by expanding the range of forms and gestures that art might take in order to reconsider and revalue the labour involved in creative making; and, thirdly, by expanding territory conceptually and physically - in order to reimagine legitimate contexts of making and, importantly, exhibiting and distributing art.

\subsection{Expanding Engagement: "Who else might participate in art?"}

\section{Engagement as Inclusion}

The question of who can participate in creative cultural practices, and in what ways, is central to socially engaged arts. As such, strategies that aim to expand engagement are concerned with multiplying the roles people might play in making art, and soliciting a wider demographic of possible participants to fill these roles. Leah Houston hints at the inclusive approach to engagement taken by her organization, MABELLEarts: "We work with people of all ages and we try very hard to work across ages as well. Our work is intergenerational as much as possible, rather than [split] into youth, kid, adult, senior (though we do some of that as well)."

Here Houston not only outlines an inclusive approach that attempts to draw many different groups into artistic activities; she describes an approach that depends on a collectivization of those activities. In my experience at MABELLEarts, this particular idea of inclusiveness took the form of several distinct activities occurring simultaneously and 
contiguously within a single common space. Participants could engage in any of these activities, in whole or in part, or even choose non-participation in order to simply be present in the space with friends, family, neighbours, or colleagues.

MABELLEarts provides a single example of engagement, however: other socially engaged arts practices might prefer a more singular focus for their activities, or offer a more guided or facilitated experience for their participants. Such facilitation might range between greater or lesser pedagogical direction - that is, more or less traditional instruction in an artistic method or process. However, as Michael Burtt suggests, what is significant is that these strategies are generative: “It's important to me that there's a mix of people, that it wasn't [ever] just 'This is about [Parkdale community] members!' but it was about a group of people who find themselves in this room."

As we shall explore below, this generativity may inform art and organizational practice in widely different ways. In general though, and with both Houston and Burtt as examples, we might claim that the strategies practitioners deploy to include and engage participants impact upon the decisions they make about the artistic direction of their organizations.

That said, inclusion and engagement takes numerous forms. For example, for some artists and organizations - particularly with those working with communities that face discrimination or even open threats of violence - open door policies may not work. Finding and supporting participants for artistic collaboration assumes distinct challenges in these contexts, as crucial parameters about what is inclusive and what is a reasonable form of engagement change. Boundaries for safety and security may need to be explicitly developed and conscientiously maintained, for example, and ground rules to ensure equity and accessibility may need to be 
more explicitly enacted in some practices than in others.

Paradoxically, while such efforts may outwardly appear to limit access to certain groups, they may in fact ensure fuller participation, especially for distinctly marginalized individuals. In this sense, limiting who can participate and expanding engagement are not mutually exclusive strategies; indeed, for success, the latter may depend on achieving the former. For example, the work Kim Crosby does with queer spectrum youth at the People Project - who are also often youth of colour - typically demands work be done in spaces that ensure a certain level of physical and emotional safety and security. Since such spaces typically feature practices that may be uncommon in other spheres of participants' lives (for example, by actively deploying equity or anti-oppression frameworks), they are crucial to such cultural practice. At Regent Park Focus, where the majority of participants are school-aged minors, physical access to the studio space is secured, requiring both participants and practitioners to log themselves in and out on timesheets as they enter and leave the premises. Each practitioner at Focus is additionally required to obtain a criminal record check before they may even begin and in order to continue to work - whether in a volunteer or a paid capacity. Here, both limited, secure access and negotiated ground rules (guided by anti-oppression principles, institutional conventions, and so on) contribute to realizing a space that is intended to be both safe and inclusive.

For critical, activist art-making that aims to be inclusive, the need to establish formal conventions regarding access raises necessary and important complexities. For example, Phyllis Novak at Sketch described to me the need for drop-in spaces that were both inviting for the street-involved youth her organization typically welcomes, but that also acknowledged and worked to limit the kinds of stimuli or "triggers" that might adversely affect artist-participants 
from this particular demographic. Novak acknowledged that Sketch can neither prevent crises nor anticipate all potential conflict, but she argued that socially engaged arts spaces and practitioners can and should nevertheless strive towards such a goal through whatever means are available. For Sketch, this has meant developing a range of strategies which include designing and furnishing shared spaces to maximize visibility in common areas, mandating anti-oppressive training for paid and volunteer staff, maintaining a responsive and emergent organizational practice that can ideally adapt to the changing needs of participants and practitioners, among other, not strictly artistic, innovations.

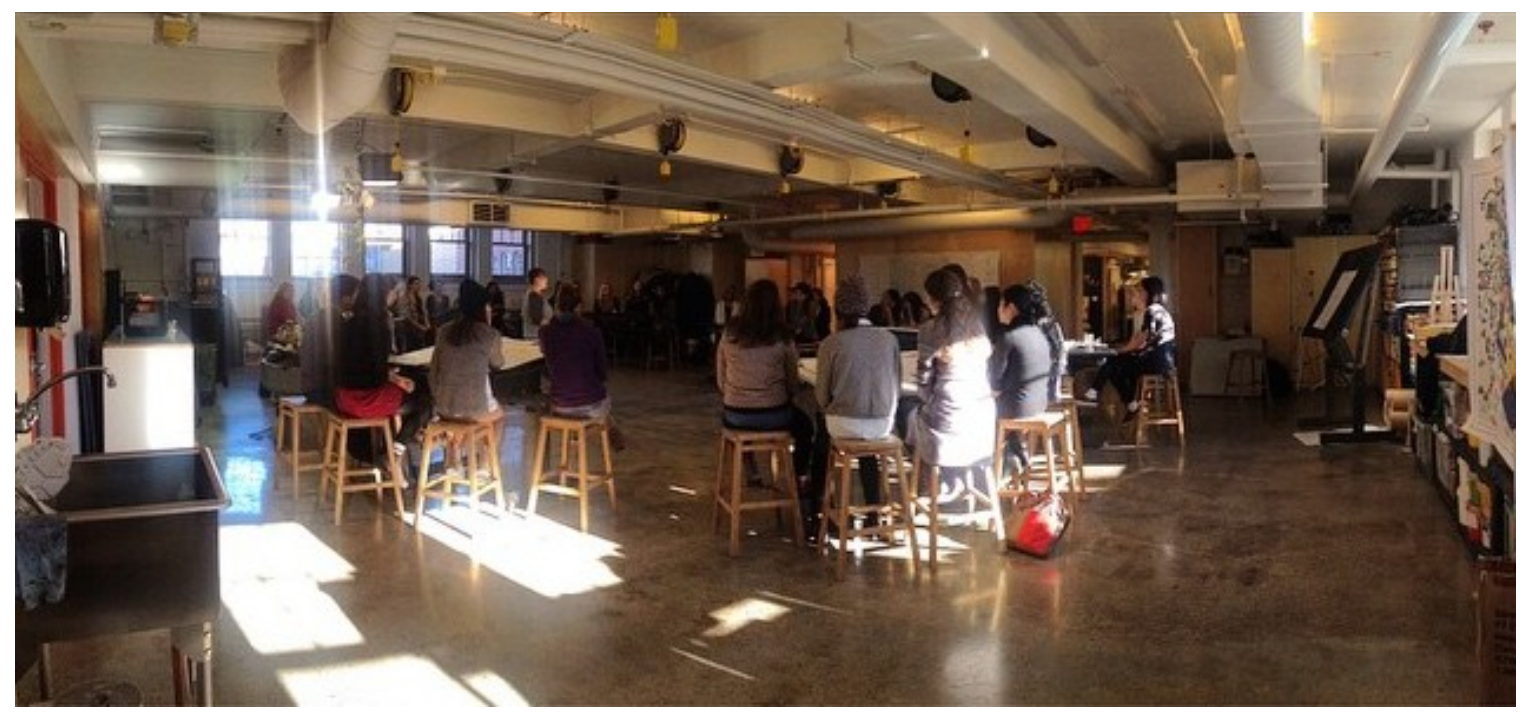

Plate 5 - Panorama of the Sketch studio space during a workshop on Art and Public Health.

In general, the socially engaged artists with whom I spoke were keen to make art in cooperation with an expanded group of participants, and were willing to go to great lengths to do so, often in spite of the technical challenges or conflict that this mode of art-making might bring to organizations, fellow practitioners, and the community of participants. Indeed, it would be misleading for me even to assert that the practitioners with whom I spoke identified these challenges as challenges rather than simply, and more neutrally, as the context within which such work gets done. 

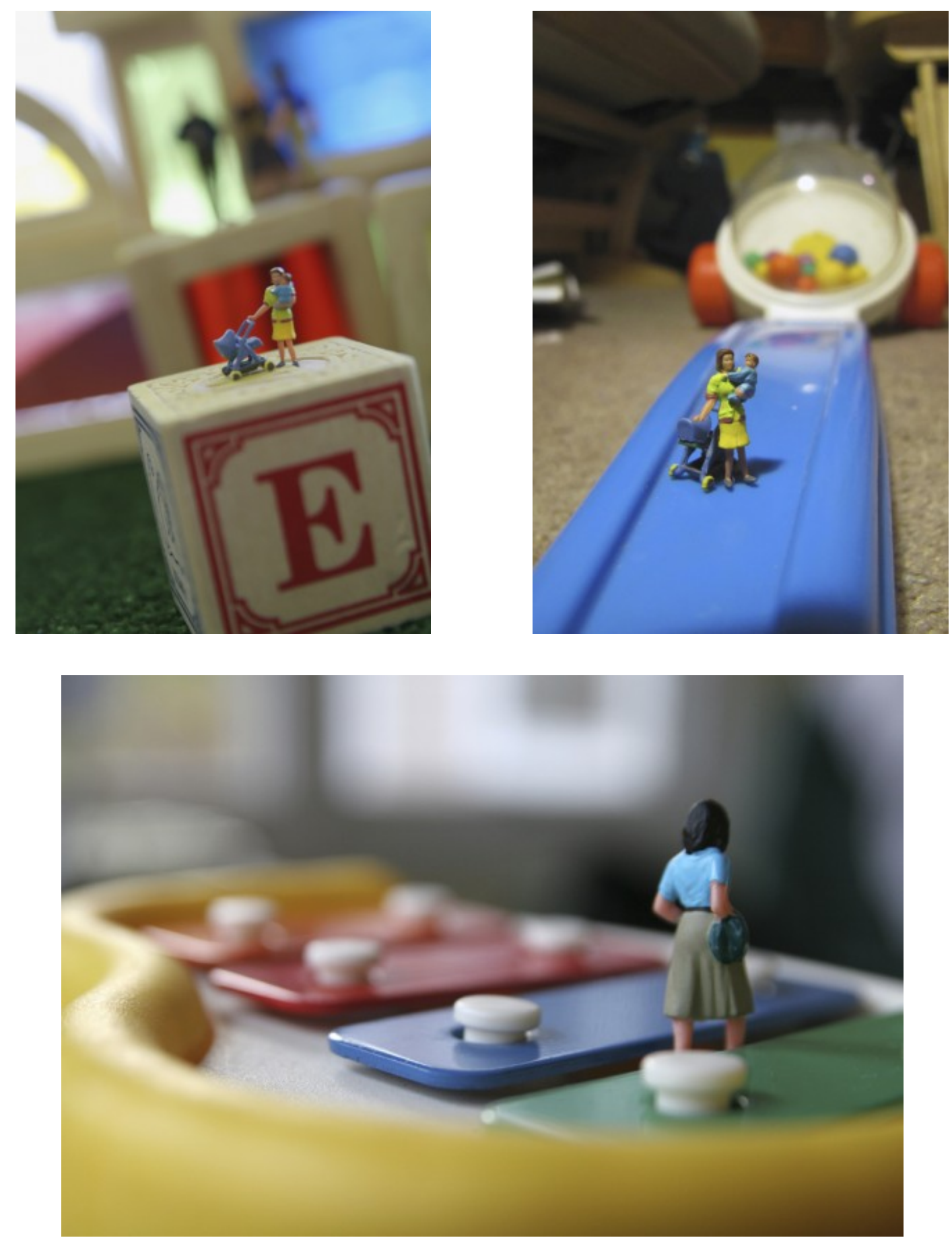

Plates 6 (left), 7 (right), 8 - Mindy Stricke, et al. 2010. From You Are Not Where You Were.

Stricke's socially engaged work - as seen, for example, in both the You Are Not Where You Were (Plates 6-8) and in the Good Eater projects (Plates 10-11) - provides a compelling example of engaged and participatory camera arts use.

In addition to collaboratively composing many of the images for You Are Not Where You Were, Stricke presented the images as transparencies in keychain-style slide viewers. To see the images, visitors to the installation needed to interactively approach each viewer, holding and peering into them one by one. 
Thus it is perhaps more important to note that such work is typically perceived as aesthetically and experientially enriching rather than personally challenging. As I suggested earlier, for many it is rewarding both in formal terms - in terms of the novel varieties of art that can be

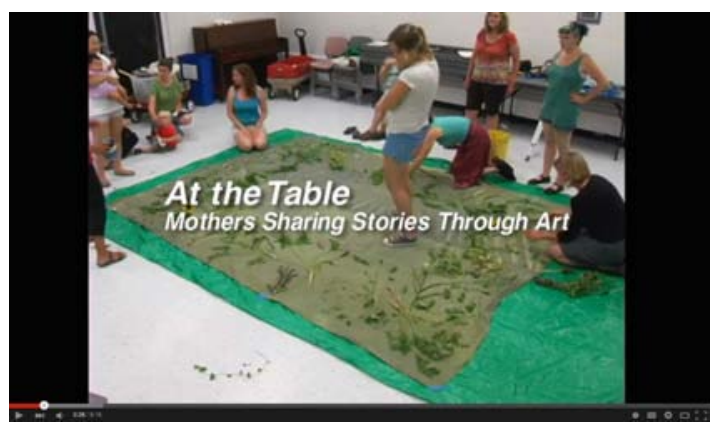

Plate 9 - Screenshot from At the Table: Mothers Sharing Stories Through Art (2011). Dir. Brijetta Hall Waller. produced - and in terms of artistic process, or the experiences that result from cooperative engagement and exchange. Mindy Stricke hints at this as she describes what motivates her own practice in socially engaged arts: "I really like that process of collaborating with other people from the beginning, and really having them be ... not equal partners, necessarily, but certainly active partners in the direction of the work. I really like working with non-artists, and I get excited by that combination of things."
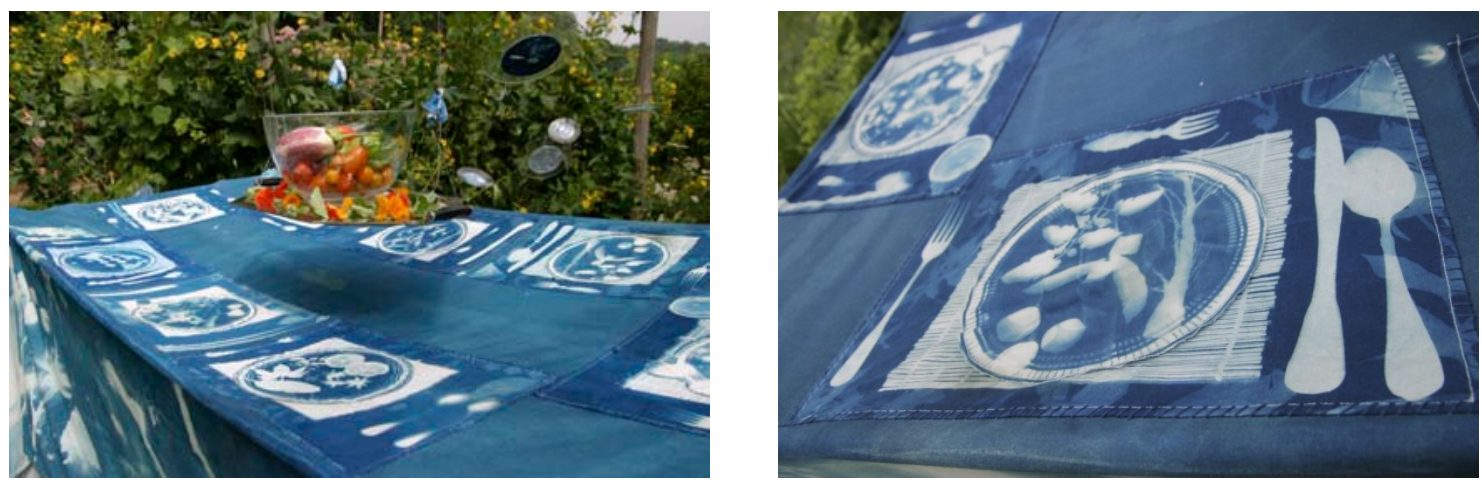

Plates 10 (left), 11 - Mindy Stricke, et al. 2010. Good Eater.

Like other socially engaged practices, Stricke's Greetings from Motherland project involves a range of people, including artists and non-artists - what I prefer to call practitioners and participants - taking on a variety of roles. Her acknowledgement of a relational hierarchy inherent in this engagement (some division of labour is implied by the distinction between 
"active" but not necessarily "equal" partners) may indicate, in part, Stricke's nuanced understanding of collaborative processes. That is, although similar hierarchies may vary from practice to practice and produce more or less clear divisions of labour, Stricke's distinction implies a sense of commitment to the art that is different from one's responsibility for it. Such commitment and responsibility, furthermore, are somewhat independent of one's status as either practitioner or participant.

Of course, and as we will see below, the varying degrees to which practitioners and participants each contribute to processes that shape the direction of socially engaged arts is never settled. For some participants, engagement means willful subservience - "Just tell me what to do, and I'll do it," to paraphrase one long time participant, content to follow orders. For others it means something more active and resistant to authority, control, or authorial vision (or the semblance of it). For some, participation is strategic - about gaining skill in a certain medium or form - while for others, participation is more about the experience - about passing the time in a calming way, or in pleasant company. For most, however, it is a complex combination of factors that bring them into the room to participate, and that may either discourage them from returning or engage them to remain and even, ultimately, take on different roles and responsibilities commensurate with such commitment. A more fundamental matter for considering issues of engagement, commitment, and responsibility hinges on remuneration, where being paid to make art and participating voluntarily are crucial to distinguishing practitioner and participant roles.

The various inflections of "capital" may be explored here, since it is not only economic capital but social and cultural capital that bear upon matters of engagement. However, it would be impossible to list all the myriad and intersecting ways that art through social engagement 
produces capital - or is simply meaningful - to either participants or practitioners. Do people participate because they are promised an honorarium, or because they learn something that might turn into a job or career? Are they there because they feel empowered to instigate change in their community, or simply because they want to hang out with their friends? Is "capital" - whether cultural, social, economic, and so on - even appropriate in such cooperative, arts-engaged contexts?

To avoid this rather unresolvable matter, I will simply point to the two most explicitly stated reasons, according to practitioners, why they and their participants chose to engage in these arts; namely, to make things and to change things. Indeed, and although these essentially artistic and activist impulses might be understood differently by practitioners than by participants, practitioners spoke of the tendency for these ultimately political and aesthetic concerns to be deeply intertwined.

For example, Phyllis Novak spoke of this intersection between art and activism in terms of recent programming at Sketch. She muses:

How does community arts engagement affect the social good in both - yes, the community-engagement way in solving problems, I suppose. But how does it also affect social good in declaring a new possibility, a new way of living, and a new way of framing our communities around cultural expression?

Sketch not only aims to engage so-called "at risk" youth, but it attempts to do so by challenging the stigmatization that surrounds these youth and their experiences. "At risk" often implies, as a number of commentators have pointed out, a problem to be corrected. For example, 
Anna Hickey-Moody (2013) argues that “"at-risk' youth discourse” is “a governmental strategy that reproduces selected young people as deviant and thus in need of control." In this context, she continues, art may be one such "means of governance" (Hickey-Moody 2013, 21).

By framing artistic activity as broadly cultural rather than narrowly governmental or supplemental, Sketch seems actively to resist supporting hegemonic discourses such as this. As with other practices, Sketch seems to prefer that participants engage rather than simply participate in activities. Such engagement often implies an invitation into essentially organizational activities, those that are substantively different from mere participation - what I might describe as purely curricular activities. Whereas curricular and organizational activities might both encourage the acquisition of a kind of social, and even economic, capital, the latter might do so in a more radical, unpredictable way.
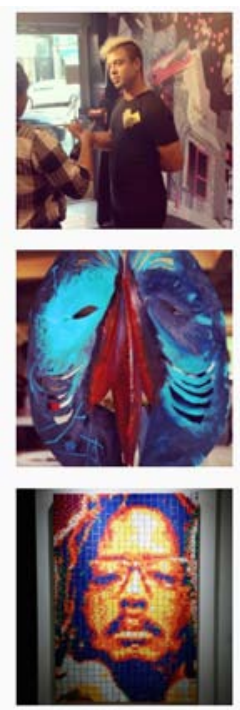
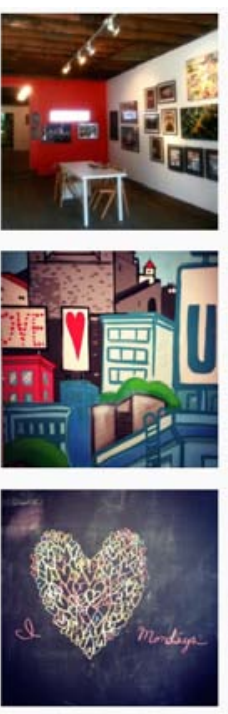
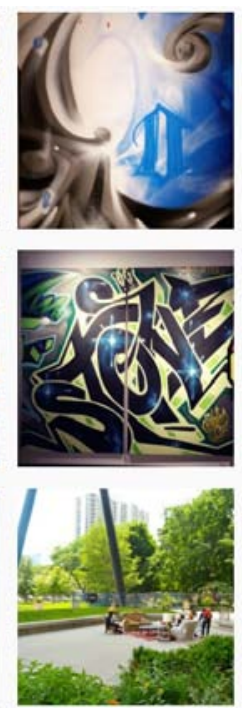
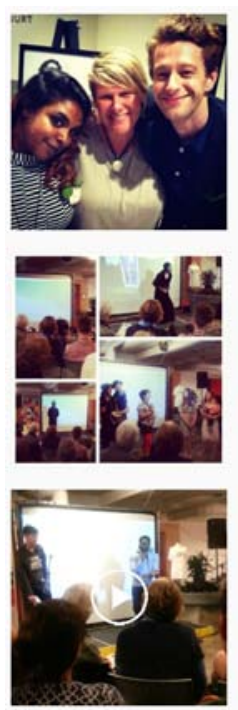
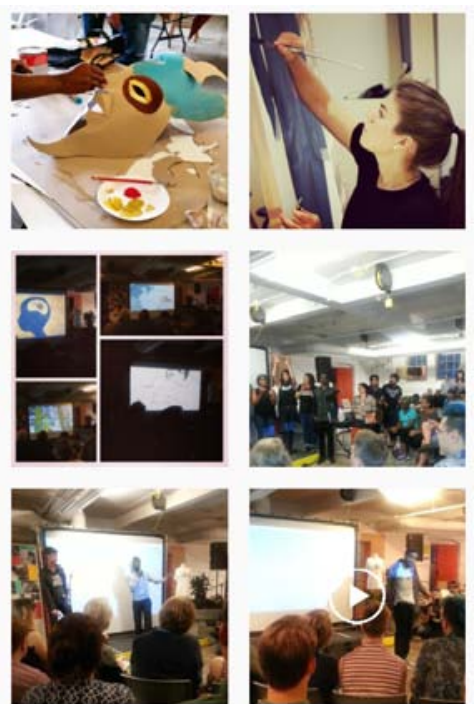
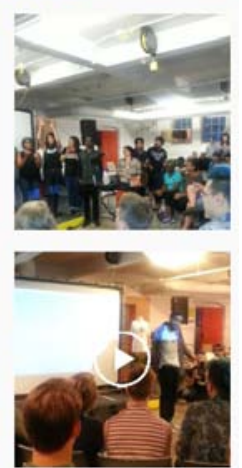

Plates 12 (left), 13 - Screen shots of the Sketch Toronto Instagram account.

Visual social media, like Instagram or Flickr, allow practitioners and participants distinct opportunities to share and communicate beyond face-to-face encounters, and potentially reconfigure the physical and conceptual spaces within which organizations (like Sketch, shown here) operate.

Nevertheless, the platforms are not identical, and the technical attributes of each may variously enhance or undermine the goals of socially engaged arts practitioners, participants, and their organizations. 
Again, the specific forms and practices that this more fundamental interrelation of aesthetic and political engagement might take would be difficult to enumerate. Instead, let me just point out the kinds of discursive and embodied possibilities this opens up. I would argue, for example, that this intersection allows Novak to speak of artistic development as precursor to a political act. As she put it in the context of Sketch:

[Youth] should also know that they can be an aesthetic driver [...] They don't always have to tell their story through their art. They can actually move beyond their story and actually just create their images: just be a creator. I think that that's where we still have a lot of work to do, in the field, so we can say 'How do we embrace what the quality of an evolving aesthetic is?'

Here, Novak is not speaking of a deracinated creative production, but a mode in which aesthetic concerns play a key role in broader social and political action. Like other socially engaged arts organizations, Sketch maintains more or less formal partnerships with agencies that provide a range of supports that its participants may individually need. In my brief experience in the field I have encountered participants relying on mental health, crisis intervention, settlement, family planning, English as an additional language (EAL), employment, and other social support services: sometimes singly, sometimes severally.

However, by positioning art as the main point of engagement, it is clear that socially engaged arts practitioners like Novak believe that realms that are germane to creative practice such as affect, knowledge, or vision - are imperative to social change and political activism, and are not merely entry points to more conventional social services. 
That this engagement is designed to happen through aesthetic ideas and artistic actions attests to the unique interventions that socially engaged artists seek to instantiate. Equally important is the desire that it happen cooperatively and collectively, rather than individually or individualistically.

Speaking from his own practice, for example, Burtt offers some thoughts that help to contextualize this differentiation between socially engaged arts as a governmental problemsolving technique and socially engaged arts as a strategy for creatively, and collectively, reimagining and remaking the fabric of our common culture. From a longer conversation about the problematic tendency of some practitioners to assume that these arts inherently embody a "democratic practice," he argues that notions of individualistic or atomized artistic practice persist, even in certain socially engaged practices. As he puts it, "It is possible to talk the talk of democracy, working together without challenging that individualistic art."

Democracy, of course, is a complex term, but the commonplace usage to which Burtt is referring seems to be about mere co-presence - "working ... together" to paraphrase the atomization that his use of "individualistic" implies. Indeed, Burtt is not alone in this opinion. A number of those with whom I spoke voiced a concern that some in the field - particularly interlopers from other disciplines enthralled with art but not committed to its principles perceive art as merely a means to other ends (again, a kind of governmentality, for example). This approach to art - as a "well-meaning" but effectively unaesthetic and depoliticized "gesture" (as Burtt later puts it) - risks deploying a rather depoliticized notion of democratic engagement:

It's just because creativity has been so squashed in people that they feel there's a 
defensive posture: 'Well, we can all be creative! We can all be artists!' That's true, but there's also a place for people who spend their life doing that, for whatever reason, and who work in a community-context not as a well-meaning gesture, but because it makes better art! It makes more interesting art if you're working with more people! For me, that's just common sense.

Burtt's seemingly pragmatic position, "Collaboration makes better art!" partly masks his sharper critique of the notion of democracy deployed in certain practices of socially engaged art, particularly those on the periphery of the field. For Burtt, working together is not synonymous with cooperative practice, which may demand a seemingly contradictory vertical hierarchy alongside a horizontal collaboration. In other words, tasking participants with all the variety of actions an arts organization needs to accomplish in some egalitarian move may not - and, arguably, will not make better art. Indeed, it may fail altogether.

For example, in his practice at Making Room, Burtt's emphasis is on working across practices - such as with local food organizations or mental health support agencies - to support the specific work each organization does and generate interest in the artistic work done by his own. The intent is to make art in novel contexts that is also richly informed by those contexts; engagement extends beyond any notion of self-contained artistic activities - democratically executed or otherwise - and into the day-to-day lives of participants and practitioners.

\section{Community Leaders: Engaging Responsibility}

The redefinition of art that these strategies of engagement imply is worth drawing out, because it suggests a model of cooperation that extends beyond the disciplinary focus of any single community organization or organizational expertise - something inherently necessary to 
creating sustainable cultural alternatives. Put another way, strategies of engagement in socially engaged arts aim to democratize and disperse expertise by actively recruiting a broad range of artist-participants, potential and actual, and redistribute the responsibility inherent in art-making activities. Arguably it is this kind of engagement that is more democratic, in that it meaningfully envisions a political and aesthetic practice that permeates a wider variety of our social interactions by occupying distinct spheres of action and appealing creatively to distinct forms that such action might take.

As I suggested above, such strategies for expanding engagement afford new opportunities for the roles artist-participants might play as experts themselves in socially engaged practices. One strategy that a number of artist-practitioners have developed with artist-participants has grown out of these more enduring affiliations. Several practitioners have spoken of the importance of community leaders to, and the broader creation of leadership opportunities within, their practices.

Houston, for example, speaks of the range of support she has received at MABELLEarts, from both resident community leaders and emergent artist-practitioners (the names she mentions, in square brackets, are pseudonyms):

The relationships are definitely at the center of it all. We work with a whole bunch of artists from a variety of disciplines. We work with community members of all ages. Anabelle and Melinda are really at the heart of Mabelle with me. Anabelle is the lead artist, she has a theater background, and Melinda is our general manager and food artist, culinary artist, and she has an environmental studies background, which is also my background. Their interests and inclinations really drive what happens here. 
Although Houston doesn't mention it here, Anabelle and Melinda came to

MABELLEarts with only minimal prior experience with socially engaged arts. Thus in key ways, although with important caveats, their roles at MABELLEarts can be seen to mirror those played by the unpaid community leaders Houston goes on to describe:

Paula and Moira, and more and more Roeena, Seeta and Saud are people we call “community leaders." They play a really big role in what happens at MABELLE[arts]. They receive honoraria for all the work they do because they do so much, and they are responsible for so much. They also play a really important role in stabilizing us, and making sure that our inclination isn't running away on us; that we are staying grounded in this neighborhood. So if I propose something that's ultimately really stupid, Paula will let me know in a very Paula way. [Laughs.]

Houston describes a rather complex and dynamic model of practice, where community leaders take on responsibilities normally assumed by artist-practitioners, and where artistpractitioners are continuously learning aspects of their practice. Experience and expertise become reconfigured - and even inverted - so that the roles participants and practitioners are each to play is never entirely fixed. At several practices, for example, practitioners spoke of how figures like these community leaders took on the mantle of host, performing a set of functions that might typically be relegated to workshop leaders or artists as an organization's official "practitioners." Burtt suggests how playing this role has been valuable to participants at Making Room (again, names have become pseudonyms):

One of the really profound things that I see is that the members, who [for] their whole life they've been called transient, are the ones who remain. Three of them have been with me 
since the beginning, and you, of course, know people have different lives. But what I notice is the incredible ability of members to host. [...] They're the first to introduce themselves. One [in] particular, sort of my right hand member - if three minutes go by and I forget to introduce somebody new, she would say - I'm Amy. It's almost a physical need that people aren't excluded. I think that's something really important about our little group.

From Burtt's words we can glean a complex sense of ownership and responsibility distributed between and amongst practitioners and participants. Indeed, this compunction to host exists as a core part of certain socially engaged arts processes, and becomes manifest in the almost ubiquitous presence of food and tea, among other aspects of gifting, welcoming, and sharing, found in these activities. This valuation of sharing as an artistic principle has important consequences, as I will argue below, for the idea of authorship that gets materialized in socially engaged arts practices.

\section{Engagement and Re-engagement: Revitalizing Life Practices}

Another point worth mentioning about engagement relates to how the emergent character of socially engaged arts, along with the emerging responsibilities it demands, might activate or reactivate certain cultural practices that, for one reason or another, individuals have been unable to pursue. For instance, Jennifer Lafontaine of the North York Community House and the Toronto Centre for Digital Storytelling speaks of the challenges facing newcomer artists as they attempt to adjust to life in a new cultural milieux. For many, pursuing their practice becomes difficult because existing artist networks can be tricky to access - due to language barriers, physical distances between home (in the inner suburbs) and studio work space (in the downtown 
core), work and/or family requirements, among other reasons.

As I will argue below, socially engaged arts methodologies expand the sites in which legitimate artistic practice can occur. Artists like Lafontaine described how settlement organizations, schools, health centres, community centres, and other non-traditional "studio" and production spaces may all become sites where arts can enter the lives of participants, or re-enter those of practitioners whose practices have been put on hold. In terms of engagement strategies, the proximity of socially engaged arts to everyday life is crucial to materializing the forms such art takes. That is, only by bringing art into everyday life rather than exclusively deriving art from it does socially engaged arts become possible.

The transformative possibilities of everyday life on socially engaged arts, and vice versa, are potentially enormous - for engagement as much as any other aspect. Not only might participants engage in hosting and mentorship responsibilities, but they may pursue artistic practices themselves: either by entering formal training (as new students, or by securing high school equivalency or enrolling as so-called "mature" students), or by remaining active in existing sites (Regent Park Focus is particularly notable for its strong contingent of former participants having become mentors and paid practitioners). Stricke, for example, speaks of how participants from one of her projects personally rediscovered their creative practice after devoting themselves to work, motherhood, and other (domestic and non-domestic) life pursuits: "Two women in the group were trained artists, and had taken a break and [were] wondering how they were going to get back into their practice. By doing the project, it got their spark lit again. I know it did. [One of these women] made a documentary about my second project."

While Stricke's enthusiasm may mask other key factors that might have led these 
participants to return to art, the recurrent theme of everyday life in and as the context of socially engaged practice makes her idea of instigation or regeneration more than simply plausible.

\section{Engaging the Everyday: Politics Meets Aesthetics}

Engagement is neither simply a matter of practitioner(s) engaging with participant(s), nor of participants with other participants, but also - crucially - of participant self-engagement. Put another way, and in order to insist on the co-presence of the other strategies of engagement mentioned earlier (namely inclusion and a sharing of responsibility), such self-engagement concerns one's public actions: how one intervenes, politically and aesthetically, in the material conditions of one's existence and in the context of one's community. Furthermore, socially engaged arts' preoccupation with minority, marginalized, and even stigmatized populations suggests a generous and expansive vision of the public sphere, one in which a diversity of agents rather than an elite political class can and must participate, singly and collectively.

Because participants of socially engaged arts are typically from minority groups, and are therefore excluded from, or at least at the periphery of, the cultural mainstream or statistical norms that these relations are so often framed around, their experiences are often marked by antagonism and struggle.

Governmental misunderstanding of minority groups - whether naive or willful - has important implications for political engagement through arts. For example, Adonis Huggins, the Director of Regent Park Focus, discussed the negative role played by mainstream media in framing representations of the Regent Park community:

When we began, one of the things that was identified was how the community was 
stereotyped. [...] Even though there was drug dealing and drug issues at the time, it was really overblown in the media, and overblown by people's imagination, as to what goes on here. [This] even [included] a stigmatization about poverty itself, [about] people who are essentially low income $[\ldots]$

This negative public representation - local and national news media denigrating Regent Park based on an amalgam of externally imposed narratives - galvanized community leaders to form the coalition that would later create Regent Park Focus. Their initial resistance first became manifest through traditional forms of activism. As Huggins continues,

One of the things the organization wanted to do was to challenge those stereotypes. [...] Initially it was advocating. We would get letter writing campaigns when people felt that their neighbourhood wasn't portrayed properly. We'd go meet editors of the newspapers, and meet with reporters who wrote the articles. We would join with other communities that were low income and try to support each other as well.

Yet, as he makes clear, such conventional strategies seemed to have little effect beyond local borders:

[O] ur challenge was we would meet one day with [journalists], and then the next day another article would come out. Another reporter would do that [inaccurately portray the community], or, two weeks later, even the same reporter would do that. We felt we weren't getting our message across. We weren't being very effective. So this idea of 'Why not? Why do we have to go with mainstream media? Why don't we produce our own community media?' So that's what we did, essentially: using the arts, using popular 
culture, and using the media around community issues. And that's where we're at.

As with other practices, the role played by socially engaged media arts production at Focus has been rich and complex. While it has encouraged certain, particularly local, forms of engagement, Huggins laments the organization's challenges with fostering broader public engagement. When asked what he would like to be different about Focus, Huggins suggests:

I'd like to see more of the impact - I guess what happens, and what's frustrating, is that youth produce things here, [... but] we're so busy producing that we don't spend a lot of time disseminating - and don't have a lot of resources to disseminate. [...]

[I]t would be great if - each project that we do, there was a whole campaign to get it out there, to get it in people's hands - to talk about the issues that they're talking about.

As Huggins suggests, the effect has not only been that youth participation - and minority youth participation in particular - continued to be limited in public discourse. More fundamentally, the role that youth could and should play in determining and crucially reformulating that discourse remained relatively unchanged: "What tends to happen is they say 'Oh, that's great! Youth produced that. Great!' There's not any kind of discussion about [...] the content of what they made, rather than 'Oh, great! Skills. Look at that, doing something positive."”

The particular "they" to which Huggins ambiguously refers is unimportant. Regardless of whether he means a particular funding body, the broader public, or some other group, the effect is the same: "they" is a group of some consequence with whom youth should be engaging, and vice versa; such engagement seems to have not been adequately happening, or is being 
trivialized.

I raise this point because, although in key ways the kind of engagement that socially engaged arts implies is and should be focused on making art with minority participants, engagement could also be defined as expansively as possible, particularly to limit appeals to a governmental approach it might otherwise inherently suggest. That said, other strategies may temper this approach; it is to those that I now turn.

\subsection{Expanding Form: "How else might art be done?"}

\section{Legitimate Practice}

Although an inclusive practice, there was some contention over the practical and experiential forms that the processes of socially engaged arts might take. In particular, and continuing the argument raised in the previous section, a number of practitioners with whom I spoke took issue with an impoverished conception of art that some in the field seemed to espouse. While often this criticism was levelled at practitioners from non-arts backgrounds (such as academics, social workers, and even certain artists), it was also occasionally directed towards some in the Toronto community arts field. Most importantly, however, such criticism was directed toward the practical and pedagogical encounters - the so-called participatory or collaborative processes - through which art was made, rather than toward the products and forms that resulted.

Of the practitioners with whom I spoke, many felt that authentic socially engaged art hinges on the type of relationship that gets produced. To put it another way, while the quality of product is as important an end as any other art, the quality of labour is at least equally important. 
For example, one artist, whom I will call Mavis, lamented the lack of participatory practice evident in a group that was organized by a rather prominent Toronto community arts organization. While she sought to engage with participants to collaboratively construct portraits, Mavis encountered an inherited organizational structure within which art was made with limited interaction. Indeed, although artwork was produced in the sessions this organization hosted, it was typically done with little formal interaction between practitioners and participants, and especially amongst participants themselves. It may be that this model was developed interactively with past or present participants, but Mavis seemed to think it wasn't or, more likely, that they would be interested in and capable of doing more.

Of her project in particular, Mavis admits, "They [both participants and the organization's director] were very open to it." However, she adds critically, "Clearly what I was doing was different than what they normally [did during these sessions]." Typically structured as weekly workshops in eight week blocks, the main purpose of the sessions was nominally social rather than artistic, she argued, and certainly not directed towards cooperatively composing some larger artistic project as she would have expected. As Mavis observed, the work from previous sessions was "clearly craft-oriented" - a comment seeming to imply a problematic aesthetics while also pointing to a hierarchy of artistic legitimacy.

Mavis continues, "I would say the bar is extremely low for the quality of what they're doing. [...] Sort of like, 'Yeah, let's give [these participants] a break, we're letting them do art."' Again, it's difficult to know the context of the workshop, and the degree to which participants were involved in its development and current direction. The sessional nature of the artistpractitioner - in this case, Mavis - makes such involvement doubtful, however, as it seems to 
indicate a rather passive, although willing, group of participants.

Mavis went on to observe a kind of atomization resulting from this process of participants working individually on separate art works rather than on broader, collective ones. She attributed much of it to the vision of the organization's director: "It definitely was very important to the director [to know] 'What are people taking home?"' Such an emphasis, Mavis seems to assert, reinforces the periodic and discrete nature of these sessions, as distinct from the kind of cooperative and holistic practice she prefers. As we shall see, her observations echo what others said about practices in socially engaged arts: that is, that some practices seemed stronger, others weaker, as socially engaged arts processes. Although the emphasis of the critiques varied, they tended to be about the ways such arts were formally structured at least as much as about the formal results of such practices. Moreover, such criticism begins to illustrate a differentiation between legitimate and illegitimate, or perhaps strong and weak, socially engaged arts practice.

In this discussion, for example, Mavis stops short of levelling an explicit critique at the organizational leadership active in positioning such a version of art as sufficient. It isn't clear from what life situations the sessions were a supposed "break" for participants; nevertheless, the organization's seemingly therapeutic framing of participant engagement suggests a paternal process, one that devalues art as a more broadly social and collaborative process (preferring, instead, "craft") and underestimates participants as capable and knowledgeable agents who may be committed to that process. Further, by emphasizing that participants should go home with something, the organization seems to give up on social change - whether through art or through agential action more generally - as a reward in and of itself.

In short, Mavis' experiences begin to suggest a paradigm wherein certain arts or 
community organizations may operate as socially engaged in name only. The selective application of social engagement (or "community") strategies to art practices risks impoverishing the experiences of both participants and practitioners. How pervasive such devaluation is remains unclear; however, Mavis' account is not an isolated one.

One apparent effect of an impoverished socially engaged arts model is, as I have suggested above, to atomize the collective experience of participants. By valuing individualized production, such a process risks further alienating marginalized groups despite being ostensibly social. Another possible effect might be felt by practitioners, particularly those committed to more radical values. For example, concluding from her experiences with this organization, Mavis theorizes:

I realize from [my experiences] that, that was fine to be hired, but I need to do my own thing, even if it's more work to raise money. If someone hires me, then that's their thing. They have their idea of what they want me to do ... It's not that [this organization] wasn't open [to my ideas]. I did exactly what I wanted to do. But, like I said, I had to finesse it ... They wanted me to be more craft-oriented, and they didn't totally get what I was doing. I just don't want to be in that position. I'd rather not be for hire in that way. [...] Now, as I'm figuring out where things are going, I need to do it on my own, as my own thing, as my own production company, essentially.

Mavis appears able to glean some personal value from what seems to have been a generally disappointing professional experience. However, it is arguable whether her conclusion - namely, "I need to do [art] on my own" - is a sound one to be made by an aspiring socially engaged artist. There exists a clear contradiction in this sentiment between, on the one hand, 
theoretically committing to a collaborative, cooperative approach to art-making and, on the other hand, engaging in a process that embodies a skepticism, or even antagonism, towards such a commitment.

\section{Process and Relationship}

In any event, it is clear that organizational relations play an important role in impacting the aesthetic vision of practitioners, simultaneously presenting them with myriad challenges while affording them a variety of material resources and models for coordinating labour. It is also clear that, given their complexity, the organization of practitioners and participants influences socially engaged arts in subtle ways. For example, an artist whom I will call Markus bases his practice at a Toronto multi-service centre. As an artist who aims to work cooperatively with his participants, he remains acutely aware of the organizational culture the centre habitually fosters:

[One day] a staff person said 'There can be a bit of a crisis culture [here], where if somebody is freaking out and you calm them down and you give them a token, then you've done something for the day. Your reason for being there has just been justified.'

That keeps things at a level of 'It's a good day when nothing happens.' You know, when there's not a freakout $[\ldots]$

Markus' anecdote does not seem to imply a critique of the organizations with whom he works - some of these his participants utilize and benefit from, others with which his practice actively collaborates. If there is any direction to the critique, it is toward the status quo or passive approach to practice to which certain agents and organizations seem to ascribe. In his practice, Markus asserts, there is an active engagement in envisioning how to challenge such inertia. "I 
see art's role," he continues, "as very, very strong in building [a] sense of community, of sustenance, especially if it's not ghettoized as the 'Arts and crafts group at two o'clock,' but it is seen as $[\ldots]$ being aligned with, in connection with" other community-engaged organizations. For Markus, socially engaged arts processes must take a rather expansive and visionary form, one beyond simply collaboration between artists and participants and into an engagement with in "align[ment] with, in connection with" - the conditions that constitute the broader public:

In the way that we're making things, from the place that we're making them, we're creating things that could not have happened anywhere else, on all sorts of levels simultaneously. It's not craft. It's not handicraft. [...] This post-mass-production, this post-individualistic art [it's] a return to the art of everyday life.

The formal aesthetic interventions of socially engaged arts are deeply interrelated with organizational relations and the simultaneously radical and governmental processes which result from them. As such, it makes sense for practitioners to characterize organizational practice in aesthetic terms. For example, both Mavis and Markus deploy the term "craft" in their discussions of organizational practice. The term is typically neutral, referring to relatively low-cost materials such as textiles, papercrafts, and other low-tech, typically non-electronic tools common to socially engaged arts practices, among others.

However, these artists seem to deploy the term in a distinct and derogatory way - that is, by using it to suggest a formal approach to art that is conventional and, further, that exists at odds with socially engaged arts' more radical processes. An organizational approach that favours the forms and processes of craft production, so the argument seems to go, is concerned with minimizing and atomizing the experiences of participants and trivializing the products of their 
making. Socially engaged arts production seems rather to oppose this simplifying intention, challenging the idea that art is about making rather than, more crucially, making together.

Yet given that the context for socially engaged arts maintains such permeable boundaries, it becomes difficult to differentiate it from a more craft-oriented approach, nor indeed to appreciate why such a differentiation matters. For some, the distinction is disciplinary: several practitioners I spoke with believed that a craft-approach to art was favoured by those practices developed by a social worker or located in a primarily social service setting. Of course, as Mavis asserts, a craft-approach was being developed at a self-proclaimed community arts organization.

In other words, the presence of craft alone does not determine the success or failure of a socially engaged practice. Of more general concern is how an organization's agents choose to deploy the power of their organization to variously support or undermine socially engaged arts. Echoing the experiences Mavis described earlier, for example, another artist (whom I will call Kay) speaks candidly of her own frustrations at a different Toronto multi-service organization. Kay speaks of her two-year tenure as a kind of artist-in-residence, hired and directed by a social worker under an Arts Access grant, to work with what she says they would call "underhoused, marginalized adults ... [who] may or may not have been dealing with mental health issues - [but who were] not in crisis at the moment."

“[The] first year,” Kay laments, "I had a horrific struggle. I often came home and said 'Oh my god. I'm going to barf at this job. [...] It was very, in my mind, patronizing to the clients." The source of this frustration, Kay explains, came from profound disagreements she had with the counsellor/social worker, her co-worker and superior, which she felt she needed to remain largely silent about. The most significant of these, Kay argues, hinged on her co- 
worker/superior's assertion that she was an equal with the program's participants. Her coworker's rather technical and certainly problematic definition of equality, Kay suggests, effectively made it seem as if "everyone was equal in the room because everyone was trying." Kay was vociferous in her disagreement; she recounts: "I was like 'Dude! You're getting paid like $\$ 40$ an hour to be here! You're not all the same. This is bullshit! You're getting paid more than I am to be here!'”

Kay indicated to me that she felt she had little ability to impact either the formal proceedings of the workshops or the pedagogical approach that was being enacted. However, she also mentioned that she was reasonably well paid for the experience, and so her ability to dissent may also have been tied to an unwillingness to do so. Being an outsider to the multi-service organization, and a tenuously employed (self-employed) artist may certainly also have complicated Kay's choice of actions and capacity to direct the processes of which she was a part.

In any event, the organization of the activities seemed largely under the control of the counsellor, and certainly did not seem cooperatively determined as in other socially engaged arts processes. Indeed, a wide variety of activities - not merely art-making - was being carefully managed, according to Kay. She recalls, for example, how the counsellor developed an assessment scheme that would result in feedback that was largely favourable to her approach:

[The organizer said] 'This is really great! Everyone is expressing, and being free. This is such a great experience for you. Tell me about the experience for yourself,' and everyone is being told that they're a chosen person to be in [this program]. They're having this great experience, so they're going to parrot back ... When we did evaluations, they said exactly [the same thing] ... 
"And it's that model," Kay theorizes, "that people get shoved down their throat when they're in social services or in the system, where they feel like they should think 'it's a great experience!' because they're being told it's a great experience, and that this is this program that's being run for them."

Being primarily responsible for engaging participants in art-making activities, Kay became acutely aware of how the counsellor's management style determined and, in her opinion, ultimately constrained the quality and sophistication of the art that could be produced in the workshops. Unlike Mavis or Markus, Kay doesn't explicitly use the term "craft" to describe either the activities or their results. Nevertheless, she describes a similar process, one that seems largely atomizing and ambivalent about the aesthetic quality of product:

In terms of the artistic quality, sometimes we did painting stuff, and the counsellor was always trying to be like 'Let's just be free, and express, and move paints [around].' We'd look at the work. [Pause.] It was awful. There was no way around it. Everyone was like 'Oh, this is so great!' But everybody knows when they look at something and it's bad. Nobody feels good when they make bad stuff. [...]

Certainly there are differing aesthetics, and it would be problematic to assess the quality of these works even if they were reproduced here. Kay's critique seems to imply that this kind of artistic practice was the limit of what was offered; that other, more representational genres and modes were left underexplored.

As with Mavis, Kay's reaction to her negative experiences led her to imagine other ways of engaging participants and continuing to do art with others. Indeed, like Mavis' desire to "go it 
alone," Kay's response to her clearly negative experiences seems about insisting on artistic authority:

I think it's lying to people to tell them something's good when it's actually really bad. It would be better to say 'I'm the artist. I'm in charge. I'm going to tell you how to do this.' And then people would master that skill. I think there's some idea in these things that people will just express their emotions, and be empowered. It's kind of bullshit ... You've got to treat people like people. And if you piled a shitload of paint on a canvas and you were [told] 'You should be proud!' you'd be like 'That's awful. But, OK! I'll be proud because I've been told.'

This is a rich but complex set of experiences to address. On the one hand, Kay is clearly critical of the nature of the artistic process her counsellor colleague had developed and promoted. As a proper example of socially engaged arts, this simply does not pass muster as it is clearly seems not to be cooperative, process-oriented, experientially-based, and so on. On the other hand, it remains unclear whether Kay's tentative solution - ostensibly to reclaim authority, assert her expertise as an artist, and create a more directive practice by attempting to teach "hard skills" related to canonically accepted technique - would contribute any more positively to fostering a socially engaged art.

It would be wrong, of course, to assert that Kay in fact takes such an authoritarian position - her's might simply be an off-the-cuff remark. Yet her opinions raise important formal questions: is didacticism in whatever form amenable to socially engaged practice or the formal strategies we are considering here? Can a socially engaged art, properly defined, ever contain such a directive pedagogy, however momentarily? That is, can it or should it maintain a process 
that demands, at times, hierarchical relationships between and amongst artist-practitioners and artist-participants - both in order that the work gets done, and so that it is made with a certain formal integrity (or "quality")?

\section{Democracy and Participation}

Many practitioners assert that socially engaged art can and should draw clear demarcations between and amongst its members. This is not to marginalize or tokenize the role that participants might play in an process led by practitioners, but rather to be realistic about the different commitments each are able to make to an artistic organization. Ideas about democracy or at least about democratic participation in socially engaged arts - emerged as a common theme to my interviews. For Burtt, for example, insisting on the integrity of an artistic vision means forgoing one kind of participatory practice since it is incompatible with another:

To me community arts does a profound work with the ego, because you're not saying 'The community is building this! We're just one part of a big community!' No. There is an artistic director, and an artistic vision, and a sense of direction - at least the way that we do it. You're there as an artist to support, with those skills; to do something that would not have happened otherwise. So it isn't a democratic thing of 'OK! What does everyone want to do? OK, let's do that!' That is a way that we differ from some other companies that really see their role as facilitators or animators. Whereas we see our roles as artists.

Insisting on the title "artist," and resisting attempts to make it synonymous with other possibilities (such as "facilitator" or "animator" - or perhaps even my preferred term, practitioner), seems imperative for Burtt, and key to the kind of work he does with participants 
to, as he says, "do something that would not have happened otherwise." Moreover, by

legitimizing art as an end itself rather than a means to other ends, and by specifically valorizing artistic work and not simply community arts or socially engaged arts in an abstract way, Burtt can shape an artistic process that is responsive to both his needs as practitioner and those he perceives to be of his participants.

\section{Technique and Form in Socially Engaged Arts}

An artistic process is neither foisted upon participants, nor is it left to them to direct and determine. Instead, it is achieved by engaging participants, and gauging the various responses to such engagement. For Burtt, one strategy for engagement has been to include meditation into workshops for Making Room. Describing a typical workshop, he says:

What we do is, when people arrive, we have formal conversation, then we do a check-in. Then we do our sit, which begins with me doing a relax[ation technique] that I learned many years ago, where you just start, at the top of your head, and you do a few sweeps down your body. Relax your arms, relax everything. Then we sit in silence for five, ten, fifteen minutes. Then, out of that, we do some sort of art work, often around writing, or paperwork, or making lanterns - whatever it is. Then we do a quick sit at the end, and that's it. An hour and a half, two hours - it's very simple.

"But," he adds, referring to the part meditation plays in anchoring the arts-based workshop, “it is incredibly powerful.” Indeed, in my (anecdotal) experience of his workshops, I personally found the meditation helpful for focusing on the activities that were to follow. Burtt agreed that this was one of several common responses, adding that such focus is not an attempt to ignore the outside world, but to better attend to the task at hand: "What we're learning to do is 
the dance of that inward to outward movement. It's hard enough going inward, and it's hard enough to do that outward, artistic work, but that they actually feed each other - they actually buttress and support each other."

The practice is neither therapeutic nor atomizing in the sense that meditation commonly implies. At Making Room, it becomes part of an artistic process that challenges Burtt - and his fellow practitioners and participants - to balance personal interests with those of the community (or communities) with which one claims affinity:

My drive to being present, and to really listen to people, becomes more true when I realize that there's something that we're trying to do together. When I realize that I am dependent on them to finish the project. That we're not sitting around having tea because we're nice people, but we have decided that we have a job.

Thus neither art nor meditation appear to be standalone concepts for Burtt. Indeed, both are privileged sites of formal practice for the kind of socially engaged art he envisions. To this list, Burtt also adds listening, an aspect of process that we might categorize amongst more generally communicative practices. As with the others, listening is attached to action in socially engaged arts, and is not merely empathic or aimed at more purposive problem-solving.

“The question for me," Burtt adds later, elaborating his artistic vision, "is how do we work together? How do we find ways to work together that actually has some sustenance to it, rather than things coming and going? How do members take more leadership roles in what we do?" Through listening, mediation, art-making, and other formal strategies, Burtt appears intent on not merely creating works of art, but establishing the grounds upon which his artistic work at 
Making Room can carry on and expand into the lives of both the community and its respective members.

Communicative practices like those to which Burtt refers are fairly integral formal strategies for a number of practitioners with whom I spoke. For Mindy Stricke, for example, they are also a pretty central component of her collaborative practice. In the context of the question I quoted her raising at the beginning of the section - that is, "What are the things people aren't saying?" - Stricke went on to discuss a particular workshop making art with mothers and caregivers:

[We did] some writing, and we ended up making some photographs. They weren't very successful as photographs. But, [...] ultimately, I have to try things out with people, and see what works. It really doesn't have to work on both levels - I think people really loved it. They had a great time. But, artistically, it didn't work for me at all. [...] It just wasn't good. But it was fine. At least I learned something. I always learn something from everything I do.

As with Burtt, answers to Stricke's question are not found in conversation alone - not found, that is, by listening in the most literal sense of the word. In its broader sense, listening is an apt term to describe the communication strategies a practitioner uses to attend to how socially engaged arts are experienced by both participants and practitioners.

For example, Stricke's participants seemed to have "really loved" their experiences even though Stricke herself wasn't satisfied with the aesthetic outcomes of their otherwise rewarding engagement. By listening to both sets of experiences - or, as she puts it, those "on both levels"- 
Stricke can mine a rich set of resources to self-reflexively augment her artistic processes.

For Stricke, who concludes “At least I learned something," it is clear that there's a place in her on-going project, Greetings from the Motherland, for communicative strategies to inform formal practices. For some, like Flora, this realization may be both aesthetically important and personally liberating as well:

More and more, as I do this work, I realize that I'm not holding something back in terms of vision because I want to make sure people have their voice. I actually need those voices to have a vision. I'm not secretly [saying] 'Oh! I really want it to be about this, so I'm just going to let people say what they want, and then do [whatever I want].' I need those voices [...] that's why I couldn't make it as an individual, capital "A" artist on my own.

Although I have been referring to communicational strategies as formal strategies, Flora's words here remind us that the prevalent division between form and content in conventional art theory is not universal. Thus while communicative strategies applied to artistic practice might create the grounds for participants to formulate their expressive voices, Flora seems to imply that they can - and should - do more; at least for her own practice, where communicative strategies like listening become formal strategies of art-making capable of creating a reciprocal exchange of knowledge and experience.

\section{Method and Form in Socially Engaged Arts}

A formal challenge faced by practitioners who seek active participant engagement revolves around making local experience more broadly accessible as art. As the preceding 
examples suggest, this signals neither an appeal to ideas of art's "universality," nor a subjection of aesthetic forms to exclusively political ends (as in some kind of propaganda). For many practitioners, being methodical about art is an attempt to continue their practice: by expanding their participant-base, their cast of partnering practitioners, or their funding sources. For a few, it is also about developing and deepening their practice as an art - not merely continuing it - by deploying more refined strategies and techniques related to the partnerships they foster and the technologies they deploy.

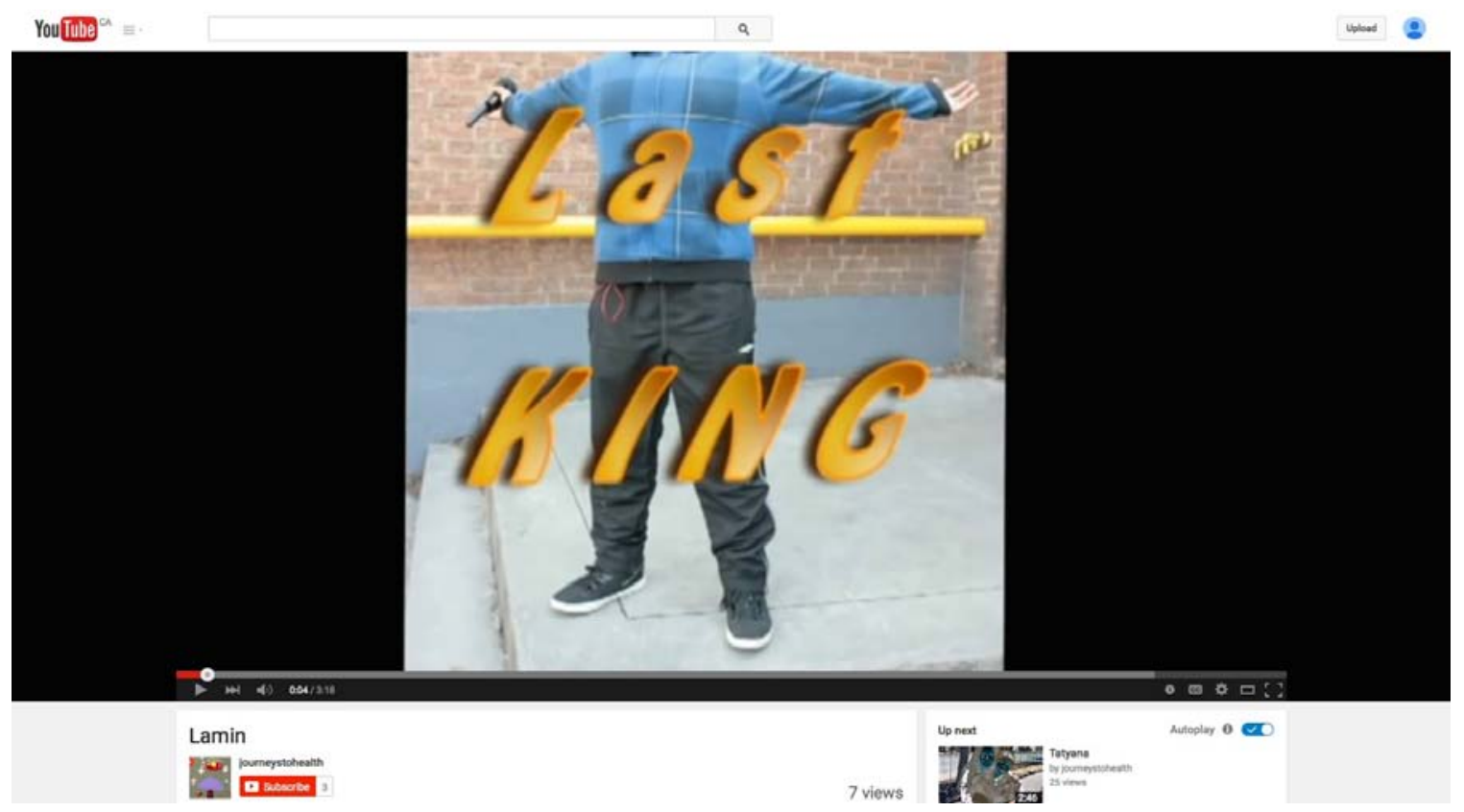

Plate 14 - Lamin and journeystohealth. 2013. From Lamin/Last King.

A significant example of methodical approach to socially engaged art may be found in certain incarnations of the practice of digital story. While a number of practices claim to deploy video documentary production as part of their practice, digital story has been elaborated in particular ways that other ostensibly similar practices have not. Emmy Pantin describes the particular digital story process she and her partner, Jennifer Lafontaine, have developed in Toronto, having been influenced in turn by Joe Lambert and the Center for Digital Storytelling in 
Berkeley:

The story circle. The way it works is that every person has a few minutes, five, ten, fifteen minutes, to tell their story. We talk about it being completely up to you about how you tell your story. Some people come with a script, [...] they read it and that's how they tell their story. Other people come to the workshop not totally sure what they're going to say, so they say "I was thinking about this or that," and some people tell a story from their lives, they tell a moment.

"Before we get to the story circle," she adds,

[W]e do talk about the theme [of the workshop], whatever that is, and we talk about how stories are told: talking about moments, why you're telling that story, et cetera, so [that], by the time people get to the story circle, they have an idea. And then, once they're finished speaking, we invite other people to make comments, give feedback or whatever. And the story circle always has an introduction around basic things around confidentiality, around when the storyteller is speaking they're the only ones speaking, and then, once they're done, then other people can give feedback to stick to their story.

Unlike other forms of socially engaged arts, digital story does not assume a preexisting community. While at times this may be detrimental, often it is beneficial. For example, while digital story often works with long-standing community or neighbourhood groups, at other times it draws together participants based on other affinities, helping to construct communities in novel ways. The method Emmy briefly described above can and has been deployed with relative uniformity across a number of different sites, both locally in the Greater Toronto Area, as well as 
at sites across the province and with groups around the country, though other distinct variations are also in use (see Bromley 2010).

As a method for socially engaged arts, digital story seems to offer the kind of integrative and reciprocal listening preferred by practitioners in the field. As Pantin suggests, it doesn't merely provide a decontextualized platform for individual participants to work in isolation but, through the collectivized "story circle," it continuously highlights the underlying context (or contexts) within which these participants tell their stories. Although formally digital story demands a good deal of individualized work in order to produce personal stories, a collectivized and collaborative sharing process bookends and frames this work, attempting to assure that some sense of community persists. Pantin and Lafontaine also go to great lengths to ensure that a final screening takes place both so that individual projects can be collectively celebrated, but also so that a sense of transformation - from story circle to end product - can be affectively shared amongst participants and, often, members of the community as well.

\section{Form and Engagement}

By now it should be clear that, although socially engaged arts value engagement strategies, they are not purely or simply about engagement. Although formally emergent, iterative, and reciprocal, and although they are concerned with changed social relations and other factors that align them with traditional forms of activism, they are nonetheless productive arts. Thus for many practices, the relationship between engagement and form is defined less by a tension between the two than by how the two are mutually interdependent, and how each develops in relation to the other, and how they do so in a cyclical fashion. Changes in form, in other words, demand different strategies of engagement while novel types of engagement 
invariably reshape form.

One particularly salient example of this can be found in a session of Burtt's meditative practice at Making Room. Often a component of a larger process, one day meditation became the grounds for a project in and of itself. In the project, members of and visitors to his group were photographed while in various, usually cross-legged, meditative states. These images were subsequently wheatpasted, as large scale posters, on buildings and in storefronts around Toronto's Parkdale community, particularly along Queen Street West. The images became a temporary part of the urban landscape in what Burtt called a kind of response or reaction to the dominance of advertising images and the underrepresentation of average, local people in modern public spaces like Parkdale. Borrowing from contemporary street art forms - notably the work of artists like JR and Dan Bergeron - the images expanded an internal, group-oriented practice and process of listening, and opened it outwards, beyond the direct involvement of artists and participants in order to engage the broader community.

One of Burtt's key artistic collaborators on the project, Joshua Barndt, discusses how this formal intervention in public spaces influenced a subsequent intervention into local public discourse:

You don't often find large scale images of people from the demographics we were working with. These [...] are people who are really poor, and some people deal with mental illness, or some people deal with a whole series of other issues relating to dealing with poverty. Those aren't usually the people who get asked to be on billboards, or get invited to have their image up in their area. I think, for some of the people involved, and for myself even, it was really awesome to have ourselves up on a wall - then people 
noticed us, and you get into a conversation with someone new and people ask "What's it about?" "Oh, we're making art together. We sit and we meditate.” Then you start having a conversation about that. And the conversation continues on. It also sparks the potential to have a different relationship ... with the people in their neighbourhood.
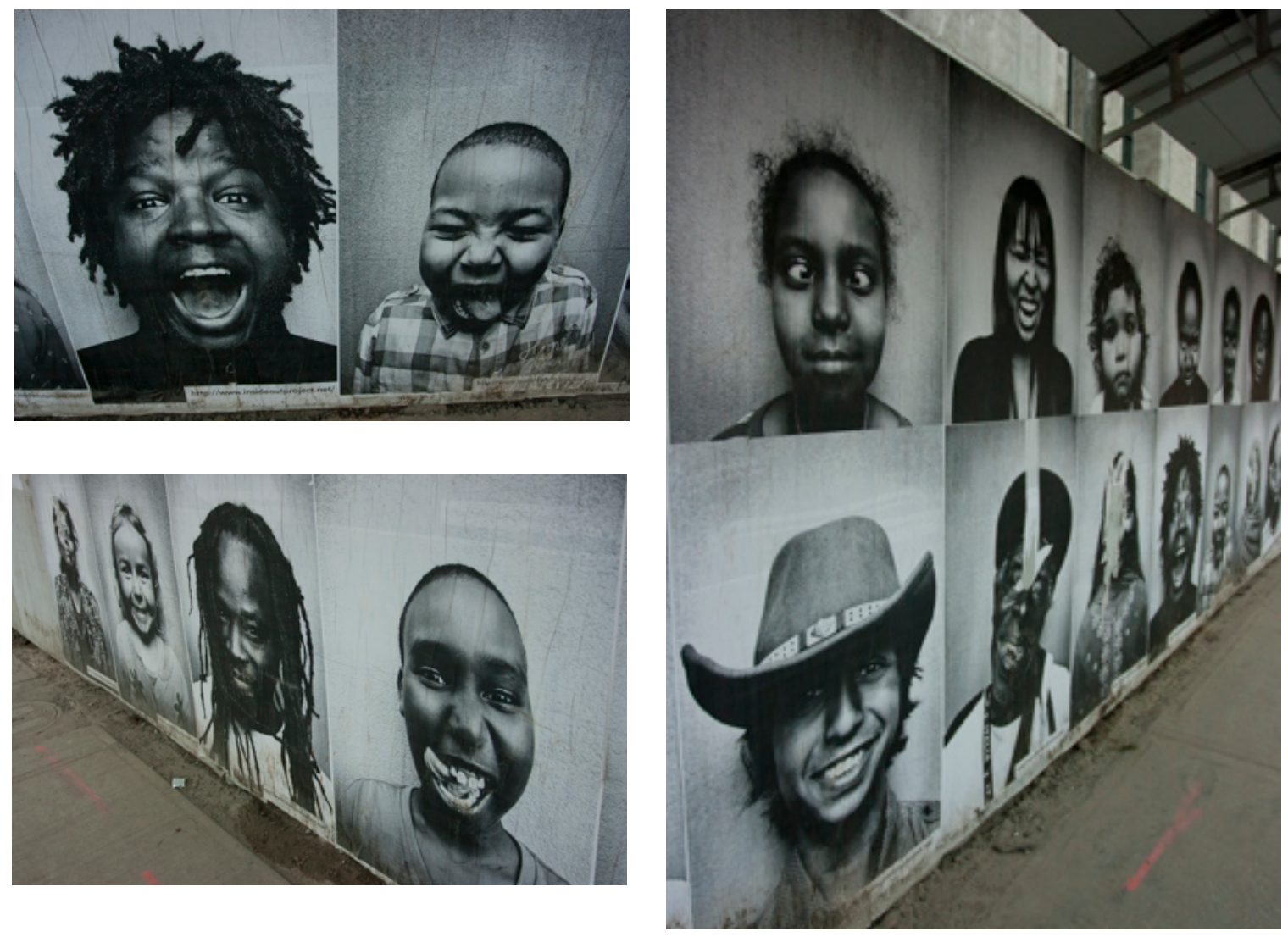

Plate 15, 16, 17 - Photographer(s) unknown; rephotographed by the author. 2011. From the Inside Out Project. Regent Park, Toronto.

Plates 15-17 are details of a contribution to international artist JR's Inside Out project coordinated by another Toronto community arts and media organization, Manifesto, and wheatpasted in several locations across the city, including this construction hoarding along Dundas. Practitioners and participants at Focus also played varying roles - as models and as image-makers in this city-wide endeavour.

Barndt suggests that socially engaged art such as this - the type he prefers to develop in his own practice - is "propositional" in nature, meaning that it intervenes into public discourse through formal actions taken in public spaces in unexpected, and possibly unprecedented ways. Certainly deploying realistic imagery in a context that seems to lead neither to an advertising 
campaign nor to archival preservation but to conversation or relationships is a novel kind of intervention. He continues, elaborating on the idea of ephemerality:

I'm starting to reconsider the role that street-based practices, in terms of autonomous [or] temporary actions, play in the overall social transformation of the space, or of people's understanding of that space. [...] Since it's temporary, it's low risk. It's not like if a city department does that kind of thing, and it has to fit into this specific framework of having longevity. We take those small risks, which are propositions that then other people can build off of. It's the sort of organic research work that's happening, and it's generally being done by autonomous individuals.

The idea that a socially engaged art practice may be admittedly ephemeral yet may simultaneously strive towards transformative goals may seem a contradiction. Yet whether it is described as "propositional" or something else, the idea encapsulates an expansive approach to form common to the most compelling of socially engaged arts practices. This expansion seems to include: first, a shift of emphasis from product to process; secondly, an imperative for an authentic communication that privileges both personal and shared experience; and thirdly, a belief that a key measure of success is achieved not merely by engagement based on democratic participation but also through a more formal and aesthetic engagement in the material conditions of everyday life. That such practices are formally innovative should be clear; so should the fact that such formal innovations are not isolated.

\subsection{Expanding Territory: "Where else might art be done?"}

Space and Socially Engaged Arts

The third area that socially engaged arts seeks to expand concerns spatial practices. If in 
the previous sections the concerns were summarized as "Who else might participate in art?" and "What other forms might art take?" this third, about expanding the terrain of artistic experience, might ask "Where else might art take place?"

This question is meant to represent the concern that the practitioners with whom I spoke frequently expressed over the physical, material spaces and situations within which art is made and experienced. Typically, socially engaged artists were interested not merely in physical or geographical senses of space, but in social and cultural senses as well. For many this concern was related to a desire to bring their practice more fully into public spaces like city streets and parks. However, there was also a fairly common concern with space as a symbolic terrain over which competing public and private, local and non-local, and mainstream and marginalized actors struggle - both individually and as communities.

Indeed, as another of what I am calling socially engaged arts' strategies of expansion, this concern with expanding territory signals an attempt to make art occupy a range of physical and virtual spaces in novel ways. Joshua Barndt, for example, speaks of his interest in how communities have historically drawn on artistic methods to "reclaim" urban spaces from the various effects that modernity and capitalism have had on cities. Of particular interest to him is the history (or histories) of collective and collaborative mural making:

When I went to university, I did more research into the history of community mural making [...] back as far as the Mexican muralists at the turn of the century, and then into the United States there was the Chicano movement in L.A. and California. Another movement came out of the black community in Chicago and other cities, where there were, basically, a series of projects that were facilitated sometimes by artists, but also 
often by community members, wherein trained and not-trained artists would work together to try to tackle both the issue of lack of representation of those demographics the Chicano community and the black community - by telling relevant stories and addressing issues relevant to those communities on public walls.

In part, it would seem, Barndt's interest in the mural form relates to the kind of content he feels it best lends itself to: community stories and life histories, tales often lost or forgotten. "But," he adds, the practices were also,

[...] a reclamation of public spaces in cities that were dealing with some severe urban transformation. It was a way for people to actually react and take ownership over space, especially in Chicago and L.A. The biggest mural movements were happening in areas where it was like massive displacement happening due to freeways being built, or other economic crises that were making housing and access to space really complex. There's a political undertone that those movements, mural movements, evolved out of.

In Barndt's estimation, the kind of knowledge-sharing and community-building project offered by the storytelling process is inseparable from the visionary repurposing of space that such mural-making demands. The movements Barndt describes seem keen to resist and reverse the dual erasure from modern urban space of both narrative-historical and visual-spatial realms through a process of, as he puts it, "reclamation."

Barndt's own practice seems interested in such a politicization of space through art, or at least he seems keen to mount critical aesthetic responses to processes of urban change - change that often continues to be imposed upon communities rather than enacted in meaningful 
consultation with them. For example, he recounts a project he helped to develop that was an attempt to engage a community - particularly its youth (see Goudge 2011). However, because the community's spaces were about to dramatically change - the area was slated for a so-called "revitalization" process: a multi-year, full-scale demolition and rebuild - Barndt felt the need to address this very process instead:

I said, 'You know what? I don't think we can necessarily focus on the mural. I feel like Alexandra Park is about to go through this major revit[alization] - all those walls are coming down, so I don't know if a mural is going to be an appropriate thing to go up.' There's all these narratives going on, and there's a lot of fear. That community's being totally demolished over this amount of time. There's a lot of anxiety.

Although experienced in and comfortable with processes of group mural-making, particularly with youth, Barndt nevertheless seemed confident with the more unpredictable direction this project might take. Recognizing the uncertainty of redevelopment as a core thematic seemed part of the emergent process Barndt sought to pursue. "A mural has something that's stagnant about it," he argues, "It tries to tell a narrative, but it's really still - it holds a stillness." He continues,

That's something that I just couldn't, conceptually, get my head around for this. So I pitched it to [the arts organization funding the project]. They were really forwardthinking, and able to take on experimental projects. We designed a project where we would do action research by working with a group of youth and a series of street artists to do temporary public interventions about the spaces in the neighbourhood, about how they're being used, about how they could be used, [and then] using those experiences to 
start having conversations with people, and foster conversations between the youth about how important those spaces were, about the revit, about the tension in the community, about the actual design of this - of the community currently - which has been identified as 'flawed.'

As I suggested above, the three strategies I have been discussing in this chapter are interconnected, one with the other. Here Barndt seems to realize that while mural-making (as a form) may be a worthwhile venture (in terms of engagement), he feels the pace of change related to the revitalization process in the community space (alternatively, given the community's current situation) demands something less monumental, perhaps, than a singular image affixed to a wall. I don't mean to misrepresent Barndt's words beyond their explicit meaning: I simply want to point out how his awareness of the space in which the art will be made and experienced comes to influence his thinking about its form and the ways participants will engage with it both during and after its development. As he suggests:

If we were going to really respond to [the revitalization], you have to pick sides in a stagnant mural. And then it sits there: it's almost too much of a document. It's too stagnant, [while] this issue is so alive! It's changing every day. The community is actually deciding what the design is going to be, and what the real goals of it are - and if it's going to happen! It's not even for sure. There's so much in the air.

In the end, there were limits to what could be done via the emergent process Barndt helped instigate. Although he was contractually obligated to produce a mural, the processes through which that mural was to be generated were varied, and took many forms, including phases of performative, photographic, and videographic, as well as sculptural creative work: 
"We did these actions, and we ended up documenting each one as we went. We had to make a mural based on our funding - one thing with our funding, we had to output some kind of mural. Our mural is basically large-scale documentation of the actions."

"It's huge," he continues, referring to the mural itself, "maybe 80 feet long. [Made up of] large scale colour photos printed on really shitty enlarged photo-print, and installed on this wall with pieces of the different sculptures - the debris of the sculptures - nailed onto it."

It's a document of those actions, which were experiments. I'm still figuring out what exactly the meaning of that is. But I feel like that was, for me, a really dynamic experience that, as an artist and as a community artist, we're not always making things that are permanent. Sometimes we're just making gestures that help us inform our next action. A lot of it is research.

For Barndt, and presumably for his participants, the principal emphasis seems to have been on the actions, what he later calls the "temporary public interventions," that were taken with street artists at several locations within the Alexandra Park footprint as part of the mural development process. In this sense, and similarly to other socially engaged arts practices, the concern to attend aesthetically to specific spaces often culminates - at least in part - in performative processes and products. The location of such performances (in public spaces), their proximity to the conditions of a community's everyday living, and their co-produced status (as collaborative between participants and practitioners) mark them in unique ways.

\section{A Fluid Art}

Indeed, for many of the practitioners with whom I spoke, the dynamism of urban spaces 
and populations seemed to demand a flexible, fluid art: if not ephemeral in form, then emergent in process and, ultimately, responsive to the physical and affective comings and goings of collaborator-participants. Nevertheless, the question of duration and permanence so central to art remains ever-present, at times merely as a point of contention, elsewhere as a substantive matter of concern.

This concern emerges most clearly in contexts that perceive art as cultural expression, where asserting the value of permanence in art is a matter of fostering, amplifying, and even legitimizing resistant voices and visions issuing from the margins. Barndt, for example, is not alone in deploying a range of artistic techniques to aesthetically respond to anxieties about the state of urban communities in the face of rapid, and profoundly urban, change. Regent Park Focus and Sketch have also responded to the major redevelopment of their Regent Park and Queen West communities, respectively, creating a variety of media and staging a range of performances that foreground the experiences and aesthetics of their participant-collaborators.

These and other organizations have worked to develop strategies that critically engage notions about the rights of locals to have a say in the governmental policies that affect the spaces in which they live, work, and play. Some strategies and practices work to challenge the formal methods by which urban development happens: for instance, practitioners at these and other sites have engaged with developers, city councillors, municipal agencies, and other organizations (such as non-profit, non-arts community groups) - and have done so in distinctly non-arts capacities - in order to advocate for a groundwork upon which a better art might be built.

Other strategies, however, take a decidedly less contentious approach, deploying techniques that, while still critical, are more imaginative and visionary about the possibilities of 
community spaces. For example, a good deal of the development of MABELLEarts as a community arts organization has been centered on the development and rehabilitation of Mabelle Park at the material (physical) and symbolic heart of the community. Houston and her colleagues have worked with a number of agents and agencies - such as Toronto Community Housing, recent ward councillor Peter Milczyn and his office, and other City of Toronto staff - in order to advocate for a variety of formal changes to public policy around how the park can be best utilized. However, MABELLEarts has also elaborated a vision of the park (a park of many paths, as the organization's tagline states; see MABELLEarts 2015) that metaphorizes the space as variously a cultural, social, spiritual, or emotional centre of the place participants-as-residents call (whether temporarily or permanently) their "home."

It is perhaps in this vein of envisioning alternatives, additional possibilities for a space and its inhabitants, that Michael Burtt describes a recent iteration of his practice with Making Room in Parkdale:

I was imagining Parkdale as a river in itself, as an imaginary river that carried people to the shores and take other people away. The people that I was hanging out with, and continue hanging out with, often go for lunch at [a local outreach centre], and then they go see people at [a neighbouring multi-service organization]. [In doing so,] there's a kind of flowing up and down the street. As someone pointed out the other day 'Of course we move around. They don't have any benches!' recognizing that there's a sort of forced moving of people up and down Parkdale.

Making Room subsequently developed a project that resulted in the construction of a raft and a parade from Queen Street West down to the lakeshore to perform a ceremonial launch in 
an attempt to both reclaim past visions of the neighbourhood and reassert a material connection to the adjacent city and lake that challenges externally imposed physical and social boundaries (particularly the Gardiner Expressway). The significance of visionary strategies such as these on expanding the creative possibilities of community spaces cannot be overstated; indeed, while the contentious work of challenging governmental discourse is also crucial to socially engaged arts both in how it helps ensure that strategies of engagement are thoroughly authentic, and in how it redefines the contexts wherein new strategies of form become possible - so too is a communicable vision of alternatives that helps drive political action. In other words, just as contentious action helps manifest vision, vision helps clarify what action must be taken. The material grounds of everyday life - both as the material context of cultural practices and the physical spaces within, between, and across which such practices occur - provide a crucial locus for socially engaged arts. 


\section{FINDINGS, II: CAMERAS AND STRATEGIES OF EXPANSION}

As I suggested in the previous chapter, the forms that socially engaged arts take are typically tempered by the process-orientation common to these arts. Even in cases where practitioners and participants are concerned with products (determined to put on a play, for example, or make a film, and so on), there is often great variability in the processes involved in developing such products. In other words, there is a fundamentally emergent character to socially engaged arts, as well as a corollary adaptability on the part of organizations to accommodate unforeseen intermediate steps in production processes.

Such production processes invariably shape the ways in which camera arts get deployed. In this chapter, I argue that the principal strategies of expansion I explored in the previous chapter - namely, of engagement, of form, and of territory - affect camera-based production in particular ways. Specifically, the primacy of image-production most commonly associated with camera-based production - that is, of making, archiving, and/or distributing images - is significantly disrupted in socially engaged arts. While discrete moving and still images remain important to the field and its agents, so too do the processes by which such images are conceived and made.

In this chapter, I explore three modes of camera-based image-making experience I found to be most vital to the practices I observed. First, I look at ways cameras are being deployed to react to the world that participants and practitioners find themselves in. In this mode, I argue, cameras are being used to develop a vernacular through which aspects of this world become marked and identified. Secondly, I look at ways cameras are being used to depict underrepresented and unrepresented expressions and relations. These include matters and 
relations that are beyond any vernacular, beyond what can be descriptively identified. I argue that cameras, in this mode, are turned to the task of making visible. Thirdly, I look at ways cameras are being used to reconceive and resist the discourses and images normally associated with participants and the communities with which they are associated. In this mode, cameras are being deployed performatively.

\subsection{Expanding the Vernacular}

In the socially engaged arts practices I encountered, cameras were used to represent either aspects of practitioners' and participants' practices, or their experiences of those, and others', practices. That is, cameras were brought out in moments during which it seemed aesthetically and socially necessary to not only create art, but also to capture or record, with a greater or lesser degree of realism, what appeared to be going on (or, perhaps, the appearances of what was going on). For many practitioners this seemed most commonly the result of the necessity for documentation - the need to narrate the story of an activity, perhaps in relation to illustrating a broader history of an organization - though it was also, of course, for aesthetic or pictorial purposes.

Cameras were often put to distinctly different ends by participants, however, since the primary aim of using a camera may not have necessarily been to make pictorial or documentary pictures, but rather to engage in processes wherein image-making was a primary activity. The difference lies in the intention toward process: for practitioners in a documentary or pictorial mode, the predominant aim is to make communicable or expressive imagery - "texts," in an arguably discursive sense, to be interpreted, experienced, or otherwise consumed. Images, in short, as an end product. For practitioners and participants in socially engaged arts, however, the 
goal may in fact have more to do with learning the processes by which such communicability and expressivity is formally and technically - in short, practically - done. Image-making, in this sense, is the so-called "end"; though such an end is less finite, and arguably more experiential than material.

That said, it is of course virtually inevitable that images of some kind ultimately get made by or with the contributions of participants in a socially engaged camera arts process. My point is rather that the particular orientation to cameras as more than or other than mere production tools (and instead of other artistic media) signals a shift in which process becomes primary. It is within this shift of attention and intention - towards greater or lesser selfreflexivity, criticality, sociality, and so on - that we may first explore what I found to be the vernacular in socially engaged camera arts.

\section{Vernacular's connotations}

The term "vernacular" is frequently used in photographic theory to describe pictures taken from the perspective(s) of an aesthetically interested subject: pictures which are formally constructed using the tacit, ad hoc skill set of an image-maker

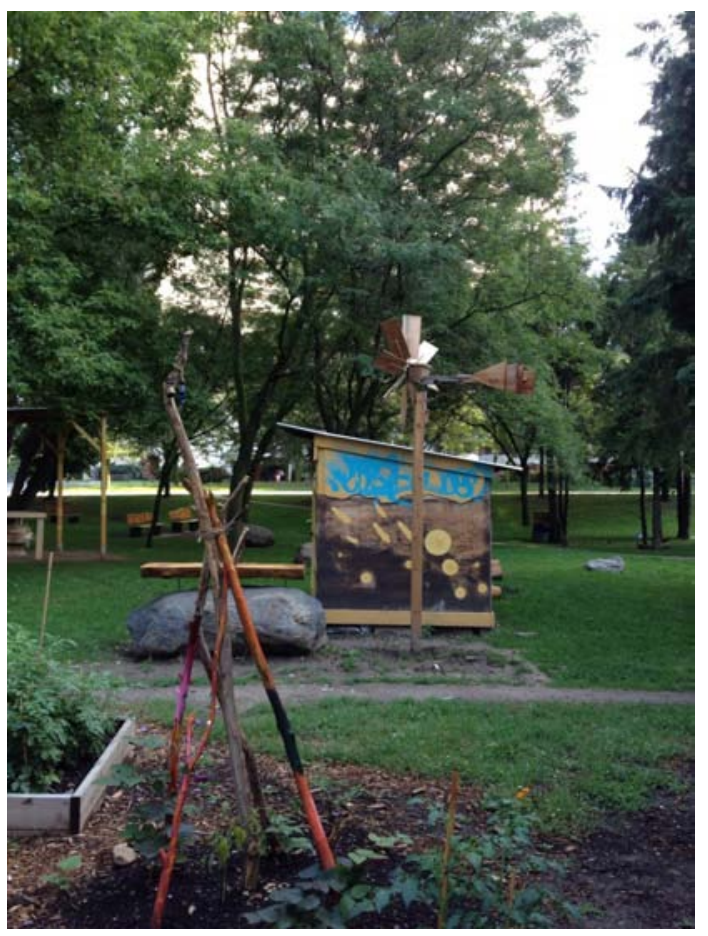

Plate 18 - Photographer unknown. 2014. Mabelle Park Bread Oven.

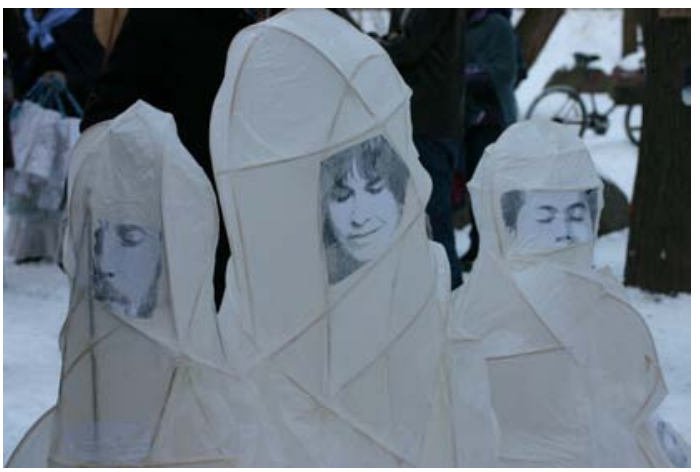

Plate 19 - Photographer unknown. 2011. From $A$ Light in Midwinter. 
(or makers) who has not been formally trained as such (or, occasionally, by one who purposely disregards her formal training). Such images are typically made reactively, as a kind of a snapshot, with inconsistent use of supporting technical equipment (such as lighting equipment or tripods or even dedicated cameras - often times multipurpose technologies like camera-phones are adequate, and even preferred), with similarly inconsistent application of techniques commonly used by professional photographers (such as metering, framing and composing, focusing, colour correcting, and so on), and without the kind of aesthetic disinterest or objectivity that typically accompanies camera-based documentary production.

The term is often a pejorative - used to characterize, for example, a composition as aesthetically weak or conceptually naive. However, vernacular could also be used more neutrally; that is, to describe an image and its process of production without passing judgment on either its content or form, or its maker for deploying it as a method. In this strategy, the naiveté of the vernacular becomes less a defect of vision, but rather a presence of visual style uniquely marked by reaction and impulsive response. As a feature of socially engaged arts, vernacular might be further taken to refer to participants' focus on constructing common or shared visual understandings of a world in which they all - in whatever ways - play a part.

In this sense, the vernacular is similar to other communicative modes; and, like these, is therefore done with a greater or lesser degree of intentionality, of intuitiveness with the medium, and self-consciousness over engaging in non-habitual activities. This latter is particularly important, because while for many people - participants and practitioners alike - camera-based practices are ubiquitous, critical and self-reflexive habits with the medium are not.

Thus the vernacular signals certain contradictions: it can imply both skilled and unskilled 
labour with cameras, both naiveté and self-awareness. Ultimately and irreducibly, I argue, the vernacular implies a predisposition to responsively and publicly depict the world at large. It is, paradoxically, to react with intention. For many practitioners, this very contradiction is a primary point of departure.

For Nick Kozak, a photojournalist who has run photography workshops for several Torontoarea socially engaged arts organizations, for example, photography is an important means for engaging with the world. Although he does not use the term as such, Kozak seems concerned with the vernacular, both in his own practice and in that with his participants. For him, documentary photography is a principal means by which to communicate with and about the world. While he recognizes that his is a subjective opinion, he provides compelling reasons for privileging this

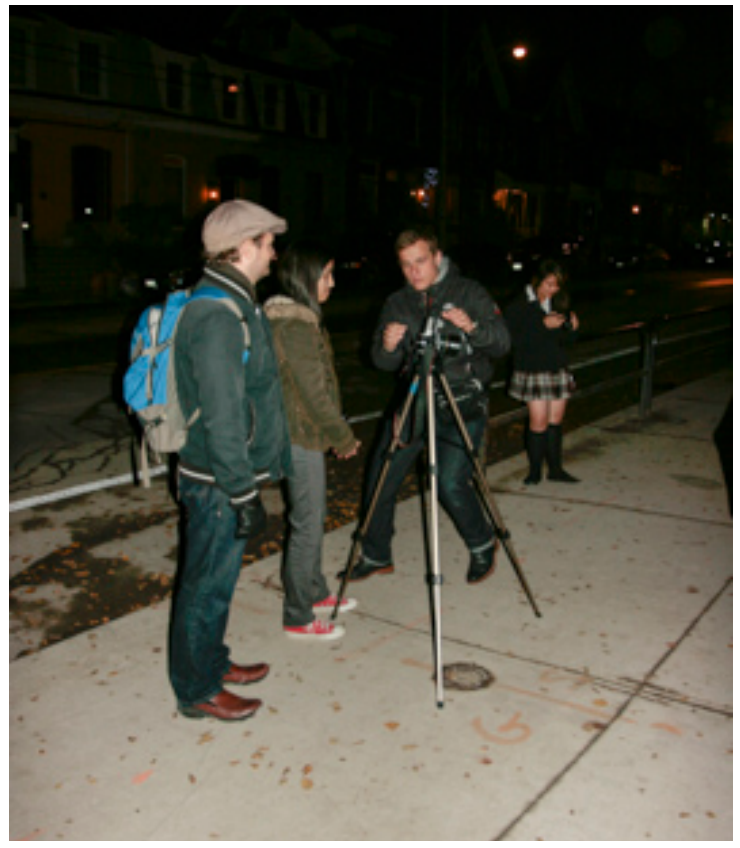

Plate 20 - Photographer unknown. 2011. Nick Kozak (centre) providing some framing and composition guidance to a participant during a workshop. Regent Park, Toronto. mode:

To me, this is photography. To me, all the other photography I could live without, in a sense. This is [how] I think that photography is most beneficial, most interesting, and most useful for us, as people. ... This is my ideal, that photography is about storytelling, and capturing history. That, I find, is most easily, most effectively shown, through repeated sessions of viewing, whether it be street photography, or classical 
photojournalism, social issues photographed by famous photographers, or photographers [that I know] who I have a high regard for.

Here Kozak also lays out an implicit pedagogy, suggesting that viewing a range of the genre's exemplars serves an educational purpose, that of demonstrating to aspiring participants how photography - or how "storytelling" or "capturing history" through documentary photography - has been and might continue to be done. The implication that for participants this isn't instinctively done soon becomes apparent:

It was very rare that that person would just, out of the blue, get something like that, come back with images after grabbing a camera. Because initially the instinct is to take photos of whatever's easy to take photos of, whatever's closest, and that's usually your friends or yourself - again, that Facebook shot of turning the camera on yourself. And there was a lot of that.

Kozak differentiates the terms "images" from "photos" here to signal at least two distinct genres: images that appeal to his aesthetic criteria, and photos that do not. Images, for Kozak, seem to be documents which are made with some degree of broad communicability, while mere photos seem instead to be limited by their self-referentiality or even narcissism.

I would argue, however, that Kozak's distinction is more nuanced than this. It is difficult, in these brief quotes, to discern his preferences (and problematic, of course, to attribute too much to his words). His commitment to supporting participant-generated photography and his belief in the value of his participants' experiences are not readily communicated through his words.

Instead, it is to his insistence on iterative experience - "repeated sessions of viewing" - 
that we might attend, since this is a method he deployed in the workshops in which I participated. During these sessions, Kozak discussed concepts and demonstrated techniques for achieving more compelling photographic images about a participant's chosen subject in order to get beyond conventional, instinctual image-making.

During his sessions, Kozak would review the day's photos through a laptop connected to a projector - initially those of photographers whose work he thought might be of interest to participants; later those of participants themselves, taken earlier in the day. Kozak would frequently use the term 'distracting' to describe aspects of a participant's images that suggested an unintentional rather than deliberate aesthetic choice. This might include arbitrary imaging where a subject's feet or head were partially outside the frame, or where there was an excessive and unnecessary distance between a photographer and her subject, or where there was evidence of blurriness due to camera shake or movement. Typically, Kozak used 'distracting' as a term to succinctly describe an element of a photograph that did not appear to be a part of a participant's deliberate intention. Moreover, I argue, by talking about and showing images - and, further, by tentatively editing them with a digital-imaging manipulation tool to actively and interactively demonstrate possible alternatives (he used Adobe Lightroom) - Kozak modelled a particular approach to image-making that referred not simply to images as static forms, but to images as dynamic constructions over which participants could (and should) exercise some control and agency.

Thus Kozak's attention to the documentary or photojournalistic mode at these moments seems an invitation to participants to consider their own technical and aesthetic development with the medium. In key ways, of course, his preference for documentary may signal an attempt 
at normalization: for example, by modelling and imitating certain forms, participants may inadvertently limit the emergence of more spontaneous and arbitrary ones. At the same time, however, Kozak's insistence on photographing in groups is an attempt to constrain exploration of content to dimensions which, in a collaborative (or at least collective), socially engaged process, suggest an interest in the range of urban experiences that might be common to participants. This dual movement, marked by a concern for technical proficiency and an interest in deepening local knowledge, promises a rich vernacular of emergent experience.

Other practitioners are also interested in the capacity of camera practices in socially engaged arts to develop common or shared vernaculars to bridge diverse experiences. Phyllis Novak at Sketch, for example, also speaks of tacit, un-self-reflexive uses to which cameras are habitually put:

Definitely there's a lot of photography that has been about processing your current situation. The usual thing of 'Me and my friends. We're boozed up, or we're asleep, or we're out on the porch, or we're ...' you know. 'Oh, now we're on trips.' Or, 'Oh this is something I see on a trip. Oh, this is something I actually love on a trip, and here's me on my trip.' And, 'Oh, now I'm interested in this area of the world.'

Like Kozak, Novak also lays out a kind of pedagogy at the heart of her practice, implying a kind of scaffolding of experience towards increasing self-reflexivity in both the previous and the following quotes:

It's a similar trajectory to the community arts thing, right? You're using the form as a way of making image and story to locate yourself. Then you're building a conversation 
with the medium about how you, in your social location, fit in the world. Then things that interest you that you want to zero in on, and then how you can become more engaged with it.

Whereas Kozak is concerned to model forms and processes in a seeming mentorapprentice approach, Novak's pedagogy seems more emergent, putting the onus on participants to determine the direction of their own development.

I do not mean to imply a preference for either method; indeed, these are different practitioners, working with different groups of participants under distinct circumstances, and committed to each in particular ways. The degree to which they succeed or fail rests on a wide variety of matters. As such, while there may be similarities amongst socially engaged camera arts and socially engaged arts practices, their dissimilarity from one another cannot be overstated. I simply wish to point to how these camera arts practices may have allowed participants and practitioners to engage individual and collective experiences of the everyday in novel visual ways. Certainly, the equalizing force of the vernacular is epistemologically invaluable - it is, after all, towards participants' everyday visual experiences that such imaging processes are directed.

There tended to be two roles practitioners chose to play in supporting the development of vernacular through camera-based methods. In one case, practitioners might overtly encourage a critical practice where participants' technical capacities with their particular camera-based media and related practices could be shaped in accordance with their substantive interests. Alternatively, practitioners might prefer to foster a more emergent practice, one where participants' substantive interests could drive their technical skill development in attempts to 
shape a primarily participant-led project.

This is not to say these latter were acritical compared with the former; rather, it suggests a different target to their critique. Whereas the former concerns camera-based practice, the latter concerns more broadly political and activist practice. While it is true that practitioners tended to favour one over the other of these positions, both were typically present in my experiences of socially engaged camera arts. Moreover, practitioners frequently chose to favour one role over the other at different times during a workshop, or at different stages of a project's development.
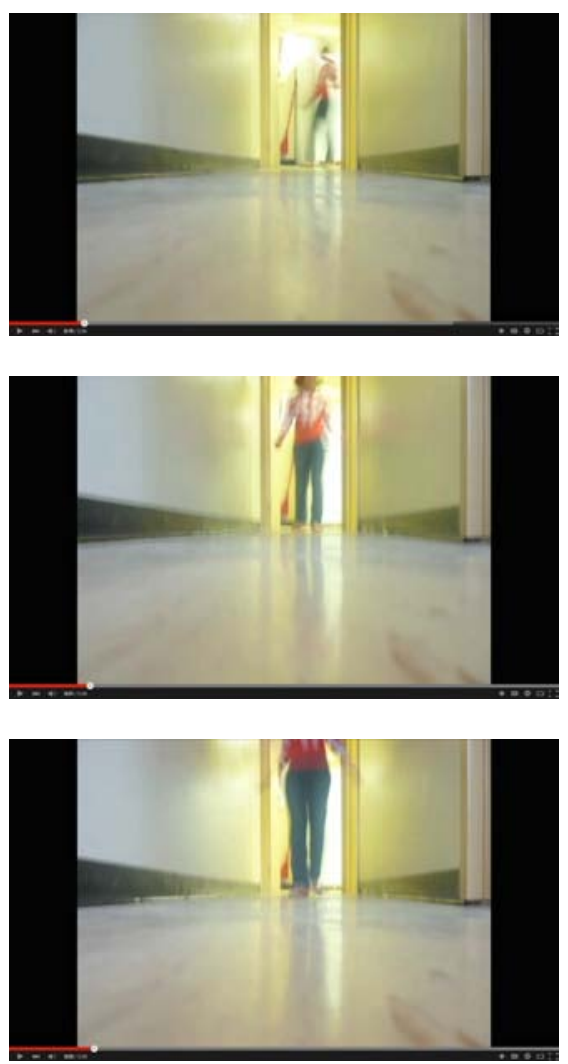

For example, the method of digital storytelling provides an instance of a socially engaged camera art simultaneously concerned with both technical proficiency and an emergent, participant-driven practice. Emmy Pantin describes the variation of the process she has developed with Jennifer Lafontaine, formerly of the Centre for Digital Storytelling Toronto:

A digital story is a two- to five-minute video, a digital video, and it's always a first-person narrative,

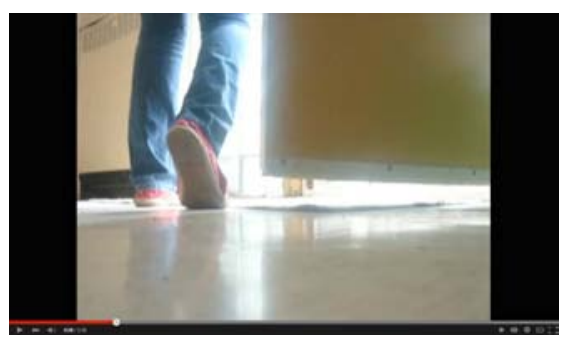

Plates 21 (top), 22, 23, 24 Kayondra and journeystohealth. 2013. Stills from Kayondra/A Moment in Life.

The relatively invariable restrictions to the method of digital story Lafontaine and Pantin have developed do not seem to hinder participants. Most are capable of producing sophisticated sequences of expressive and performative images within such parameters (also see Plates 14, and 25-26).

always a personal story. In this particular iteration, methodology requires that people tell

a story. It begins with a story circle, and then people tell a personal story - often based on 
a theme, but sometimes just based on whatever they want to tell, whatever story is important to them. They then produce a script that's 250 to 350 words, then that script becomes the narrative that they read into an audio recorder. So that story, the narrative, is the basis of the movie. It's the thing that never changes. The pictures, et cetera, can change but if the script is two minutes long, then that's how long the movie is - you know, [along] with credits or whatever.

Both the specificity of the technique and the open-endedness of the method are evident, with the participant-generated script being developed emergently only to a point, after which it becomes an invariable anchor to which audio effects and visual media might be attached. Pantin continues, highlighting the kind of focus and hands-off direction this offers participants as they proceed to complete their projects:

Although it's scripted, it's meant to stay in an oral kind of tone. The reason it's scripted is about concision: to keep it within that two to five minutes, so it's about editing and control. The whole thing happens over a 24-hour period, and it uses a popular education methodology to teach people how to edit videos, so as much paper editing as can possibly be done is helpful - it helps keep it all contained.

Although from one perspective digital story's limitations seem likely to circumscribe a creative process, Pantin emphasized that such constraints help to ensure that a fairly sophisticated, if brief, project can be completed. Moreover, such focus helps highlight two distinct vernaculars: first, that which is related to technical proficiency with digital video editing and audio and video field production; and secondly, that which is related to storytelling as both a personal skill and particularly as a social activity. 
The passing allusion to popular education in Pantin's quote is actually quite important in this respect, since it contextualizes the production process as more than simply instrumental. Rather, by adopting a popular education methodology, digital story is intended to be, following the work of Paulo Freire, a consciousness-raising project directed beyond mere community selfexpression and toward culturally-informed structural change. By centring on participantdetermined stories the process allows for an emergent process that extends beyond the immediate vernacular of a workshop's temporal and physical location. Participants might develop a story from a personal matter that is contemporary, or they might explore a memory from their past whether here or a continent away, from their youth or about the life of another in their family. As a result, a number of discrete vernaculars might intertwine - visual and aural, discursive and experiential, local and distal, and so on - resulting in a novel configuration of digital narrative expression.

At the beginning of a workshop process, Pantin and Lafontaine typically screen a selection of exemplary stories from previous workshops to provide a range of conceptual ideas and formal models that participants might bring to their own story development. These exemplars change from workshop to workshop, but are chosen to address a range of both thematic and technical concerns. The story of a young immigrant boy's passion for soccer, for example, might be used to appeal to newcomers to Canada, to sports enthusiasts, and so on. Or instead it might be used to demonstrate a particular editing technique, the use of music or sound effects, a novel use of implicit imagery (Lambert 2012), and so on. Most often, it is screened for both thematic and technical reasons.

Because participants are encouraged to submit their story ideas prior to the workshop, 
Pantin and Lafontaine curate the material to be screened in accordance with the concerns and interests their participants raise. Along with small workshop size, frequent one-on-one support during workshops, a growing repository of past videos, and a mentorship model that seeks to support the development of the method at the hands of other practitioners, Pantin and Lafontaine's practice provides a fascinating model of socially engaged camera practice.

Although no practitioner used the term vernacular, terms and notions related to the use of cameras for evoking personal and affective experience were nevertheless common. For instance, Lafontaine recalls her initial interest in the method:

What appealed to me [about digital storytelling] as a methodology is that it was drawing on all the things I valued about the visual work that I had done. It was getting people to take photos, and it was also drawing on your own family photos. It was still image-based, but it was video. It was this really ideal place, visually, for me where it wasn't having to be 'I'm making a documentary right now, and I'm doing a video of your face.' Or I didn't have to go back to film school to figure out how to enter the digital era.

As Lafontaine suggests, digital story seems to blend acquired knowledge and innate experience in equal amounts, centred as it is on practical skill-development, on the one hand, and an emergent, participant-driven learning on the other. It is worth considering, however, the degree to which the method's necessary limiting of technical and emergent possibilities to a fairly uniform set of parameters impacts this appeal. These limitations include being a 2-5 minute narrative, for example, being structured from a first-person perspective, recorded solely in the voice of its author, and produced within a typically 24-hour timeline, germination to final file. 
Based on the above, we might argue that there is little impact at all, at least based on these examples of limitation. Indeed, the limitations it imposes may work not to hinder but to focus participants - most of whom are novices to the processes - on the twin goals of technical proficiency and self-reflexivity. Indeed, although the method sidesteps the formal training common to more conventional media production practices, its ostensible accessibility may make this learning more enduring. A more important assessment of its effectiveness may be located in its commitment to popular education aims; that is, the degree to which it claims to foment change in and beyond local communities, and the ways it actually accomplishes this.

\section{Shared Vernaculars?}

A more serious critique may rest with the method's concern with individual authorship. Ultimately, digital story results in a collection of individual tales, despite the emphasis that is placed on collectivizing the process and distributing the stories online and in shared screenings. It would be a mistake, however, to perceive this tension between individual authorship and practical cooperation - between individualized skill acquisition and community building through storytelling - as fundamentally undermining the process. Certainly this tension is acknowledged by Pantin and Lafontaine. For Pantin, for example, it is addressed by their focus on the social aspects of story rather than the personal aspects of technical skill-development:

In the end, the key place for us in the work that we do is around the craft of storytelling. That's really where we spend a lot of the work. Even if it appears that we spent two of three days on the computer digitally manipulating stuff, that's about telling the visual story, or whatever. It's really about story craft.

(As a brief aside, Pantin's notion of "craft" should be distinguished from the product- 
oriented, politically impoverished usage discussed in the previous chapter. As should be clear, her usage of the term is much more about an emergent, self-reflexive, and expressive process related to practicing a range of social and technical skills, rather than about acquiring a conventionally fixed set of orientations to a genre of material production. I return to this matter later in the chapter.)

Pantin continues, framing her priorities in deploying the method:

That's where the oral nature of the story is so important, right? At the beginning, [during the collaborative story circle group process,] it's about building that. It's that philosophical piece around 'Why this story? Why now? Why are you telling the story? What makes you want to tell stories at all?' I think that's the craft piece, the value piece, that comes in that's really important to us. That's connected to the aesthetics. It's not just the skills, it's not just the technology, it's the why.

\section{Vernacular's Techniques}

These matters of why suggest Pantin's ethical and political commitments. As such, they may be questionable, even contestable, by another practitioner's standards. It would seem, however, that such emphasis is imperative - indeed, I would argue that frank discussion of political and ethical views is universal to socially engaged arts and socially engaged camera arts. Not only does Pantin's system of valuation help lend a particular shape to the self-reflexivity inherent in digital storytelling, it legitimizes the place of politics in art, and offers a glimpse of what those politics might be.

In this case - specifically by iterating through questions of "why?" - Pantin argues that 
the social implications of storytelling must be connected to the aesthetics of the method. Not only might this be significant for the internal, grassroots development of communities (a matter that seems to concern both Lafontaine and Pantin, and many others), but because it begins to challenge dominant representations more commonly found in public life - particularly related to mainstream media and schooling.

Indeed, during our interview, Pantin went on to talk about her own experiences developing local documentary pieces for a mainstream Canadian media conglomerate. Contrasting that past with her contemporary experiences with digital story, Pantin addresses the distinct possibilities each offers: “[With digital story you're] talking about someone [...] integrating and understanding the meaning of something for their lives, which leads to some sort of transformation, which is not what [that media conglomerate claims it] is looking for as much as they pretend."

"I still love [mainstream media]," she continues,

I love consuming it. But [...] I feel like we offer people a method or a platform [for people] to tell their stories. What [this media conglomerate] does is tell other people's stories. They take people's stories and interpret them [for them]. This is a way I'm giving people a platform to interpret their own stories. I'm saying 'Here's some tools. Tell me.' I have a method, so there is a framework. It doesn't work for everybody, but it's easy for most people to understand 'That's a tool, just tell your story using it.' And they tell beautiful stories using it.

There's something about [that media conglomerate], or mainstream media, [that] sees 
itself as artist, itself as the storyteller. [To my participants] I'm like, 'You're the storyteller, you're the artist. I'm giving you tools, we're collaborating, I'm helping you figure it out, but it really is your story, and it belongs to you, and the choices are yours.'

In her critique of mainstream media's claims to agency-building, Pantin metaphorizes the digital story method in a number of ways; specifically, she refers to digital storytelling as a "platform," a "framework," and a set of "tools." Each term has its own implications: "platform," for example, suggests the possibility for engaging broader conceptions of public discourse and action; while "tools" emphasizes an individualized process of skill development and aesthetic experiencing.

Each, however, signals an intention for digital story to sustain its principal features beyond the immediate encounters within which it occurs. Digital story seems not merely technique, in other words, but an activist artistic methodology. Accordingly, the emergent, process-oriented, and self-reflexive - even auto-didactic - dimensions of digital story's method must be sustained in something more than an ad hoc way. This is done by attempting to build a personal vernacular of personal experience, as well as a shared vernacular of narrative in acknowledgement of and resistance to mainstream media.

\section{Limitations of the Vernacular}

However, and as I will argue below, more than either a critical or celebratory engagement with mainstream media is needed to develop a vernacular. After all, a vernacular is inclusive, unselective, and acritical about naming and depicting a cultural practice. Yet not all of cultural practice is germane to the goals of a socially engaged art. Neither is all vernacular production of any value beyond the moment within which it is made. 
To illustrate: on several occasions during my interviews practitioners mentioned the existence of underused material, such as projects from past practice that had limited connections with ongoing learning and socially engaged art practice - despite their formal and thematic relevance to active efforts. Several practitioners spoke of harddrives of unsorted media (including videos and still images), while one even spoke about a "pile of photos" which, whether literal or metaphorical, suggests their inaccessibility as source material, and a need for techniques and structures that can draw such images, as evidence of past practice, into contemporary forms and techniques.

Yet perhaps such materials exist as such for a reason. Perhaps they are no longer meaningful; perhaps they never were - except, again, as process. As discussed in Chapter 3 (see 100) in relation to this quote from Regent Park Focus Director Adonis Huggins, this affects an organization's ability to engage with its broader audience or public:

I'd like to see more of the impact. I guess what happens, and what's frustrating, is that youth produce things here. It has the potential to affect change, but [...] we're so busy producing that we don't spend a lot of time disseminating - and don't have a lot of resources to disseminate. The Internet's great, but are we doing social media [presumably Twitter or Facebook] about that thing? If you happen to come to the website, that's great, but it would be great if, each project that we do, there was a whole campaign to get it out there, to get it in people's hands. To talk about the issues that they're talking about. What tends to happen is they say 'Oh, that's great! Youth produced that. Great!' and there's not any kind of discussion about [...] the content of what they made, rather than 'Oh, great! Skills. Look at that, doing something positive.' [...] There are very few examples of that 
happening. [...] We don't have the resources, so most of our full focus has gone on process and production, and [then] hope for the best!

It may be that some degree of technological infrastructure is needed to address the kind of archival challenge raised here. Yet perhaps what is needed even more is a different type of infrastructure - a cultural organization or reorganization of relations and practices that would

place impact and dissemination at the fore. To be sure, Regent Park Focus is highly successful at doing - and pioneering - what it does in terms of youth media production; there's no guarantee that such a shift in priorities would yield preferable results. Yet it is likely at the level of the repertorial rather than the technological that success might be gained. I will now turn to another aspect of socially engaged camera arts practice to further explore how such concrete demands may be addressed.

\subsection{Expanding What's Visible}

A concern with vernacular suggests an active, but ultimately reactive, practice of identifying aspects of one's experiential world. Contributing to that vernacular - adding to, modifying, or otherwise intervening in it, through socially engaged camera arts or some other aesthetic, communicational form - is an interrelated activity, yet a distinct one. As such, I want to explore practices that seek to expand on what's visible independently of those that seek to expand vernacular. The use of camera technologies in socially engaged arts I am calling making visible in order to suggest activities and practices that seek to address affective, expressive, and tacit domains of experience. Although they both appeal to emergent and self-reflexive processes, I argue that these strategies are distinct. 

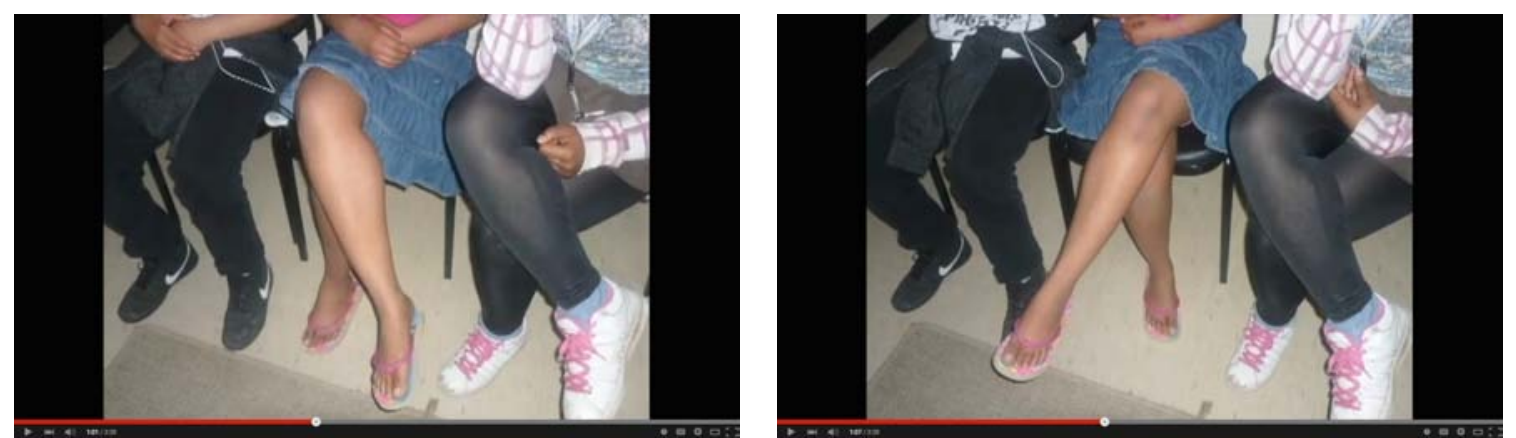

Plates 25, 26 - Kayondra and journeystohealth. 2013. Stills from Kayondra/A Moment in Life.

\section{Making Visible}

Although the term is meant to draw on affect and emotion, by making visible I am not referring to the production of camera-based images that are conceptual, theoretical, or otherwise conjured up from thin air. Indeed, the formal constraints of the medium negate this possibility cameras must engage the material appearances of the external world that exists before their lenses, regardless of whether that world is found or fabricated. (Such fabricated or fantastical elements to be captured or recorded may, perhaps, constitute performances - a matter to be discussed below). Rather, by using the term making visible I am trying to evoke those elements of camera arts practice that attend to the contingency and ambiguity of human experience. Unlike the vernacular, which is of things seen in the world, making visible implies the ways non-visible aspects of the world - social structures, for example, or affect, or relationships - may get depicted.

For example, we might consider the distinction made in digital storytelling methodology between implicit and explicit imagery. Emmy Pantin considers it this way: "Part of how to make those videos is talking about the visual story. We talk about implicit versus explicit images, so that rather than always repeating what's happening in your script [it means] trying to let the images $[\ldots]$ deepen that story." 
We might locate in the expressive desire for "deepening," as Pantin puts it, an aspect of what I am calling making visible. For example, in a digital story about how soccer helps bridge a youth's recent experiences of emigrating to Canada with her past experiences of "home," an explicit image might be of a game of soccer, or of a citizenship ceremony, or of anything largely descriptive or illustrative of the story itself. An implicit image is more connotative than denotative (in Barthes' sense, see 1972); as such, implicit imagery is connected less literally to the story. A dated family photo of a soccer match "back home," for example, or the author playing soccer alone in a field begin to have implicit aspects, as they suggest properties and relations that are unspoken or hinted at in the narrative (such as, in these decontextualized examples, nostalgia or cultural isolation; context may dramatically shift what these images imply). Imagery having nothing to do with soccer whatsoever may be a further example of implicit imagery, one where the juxtaposition of story with visuals demands unique interpretive strategies of the viewer in order for her to reconcile the separation of meaning between what is perceived and what is narrated.

Pantin's concern for "deepening" in the digital story method seems a way of exploring the contradictions between and amongst various ways of communicating. Indeed, the subterranean metaphor she uses suggests (among other things) a process of proliferation, where meanings intertwine and interconnect, possibly "below the surface" of conscious experience.

Certainly a model of making visible has advantages for the aesthetic exploration of subjective experience. Jennifer Lafontaine celebrates the capacity for digital story to offer individual makers a degree of experiential liberation: "If someone said, 'This is what I see in this photo,' or somebody else said 'I took this! You might not think it's amazing, but this is the 
whole story behind this picture. ... That was my experience! ..."

This sense of personal accomplishment is furthered with shared and collectivized screenings. When the social aspects of the method are also systematically pursued - group storytelling, group screening, and so on - digital storytelling has a unique capacity to engage participants in a process of aesthetically exploring aspects of their common, intersubjective experience. At the least, participants share the unique experiences bound by the duration of the workshop. As infrastructure is developed to share videos, introduce participants from different workshops and distinct sites to one another, and to mentor a new cadre of practitioner-instructors (as Pantin and Lafontaine have actively sought to do), digital story further distinguishes itself from both conventional media practice and the more insular and atomized aspects of personal or "home-mode" communications (see Chalfen 1987).

As I will explore in more detail below, a principal challenge to strategies of making visible - as much as strategies of expanding vernacular or any other aspect of socially engaged camera arts - consists in maintaining an infrastructure that supports such processes. The cooperative process upon which digital story is built consists, in large part, on a relatively continuous engagement. Such engagement is different from that offered by the periodic screening and sharing of videos or the episodic nature of workshop offerings. For Lafontaine and Pantin, this has indicated an imperative to secure organizational support for digital story, a process which, in turn, has allowed them opportunities to train other practitioners in the method, devote resources to archive and catalog existing materials, and apply for resources to see these and related efforts through. 


\section{Techniques of Making Visible: Images and Beyond}

The example of digital storytelling suggests that there are a variety of ends to which cameras are put in socially engaged arts. This example also suggests that these ends are not discrete: it would be just as unfair to claim that digital story's sole aim is social activism as it would be to suggest its sole aim is to be art. As a strategy for expansion, digital story is concerned, of course, to do both of these things, and more besides. A more productive inquiry would instead be into the techniques of the method - and, indeed, the methods of other socially engaged camera arts - to explore the range of what it might be to make visible.

Obviously, the intention of camera-based methods in socially engaged arts is often about constructing forms of imagery. Yet it is also often about engaging with vision itself: to deepen that which one already sees, or to see in ways which are new, long forgotten, or forcibly repressed. Thus while in some ways making visible is a deeply political process, in that it seeks to engage a range of visual discourses and recover affective visual experiences, it may also be a technical one in the ways it seeks to pedagogically explore the conditions that ground such discourse.

For example, Nick Kozak's use of photo-manipulation software to edit participants' photos (mentioned in the previous section) produces a process within which certain formal conventions of photorealistic imaging get foregrounded. The software that Kozak used allows for quick adjustments to cropping, colour balance, and it even supports the incorporation of text, producing fairly significant effects that may work to "deepen" (to borrow Pantin's language used earlier) the expressive intent of an image. His modelling the use of such tools - by projecting the screen of his laptop for all participants to see and by narrating his interactions with the software 
- demonstrates techniques of image making that assumes as a precondition ways of seeing that are modulated by camera use. As such, Kozak's techniques offer models of or workflows for working with images that may be unfamiliar to participants.

While Kozak's techniques are his own, the intention behind them is common to uses of camera practices in socially engaged arts. To put it succinctly, a core technique of making visible consists of inviting participants to symbolically recast aspects of their everyday lives. As Kozak's work suggests, this may mean learning new habits as much as unmaking old ones. For Kozak, this has meant a more deliberative use of still camera production techniques than what a naive, "Facebook shot" demands; this would seem to imply an intentionality over framing, composition, shooting multiple photos, physical proximity to one's intended subject, and so on. More than this, however, intentionality also means reorienting oneself to the visible world; it means shifting one's perceptual relations to her visual cultures.

It is in a similar context that the concept of framing and reframing came up. Mindy Stricke, for instance, metaphorizes the pictorial practice of framing, applying it to a genre of activity rather than to the literal technique of artistic perception:

One of my goals, one thing I'm interested in, artistically, is taking the everyday and reframing it. That's what I do - whether it's photography, or whatever I'm interested in. Same with the poetry. If you look at all my work, whether it's photography or it isn't photography, it's found. It's like [the] perspective is changed. Like a page of text is reconfigured.

Stricke is referring to cross-out or blackout or erasure poetry, a technique where pages 
from found texts (usually pulp paperbacks or newspapers) are covered over in black ink save a few words that find new pictorial, narrative, or poetic meaning (depending on the criteria the artist used to select them). Stricke goes on to argue that applying oneself to "reframe" and "reconfigure" aspects of one's everyday life also supports the emphasis on participant knowledge that socially engaged arts so fundamentally value:

I actually think it works really, really well for community art because it means you're not giving someone a blank piece of paper and saying, 'OK, draw something!' which I wouldn't be comfortable with doing, either. I'm saying 'Here. Here's a piece of text. Just cross things out.' It works really well.

The simplicity of Stricke's approach is in how it fundamentally recasts the conditions of her art. Although her preferred practice is photographic, and she ultimately would like to produce a series of work based in the medium, her approach also places a primary emphasis on engaging with her participants. In addition to experimenting with found texts, Stricke has invited participants to collage images from homemaking and beauty magazines and respond anonymously to open-ended questions using vintage typewriters. As with other practitioners, her technique is to deploy a relatively uncomplicated and ready-to-hand variety of artistic media and materials that both recognize the limitations to commitment her prospective partners may have (in terms of time, for example, or comfort with particular media, and so on), yet that nevertheless tap into the everyday experiences where commonalities, despite distinctions, might be found. Ultimately, the combination of emergent, participant-centered activities and attention to the habits and relations of everyday living allow Stricke, her fellow artists, and her fellow participants, to pursue an art that acknowledges these multiple factors and, through a 
combination of iteration and accumulation, to begin to contend with them, discover some pattern in them, and render those patterns in visible and perceivable forms.

Despite their similar attention to and concern with the everyday, Stricke sees her work as distinct from the kind of documentary photography mentioned earlier:

A lot of community art projects of photography have been documentary, street style photography. (A) I don't do that kind of photography, really. But (B) that's fine, telling stories about your neighbourhood. That could be really interesting. But I think it's really interesting to use photography in different ways. Also, if you have constraints ... I think I started this project in February. So [...] what can you do in a workshop so that you have two hours? What can you do with photography that's there? Right there? There's tons, obviously.

Rather than a critique of documentary, however, Stricke's concern here is, in part, pragmatic. While there's an implication that documentary is a prevalent mode in socially engaged arts, her main argument seems to be that photography might also be done in other keys and registers, within a variable range of circumstances and spaces (wider or narrower, as the case may be). As with digital storytelling, Stricke's cooperative process may productively benefit from naming and working within particular constraints.

However, there may also be a thematic connection to this way of working. Stricke's work deals with the dynamics of motherhood and the gendered and often also racialized constraints that go along with what being a mother, parent, or care-giver means in the eyes of those with whom one interacts at home, at work, in public, and in other social and institutional spaces. Such 
constraints impact the time Stricke's participants can be in the room with her, thereby affecting the ways they can engage with her project.

Stricke's implied assertion of the prevalence of documentary in socially engaged arts and her preference for engaging the everyday differently - hinges on a distinct sense of community, one where concerns with aspects of urban experience may be inappropriate or too non-specific. It is in this sense of community that making visible, rather than expanding on a vernacular, seems a preferred general strategy, though Stricke does not use these terms as such.

For example, Stricke's own preferred strategies for making images - her goals of reframing and reconfiguring, as she puts it - were deployed to develop the series You Are Not Where You Were. Here Stricke worked collaboratively with participants from her workshops to produce compositions that utilized miniature, model railroad figurines foregrounded against child - particularly infant - consumer items such as toy pianos, baby bottles, stroller wheels, toy blocks, and so on.

Echoing the miniature work of studio photographers like David Levinthal (1996; 1997), these images were constructed similarly, using a shallow depth of field (so that much of the foreground and background of the images becomes distorted by a focal blurring), and tight cropping to resize small objects to a disproportionate scale.

Although rendered with more vivid colour and with less image area cast into deep shadow than Levinthal's images tend to be, the condensed visual territory nevertheless seems to symbolize a restricted conceptual, and indeed social, terrain. The necessary narrowing of usable physical space for these compositions, which is also achieved by placing the figures in 
precarious locations, contrasts sharply with the bright colours and normative, pacific countenances of the stylized figurines, which were originally made, of course, for different purposes. As such, a tension is created: seemingly at ease despite their obvious contortions and treacherous positioning, the figures become caricatures. Photographed as such, they seem to echo the anxieties of their creators: women concerned, perhaps, about living up to social expectations of motherhood and femininity in the face of pressures that seek to both critique and minimize the complexity of their identities as public and private beings.

In various ways, the images echo the sentiments shared amongst many mothers throughout Stricke's sessions regarding the expectations of friends and family about how they should now be and act. Making visible here, as elsewhere, begins at the vernacular by both objectively and selectively portraying the world as it is. It continues and deepens this model by rendering unto perceptibility those conditions, relations, and experiences that might otherwise remain unnoticed. As Stricke describes the broader project, Greetings from the Motherland: "I guess it's about looking at motherhood through a skewed lens as well. One thing I did when I started the project, because I knew there were a lot of representations [that were] very sentimental, and expected [was to ask,] how can we take what's expected, and make it unexpected?"

For Stricke, such expectations might include, for example: a belief that a new mother's experiences are limited to a dutiful few (happy, loving, and nurturing); that any atypical feelings and emotions are merely temporary and will - or should be made to - pass; that their previously multidimensional identities - as partners, employees, caregivers, erotic bodies, political entities have become simplified and singularized, often even by friends and loved ones who formerly 
acknowledged their complexity. And so on.

In short, the point for Stricke, it would seem, is to use creative processes - including, but not limited to, camera-based media and socially engaged art - to cooperatively engage in the critical, self-reflexive, and emergent processes that make possible new forms of collective agency that contend with, rather than submit to, these and related efforts to steer mothers toward cultural normativity.

Although, like with Lafontaine and Pantin's digital stories, images were eventually produced, Stricke's creative process seems at least as important as the final product, since it is in Stricke's engagement with her participants that commonplace relations and sentiments could be iteratively explored in spaces where such experiences might be rendered visible and palpable.

\section{Infrastructures of Making Visible}

Alongside discussions of how these iterative aesthetic processes were developed came concerns over how they might be sustained, and how spaces to support such involved processes might be developed. Phyllis Novak, for instance, voices optimism that a shift to digital photography might offer greater conceptual space to visualize instead of simply document experience:

I hope in the new space [Artscape Youngplace] we can do more work around digital manipulation, because I think when people start to understand it as another tool, as a visual art form, then I think [...] it'll have an interesting aesthetic that will live beyond just the personal narrative.

That's always my only thing with all these projects. There's no question that it is a tool 
for people to realize themselves, and to build skills, and to offer something to the community. Their stories are significant - we know storytelling is a huge part of this.

But I feel like there is a certain kind of power in becoming an architect of images that will have a social change component to it. That's where they can posit their own ...

Novak trailed off before finishing her thought (as we're all wont to do in our own conversations), but it not hard to imagine that she might have concluded her thought with the single word "vision." Certainly her passion for youth expression to strive towards visionary artmaking becomes clearer as she continues:

We have to take the work to the next level. I think, actually, across disciplines, [this] is the case. Those of us in community arts have to also reclaim the importance of good quality, really ensuring that the image is not just a story for the story itself, but that ' $\mathrm{Oh}$, look! You can have some other tools where you can author this into an aesthetic piece that's going to have a really broad impact.'

By resisting any conventional "story for the story" aesthetic (effectively similar to the autotelic expression l'art pour l'art, or art for art's sake), Novak tacitly insists on the necessary place of art in social life. For her, it would seem, the offer of mere expression is insufficient: socially engaged arts and, presumably socially engaged camera arts, need to circulate in broader discourses and fields of expressivity. Her use of the term impact seems to further characterize the diverse goals of specific, "aesthetic piece(s)," of socially engaged arts as artistic, political, social, and, in general, cultural forms.

As such, discourses that frame images textually - indeed, even the concept of 
"discourse," which is itself a privileging of those experiences that centre on the spoken and written word - must be fundamentally challenged if a socially engaged art is to be authentic. I have attempted to argue in this section that practitioners of socially engaged arts who are committed to making visible are doing just that: rendering experience into perceptual forms that remain different from, even if compatible with, discursive forms.

It is with this radical gesture in mind that I now turn to one additional strategy at the heart of socially engaged arts' deployment of camera practices: an expansion of the performative.

\subsection{Expanding the Performative}

A third type of camera use I observed in the socially engaged arts practices in which I participated centred around deploying cameras in performative ways. This, of course, goes beyond the documentation of theatrical or musical performances common to socially engaged arts, instead understanding the term "performative" in its most anthropological sense. As such, performative camera use implies the bodily actions inherent in making photorealistic images, particularly those made of other people, in relation to them, and in cooperation with them. This sense of performativity is concerned neither simply with fabrication nor play, but with what Diana Taylor (2003) calls "vital acts of transfer" (2), implying embodied actions and interactions from which the very fabric of culture is made. Performative camera use is a key means by which cultural knowledge, identity, and memory is transmitted, redistributed, and - importantly constituted through the use of camera arts.

We can already glimpse attempts to address and expand the performative in the examples of socially engaged camera arts discussed earlier. For instance, performativity may be discerned from amongst the discrete stages of composing one's own digital story: in the decisions made 
during script-writing, editing, audio recording, appearing before the camera - even in how participants acted and reacted following the final community screening of stories from a digital story workshop. Such decisions and experiences are not the effect of mere cerebration, but are enacted bodily, and occur in the real world. In the Greeting from the Motherland photographs, performativity might be located in the particular configurations of the miniature still life compositions, where the placement of objects in particular spatial arrangements might seem to yield a sense of an author's intentions, knowledge, concerns, and experiences.

Yet these examples seem to remain a little too vague - aren't all camera practices inherently performative in some sense? A more precise sense in which the performative becomes an important component of a properly socially engaged camera arts practice may be found in activities that draw directly and actively on participant knowledge and experience in the realm of visual culture.

In verisimilitudinous media like photography, film, and video, the position of imagemaker and image-subject, of the person behind the lens and the person before it, are more readily reversible than they may be in other media. It's true that the conventional structures of mainstream media have meant that little has been typically made of such reversibility: stories are typically told on another's behalf, and rarely through his or her or their own words (at least not without a substantial amount of editing); images may sympathize with the affective experiences of those they depict, but they also commonly objectify their subjects, particularly as their creators cleave to normative rhetorics of visual narrativity. Assuming, as socially engaged arts ideally does, that such reversibility is fundamental to practice, new possibilities for empathy emerge. The performative, like the vernacular, becomes a crucial means for communicating the 
possibilities and limits of shared experience.

With the historical increase in the ubiquity of camera technologies and the progressive simplification of camera use, conventional production and distribution channels have changed dramatically. Whether such a "democratization" of camera technology (see Braden 1983) results in narrowly "home-mode" production (see Chalfen 1987) or more broadly social practices makes no difference. What is crucial in an appeal to the performative in socially engaged camera arts is that camera use becomes a component of broader personal and cultural actions, rather than simply a means to represent them. It adopts the strategies of socially engaged arts to pursue camera-based practice that is both self- and culturally-reflexive.

In my experience with digital storytelling, for example, camera use helped shape participants' processes and experiences in addition to helping create representational forms. The afternoon I spent with participants gathering source material to include in their videos served several distinct functions. One of these, of course, included generating imagery to include in the video. Much of the time was incidental to that, however, and included participants acquainting themselves with video and still photographic technology, participants learning more about the stories each planned to tell, and participants developing and altering plans to develop images to support their stories. While the production of images remained important, the processes coinciding with camera production seemed, in this as in other instances, crucial as well. Indeed, these were the main times and spaces in which visualization strategies with cameras - looking through viewfinders, trying to shape the content of visual images by directing the on-screen/inframe actions of colleagues, shifting points of view on other objects and subjects, and so on were rehearsed in an unstructured way; both for those unused to such camera equipment, but 
even for those familiar with its use in different contexts.

Another example: during my experience at MABELLEarts, a facilitator had strong words with a participant during a photography workshop. The participant had taken some pride in demonstrating some technical proficiency and, for one reason or another, conceived of this as a pretense to utter some derogatory comments about the ethnic and religious background of her fellow participants. The practitioner was having none of it, and called out her use of racist language, quite publicly and within earshot of several youth of colour (who made no indication whether or not they had heard the initial slur). It is unclear what would have happened had the practitioner said or done nothing in response to these comments, yet it seems difficult to imagine witnesses being unaffected by the anti-oppressive performance of this photographic artist.

Some might argue, of either or both examples, that cameras were only incidental to such encounters; I disagree. I argue that the presence of cameras, and the host of activities related to them, has a direct and pervasive effect on all actions that precipitate from these and similar encounters. I agree with Vivian Sobchack (2004), who argues that we have been radically “"remade' by the perceptive [and expressive] technologies of photography, cinema, and the electronic media of television and computer" (135), but I would further add that such making and remaking is part of an on-going process. Cameras are ubiquitous, it is true, but so is the flux of change around their technological forms. Moreover, this ubiquity does not dull us to their use; rather, we continue to notice when people use cameras, or when they engage in their forms and practices, and we pay particular attention when such use is novel to our experiences.

Thus in the first example, usable images may not have been made, but participants were still faced with some of the interpersonal and ethical challenges that publicly using cameras are 
likely to present. For example, when acting as subjects for their colleagues' pictures, they alternated between cooperating with and challenging directorial requests; when acting as imagemakers, they made requests of their own to colleagues, and sometimes augmented those requests; and they variously addressed (or ignored) the possible implications of imaging people other than their colleagues. Such performativity may be ephemeral, but it is also undeniably experienced.

In the latter example, the calling out or racist behaviour by a photographer may have signalled the idea that someone from this field of practice could - and did - participate in an antioppressive practice. Of course anyone can theoretically call out such behaviour - for example, a teacher doing this might signal novel ways of teaching. Cameras offer their users, however, access to visual representational systems which makes their interventions qualitatively distinct, in that they can mediate between performativity as a social experience and as a visual practice. For socially engaged camera arts, this implies a reflexivity that can be visually communicated about: providing, like the vernacular and making visible, critical substance to art, but also critical models of practice that can inform action in the social realm.

\section{Contradictions of Visuality and Performativity}

Concerned with experience and action, the very concept of the performative invariably impacts upon the unspoken - indeed, the unspeakable and unrepresentable - in camera practices. This is not to say that the performative necessarily equates with whatever is culturally profane or taboo, but certainly it evokes the mundane and the prosaic in our encounters with the material world: that which is variously beyond or beneath language. As I have already argued in terms of both the vernacular and making visible, it is to these aspects of everyday experience - and to the simultaneously personal yet commonly shared forms that such experience takes - that socially 
engaged arts, its participants and practitioners, most often attend; indeed, doing so often with the greatest of interest.

To some degree then, a consideration of performance and camera practices raises contradictions as the seemingly unknowable and the purportedly self-evident clash. Yet far from proving a stymie to artistic work, the very recognition of such contradictions presents productive challenges to participants and practitioners committed to cooperative creative processes. Musing on why he likes to incorporate photography into his process, Michael Burtt considers the matter in relation to an upcoming project, a boat launch preceded by a parade from Parkdale to the lakeshore:

[There's an] aspect of just wanting to see what's right in front of our nose, of really wanting to see the bridge as exactly that bridge. What is that bridge that we're going to be crossing? And how can we, as artists - whether we're drawing or writing or using photography - how can we really see that bridge? [...] My immediate sense is that, by using photography, by taking a picture of that corner of the bridge, you're summoning a quality of it that's different than if you drew the bridge, or if you wrote a story about the bridge.

There seems a concern here with photography's specific appeal to realism. In committing to a realistic understanding of the bridge, participants and practitioners - or at least Burtt - seem intent on reaching some form of agreement about what role the site might play in their preparations, what significance it might have in their upcoming performance, and so on. 


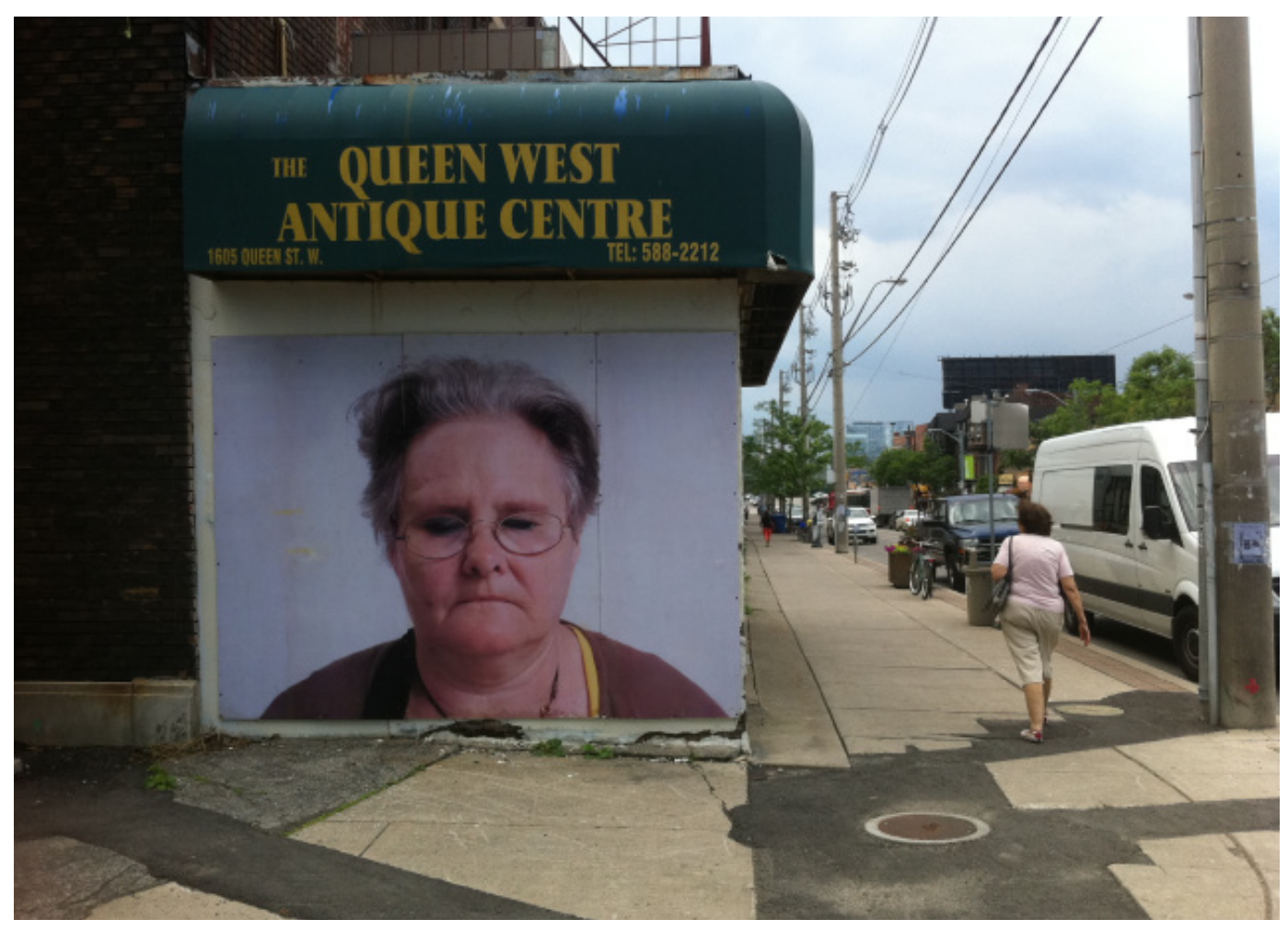

Plate 27 - Photographer unknown. 2011. From Portraits of Silence.

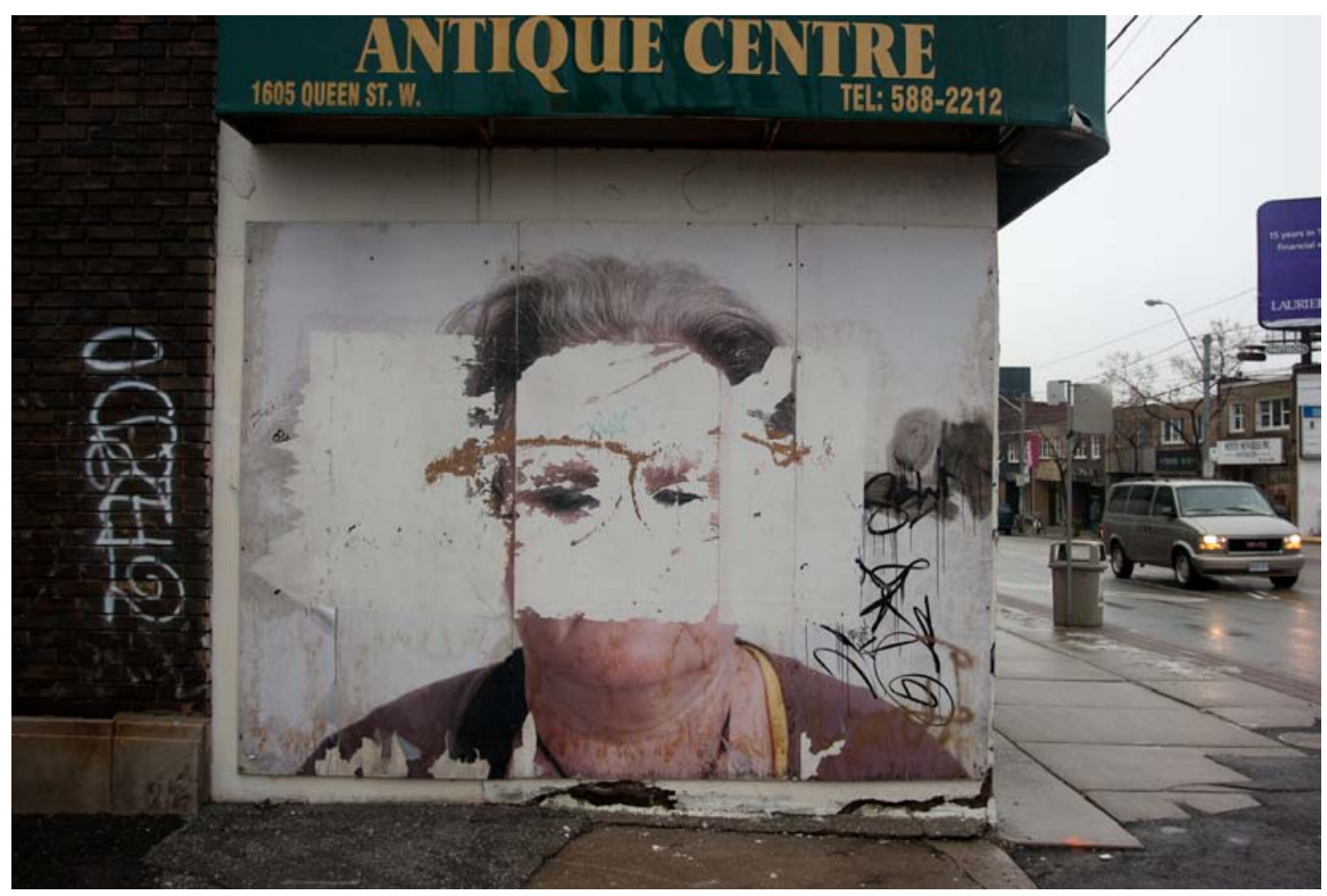

Plate 28 - Photographer unknown; rephotographed by the author. 2012. From Portraits of Silence. 
Yet there also seems to be a desire to envision oneself and one's practice in the actual, material space depicted in a photographic image; a performance accomplished, at least partially, by making a normalized representation (or document) of the physical place from within that space. Moreover, and although we only have Burtt's opinion here, the "we" suggests that such an act of perceiving aims beyond the atomistically subjective, or even the positivistically objective. This suggests the possibility that perception may be intersubjective, or at least multiple: a visual experiencing that might be shared and sustained across processes of public intervention marshalled through an active and intentional use of camera arts and technologies.

There is something utopian, and possibly unrealistic, about this shift from camera images being a collection of embodied perceptions to camera practices activating a space within which individual experiences might be collectivized and coordinated. Such a shift may be built more on faith than on reality, particularly as the life experiences between and amongst participants and practitioners diverge. Yet given that such utopian and convivial tendencies are common in socially engaged arts, it seems only appropriate for such tendencies to emerge in socially engaged camera arts practices as well - even if we remain cautious about what they seek to accomplish.

Such a sense of the performative in socially engaged camera arts - that is, that practitioners' and participants' distinct experiences in and with cameras might be coordinated rather than left tacit and atomized - implies a degree of trust and commitment in the processes by which such art gets made. At the same time, it does not necessarily preclude a criticality - even skepticism - over process.

The example provided by Making Room's Portraits of Silence project is compelling. The 
project consisted of a series of portraits of Making Room participants who are also Parkdale community members, some who live and others who work in the community. (I discussed the project in the previous chapter; however, I will briefly redescribe it here: the participants were photographed in meditative poses in front of an off-white seamless background. The portraits were cropped more or less tightly on faces and upper bodies, and were conceived to be enlarged to poster size, and then wheatpasted on walls or placed in several street level and storefront windows around the neighbourhood.) According to Burtt and Joshua Barndt, who developed the series with participants, those who were photographed knew about how the images would be displayed and had some sense that the images would be impermanent.

The resulting natural deterioration of images was anticipated (though the vandalism was unexpected), and it was intended to emphasize the aleatory processes so often involved in creative making, both in terms of the emergent qualities inherent in authorship and the loss of a certain degree of control over images put out in the world. This emphasis on process rather than image - or perhaps emphasis on image as constituent of broader processes - signalled an effort to encourage participants and outside observers to view spaces non-normatively; that is, to imagine distinct uses for common spaces, and even to assert a possibility for new relations amongst communities and the spaces they inhabit. For example, while participants arguably lost some control over their self-representation in the uniform pose they were asked to sit for, a degree of agency reemerged in the inevitable conversations Parkdale locals started with many of the participants after the images had been posted.

Generally speaking, the performative character of any socially engaged camera art is variable. Performativity might remain implicit in specific artistic projects and practices while in 
others it might be considered more explicitly or consciously, particularly when certain actions are desired as outcomes.

A more salient consideration is the degree to which socially engaged camera arts cleaves to a performativity explicitly related to visuality and the visual cultures of participants. A related consideration concerns the extent to which such performativity commits to the methods and values of socially engaged arts more generally - such as the previously discussed strategies of expansion. This configuration of practice - aesthetic, ethical, and political - is complex and, while it relies on emergent, iterative, and participatory methods, is not inevitable. Socially engaged camera arts do not simply fall into place; neither are they willed into being.

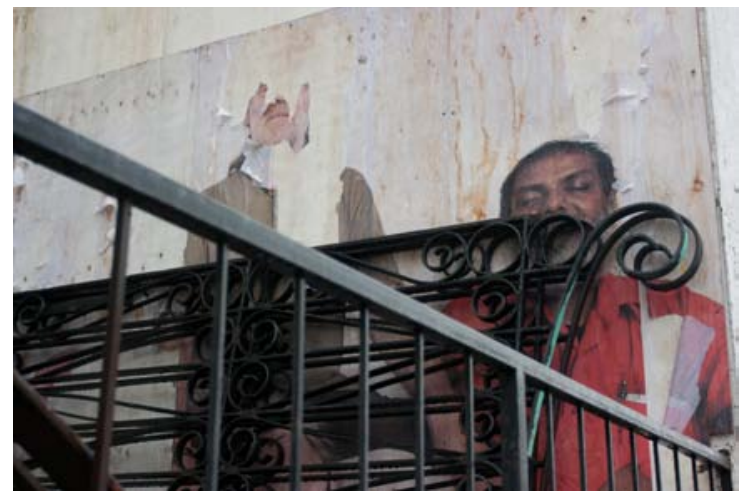

Plate 29 - Photographer unknown; rephotographed by the author. 2012. From Portraits of Silence.

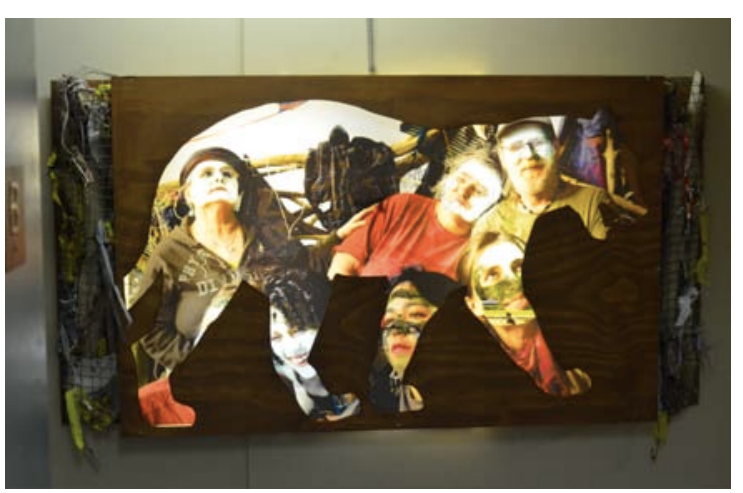

Plate 30 - Photographer(s) unknown. 2011. From Sparks that Fly.

Making Room has maintained a particularly rich archive of videos and photographic images, in part due to the attention practitioners and participants from the organization have paid to the documentation of its history, since its inception in 2008, and in part due to the aesthetic interest in camera arts of its participants and practitioners.

For example, in the context of a discussion on photography, community arts, and his own practice as an artist and as a curator at Whippersnapper Gallery, Joshua Barndt described a project that sought to radically redefine cultural spaces through a feedback process where experiences with images were documented and brought to new audiences. The process began 
with an interactive performance centred at the Gallery:

We started getting involved in participatory projects, like [with] this artist Zeesy Powers. She turned the space into a site where she shot a reality television show. People in the reality television show were just people who wandered in off the street. She was acting as this performer who was giving therapy, but not real therapy - just sitting in on that. She would ask a leading question, and then people would divulge really intense things about their lives, and be really candid and honest. [...]

Already we can glimpse a project that, while maintaining several consistencies with socially engaged camera arts (participatory and emergent methods, appropriation of space, an interest in the everyday), seems also to fundamentally undermine it ("people off the street" can hardly constitute an engaged community). Barndt continues:

So that's one level - the sharing between the artist, or the crew, and this person. And then there was the people who were sharing, connecting with each other. And then Zeesy edited it and put it online, so there's this whole other community that's accessing it and narrative that's happening, people who are accessing through this other semi-public stream of this online show.

And then, after that, we had a screening at the Toronto Underground Cinema, where there's a public viewing, where we all sit together and watch people divulge this personal, honest, candid, really intense stuff.

When there's space for people to share, and then for us to talk about that, and for us to take that in, and then to continue to move forward again - the projects grow. [...] 
As indicated above, I am reluctant to describe Powers' work as socially engaged in the sense outlined so far; there are key contradictions between the two. For example, there is no clear sense from Barndt's description about the degree to which participants of the initial gallery session were involved in subsequent stages of the project - though I suspect there wasn't much involvement. This raises the question for me about the legitimacy of such engagement and concerns over the possibility of voyeurism, exploitation, or an exoticization of participants.

Nevertheless, I include the example here because it seemed for Barndt to resonate with aspects of socially engaged camera arts practice. Ultimately, his account may reveal more about his own concerns with socially engaged arts and socially engaged camera arts than Powers' project ever intended. While Powers' project seems concerned with the image as simulacrum, Barndt seemed more concerned with the positive performances of "sharing," "connecting," and “sitting together" that Powers' project allowed participants to rehearse. Such performative possibilities, for cooperative making and critical public intervention, seem to remain latent in her practice.

Indeed, Barndt's sense of what he would go on to call the propositional nature of this art (as discussed in the previous chapter) seems far less confrontational and agonistic, and far more generative and cooperative than does Powers'. As he suggests, “I don't come with my artwork and then say 'This is the art!' The art is a proposition, and so many things grow out of it." Based on the descriptions he provided of his own work in socially engaged arts, much of his recent mural and sculptural work seem to be attempts to operationalize this idea of "proposition."

\section{A Propositional Art}

Barndt's suggestion of the propositional nature of socially engaged arts is useful for 
understanding the role that camera-based processes often currently play in expanding the performative. Proposition captures the sense of experimentation and dynamism that is inherent in practices centred on process. Proposition also - albeit more subtly - implies an active and practice-based critique of expertise and authority common to conventional artistic practice. Near the end of our interview, Barndt described his own practice with cameras, a matter separate from his work with Whippersnapper:

In my practice, that photo starts off as a document, but then enters back into the process as an actual work - another element or another extension of the project that I would consider an artwork within the long term process of a piece. I think that video works and other forms of documentation are existing in similar ways - and are often feeding back to another encounter.

For Barndt, as for many other socially engaged artists, it seems that camera-based documentation is an integral component of a process in which participants are engaged. However, what he terms "documentation" seems to feature different characteristics than has traditional forms. Barndt seems to make active use of the immediacy of digital photography, for instance, performatively inserting images taken moments ago into current compositions. Such an iterative process, he continues:

It's cyclical. It's not - I don't think photo is actually - I'm not a photographer, so I don't have this nostalgia for the history and the object of the photo. For me, it's a way to distill that experience that's preexisted, document something that's powerful, and then allow for another moment to be confronted again with that. It's bringing us back to a new moment to connect and contrast. 
Barndt seems to utilize the contradictions between fixed and mutable camera-based forms and processes in his practice. Yet such frenetic and energetic practices are but one example of the performative in camera-based practices. Others speak more pedagogically of camera-use; for example, in terms of learning a craft. While I highlighted the pejorative use of the term "craft" earlier to signal a range of participant-centered arts that typically fail to meet the criteria of socially engaged arts set out in the previous chapter, I encountered another non-pejorative sense of the term. Emmy Pantin, for example, used the term to refer to the core of the digital story process she prefers, one which values the processes of skilled making over the products that may result:

In the end, the key place for us in the work that we do is around the craft of storytelling that's really where we spend a lot of the work. Even if it appears that we spent two of three days on the computer digitally manipulating stuff, that's about telling the visual story, or whatever - it's really about story craft.

The kinds of performances these practitioners model for their participants - both in terms of technical actions but also political and ethical questioning - are meant to encourage the latter to conceive of their actions beyond individualized meaning making. This is in part due to the commitments such practitioners typically make to socially engaged arts and the political positions they espouse in relation to engaging marginalized populations.

However, it is also in part a result of the intrinsic nature of networked digital media - of which camera-based media are, of course, a significant part. As Pantin suggests, their digital story processes are structured as part of a "much bigger conversation," the boundaries of which are designed to extend beyond the immediate community, and engage with the broader public 
sphere that can be addressed, at least in part, via the Internet. "On the one [hand] it's that person's personal journey - both in terms of reflection, just thinking through their story and coming out the other side of that, and moving somewhere along that - and then what that story does for a community."

Pantin and Lafontaine screen many of these films frequently: whether near the beginning of a digital story workshop to provide exemplars to community members of what might be technically and stylistically done, or at the end of a workshop or project to showcase the stories and celebrate their completion. Although such screenings do not necessarily emphasize the portability of the videos, or showcase their online presence, the physical properties of the images demonstrate that they can be shared, technically speaking, while the screening process demonstrates the pedagogical and political commitments to cooperative practice that underly their performative use.

The culminating screening that ends a digital story process is particularly important for the method, as it echoes the collective story circle that initiates the workshop process for participants and expands the community building initiated by the method beyond its circle of participants. Both this screening and the sharing at other workshops signal the most socially performative aspects of the process. Thus even though the stories that develop are personal, there's an attempt to anchor the process of crafting image and narrative in shared experience that attempts to extend beyond local community.

\subsection{Across and Beyond Genres}

One commonality to the methods explored here rests on the immateriality of digital technologies. Socially engaged arts' dependence upon process has, for example, made the 
immediate reproduction of images a vital feature of what camera arts can offer its practitioners. Thus, because images can now be quickly shared, uploaded to the internet, displayed on a screen, and even printed out, they can enter into processes in rather distinct ways than can their analog counterparts. While it's true that digital camera practices have neither universally supplanted analog (or photochemical) tools and techniques, digital nevertheless seems to set the current standard for all modes of camera practice in socially engaged arts.

Because of the rather distinct ways that digital camera technologies help coordinate art and work in these settings, I have actively avoided using traditional classifications for the types of strategies that seem to result. It is true that certain practices might seem indebted to a documentary realist mode, others to a pictorial or experimental or satirical one. However, given the variability of such practices, it seems confusing and counterproductive to try to pin any practice down to a single mode. I have seen a number of examples of digital stories that defy simple classifications such as matter-of-fact reportage or experimental film and poetry. I have seen photovoice projects that echo the compositional style of photographes humaniste like Dave Heath (see Heath 2000), and others more in the vernacular or snapshot style of Garry Winogrand or Nan Goldin (for example, see Winogrand 2004; Goldin 1986). I have also seen examples where cameras are used selectively in processes: developed as a distinct stage of a broader project, or used periodically throughout an on-going process. The emergent, dynamic, processoriented nature of socially engaged arts, along with its appeal to participant knowledge and experience and cooperative production, means that genre analysis has a tenuous place in any critical understanding of these practices.

It strikes me that characterizing socially engaged camera practices by their primary 
intention(s) as I have done here provides a more meaningful analytical frame for understanding the twin artistic and activist goals to which socially engaged arts gets put - a matter I turn to in the following chapter.

Nevertheless, I do want to recognize the challenges that a non-systematic, processoriented camera practice presents. Although socially engaged camera practices create innovative images, processes, and interactions, their novelty may also be their idiosyncrasy. That is, while they may challenge dominant and canonical forms and practices, they may simultaneously render themselves inaccessible and indecipherable beyond the local contexts in which they were developed - and even here, with the attrition of practitioners and participants alike, one project may differ widely from the next.

The matter, in short, is not easily resolved. I simply want to point out that inherited methods and practices, standardized techniques of making, exhibiting, and distributing camerabased images still have a place in critical practices of socially engaged camera arts - albeit a cautious one. The work of structural change - to aesthetic, cultural, political, social, and other infrastructures - remains the principal, if broad-based, goal. 


\section{SYNTHESIS, I: ORGANIZING EXPANSION}

Up this point, I have been largely focused on the interpersonal or face-to-face relations of socially engaged arts and socially engaged camera arts. To be certain, this is in large part because in interviewing practitioners and observing them interacting with participants, a good deal of time was spent actively discussing or reflecting upon this particular strata of relations.

However, the practitioners whom I interviewed also spent a large amount of time talking about the other relations that inform and structure their artistic and organizational practices. In this chapter I will examine those relations - what I am calling the intraorganizational, the extraorganizational, and the interorganizational - in order to explore several key ways that socially engaged arts gets coordinated by agents within, beyond, and between organizations.

\subsection{Structure and Labour in Socially Engaged Arts}

There are, I would suggest, three distinct ways of categorizing the myriad relations within and across the field of socially engaged arts practice. Even though relations typically exist between and amongst individuals in socially engaged arts, a complexity enters into those relationships depending on the role or roles people assume, the perceived degree of reversibility in that relationship, and the specific agency or organization represented by such roles. In order to characterize this complexity, I am proposing three categories of relationship that seem crucial to various aspects of socially engaged arts: (1) the intraorganizational, (2) the extraorganizational, and (3) the interorganizational. Even though I will explore each separately, I will insist that these terms nevertheless comprise interrelated aspects of a broader ecology of the field of socially engaged art. Although I will get into specific examples in each section, I will begin with a brief overview. 
By the intraorganizational I mean those relationships that exist between a representative of an organization and an individual. These relationships tend to be vertical, such that an organizational agent typically helps coordinate the activities of a participant, and often the activities of other practitioners within that organization as well. In socially engaged arts there tends to be a tension here: namely, between the reversibility and equality promised in the valuing of participant experience and knowledge, and the unidirectionality inherent in hierarchical practices. Thus although organizational participants may themselves contribute to shaping the circumstances of activities, this is not always done without some tension.

The three primary forms of intraorganizational relation I encountered, and that I will discuss below, include (1) (community) participant <=organization, (2) artist/practitioner $<=$ organization, and (3) volunteer $<=$ organization (where the " $<=>$ " symbol is meant to indicate a relationship that is generally reversible and reciprocal, rather than unidirectional). It is true that such relations only really exist between and amongst individuals; nevertheless, individuals often work as agents of other forces, and not merely from their own self-interest. In this case, the term "organization" in the above three pairings could be replaced by any one of community participant, artist/practitioner, or volunteer in any case, with the understanding that she is working as an agent of the organization, while her collaborator may be working for similar or different reasons.

By the extraorganizational I mean those relationships between socially engaged arts organizations and broader social and, particularly, governance institutions. Usually another type of vertical relation, this category mainly implies relationships with those organizations that exert direct sociopolitical and socioeconomic power over socially engaged arts practices, such as 
funding bodies and non-funding government agencies (such as the Canada Revenue Agency at the federal level, or various arms of the City of Toronto at a municipal level). Although there continues to be a good deal of face-to-face engagement in these relationships, a number of formal, bureaucratic, or governmental factors mediate between individual agents in these relations, often in crucial ways.

As such, the reversibility of these relations is more highly variable than it is with intraorganizational relations. In terms of governance relationships, socially engaged arts organizations may have little input into how things get done. For example, the Canada Revenue Agency has recently established requirements for certain non-profit organizations (including arts organizations) to conduct annual third-party audits. Many claim a targeting of left-leaning organizations, including those overtly critical of the government (see Beeby 2014; Caplan 2014); nevertheless, these audits have been non-negotiable, even though the expense may be as much as $10-20 \%$ of an organization's already austere annual operating budget. With organizations at arms-length, like arts funding bodies and their affiliates (like the Neighbourhood Arts Network) or educational organizations (such as colleges, universities, or other community-based programs, like Pathways to Education), there may be a greater degree of reciprocity, where socially engaged arts organizations have a clearer say in how these others proceed.

Finally, by the interorganizational I mean those relationships that exist between and amongst distinct socially engaged arts organizations. These relations are more horizontal than the other two, since they are between peers and peer groups, most often between supporters and allies mutually engaged in creating and performing socially engaged arts. Often these are ad hoc relations between specific agents - participants or practitioners from different organizations - but 
occasionally they take more durable form, albeit with mixed results. (For example, the Jumblies family has resulted in the development of several successful offshoots; however, the recently shuttered Community Arts Ontario and the defunct Community Arts Network have had a different trajectory.) Interorganizational relations may also be antagonistic; for example, between and amongst organizations competing for scarce resources, or those critical of the practices of others.

As I will argue, the ecology of the field consists of numerous organizations in a cluster of relations which take one of these three forms. Any single organization invariably maintains several relations of each type, although the organizations that thrive seem to do so because they actively and critically cultivate their network of such relations. Importantly, it may be said that the cultivation of these relations is as much a part of the artwork of socially engaged arts and camera arts as is the practice of creative production itself. At the very least, it is as important as the art itself in the crucial role it plays in creating the context within which it may be sustained.

Finally, I should add what should seem obvious: namely, that these relations do not exist in a vacuum. Broader social relations continue to strongly influence the ecology I describe here, and often in decisive ways. For example, although the concept of interorganizational relations is an attempt to describe a rather rosy picture of practitioners working amongst peers across organizations, the fundamental constitution of who is typically in this peer group and who is not is profoundly influenced by broader social relations. People of colour are significantly underrepresented in the organization and administration of socially engaged arts, for instance, and as such may maintain distinct relations with their peer groups in ways that echo or perhaps even amplify broader social and structural inequalities. Such realities are important but often 
overlooked complications in the development and theorization of socially engaged arts and socially engaged camera arts (including this one! For an important discussion, see Louis and Burns 2012).

\subsection{Within: Intraorganizational Relations}

This type of relationship concerns at least three key relations occurring directly within the day-to-day operating boundaries of organizations. They include: (1) those between and amongst supervisors and paid employees, such as artistic directors and commissioned artists, respectively; (2) those between and amongst an organization's paid employees and its unpaid volunteers or interns; and (3) those between and amongst an organization's artists and practitioners and community members (including participants). In all cases, intraorganizational relations are those that most directly characterize the practice of socially engaged art.

As I have said, intraorganizational relations are often vertical; in socially engaged arts, these relations become manifest when organizations employ artists, fill internship and volunteer positions in exchange for honoraria or for references as experience (for future paid employment or educational opportunities), or when they host meals, put on free events, and coordinate art activities for and with community-based participants.

There is a labour relationship here, in short, inasmuch as someone directs the actions of others, and even if a wage is effectively absent from the relation. (Indeed, one practitioner spoke about Genevieve Vaughan's idea of the "gift economy," suggesting much of her work as an artist, and much of that of her peers, participants and practitioners alike, was "gift" in that labour was given with little expectation, if any, of recompense; see Vaughan 2007). 
Because of this labour relationship, the inherently vertical nature of intraorganizational relations cannot be overlooked. Thus, even with efforts that strive to minimize power differences between and amongst those in charge and their subordinates (participants and practitioners alike), the success of such efforts might continually be called into question. Even though the idea in every instance is to do socially engaged arts, with all that that should entail (emergent, collaborative practice based on egalitarian and anti-oppression principles), these relations always introduce the possibility that some organizations might end up moving towards a model of practice that should ideally be avoided. Of the practices I visited and spoke to practitioners about, the most successful seemed to have developed techniques to routinely, critically, and collaboratively attend to their inherent contingencies.

Nevertheless, it isn't always a simple matter to determine where or how a failed socially engaged arts practice went wrong. Consider, for example, the discussion I raised in the section on socially engaged arts' engagement with form (in Chapter 4.2). There I cited comments made by two artists (pseudonymously, Mavis and Kay) who were critical of two different multi-service organizations - one mostly an arts organization, the other predominantly a social service agency. In both cases, these artists were hired to conduct a series of workshops with non-paying participants. In both cases, they were dissatisfied with what was being passed off as "socially engaged arts" practice by each organization's coordinators.

In the first example, Mavis was contracted to coordinate workshops that related to the core themes of her project. In doing so, however, she felt she was required to adjust her program to produce material products that participants could take home with them. This, she seemed to feel, contradicted with an emergent dimension of her practice and short-changed a process where 
she and her participants could collaboratively determine what products, if any, the latter might bring home.

The resulting contradiction - between what Mavis was approved to do and what subsequently seemed expected of her - contributed to her desire for greater autonomy. For Mavis, autonomy became a goal with which organizational involvement seemed incompatible (both with this organization, but also, she seemed to suggest, with other organizations). Indeed, as a result of her experience, she subsequently chose to pursue more traditional sources of arts funding when her contract ended. Although this arrangement deprived her of an income, she felt it would allow her to be autonomous with her organization and in the direction of her art. (Recipients of state and other forms of arts funding are, of course, subject to their own vertical pressures, a matter I will address in more detail in the section on extraorganizational relations below.)

The other artist I spoke of in the chapter on expanding form, Kay, also delivered arts workshops to participants. Yet despite delivering them, these workshops, which were for lowincome or otherwise marginalized participants, were largely coordinated by another agent (a social worker, who was also her superior) from the multi-service organization that employed her. In essence, Kay felt, she was simply tasked with running the series under the authority of her supervisor.

As I interpret her comments, Kay became critical of her role in this program in at least two ways. First, she believed that the coordinator encouraged the pursuit of a celebratory and uncritical art, one that valorized atomized expression over critical, collaborative production. Her second criticism was more pointedly about the behaviour of the social worker coordinating the 
program. Besides perpetuating a selective view of art, Kay felt, the social worker also seemed to coerce her participants to praise the program in evaluative feedback. As her quotes graphically portrayed, Kay was clearly upset with this behaviour, and was aware of the power differences that may have led to the servile responses of her participants.

In both examples, a concern with control and autonomy emerges: in the former, Mavis indicates a disagreement with the organization's expectations that leads, ultimately, to a parting of ways and the decision to develop her project independently. In the case of Kay, there is also a parting of ways based on a fundamental disagreement over what seemed to be manipulative behaviour and actions on the part of the coordinator that seemed self-interested and willfully ignorant of the experiences of her participants. Yet whereas Mavis resigned willingly, Kay did so with reluctance; she felt more dependent on the wage that her employment provided, even though she was clearly at odds with what was being asked of her.

While the example of Kay is quite extreme, that of Mavis is perhaps more common. Indeed, it is difficult to find any data on turnover or "job satisfaction" in the field, perhaps due to the porous nature of socially engaged arts within the broader fields of arts and culture or community development work, or because of the relative instability of the labour market. However, even with greater clarity and stability, concerns over autonomy and control in artistic organizations may remain. Indeed, these matters will emerge again in the section on extraorganizational relations, particularly in terms of the funding of artists. For now, let me simply point out the conflict inherent in being employed as an artist by an organization that often operates in invariably non-artistic ways. It may be obvious to point this out, yet whether such an organization operates democratically or bureaucratically, a tension nevertheless remains between 
artistic intention and the processes involved in artistic execution.

Another artist, whom I will call Vera, and who is affiliated with a different multi-service centre in a seemingly more simpatico arrangement, nevertheless discusses this tension as well. In her case, she seems to feel that it exists between the sense of stability that comes from having a formal affiliation with an organization and the threat to artistic autonomy that such affiliation might pose:

We're in a conversation where there's a tension for us [...] about notions of stability and notions of autonomy. Right now it feels like you sacrifice one over the other, and we've chosen stability, and that's what [this multi-service organization] offers us by fronting our salary, by fronting all the kind of cash for benefits, equipment, and then just offering us resources - really basic overhead like access to a photocopier, telephone, whatever. Email account. Those things are really, really, really valuable.

And it's a bigger relationship than that. They have a community that they're really connected to that we're really interested in tapping into, they have a network that we want to be a part of. They bring a lot to the table.

But, in the end, we're responsible for $100 \%$ of those expenses. They front it, but we have to $[\ldots]$ recoup that. We're not totally sure that it's the best model for us [...] It was a decision I think we struggled with ...

Although Vera leaves her concerns implicit, the gist of it may be glimpsed in the final paragraph. With a pressure to "recoup" expenses, there is an unspoken need to commodify the practice, at least in part. The struggle of which she speaks is presumably due to the process 
nature of socially engaged arts, where collaborative practice (multiple authorship) and an iterative process (little material production) means revenue needs to come from more limited sources than it might in more formally established modes. Such funding includes (at least partially) rather inconsistent sources as arts council funding, nonprofit (non-arts) funding, commercial sponsorship, in-kind donations, patronage (including charitable donations), commissioned workshops, and program fees.

In the case of the latter two options, asking participants, many of whom come from marginalized communities, to pay for workshops or simply to pay a kind of admission for their participation is both undesirable and possibly fatal for a socially engaged arts organization. Indeed, it was an assumed non-starter during interviews; a matter that was never raised by Mavis, Kay, Vera, nor any other person I interviewed. As we will see in the next section, much of the revenue for socially engaged arts comes from arts and non-arts funding sources, and is typically directed to wages and material costs. Whereas funding from the arts sector has remained largely arms-length, despite profound governmental pressures to shift away from this model, other funding sources do not always maintain similar standards, meaning that other factors may enter into funding arrangements.

\section{Too Much Autonomy?}

However, before I go on to explore extraorganizational relations of socially engaged arts practices, let me consider one other aspect of artistic autonomy. For some practitioners, the question of autonomy was neither related to artistic integrity nor stability of practice. Instead, it was a source of concern and anxiety by those who felt they were given too much autonomy rather than too little. Accordingly, these practitioners felt they were given insufficient structure 
to be effective in their variously paid or volunteer roles.

For example, Pete, a professional media producer who volunteered to teach media skills to community participants expressed his frustration about designing and delivering a workshop with little organizational guidance. "When I started volunteering there, that's when I ran my first workshop. From February 2009 to my last workshop in 2011 - Fall/Winter 2011 - I was building on that initial experience of creating a workshop, but kind of out of the blue, without any structure provided from their end. [...]"

During this time, he asserts, he made meaningful interpersonal connections with both staff and participants, and developed an innate pedagogical approach to the materials and techniques he felt he was supposed to be teaching. Nevertheless, Pete also expressed an uncertainty about the effectiveness of his approach - "teaching" of course, in its traditional sense of moving expert knowledge to novice hands and minds, seems incongruous with the kind of engagement strategies discussed in previous chapters. However, most crucially for Pete, there seemed an apparent lack of any support for such matters. He goes on to describe an imposed autonomy that begins to sound like isolation:

In the two years, or two and a half years I worked there, the one thing that I can say that [I] lacked was any collaboration in organization, collaboration in organizing the workshops. The structure. That was the major downfall for me. [...] I think a lot of organizations struggle with this, but there just wasn't enough structure and kind of push, like 'OK. This is what you have to do,' and keeping the deadlines. I'm pretty self motivated, but I find, like most people, I need that structure where ... it's pretty basic, that your boss needs to tell you 'We want this, this, and this.' That was very loose there. 
Faced with a lack of communication - whether due to neglect or willful abandonment and contending with what he might characterize as unprofessional leadership, Pete seemed poised to abandon his voluntary role with this organization at the time of my interview with him. While it isn't entirely clear what, if anything, might have motivated him to continue, there seems to be two distinct factors contributing to his sense of isolation. I have already mentioned his stated desire for pedagogical support: implicit in this seems a desire to better understand the effectiveness of his approach, and possibly the support to explore other approaches to working with his participants.

The second factor may be the result of a feeling of dissociation from the organization's goals, whether artistic or political or otherwise. His concern over a lack of collaboration in workshop planning seems eventually to become an anxiety over perceived goals, and eventually frustration at feeling abandoned. Some of this may be affected by his volunteer status, where the episodic nature of his experiences volunteering with this organization may have yielded a partial and fragmentary understanding of its projects and goals.

Admittedly, there is much speculation here, making the idea of "too much autonomy" seem somewhat thin. I do not want to abandon the idea entirely, however: others I spoke with expressed what seemed to me similar sentiments - that is, about being overwhelmed by and unprepared for their experiences in socially engaged arts settings, and about what they felt to be a minimal amount - in some cases an utter lack - of guidance as to how they might begin to engage. Since in most cases these seemed to be the experiences of new participant-practitioners and volunteers rather than either participants or paid practitioners, it is to the matter of volunteerism that I now turn. 


\section{Volunteerism}

It is worth considering in more detail the particularities of volunteerism in terms of intraorganizational relationships, given that volunteers are quite common in a field that is simultaneously rich in experiences yet struggling for resources. By "volunteers" I am referring to those who take on an unpaid practitioner role with respect to the practice and processes of socially engaged arts; to be clear, I do not mean participants, even though there may be parallels between these roles. Although different organizations bring volunteers into socially engaged arts in different ways and with varying degrees of involvement, I failed to encounter a practice that didn't engage with and deploy volunteers in some capacity.

Based on my observations, there are several traits that seem common to practices that rely on volunteer positions. First and most obviously, despite the fact that these volunteerships are sometimes called "internships," they are generally unwaged positions (though honoraria are occasionally given). While much volunteering is done because participants live in the community or have enjoyed such programming in the past, for a significant portion of volunteers, such work is done in exchange for some form of credit. While high school and post secondary students may seek out volunteerships of their own volition, certain programs have developed more formal mechanisms to stream their cohort into socially engaged arts “placements.” Bachelor of Education “teachers-in-training” from York University’s Faculty of Education routinely volunteer at Regent Park Focus, for example. Students of York's Community Arts Program (CAP) and Environmental Studies program volunteer for Jumblies family organizations as well.

Secondly, there often seems a disconnect between an organization's stated vision or 
mission, and how this set of goals and principles gets understood by volunteers. Pete's feelings of being out-of-place and unwanted and the general sense that volunteers are prized provides an example of this disconnect. While some of this discrepancy may be attributed to the particular priorities, attentiveness, or communicativeness of individual volunteers, some of it may also be attributed to the ways in which volunteers are brought into an organization - the kinds of practices put in place by existing practitioners to orient volunteer practitioners into their role(s) and responsibilities. In any event, this disconnect may become most apparent in interactions with community participants (including, but not limited to, workshops), where volunteers (rather than paid staff or experienced participants) may become a first, and perhaps principal, point of contact or "face" of an organization for new and returning participants.

The reasons for this discrepancy - between volunteers being valued yet feeling isolated may be several. Partly, it may be because socially engaged arts is composed of dynamic encounters privileging an emergent approach to art-making. Drop-in sessions, a common format for practices to take, often assume an experimental nature where a practitioner's plans shift in relation to her participants' knowledge, experience, and interests. In such cases, where previous participation is not a requirement, activities need to prioritize engagement and flexibility over focused skill development. (There's no intrinsic need for sessions to take a drop-in format, of course - a matter to be addressed in the next chapter.) Volunteers who see their contribution as sharing expertise rather than building community are likely to feel frustrated in such circumstances.

Some organizations may make a more conscious effort than others to foster a supportive structure for their volunteer practitioners. In this context, the practices of participants assuming 
the role of "host" (raised earlier) may act both as a means of cultivating participant engagement and as a way to welcome new practitioners (volunteer as well as paid). However, a likelier and more formalized example can be found in the safety and equity policies an organization might choose to implement. For example, many sites where youth are involved require police record checks from volunteers and practitioners. Sites committed to supporting and engaging racialized or queer spectrum participants may mandate anti-oppression training for all paid and volunteer practitioners, and strategize ways of utilizing intermittent and temporary volunteers while limiting potential "triggers" for more habitual, though potentially vulnerable, participants. In addition, practices engaging at-risk or street-involved participants might develop strategies for crisis avoidance and intervention. And so on.

Nevertheless, there are key differences between formal volunteer training practices, and more informal or even affective volunteer engagement. While the two are not incompatible, and indeed signal organizational commitment to volunteers, a focus on one or the other may contribute to the kinds of discrepancy discussed above.

\section{Between Ideals and Practices}

My point in focusing on the varying ways volunteers are brought into socially engaged arts practices is that by attending to the distinct ways they take up their respective roles, a number of issues related to intraorganizational relations more generally might be raised. The dynamic understandings that various organizational agents develop, as well as the differences and commonalities amongst them, are worth critically examining, particularly in how they support or undermine an organization's collaborative artistic and political goals.

For example, while policy initiatives may address certain concerns having to do with 
participant relations, they may fail to address concerns having to do with an organization's relations to its practitioners. Additionally, although many of the sites I visited conducted "checkin" and planning meetings with practitioners, the conditions of such discussions were widely variable. For example, some practitioners would conduct formal assessments with all practitioners (including both paid and volunteer/temporary practitioners) at the end of sessions; others would conduct more informal ones at various stages - before, during, and after - with either paid practitioners, volunteers, participants, or sometimes all three groups. Such discussions varied in their structure and formality: sometimes practitioners dedicated time to debrief as a group after an event, with notes recorded about who was present, minutes taken of what was discussed, and follow-up actions delegated. In short, the realization of an organization's policies and goals demands not merely action, but a reflexive or evaluative practice, one that might bridge the engagement of participants with the work of practitioners. (This, of course, is the purview of pedagogy - theoretical thinking about practical learning - a matter I will return to in the next chapter.)

At first glance, there may seem to be incompatibility between an emergent practice and formalized strategies for assessment. Indeed, given the fluid nature of participation, where the presence of both participants and practitioners at any given event is a mutable matter, it may seem impossible to institute a systematic way to gather meaningful information about programming. Organizational leaders are perhaps the most present in such activities and, as such, might be best tasked with maintaining some consistency amidst this organizational flux. They are, however, seldom connected to every engagement event; or, if they are, they are likely connected in ways distinct from practitioners, and face a myriad other demands for their time besides. (For example, many organizational leaders in socially engaged arts are also the Artistic 
Directors for their respective organizations. Aside from this, what is effectively a full-time career as a performance or studio artist, they are also educators, fund-raisers, publicists - and so on when these roles cannot be filled by others.) What seems needed is an assessment mechanism that is both decoupled from any one practitioner, yet sensitive enough to maintain an on-going view of the goings-on of all an organization's representative agents - this includes practitioners and participants both.

Typically, it seems that ideal practice contends with practical limits; the most common strategy I found for maintaining a pulse on on-going practice is to accrue some manner of feedback from both participants and practitioners through face-to-face discussion immediately after sessions. Paradoxically, this feedback is gained in systematic and used in ad hoc ways - or the opposite. For example, feedback may be carefully structured into organizational events, yet left unused for extended periods of time. In other cases, it may be conducted very casually, involving a wide variety of people, and be committed to a shifting and inconsistent range of media - from notebooks to video, digital files to memory - yet be parsed and used almost immediately.

In any event, practitioners generally recognize the value of coordinating some amount of structured feedback, even given considerable constraints on time and labour. Several of the practitioners with whom I spoke seem to have been very successful in achieving a qualitatively and quantitatively meaningful record of their organizational achievements. Although I suspect a combination of their general gregariousness, external reporting requirements, and a sense of justice plays an instrumental part in that success, they have nevertheless been able to reflexively bring such feedback to the task of improving practice. 
Leah Houston, for example, has committed to recording much of her process and performance work to photographic and also, at times, videographic record, hiring photographers to document key events and process workshops. Houston also ensures that minutes are taken of post-activity "de-briefing" sessions (which are done with both paid and volunteer participants whenever possible). Michael Burtt maintains a blog for Making Room, and uses it as a place to share images, documents, and reflections - made either by himself or his colleagues - that simultaneously archives the organization's artistic practice, theorizes it, and distributes it to a wider audience. In Gallery 44's outreach work with youth, soJin Chung takes a decidedly more arts-based approach, striving to incorporate reflexive learning with on-going production processes. During the course of their engagement, practitioners and participants in the program have collaboratively created zines as they progress towards a cumulative exhibition of their photographic work. Although not exactly a systematic approach to collecting and addressing feedback, this collaborative zine nevertheless provides some sense of cooperative processes, and offers an intriguing approach to engaging with shared experience.

Despite the differences between and amongst these and other models, the systematic nature of these documentation-based methods does more than record feedback. Crucially, doing this kind of assessment models patterns of behaviour and action that encourage a reflexivity in practice that others - practitioners and participants alike - might begin to assume. That such reflexivity is not individually but cooperatively shared is particularly crucial. In my own experience, for example, after participating in activities at MABELLEarts for several weeks, I found myself anticipating the de-brief at the end of the workshop, and actively making mental notes of experiences I believed to be worth sharing. 
A more salient example of reflexivity emerging in practice might be identified in a conversation Jennifer Lafontaine had with a staff person at a multi-service centre. The staff person was supposed to be actively supporting Lafontaine's project, but seemed at first to understand that participation as merely "recruiting" participants:

This one staff person was like 'Well, it's great that we do all these projects last year, but usually we will recommend our star people. Like, “This person's such a great participant in this program! Let's have them join! That's really good!"' But [then] she was like 'Whose voices are missing even when we do that?' They do a lot of home visits. So, what happened was that we developed a part of our project where we trained those staff to gather stories and engage in a storytelling process in their home visits with people. Whether those are at shelters or actually in people's home apartments, they were gathering audio stories and photography.

In the process of her engagement, it would seem, this staff person shifted from merely facilitating the terms of the project - "recommend[ing their] star people" - to actively engaging in it. In particular, the staff person's sudden critical engagement with the issue of representativeness - that is, by asking "whose voices are missing?" - may be interpreted as a move beyond mere participation. As Lafontaine argues, her reflection seems to have led to an additional realm of practice where she and her co-workers began to augment their home visits by adding research practices to their workload. Such open-ended, multi-modal inquiry (relying, in other words, on visual and narrative accounts) presumably served to both broaden the access and deepen the impact of the digital story method, but also to enhance relations with their clients and patients. 
Such a shift - essentially an expansion of engagement as discussed earlier - is crucial to successful socially engaged arts as it offers to destabilize hierarchical intraorganizational relations, potentially allowing different participants and practitioners greater purchase over an artistic process. Perhaps it was Lafontaine herself who originally suggested this course of action to the staff person; perhaps it wasn't - it makes no matter. What is crucial is that it was the staff person, the one who had a fundamentally different relationship with her participants and played a drastically different role in the organization than did Lafontaine, who implemented it. Accordingly, Lafontaine reflects on the difference in roles:

It's a hard relationship for artists to come into centres - to come into a health care centre, or a school. There's a lot of navigating what that relationship is. Who takes the lead on what? How you make decisions together: where you need more autonomy; where you need collaboration? There can be a lot of places of tension around how you communicate that.

Lafontaine's encapsulation of the project might also be read as a summary of intraorganizational relations in socially engaged arts: in what circumstances must a practitioner's experience and knowledge "lead" an artistic process? When must the experience and knowledge of participants take over (or, alternatively, be curbed or redirected)? How much autonomy should be accorded to either? And, crucially, who decides, and at what point during a project?

Let me conclude this section simply by pointing out what I have been hinting at: that pedagogy exists in socially engaged arts practices - indeed, careful consideration of pedagogical matters is crucial to their success. Considering intraorganizational relations as also simultaneously pedagogical ones may yield important insights into how such practices succeed, 
and where they fail. Further, pedagogical considerations of autonomy and heteronomy in socially engaged arts - that is, where art and learning might be directed, and where they might be cooperatively developed - is also crucial. This is a pivotal discussion, but one I will return to in the next chapter. For the moment, I will consider the other relations common to socially engaged arts practice, relations which provide crucial shape and form to the direct encounters of the intraorganizational.

\subsection{Beyond: Extraorganizational Relations}

One of the most decisive relationships a socially engaged arts organization can have is that which it has with its funders. Relationships with funding partners, it should not be surprising, are also one of the most concerning aspects to socially engaged artists and practitioners who want to maintain a community-driven, participant-centered, emergent practice that remains at arms-length of external interests. Along with governmental agencies (such as the Canada Revenue Agency or Toronto Community Housing), which offer indirect financial support (such as mechanisms to reduce taxation or to provide in-kind services), relationships with funders are the primary extraorganizational relations that socially engaged arts practices maintain.

It is beyond the scope of this dissertation (which is primarily concerned with the practical implications of socially engaged camera arts as a political and pedagogical force in the lives of its participants and practitioners) to deal with the policy implications of cultural funding, underfunding, or the ethical implications of how corporate donations, "public tax dollars," or other aspects of financing these processes occur. Nevertheless, and to the extent that extraorganizational relations directly affect the practical implementation of socially engaged arts, 
I will address several concerns related to such matters that were raised in the interviews. Before I do that, however, I want to briefly trace some of the history of funding in the field since it will help contextualize these concerns.

Historically, there have been two sources of funding for community-engaged arts and media practices: first, (1) from arms-length arts funders, such as the Toronto Arts, Ontario Arts, and Canada Councils; and, secondly, (2) from outcomes-based funders (both public and private) from the social services sector. Both have tended to support community-engaged practices through limited-duration funding grants (that is, for project development and short-term staffing allocations), and both have tended to fund organizations more often - or at least more generously - than individual artists or practitioners. In Canada, both have also tended to be from the public sector - particularly the provincial government. (Cummings and Schuster 1989)

A third, emerging source of funding for socially engaged arts derives from organizations adopting a social enterprise model. In such a model, organizations working in socially engaged arts have moved towards two tendencies. In the first, artistic products or processes are commodified, so that either arts or craft pieces are sold (usually individually produced pieces, but occasionally anthologies or monographs, such as Let's Face it! Writing and Artwork from the Parkdale Activity and Recreation Centre; see Bell 2012), or events are developed following a fee-for-service model (in this case, fees are usually defrayed by third party sponsoring or host organizations, and only rarely and partially by participants themselves).

This social enterprise model may put arts organizations in a slightly different relationship to their participants or, at the very least, may complicate the structure that an organization assumes and impact the projects and processes it seeks to engage participants in. In extreme 
cases, organizations may literally (and legally) split into separate non-profit and for-profit organizations, with the non-profit arts organization being directly financed by, and notionally autonomous from, the proceeds of the for-profit company.

Historically, a fee-for-service approach has been common in community arts. In this case, at least in the US and UK traditions, community artists or community arts organizations exist as a kind of "service provider" with community organizations as their "clients." As clients, these community organizations commission community artists or arts organizations to work with community participants (the latter for whom fees are typically nominal or free). Effectively, organizations finance artistic experiences for community groups, particularly those that the former may not themselves be able to provide "in-house," and which may exist with some degree of autonomy from commonplace organizational practice. Participants are, however, subject to a host of other relational factors - at least potentially - depending on the conditions of the funding, as well as the varying interests and commitments of the host, community arts, and commissioning (or sponsoring) organizations. The degree of slippage from patronage to commission to sponsorship is certainly variable - and many community arts organizations have simply refused "strings-attached" sponsorship - but the reality of diverse interests impacting artistic autonomy exists nonetheless. The impact on artistic autonomy made by social enterprise models like fee-for-service is not likely a novel development. At times, even patronage may come with its own restrictions on the aesthetic and political possibilities of the art it ostensibly finances - regardless of whether such conditions are explicit or implied.

Yet because socially engaged art, like community art, is made in complex conditions of co-production and co-authorship, the terms are fundamentally distinct. An example of the 
complexities such financing might raise are worth noting here. For instance, public health organizations have been known to fund photovoice projects, through both initiatives led by multi-service organizations and projects of socially engaged arts organizations. This is ostensibly done for emancipatory ends: "photovoice" is a method purportedly designed to develop participant voice by giving participants cameras with which to document elements of their everyday lives, and the goings-on of their local communities. It's often meant as a participatory action research strategy, designed to encompass participant-led symbolic and material action around the conditions of their everyday living - especially, in this case, around what has been called "social determinants of health" (see Mikkonen and Raphael 2010).

However a number of contradictions may emerge as intention meets implementation. For example, although the methodology was developed with knowledge sharing as a core goal - that is, encouraging the development of grassroots facilitators for further iterations of the project, or organizing public exhibitions to showcase and celebrate images with the participants' community - there is no guarantee of follow-through on such activities. Additionally, the internal priorities of public health organizations may limit their ability to see those that participants have about the process itself; as Wang has argued, participants may even come to adopt the former as legitimate, and begin to see their own priorities as being of lesser consequence (see Wang et al. 1998, 84). Certainly aspiring to build a long-term infrastructure upon what seems to short-term project work seems profoundly difficult, if not impossible.

Because many socially engaged arts organizations perceive advantages in getting involved in coordinating and delivering such projects, or just generally affiliating with third party patrons and sponsors, it's impossible to disassociate such practices from the field of socially 
engaged arts or the practices of socially engaged camera arts. Thus even though such practices may not properly be called socially engaged, it is often the case that such affiliations seem to lead to so-called "win-win" situations for broader practices. For example, participants engage in a process of identity-building and skill-development at the same time as socially engaged organizations receive some support and even financing for hosting or accommodating such inititatives, and while public health organizations cultivate a richer sense of the public they need to support, and the particular services they require. However, to the extent that such intervention merely provides more focused service and fails to address the material conditions from which a need for such services fundamentally arises, the relative benefits to such projects seem disproportionately in favour of the sponsoring organizations.

Nevertheless, as I indicated above, while these relations are becoming increasingly prevalent, more traditional funding relations remain dominant. One such source is arts council funding, which arguably still plays a major and largely beneficial role in determining the shape and structure of many contemporary practices.

\section{Arts Councils' Support}

Arms-length arts funding, such as what has been offered by Ontario Arts Council since the mid-1970s as either Artists in the Community/Workplace or Community \& Multidisciplinary Arts grants, as well as municipally through Toronto Arts Council and federally through the Canada Council, has been one of the principal funding sources for socially engaged arts organizations working in Toronto over the past few decades. It is worth emphasizing the term organizations here, since it is largely as organizations (typically incorporated non-profits under Ontario law) that socially engaged arts funding is available to individual artists and practitioners. 
This is a tricky claim to make, because it begins to sound as if a collaborative, community-engaged practice is merely a guise for individual artists to operate individualistically; that is, within the conventional, single-authored, non-collaborative narrative of artistic creation. While this may be the case in some socially engaged arts practices, in general I found little evidence of individualism in my own research: either in my observations of practices, nor in my anecdotal conversations with several funding officers and adjudicators responsible for assessing proposals and disbursing awards.

Nevertheless, and despite being committed to a socially-minded practice, many socially engaged arts organizations centre around only one or two full-time paid practitioners. It may help to consider the matter pragmatically; that is, as a matter of labour. To support the wages of artistpractitioners, organizational grants are clearly more sufficient than individual grants: organizational grants can be upwards of $\$ 50,000$ per year, while individual grants are far less (for actual allocations, see Ontario Arts Council / Conseil des arts de l'Ontario 2013; Toronto Arts Council 2013). Without being supplemented by other sources of income - which for emerging artists invariably includes work outside the sector - such grants can only realistically support a full-time living wage for one artist living and working in the Greater Toronto Area. Based on my observations, other arts-based structural supports, such as support for the development of artist-run centres, are typically not actively pursued by organizations (although perhaps this has more to do with restrictions in funding rules than anything else: organizations applying to one funding stream usually cannot apply to another).

However, most crucially, organizations and individuals without organizational grants, or with limited individual grants, have a greatly reduced capacity to remedy this situation and 
receive improved arts council support since they are at a significant disadvantage to complete compelling grant proposals. Arms-length, state-based funding for the arts, in short, almost invariably needs to be supplemented for any hope of long term success.

\section{Outcomes-based Funding}

A range of other types of funding for socially engaged arts are available to organizations, and each bears similarities and differences to the arts model, particularly those that derive from state-derived organizations (whether federal, provincial, or municipal). Sources commonly include the Ontario Trillium Foundation, the Centre for Addiction and Mental Health, the Laidlaw Foundation, North York Community House, the National Crime Prevention Centre, as well as some municipalities and federal and provincial ministries (such as Human Resources Development Canada, or Employment Ontario).

Even for established socially engaged arts organizations, this kind of funding is often allocated in the short term. One practitioner, who I will call Anthony, describes what he perceives to be some of the logic behind such tenuous support:

The government was saying 'OK, yeah. Well, we can't we can't promise anything. Really, you have to do your own thing and become an organization.' So we did and, essentially, the funding continued for another two years. To a point where, every four years with the election cycle [our funding had to be renegotiated]. The funding was based on basically the government making that three or four your commitment to the program.

In my understanding, four years is quite a long-term funding commitment as far as such commitments tend to go. Most often, organizations are given support for one or perhaps as much 
as three years; as with arts-funding, organizations applying for this kind of funding are expected to reapply periodically (often annually). While it is true that some established organizations can generally expect to receive a consistent amount of funding each year, there is a clear recognition that this amount does not properly constitute a funding base (nor does it typically scale with the rate of inflation). Of her work with a Toronto area multi-service organization, another practitioner, whom I will call Jacinthé, points out: "Core funding - like actual, proper, core funding - is the most impossible thing to get in the world. [My organization has] some core United Way funding, but that's even hard to move or to add [to]. So it's not necessarily that kind of - although that would be ideal, a chunk of that."

It is perhaps as difficult to determine the effects of such tenuous funding on socially engaged arts practices as it would be to imagine the benefit that core funding might have on these practices. Often practices succeed because practitioners are committed to doing them: because they believe in their visions as artists, in the vitality of their participants' experiences, and in the combination of both. Funding for artists wages, material resources, and so on, may antecede such passion and commitment - often it does, but not always.

Nevertheless, there are indications that, stemming from neoliberal restructuring of public resources, both traditional arts-funding and non-traditional outcomes-based funders may have fewer resources to disburse, more accountability requirements attached to such funding, or both. In order to remain active in this context, socially engaged arts organizations face two emerging options: first (1), seek other funding sources (that is, non state-based, possibly non-arts and/or commercial sources), and secondly (2), seek direct patronage, whether from participants or, more typically, general supporters. This latter case may necessitate a turn towards self-financing 
models: either through prolific fundraising, or through emerging economic models like social enterprise (discussed above).

For those for whom experience, rather than wages, is the primary reward (such as interns to socially engaged arts practice, including participant volunteers), organizations may need to align with simpatico community development organizations in order to support programming and minimize organizational costs. In any case, as traditional means of support seem likely to continue to wither, organizations will either need to look within their own ranks to find means of support, or will need to redefine the very conditions by which their organization operates and defines its boundaries. Such redefinition may begin by searching inward but will likely be most sustainable by moving productively outward.

\subsection{Between and Amongst: Interorganizational Relations}

Distinct from the intra- and the extraorganizational, the interorganizational addresses relationships existing between and amongst socially engaged arts organizations, as well as between and amongst other arts and community development organizations. Unlike the former two, interorganizational relations are more horizontal than hierarchical, akin to networks that resemble peer relations such as those made between mutually interested equals. Unlike (or at least in different ways from) the intra- and extrarelational, these associations are often marked by a sharing rather than an exchange of resources - that is, a relation of reciprocity rather than dependency.

There seem to be three general intentions behind the support and development of interorganizational relations, three kinds of idea that an organization hopes to accomplish by forging bonds with like-minded organizations. First, (1) such relations seem to constitute the 
professional network and community of socially engaged arts practitioners and practices. Secondly, (2) they seem concerned to produce and distribute knowledge and experience as a means of supporting like-minded peers and organizations. Finally, (3) they seem a means of social movement building. Of these three varieties of interorganizational relation - which we might name the professional, the pragmatic, and the radical - the former two seem far more common in the field. (Indeed, and as I will discuss later, a number of interorganizational organizations exist principally to develop the field, rather than to elaborate a particular practice. While social movement building likely enters into such meta-organizational, interorganizational, or networking efforts, these associations seem principally occupied with legitimizing, professionalizing, and building-up the field.)

In general most people I spoke with recognized the potential value of these more distinctively horizontal relations. However, many also acknowledged the relatively weak or ad hoc infrastructure that characterized them in and beyond the Toronto area. Some practitioners thought building such relations was a great idea, but admitted having trouble making time and devoting resources to such efforts. Others were critical or suspicious of the motives of interorganizational organizations, and were unwilling to devote precious time trying to discern their aims or align with their goals.

Like others with whom I spoke, Leah Houston discussed interorganizational relations at length. Houston's own organization, MABELLEarts, is a member of the self-described Jumblies "family" of socially engaged arts organizations - itself a kind of interorganizational community, and one that has increasingly worked farther afield with groups across the province and around the country. Houston seemed concerned about the relative poverty of these relations for most 
community arts practitioners in Canada:

I think that what we have through Jumblies, and through Toronto, is very different than what a lot of people are experiencing. And I do have to admit and understand that a lot of artists are feeling very isolated. [...] I think that being a part of the Jumblies family of projects, and being in Toronto where we have [...] access to money, makes things really different for us.

From her own experience training at and working with Jumblies, Mindy Stricke echoes this feeling of isolation, and the sense of community Jumblies seemed to offer her:

I was in Tulsa, Oklahoma at the time [my interest in community arts began], and I met a woman who was doing a little bit, but it was really catch as catch can. There was no community, that's for sure.

I moved here and found Jumblies, and it was like I had gone to heaven. Not only was there an established community here of people who were doing this kind of work, but they were going to train me? And the work they were doing was so interesting! The process was so interesting! I learned so much from that internship.

No doubt a number of factors contribute to the value practitioners like Stricke have taken away from their interactions with Jumblies. Many practitioners I spoke with, whether they were affiliated with Jumblies or not, held Artistic Director Ruth Howard in high regard. Many referred, however indirectly, to the repertoire of cultural practices, pedagogical techniques, and artistic processes that Jumblies strives to deploy, and which seems to strengthen and enrich the aesthetic and political agency of emerging practitioners. 
Perhaps most notably, however, is the mutually supportive way Jumblies approaches internships. In the short term, Jumblies internships seem to offer an extended and iterative experience with different sites, with participants and their communities, and with other practitioners (both emerging and experienced). In addition to more periodic and longer term interventions, these internships typically include a week-long retreat of workshops, activities, and art-making, a kind of intensified and self-reflexive version of activities normally done with participants but which are offered for practitioners only. In the long term, former interns maintain contact with Jumblies agents and associated practitioners as they move on to other practices (including their own). Ruth and her associates routinely communicate with the former through email updates and newsletters, both directly and indirectly, and offer invitations to a range of on-going events that Jumblies organizes, or with which it is affiliated.

It should be said, however, that Jumblies is not exactly a traditional interorganizational body for the field of socially engaged arts (if there even is such a thing). Nevertheless, it does provide a compelling model for how else a community of practitioners might be developed and sustained: an organization that concerns itself with interorganizational matters, but not at the expense of its own practice (that is, it's own intraorganizational relations). Perhaps this is to Jumblies' credit: a number of interorganizational bodies have existed over the years with an express mission to support and connect diverse practices. Some have been international in scope (such as the now-defunct Community Arts Network), while others have been more local (such as ArtBridges or the Neighbourhood Arts Network in Toronto or the recently shuttered Community Arts Ontario).

Anecdotally, in my own research, I have witnessed several interorganizational groups 
fold in recent years: first the Community Arts Network, a community of practitioners which manifest as an online repository of transcribed presentations and critical writing about community-engaged practice, mostly centered on North American practice. More recently to close was Community Arts Ontario, an organization whose mission was to "To cultivate and connect the arts, artists and people across Ontario from urban, rural and remote communities." This organization announced its cessation in late 2012 (Community Arts Ontario Board of Directors 2012).

I am not pointing to these closures to suggest that these organizations were not useful (several people I interviewed referred to the resources found on the Community Arts Network as particularly formative). Neither is it my intent to suggest that such now-defunct organizations are wholly responsible for "missing the mark" in their efforts to connect disparate groups and practitioners to one another. Instead, my claim is that a broader discourse common to socially engaged arts seems likely to emphasize the value of particular relationships at the expense of others. As I suggested above, the general tendency for organizations committed to developing interorganizational relations is to espouse professionalization, in some cases functioning more or less like a job bank. What practices like Jumblies seem to also offer is the third piece: the opportunity for social movement building that is done in and through praxis.

This is a challenging argument to make: considering the truly deep impact socially engaged arts and affiliated practices seem to have on local communities, aren't all such practices fundamentally committed to building a social movement? Moreover, aren't all such practices, as practices, fundamentally committed to some version of critical praxis? As I have argued, most of the communities socially engaged arts practices work with are marginalized or stigmatized by 
many, both outside of yet even within the community. Virtually all socially engaged arts and associated groups are ideologically committed to challenging precisely this marginalization and stigmatization, and many have developed cutting edge strategies to practically achieve these goals. To claim, as I seem to be doing, that this work is not inherently and by definition social movement building seems wrong, and possibly malicious.

To be clear, this is not precisely what I am suggesting. What I am instead arguing is that socially engaged arts practices of all kinds seem prone to overlook key opportunities - however unintentionally - and that these are typically due to the myriad external pressures they face. I don't mean to suggest that socially engaged arts are responsible for creating these missed opportunities; nor do I mean to suggest that they alone are responsible for resolving them. Rather, I am suggesting that, much like other dedicated social movement organizations - unions, left-leaning political parties, minority rights organizations, and others seeking progressive change in social, cultural, economic, or environmental spheres - socially engaged arts might do more to support broad-based change. Moreover, I am arguing that socially engaged arts are particularly well suited to support and initiate this change: augmenting interorganizational relations to support intraorganizational ones is, I suggest, a key means to accomplishing this - a pedagogical matter I return to in the next chapter.

However, another means may be found in strategically cultivating existing affiliations in radically innovative ways. By this I mean not merely amongst socially engaged arts organizations, but amongst organizations from radically distinct disciplinary boundaries. As in other fields, disciplinary professionalization in socially engaged arts implies both the development of critical and collaborative creative practice (expertise), as well as recognition of 
such capacities in a formal capacity (a combination of both social and economic capital, such as through accreditation). The latter in particular is a complex issue that addresses both how practitioners are perceived in their practices, and how they finance what they do, both personally (as wages), and in terms of their practice (as budgetary expenses).

While the issue of funding is more properly an extraorganizational matter, having sufficient resources to accomplish basic creative goals does contribute to one's sense of belonging, if not to a narrower community of creative practitioners, then at least to a broader social fabric. For Stricke, for example, a funding base for socially engaged arts signalled a “cohesive, professional community" of practitioners:

Another thing I really love about this work, and being here to do this work, is there is a community here. I was in the states when I started exploring it. Now, granted, I was in Tulsa, which wasn't surprising. But there isn't - I don't know if it's a chicken and egg thing but, because of the funding bodies, there's just more of a dialogue and more of a cohesive, professional community here. [...] If I had to move back to New York right now, where my family is, I wouldn't even - it's very disparate in terms of all the work.

Funding, Stricke seems to argue, provides a sense of legitimacy to the practice of socially engaged arts, since it seems to encourage "dialogue" and greater cohesiveness with the community. Some argue quite strongly that an organization offering non-monetary "support" such as an umbrella organization established to support the field - is also needed. In some cases, such organizations - like the Neighbourhood Arts Network or Art Starts - function like real or virtual hubs to distribute news about relevant events, job postings, and the current work of fellow practitioners. Other organizations, like the former Community Arts Network (CAN), seek instead 
to distribute narrative and written resources like articles, commentaries, and reviews in a kind of online archive (it was called the Reading Room on CAN) geared toward self-directed learning.

As I have already said, others are skeptical of these types of claim, often arguing that such third-party organizations are too strongly informed by either academics or non-arts community workers (such as youth workers, community health care workers, social workers, and so on) to sufficiently consider radical social praxis. One practitioner, whom I will call Yvonne, addressed these organizations head-on:

I'm really critical of those kinds of things to be honest. And for whatever reason - I've been doing community arts for over 10 years now - there's always been some organization that feels that it's really important that there is some kind of network or association.

There's also this kind of - it's very subtle - it's kind of this 'Oh, you artists. You don't really know, and we are here to help.' that I find really annoying as well. [...] The ones that are really artist-led, I have felt over the years a kind of paternalism, like 'Let us show you how to do this properly.' which I find really annoying. Also, it remains to be seen what those organizations are actually doing.

Although many of these associations are practitioner-driven, there seems to exist a divide nevertheless. Perhaps Yvonne’s concern with “paternalism” hints at an ageism, racism, or another "very subtle" form of discriminatory practice that works, however unintentionally, to exclude or isolate certain practitioners by delegitimizing their practice. Perhaps, as others have suggested, it is simply that there's a fundamental disagreement over the weight such an 
organization gives to the various components implied in the compound term socially engaged art. Delegitimizing either art or social activism, however unintentionally, seems likely to risk the association, and even to poison the idea of interorganizational relations altogether.

\section{Arts Amongst Community Organizations}

Perhaps it is worth side-stepping the thorny issue of third party interorganizational organizations to look at a more common and arguably more effective example of interorganizational networking amongst social practices. For the most part, socially engaged arts practices have developed from broader and more organic community development struggles. While it would be inaccurate to say that socially engaged arts practices evolved from community development ones, it could be said that these practices benefitted from the groundwork laid by other, non-arts development organizations. Thus the interorganizational relations one might look to here are not necessarily between different arts organizations proper, but amongst arts and community development organizations of varying kinds.

For example, Adonis Huggins, founder and Director of Regent Park Focus Youth Media Arts Centre, speaks of the Centre's emergence from grassroots community activism:

Regent Park [Focus] essentially was formed in 1990 with this funding [from the Province of Ontario's short-lived Anti-Drug Secretariat], and that's when I came on board as a new youth worker for this new organization. It wasn't really an organization at the time either, because it was meant to be a coalition of different organizations. The whole point was that it was adding resources to the community itself. ... [I]t was very much like residents and community organizations coming together and saying, 'OK. How should we spend this money? How should we spend these resources? What should we do?' 
Some of the things we did was support 'Sunday in the Park.' It's a community festival that serves this community, that brings everybody together to celebrate. We did community kitchens, various programs for adults. So we were doing a number - really it was multi-faceted in terms of what we were doing.

Although Focus is no longer the coalition it once was, its roots in this model allowed it to experimentally explore matters of concern to the community - to "add resources" where needed, and to be "multi-faceted" in terms of its engagement efforts. As discussed in Chapter 3, Huggins argues that Focus began to take shape out of a concern over misrepresentation in local media. He recounts both successes and failures at attempting to engage interorganizationally with local media organizations. The community festivals, community kitchens, and other cultural activities help cultivate a sense of openness and generosity within the community; the letter writing and other forms of advocacy seemed to be similarly open, inviting media workers and their organizations from beyond the community a generous chance to take another, more critical, look.

In a context perhaps more skeptical of such action, these initiatives might have seemed less generous, and more pedantic. Arguably, however, by emerging from such grassroots activity, these efforts seemed to have blazed the trail for the many successful interorganizational relations Focus has developed and cultivated since, principally those between itself and other local social service organizations.

\section{Spaces of Experimentation}

Based on my research, I argue that the success of a socially engaged arts practice is directly connected to the way it maintains interorganizational relations. Moreover, and as examples like Jumblies and Focus suggest, such relations are the fruit of processes of 
autonomous experimentation rooted in a willful desire to build an aesthetically informed social movement. Buffered and supported by other simpatico organizations within a grassroots network, socially engaged arts organizations committed to such movement building can diffuse assumed risks - and perhaps take on greater ones - with different degrees of accountability than that to which singular practitioners or individual organizations might be held.

In addition to diversifying risks, such relations can redistribute resources, supporting formal, aesthetic experimentation. Such experimentation is necessary to art-making, of course, but it is also imperative to social movement building and the skill-building of individual participants and the professionalization of practitioners.

One practitioner, for example, joked that her organizational mantra when dealing with other organizations was to "Just do it, then apologize later." She then added that on occasion she had to apologize to those that funded her organization or that provided in-kind support (for painting on walls, digging in gardens, moving property, and so on); however, more often than not, these extraorganizational partners were forgiving, and often proved just as supportive of her initiative as her interorganizational peers.

In general, experimentation seems most pervasively to affect intra- and interorganizational relations. For example, Huggins acknowledges the value of experimentation in terms of Focus' internal development:

I guess the biggest thing I've learned is how valuable it is to have a space that you could experiment [with]. We don't have to get it right the first time. We can make mistakes and get better at things. I think that's been valuable. We've made mistakes in the past. In 
terms of the model that we have come with, we think it's effective. But that wasn't developed in a day, right? It wasn't developed from a blueprint that said 'OK, let's do this!' It was all kind of 'This leads to this, to this, to this, to this ...' You know?

Self-reflexively acknowledging Focus' shifting commitments, he asks, rhetorically: “Did I know many, many years ago when we started [making] a little video that this would lead to where we are, changing from a community service to a media arts organization? No, I didn't know that." Huggins then turns to his own experiences: "Personally, learning as executive director, from the change from a youth worker to handling [the centre's budget] and supervising staff. All that has been a learning process as well."

“That's what's neat," he continues, in what seems an implied parallel between his own experiences and the model Focus has attempted to develop, "individuals can be put in positions and can grow in those positions. I'm glad that we have been able to create a space where growth and development is something that we try to nourish and support." He adds,

We're not expecting [...] anybody to come in as professionals that know it all, and have all the tools, and have everything to get it done right. For the most part, all of us as staff every one of us - has come through the program as a participant or as someone who was brought aboard because of their commitment and passion, and has grown to where they are now.

It doesn't seem that Huggins is being overtly critical of or derisive towards the professionalization aims of certain third-party organizations, whether arts organizations with socalled "outreach" programs, or those umbrella organizations mentioned earlier. However, his 
recognition of the importance of participants becoming practitioners, and working with practitioners who were themselves formerly participants, cannot be overlooked.

Nevertheless, he is careful to note that this level of engagement - that is, in which participants can develop into practitioners - is not done without some loss of institutional memory:

Looking back, it's easy to overlook that. It's easy to forgot about [it], that that was part of the process of our development, both as individuals and as a community organization. And as a community. That takes investment in people, and time and resources. I'm glad that we're able to do that. It is a sense of community development - that's what I look back at - that this is a real sense of community development. We did not come up with job descriptions and hire professionals. We did it all for us.

Turning to the matter of emerging organizations, those with whom Focus increasingly collaborates, and for whom Focus provides a useful exemplar or practice and possibility, he adds: "It's great to be a model for other community groups who come in and say 'Yeah. Wow! This is a great vision that we can implement in our neighborhood!' At least to have a vision of that, whereas we just kind of did it by accident."

With this idea of vision in mind I turn to my final chapter to explore how these disparate threads - socially engaged arts, camera practices, and pedagogy - might be brought together to further enliven and enrich already sophisticated aesthetic and political practices. 


\section{SYNTHESIS, II: IMAGINATIVE SOCIALLY ENGAGED PEDAGOGIES}

This chapter will outline a theoretical frame for understanding the significance of what the artist-practitioners I spoke with had to say about their practices with socially engaged arts and with what I have been calling socially engaged camera arts. It will deploy a two-part framework to assert some generalizations about an otherwise diverse set of concerns and practices relating to engagement, on the one hand, and organization, on the other.

First, it will argue that socially engaged arts and camera arts function along a continuum of political action ranging from the contentious to the alternative. On the one hand, I am asserting that they take an activist, counterhegemonic, and politically progressive position with regards to diversity, inclusion, social change, and social justice. On the other hand, and at the same time, I am arguing that socially engaged arts and socially engaged camera arts cultivate a visionary cultural practice aimed at constructing and imagining alternatives to dominant sociocultural and political economic forms. This spectrum - activist on the one hand, utopian on the other - intersects with the strategies of expansion I explored earlier, framing them as more or less active and reactive to present day sites of struggle, while also more or less visionary and imaginative, concerned with future possibilities (whether or not such possibilities are plausible). This framing of socially engaged arts and camera arts as simultaneously contentious and alternative is meant to help address a number of key contradictions inherent in practices that oscillate between a commitment to the present and a desire to make the future.

Secondly, this chapter will highlight how socially engaged camera arts integrate with educational practice and theory - more or less aesthetically and politically, more or less intentionally - to help develop a bridge between practices of engagement and a politics of 
cultural transformation. With reference to my fieldwork, I will focus on three specific pedagogical or andragogical interventions - the workshop, the project, and the laboratory - to explore how the conscientious and participatory organization of collaborative practice through such interventions contributes to the development of a variety of cooperative engagements what I will call an imaginative socially engaged pedagogy - through which aesthetic expression instigates political activism, and vice versa, as both move towards cultural transformation.

I will conclude the chapter by addressing where the boundaries to such a vision, where the limits to this imaginative socially engaged pedagogy, must be drawn, and by briefly considering what is required to expand them beyond local concerns (that is, beyond "community" in its narrowest sense).

\subsection{Contention and Alternative}

What I want to develop in this chapter is the idea that, in addition to their aesthetic ambitions, socially engaged arts and camera arts contribute to cooperative political action directed towards broad social change by the very way they proceed to materially enact their creative and collaborative practice. I will assert that there are effectively two means of doing this: the first, the more critical but also functionally negative of the two, is through contentious action; the second, less reflexive but more positive, is through alternative action. It is of course problematic to dichotomize these two; indeed, I insist that socially engaged art and socially engaged camera arts typically resist such a dichotomy, whether tacitly or explicitly. Rather, these two qualities are more often sides of the same coin, with practices concerned with both, even if placing slight emphasis on one or the other at times. Practitioners in other fields might be tempted to label such actions "activism" and "art," respectively; however, in socially engaged 
arts, doing so can only ever be done cautiously, if at all.

I should also make it clear that the claims of "negativity" and "positivity" should not be seen as value judgements, marking a preference of one form over the other, but merely as paradigmatically distinct ways, and possibly even a dialectics, of understanding and acting upon common situations. In this sense, contentious action is premised on a lack - an impoverishment that demands fulfilling, an imbalance that requires restoration - while alternative action is premised on an excess or presence that demands formation (or form-taking: creation). As I tried to show in the introduction, and as I will continue to argue in what follows, real-world socially engaged art and socially engaged camera practices are an admixture of contentious and alternative action, critique and creation, dividing and assembling, experiential distanciation and jouissance. While individual projects and practices may lean more towards one or the other of these two poles, the most successful seem never fully polarized, and indeed remain actively conscious of the complementarity of these two positions.

Before addressing how the ideas of contention and alternative inform my definition of an imaginative socially engaged pedagogy, I would like to focus on each in turn to highlight their value and their limitations as means of understanding the interventions of socially engaged arts and socially engaged camera arts.

\section{Contention}

My conception of contention in socially engaged arts draws on the way the term has been deployed by Charles Tilly and his colleagues. For example, in Dynamics of Contention (2001), Doug McAdam, Sidney Tarrow, and Tilly define the object of their study, contentious politics, as “episodic, public, collective interaction among makers of claims and their objects when (a) at 
least one government is a claimant, an object of claims, or a party to the claims and (b) the claims would, if realized, affect the interests of at least one of the claimants" (5). "Roughly translated," they helpfully add, "the definition refers to collective political struggle" (5). They go on to develop a host of theoretical tools to describe a range of contentious politics in a variety of historically and geographically diverse situations. My claim here is that socially engaged art can, theoretically, readily adopt this formation; and indeed, in actual practice, it frequently does.

There are, however, two implications to adapting this theoretical framework to describe socially engaged arts practice. First, doing so suggests that conceptions of resistance in socially engaged arts are directed at one or more forms of government (in the case of arts practices in Toronto, this may mean antagonism towards municipal, provincial, federal, or even international bodies). I don't believe this claim is too controversial: it may be valuable to recall Jody Berland's general argument about arts production in Canada from her and Shelley Hornstein's Capital Culture (which I cited earlier; again, see 2000, 22 especially). Berland's argument is that government patronage and policy surrounding arts in Canada has created "dominant and exclusionary standards for cultural production" of the arts in general. Since in socially engaged arts virtually all practices proceed precisely from the "idiosyncratic," popular, and marginal in deploying their processes and constructing their products (22; see also Berland 2007), contention seems a given in the field. The very governmental forms and processes which "marginalize," as Berland contends, such modes of art-making seem bound to be targeted, even if indirectly, by the politicized aesthetics of socially engaged arts.

Yet if some or all levels of government are indeed targeted by the work of socially engaged arts, the effect is often so diffuse as to seem innocuous. The second more interesting 
implication is that the forms and actions of socially engaged arts - their processes and products simultaneously as they are cooperative arts, are precisely the "claims" or "collective struggle" that McAdam, Tarrow, and Tilly describe. Their very existence as multi-sensory, experiential, and extra-discursive forms and processes - rather than verbal or written discourses embedded in mainstream cultural structures and power relations - also effectively mark these modes of cultural production as contentious. This is not to say that all contention is politically transformative; indeed, as the authors suggest, contention takes two variant forms, contained and transgressive (7-8), where the scope of political action is variously narrowed or broadened. The same might be said of socially engaged art. Indeed, the distinction between contained and transgressive contention roughly aligns with that made by Margaret Ledwith (2011) between good and transformative forms of community development practice. As she argues,

If we fail to take our practice beyond the good work that goes into local issues and local projects, we fail to realise this potential, and our work is good but not transformative; it is making local lives easier, tolerable, more pleasant, but is not addressing the root source of the problems that give rise to injustice. (Ledwith 2011, 11; my emphasis.)

Thus socially engaged arts and socially engaged camera arts, simply by existing, may be materially symbolic of contentious politics which are good and progressive, and ultimately of some direct and material benefit to community actors. In this, they could be contentious, albeit (and arguably so) “contained." However, they could also be (and often are) transgressive and transformative at the level of social structures, both local and, especially, globally. The value of the concept of contention to socially engaged camera arts and socially engaged arts in general can be found in the way it helps characterize the fluidity of critical action and cultural production 
in such practices.

\section{Alternative}

Whereas a contentious politics can be seen as focusing on critique that presumes a preexisting ground against which claims can be made, alternatives might instead be seen as far less likely to make such assumptions. Instead, an alternative politics might imply the organization or reconstitution of the material conditions of everyday existence in novel and preferred ways.

A distinction between alternative and contention might be emphasized by attending to the creativity that alternativeness implies (rather than the expressivity, or "claims-making" of contention). On the one hand, contention demands attention to existing material conditions taken objectively, or at least collectively, presuming a coherence with certain practices and institutions in order to dispute them or make claims against them. On the other hand, alternative action demands material conditions be taken much more subjectively, presuming a coherence with identity positions in order to take a stand in support of them. Thus while contention implies agonistic strategies of critique with the purpose of asserting claims, alternative implies more emergent strategies of experimentation interested in reimagining the grounds upon and across which such claims might be made.

Clearly this dialectics of contention and alternative is an issue larger than what I can adequately address in this dissertation. As I schematically present it at the moment, this dialectic of political action seems rather sweepingly to include a wide range of social movements - both egalitarian and autocratic, responsible and reactive, progressive and conservative. Examples of contention and alternative might easily be located on either side of the political spectrum. While I argue that this is the wager of any educational practice like political action or socially engaged 
art - that they are all, in short, forms of social engineering, and introduce the perils inherent in attempting to change hearts and minds - the vagueness of my working terms risks homogenizing drastically different practices rather than providing a meaningful rubric with which to assess the object of my study.

In order to briefly address some of these concerns before I move on to a discussion of the kinds of pedagogical interventions that these paired forms of political action demand, let me highlight two dichotomies with which they are roughly aligned in order to highlight the critical and constructive (rather than reactionary and deconstructive) pedagogies at the heart of socially engaged arts. The first dichotomy is that between exchange and gift economies, the second is that between subjectus and subjectum (forms of subject-formation). Both of these dichotomies represent the core commitments of, and address what is at stake in, the conditions of a socially engaged art.

\section{Exchange and Gift Economies}

Genevieve Vaughan (2007) describes gift economies as constituting an alternative logic to that of a more predominant exchange logic implicit in capitalism. As alternatives, these economies maintain radically distinct perspectives on matters like labour, power, and knowledge in relation to exchange economies. Specifically, they more fully recognize the contribution of unpaid labour, particularly traditional “women's work" (i.e., that which is done in the private sphere), to the production and reproduction of daily life. Gift economies can be said to enact

alternative practices founded on collaboration and mutual interest (rather than competition and self-interest), at the same time as they support contention through the ways they expand the repertoires of conventional socioeconomic and political action beyond normative exchange 
relations.

Vaughan's notion of gift economy can be identified throughout aspects of socially engaged arts and camera arts. As one example, the turn to "community" in the terminology of many socially engaged arts (such as "community art" or "community photography") is often a nod, however implicit, both to this gift logic, and to the alternative and typically feminist values it entails. The extent to which these practices pursue a contentious agenda depends on the formal alignments they make with more traditional social movements such as environmentalist, feminist, labour, and queer movements. Thus while the alternative is clearly evident in the commitment to art-making and collaborative/cooperative cultural production, contention may be seen in the varying ways participants and practitioners address socioeconomic issues beyond the local.

Subjectus and Subjectum

Alternativeness may also be glimpsed in Hans Arthur Skott-Myhre's (2008) discussion of youth subcultures. In his argument on the unnecessarily limited potential of youth experience to public life, Skott-Myhre addresses two distinct forms of subjectivity relevant to democratic thought. The first, and far more prevalent, is the subjectus - that orientation of a subject in relation to, and specifically in submission to, authority. The subjectus exists in relation to both specific individual authority figures - as Skott-Myhre suggests in a partial enumeration: “teachers, adult relatives, coaches, youth workers, religious leaders, police, or other functionaries of the state" (Skott-Myhre 2008, 3). However, the subjectus also exists in relation to transcendent institutions (like the law), and even ourselves (in terms of our own self-discipline or self-control in relation to dominant cultural formations such as neoliberal governmentality; see 
Foucault:1991wl. Also see Cruikshank 1999; Bratich, Packer, and McCarthy 2003).

In contrast to the subjectus, Skott-Myhre argues, the subjectum "is not defined in relation to sovereign authority. Instead," he continues, "it is defined through its ability to creatively produce itself" (Skott-Myhre 2008, 4). Alternative action premised on such a position - that is, that people are not merely, or principally, subject to regimes of authority and legitimation, decision making and expertise, but rather are simultaneously subjects of their own material and existential becoming - supports a more empathetic and inclusive view of life as being defined by cultural difference. As Skott-Myhre contends, "[t]he alternate subject implied here allows youth and adults to join together in creative collusion against the forces of containment and discipline" (Skott-Myhre 2008, 9) - including the neoliberal state and corporate capitalism - that threaten to overdetermine how people take action, both individually and cooperatively.

The kinds of contention and alternative Skott-Myhre suggests here may also be found in

socially engaged camera arts and socially engaged arts, particularly in practices that resist unified visions of community identity, arguing instead for opportunities for agents to autonomously develop vision from spaces of difference. Both contention and alternative may emerge in the extent to which autonomous cultural production ceases to be individualized and leads towards collective, and particularly cooperative, forms of political and aesthetic action.

\section{Towards an Imaginative Socially Engaged Pedagogy}

As I have argued, the contention-alternative dialectic as I am proposing it is schematic. While it may be analytically useful for understanding how socially engaged arts can be understood through the literature on both art and social movement theories, it fails to examine how socially engaged arts and socially engaged camera arts proceed, practically speaking. The 
possibilities alluded to through the theoretical interventions of Vaughan and Skott-Myhre are, of course, distinct from the material interventions of socially engaged arts proper. While presuming correspondence with them, theories are nonetheless "non-isomorphic" with the objects they purport to describe (for more on this term, see Shiff 1989; Edwards 2006b). So too with the kinds of contention and alternative that can be portrayed at the centre, or centres, of socially engaged arts and camera arts practices. More practical interventions mediate amongst these broader claims and the day-to-day, mundane goings-on of socially engaged arts, their artistpractitioners, artist-participants, neighbours, and colleagues.

It is to these mediating functions that we must turn in order to understand the effectiveness of socially engaged arts' aesthetics and politics: to the depth and sophistication of their contention and alternativeness, to the success with which they engage people in making claims and simultaneously actualizing the change they imply. Thus, my argument is that one of the more significant means by which the contention and alternativeness of socially engaged arts and camera arts gets organized is through deliberate pedagogical interventions - specific educational encounters that variously induce participants to make distinct claims or support their own self-development in claims-making, all done simultaneously in, through, and as art. It is this cultural pedagogy of socially engaged arts and socially engaged camera arts - one which differs from that found in other sites and institutions (including formal education or professional art worlds) - that I have called an imaginative socially engaged pedagogy.

Although in mainstream culture textual modes of production (including images) are primary in conveying political force, the same cannot necessarily be said of texts in minority cultures. Certainly texts are crucial in inscribing broader structural norms - and entrenching 
widespread social inequalities - within and across these communities. They are not definitive, however; indeed, a whole host of other non-discursive, non text-based cultural forms and practices challenge the hegemony of mainstream textual practice in countless ways (albeit to greater or lesser effect).

In this context, I argue, practices that centre on points of engagement - social and youth work, arts and crafts groups, community gardening, mentoring, organized sports and recreation leagues, support groups - significantly augment and possibly even supplant the role of texts in activating and organizing cultural action. Further, amidst all these diverse strategies for redefining and expanding contentious claims, for practicing and enacting alternative aesthetics, for inhabiting and collaborating in novel ways, it is none other than pedagogy - or at least a range of tactics on the level of teaching and learning that we might term "pedagogy" (including "andragogy;" see Knowles, Holton, and Swanson 2005) - that works to unify the otherwise heterogeneous ambitions of these engagements. Pedagogy, in a word, is at the core of socially engaged art in that it shapes the encounters artist-participants and artist-practitioners have therein, both between and amongst themselves, and in terms of contentious and alternative forms of action.

In the remainder of the chapter I will outline three pedagogical strategies common to socially engaged arts - the workshop, the project, and the laboratory - to explore how pedagogy interacts and intersects with two other areas of praxis, community organizing and visuality, to understand the unique perspective - and difficult challenges - presented by socially engaged camera arts. 


\subsection{Exploring Where Aesthetics Meets Popular Education}

Any attempt to bridge the perceived divisions between artistic practices and social activism must invariably and practically commit material and conceptual resources to such work. I have already proposed the idea of strategies of engagement to flesh out the shape that these resources commonly take and, subsequently, I discussed the varieties of relationship that work within, beyond, and between practices to variously support or undermine local work. In this section, I will look at several common pedagogical approaches deployed in socially engaged arts to explore how they mediate between local practices and broader goals of social transformation.

Although there is a great deal of overlap amongst these pedagogical forms - workshop, project, and laboratory - I am outlining them to address some of the distinct resources they demand and the particular possibilities they each offer (while also paying attention to the contradictions raised when pedagogy gets reduced to a series of techniques). Thus while a workshop may appear as part of a project or in the context of a laboratory, or while a laboratory might need to deploy a range of discrete interventions including workshops and projects, there are advantages to making distinctions between and amongst them. Although I will attempt to highlight such distinctions below, the main difference is that they demand increasing amounts of commitment - on the part of both artist-practitioners and community participants - moving in order from workshop, to project, to laboratory. Such variable commitment, I argue, corresponds with the sophistication of the imaginative socially engaged pedagogy being developed.

Also of importance is the kind of engagement they offer: workshops are often more accommodating because they are more modular and flexible, while laboratories imply a more durable infrastructure that at once permits greater reach and sophistication, but also demands a 
more rigid organizational hierarchy that permits and ensures sustainability. Thus, while workshops might better engage new participants, the degree to which they achieve broader goals of societal transformation might be limited.

In my experience with contemporary community arts in Toronto, I can say that current practice tends to be focused squarely on projects, both short and long-term, that typically deploy interrelated workshops in series. While some of the more established organizations have begun to develop laboratory approaches (seemingly in the past few years), many organizations and individual practitioners, especially new ones to the field, continue instead to be developing more focused workshops. This distribution appears to be vital, or at least necessary, to the current community arts ecology (although it does pose significant challenges to the development of sustainable practices, a matter I will return to later).

\subsection{The Workshop}

One of the most notable aspects of community arts practice as an aesthetic practice is the workshop. Indeed, workshops are fairly ubiquitous pedagogical forms. In her recent case history of a decades old UK community arts organization, Kate Crehan (2011) emphasizes the workshop as an imperative aesthetic strategy for community arts practice. Although her treatment of the workshop is a little cursory, Crehan's general description of what it is intended to accomplish in community arts provides a useful point of departure for understanding the purpose of pedagogical engagement in socially engaged arts more broadly.

Effectively, Crehan asserts that a workshop is a space where community members can come together over shared concerns and interests. She is careful to point out, however, that a workshop is not necessarily a democratic practice by default. "In itself," she argues, a workshop 
"does not define either the nature of the nonexperts' contribution [to community arts] or the power relationship between expert and nonexpert" (Crehan 2011, 182). Other forces, she seems to imply, can and do play a fundamental role in what workshops can accomplish - which may even include challenging the presumed distinction between "expert" and "nonexpert" she seems keen to deploy.

She continues: "Workshops can be seen as having at least the potential to provide spaces in which experts and nonexperts can work collaboratively on identifying problems and coming up with solutions, and nonexperts can learn specific skills" (Crehan 2011, 182). The idea of "potential" here is important: it is a function of socially engaged arts' aesthetics that unconventional forms and practices can be made manifest. The workshop stands as the principal space where practices of envisioning and strategies for enacting contentious and alternative politics so core to an imaginative socially engaged pedagogy are initiated.

Crehan's framing of the strengths and limitations of the workshop model in socially engaged arts and camera arts is useful. Indeed, her very invocation of the terms "experts" and "nonexperts" points to the contradiction of workshops as simultaneously material events and organizational abstractions. Rooted as it may be in the singular history of a particular UK community arts group, Crehan's use of "expert" and "nonexpert" seems inappropriate to describe the relation amongst practitioners and participants in such an emergent practice as community arts, at least when deployed in the context of present-day practice in Toronto. (In this dissertation I have preferred the terms artist-practitioner and artist-participant (or simply practitioner and participant) to acknowledge similar kinds of divisions with respect to access to resources and formal training, but also in order to resist the implication of a possibly pejorative distinction 
based on presumed knowledge and experience.)

Crehan's terms, and the hierarchy of legitimacy they imply, risk simplifying the kinds of pedagogical experiences had by participants in a singular direction - as Skott-Myhre might argue, from the "sovereign" to the "subjectus"; more simply, from the knower to the novice. While it is true that professional artists and media producers do, on occasion, teach skills to community members through workshops, defining the relationship or the practice by this singular aspect of what is more typically a diffuse and reciprocal pedagogy is misleading. At worst, deploying the terms "expert" and "nonexpert" - and developing workshops based on such a dichotomy - threatens to reproduce colonial relations within what is often claimed to be a decolonizing practice. By defining expertise as an invariable term, in fixed association with some "legitimate" experiences like studio training and in opposition to those lacking in such training, Crehan's expert-nonexpert dichotomy risks devaluing the aesthetics and epistemologies of community-members and replacing them with more conventional ones.

I want to register this observation and concern because both the practitioners I interviewed and the participants I observed demonstrated to me just how consistently reversible such learning was. This reversibility was often diffuse, since what it was rarely clear what, specifically, was learned by either participants or practitioners. Importantly, the workshop provided a temporal and physical space within which such on-going back and forth learning necessary for nascent imaginative socially engaged pedagogies may be catalyzed.

Even in the instance of camera-based work, where practitioners often had to engage in more formal, unidirectional instruction on technical matters, there nevertheless existed a significant degree of reversibility. Mindy Stricke provides a compelling example from her own 
work:

One reason I do this [is] it's an interesting

balance of bringing my own artistic vision, and

then seeing what the participants bring. The

miniatures are a perfect example of this [...] I

wasn't sure how it would go as a community art

thing.

I brought it in, and people set up the most

amazing stuff. I never would have done it. One

woman ... we ended up shooting it with a breast

pump flange, and this [female model railroad

figure] trapped in it. It was this amazing scene

that I never would have done. She did another

scene that I didn't shoot well at all - I wasn't

prepared for how amazing and complex a lot of

them were.

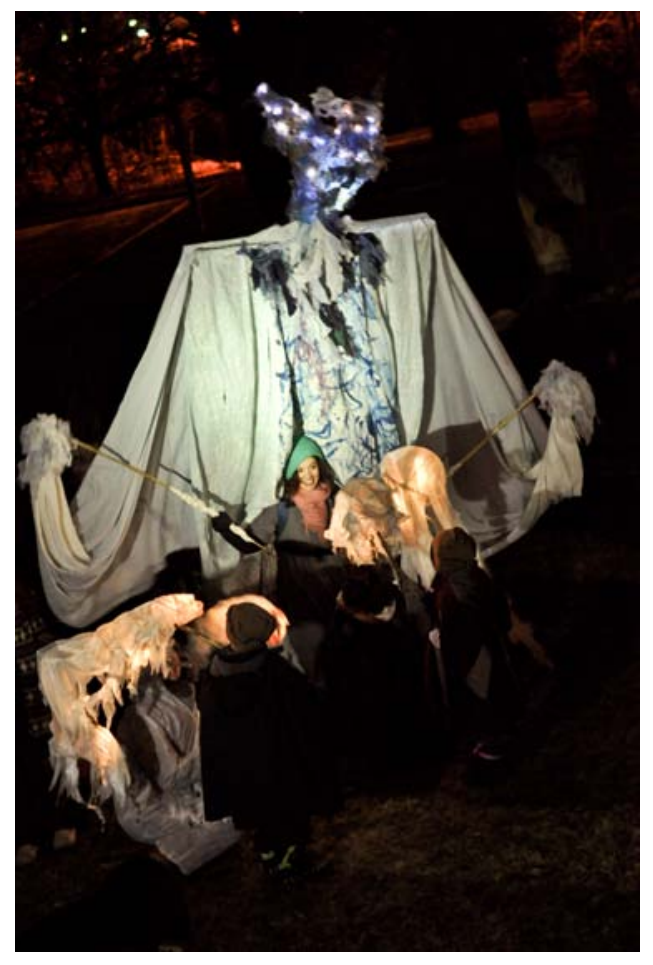

Plate 31 - Katherine Fleitas. 2012. The Ocean, from A Light in Midwinter.

MABELLEarts formal experimentation in place-based installation and performance has deployed a variety of forms and methods. Cameras and photorealistic imagery have been used to variously develop standalone projects and supplement aspects of other creations (also see Plates 18, 19, 32, and 33-40).

Thus although Stricke was a so-called "expert" in terms of her photographic equipment, her participants' understandings of the thematic and contextual concerns of the project were beyond her expectations. Such reversibility - which I would suggest is inseparable from the collaborative and experiential nature of that learning - is also important for the way it widens the scope of what counts as art, learning, and politics. Such a widening legitimizes knowledge in a far wider range of experiences than may be found in typical learning situations. As such, small, 
seemingly mundane, details become crucial to the support of diverse participants in on-going work. Learning becomes less a formal exchange of knowledge than a careful and empathic way of observing even the smallest of details. For example: "Sometimes you forget that people don't have hand strength. I'm really small, and I have tiny wrists, but I think I have pretty good hand strength, just from using tools. You forget that. You forget that people - it's hard to hold Exacto(TM) knives and cut."

This recollection, made by sculptor and community artist El Whidden ("Department of Public Memory" 2013), hints at the complexity of learning implicit in socially engaged arts and made manifest in the concrete encounters that workshops permit between and amongst artist-practitioners and artist-participants. Specifically, it reveals the kind of adaptation that practitioners - and, presumably, participants - must continually make within socially engaged arts processes.

Workshops, in short, are not intrinsically suited

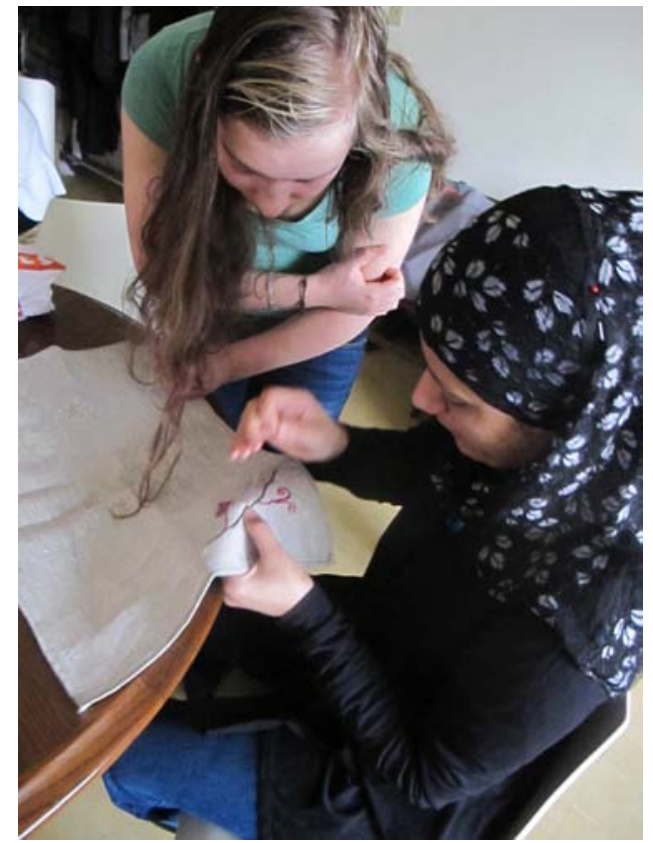

Plate 32 - Leah Houston. 2010. Sasha and Metha.

to developing egalitarian relations between and amongst practitioners and participants. However, neither are they necessarily flawed as pedagogical interventions. What they demand in socially engaged arts, however, is a broad, conscientious deployment in relation to the goals and desires of participants and practitioners beyond their immediate development. An absence of this grounding poses a variety of risks to a socially engaged practice.

Workshops are the principal means by which artist-practitioners and artist-participants 
interface and learn about one another's lives and culture. Some workshops are designed to be fairly emergent, to draw people in - both returning participants and new ones - while others are more purposive in structure and implementation and directed to a more committed faction of participants. Some workshops are clustered together, temporally - for example, to develop a project (see below) or to prepare for an event. Others may be held regularly over long durations, regardless of the particular goals of a specific project. On the one hand, most have a declared formal aim - for example, of teaching technical skills, of producing a volume of work, or of making tacit local knowledge take more explicit form (textually, verbally, visually, and so on). On the other hand, most also have sociopolitical commitments - for example, a commitment to an anti-oppression framework, or to an anti-poverty agenda, or to food security. By turning to my experiences participating in workshops at MABELLEarts, I will attempt to address what I felt to be the most common of these characteristics in order to elaborate more on this idea of a community imaginative pedagogy.

\section{Workshops at MABELLEarts}

MABELLEarts develops a wide range of artistic and cultural objects and events, from textiles to performances, sculptures to parades, meals, mentorship, and more. It does so in close collaboration with residents of the neighbouring Toronto Community Housing-run high rises, but also with friends, colleagues, and a range of other non-local guests. It provides these activities for free as a means of encouraging residents - who are often low-income, newcomers to Canada, visible minority, or otherwise non-majority Canadians - to recognize themselves, their languages, and cultures, as a part of their Etobicoke neighbourhood and, by extension, Toronto and Canada. Like other contemporary Toronto practices, it tends to frame its goings-on in terms of projects - specifically centering on winter and summer events (“A Light in Midwinter" and 
"A Park of Many Paths" are two of their ongoing projects; though the latter of which, as I will subsequently argue, seems increasingly to be in the laboratory mode - more on this below). To pursue such ongoing work, MABELLEarts tends to deploy two types of workshop, drop-in and serial (i.e., planned). In either case, the commitment of artist-participants to ongoing activities can be variable. Importantly, these types of workshop often overlap at MABELLEarts, and occur either within the same space, at the same time, or both.

I began to volunteer at MABELLE to support a commissioned artist, Elinor Whidden, as she ran pinhole camera workshops with participant residents. The workshops were to be part of a series of weekly, evening drop-in sessions, running for approximately 2.5 hours on Monday nights over eight weeks, and were to function alongside a number of other activities in which participants could engage (including a choir, and a variety of paper craft and textile activities).

The sessions also featured what Houston described as the "ladies cooking circle." This group of informally trained but knowledgeable chefs, headed by MABELLE's then operations manager and culinary artist, Miriam Ahmed, was importantly not a drop-in (participants were fewer, and each made more formal commitments to participate, in contrast to the voluntary nature of the drop-ins). The drop-in workshops that were offered were held in the Fall, and generated material objects, stories, and conceptual ideas for MABELLE's Artistic Director, Leah Houston, and Lead Artist, Alexandra Draghici, to incorporate into their plans for the organization's annual February parade, A Light in Mid-Winter. The cooking circle occurred simultaneously with the drop-ins, and focused on the preparation of a simple meal (usually a soup or stew) to be shared with the drop-in participants.

I want to highlight these two types of workshop, drop-in and serial, because they are 229 
representative of the range of core encounters socially engaged arts typically organize. While some workshops focus on skill-building and material outcomes, others focus on engagement, process, and experience where what is made, while often a point of pride, is not necessarily what will be incorporated into the culminating products or performances of the organization. For example, in terms of the pinhole cameras I helped build at MABELLEarts, approximately 20 were begun, but only about eight were completed and put into use by participants. Although the cameras were subsequently discarded (they were inexpensively made of cardboard, electrical tape and small squares cut from aluminum cans) and the images were not used as originally intended, the processes of constructing and photographing, and the relationships built amongst practitioners and participants during these processes, were nevertheless rich and constructive indeed, imaginative - in a number of ways.

I don't mean to imply that the process of relationship-building necessarily or definitively trumps product and performance (where these latter are the more traditional objects of fine art practice). It is true that, in this instance, and even in a number of other instances from my experience at MABELLEarts, neither the cameras nor the pinholes were directly incorporated into materials for the A Light in Midwinter parade (these materials included sculptures or costumes or multimedia projections). However, many materials from the other concurrent dropin workshops, including sculptures and textiles, as well as recipes developed through the cooking circle, were used in the event.

Perhaps the linear model implied by "process" and "product" - where the former leads progressively and conclusively toward the latter - is inadequate for the kind of workshops that MABELLEarts' practices, and their participants, demand. As Michael Burtt, Artistic Director of 
Making Room, and close associate of MABELLEarts through the Jumblies family of arts organizations, says:

One of the favourite things that people kick around is: 'How important is the process?

How important is the product?' [One of Michael's mentors] came at it one day and said, 'You know, it's all art. It's the process; it's [the] product. It's all one thing. Whether you're sitting down, having tea with a woman, that's the art. And when you do the play, that's the art.' That ... is anything but a relativistic statement.

Here the model is more circular or iterative, suggesting an aesthetic and cultural engagement that is more wide-ranging and holistic than either a product- or process-oriented focus alone could offer. Vaughan's gift economy comes to mind, in that the engagement implies less a strictly objective exchange - participation for product - but also a more ephemeral encounter demanding attention and commitment - participation resulting in experience. In this sense, the holistic focus of an imaginative socially engaged workshop manifests primarily in two interrelated ways: as a kind of relationship-building, and as a kind of experiential learning, both of which are committed to enhancing engagement in the social relationships and material conditions of both artist-practitioners' and artist-participants' everyday lives.

At MABELLE, as with elsewhere, both the pinhole and the cooking circle workshops maintain a dual process- and product-orientation. Although in some ways the cooking circles needed to be more pragmatic rather than exploratory - they were tasked with preparing and delivering meals to approximately 50 individuals by the midway point of each workshop - the intention was still also about cultivating an engagement amongst practitioners and participants using a hands-on, rather than language- or symbol-based, mode of cultural exchange and 
learning. The cooking - particularly the cooking together - was a novel material and conceptual imagining of community. The same could be said of the other workshops.

To reiterate, then, a workshop is a site of important interfaces between artist-practitioners and artist-participants taking up a variety of these roles, and an indivisible unit at the base of socially engaged arts pedagogy and practice. At a minimum, it represents a site of encounter where there exists - no matter how emergent or unstructured, didactic or formalized it might be a reciprocal pedagogical encounter between and amongst artist-practitioners and artistparticipants. Indeed, the literal minimum - single, one-off workshops unanchored to a broader project - do exist, albeit rarely, in such practice. However, the limitations such anomalies face particularly in mobilizing the contentious and alternative politics I raised in the beginning of the chapter - are commensurate with their singularity: they are largely ineffective (and, as such, vanishingly rare) because they minimize the pedagogical relationship between and amongst artist-practitioners and participants through underdevelopment and lack of commitment to community engagement. Their pedagogy, in other words, is rather weak and underdeveloped.

In the next sections, I'll explore the cumulative strategies of workshops taken serially and, indeed, sometimes done away with altogether - first by addressing a variety of what might be called project-work common to socially engaged arts, and subsequently by looking at the far less common phenomenon of the laboratory. I will explore the kinds of commitments these practices demand, both of aesthetic and social values as well as of the pedagogical relationships they engage in and expand. 


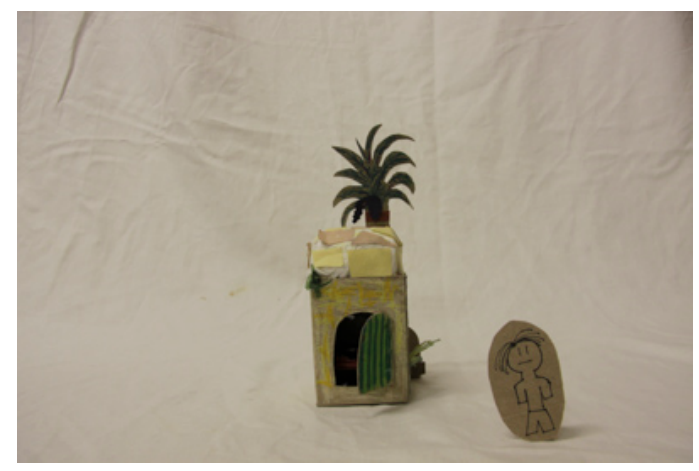

Plate 33

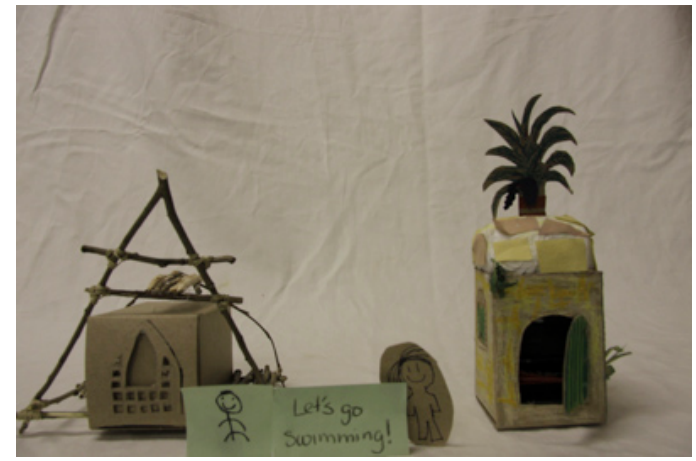

Plate 35

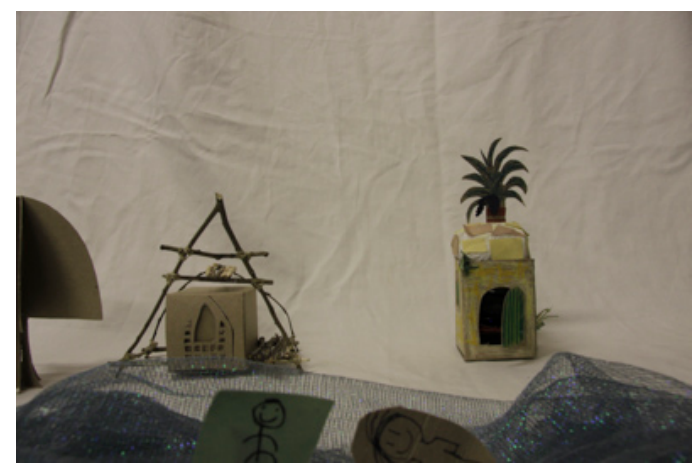

Plate 37

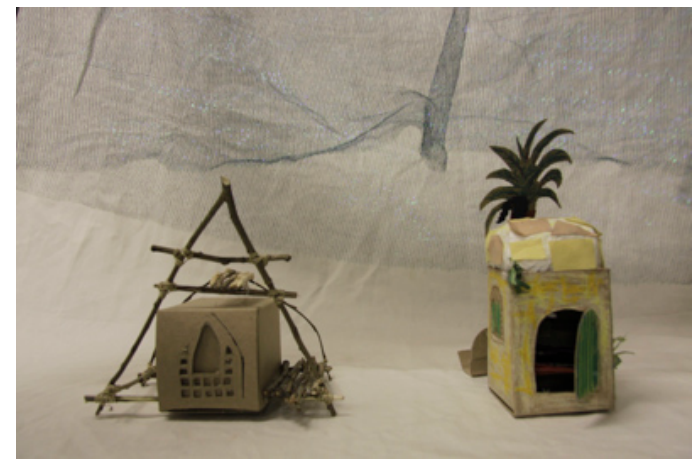

Plate 39

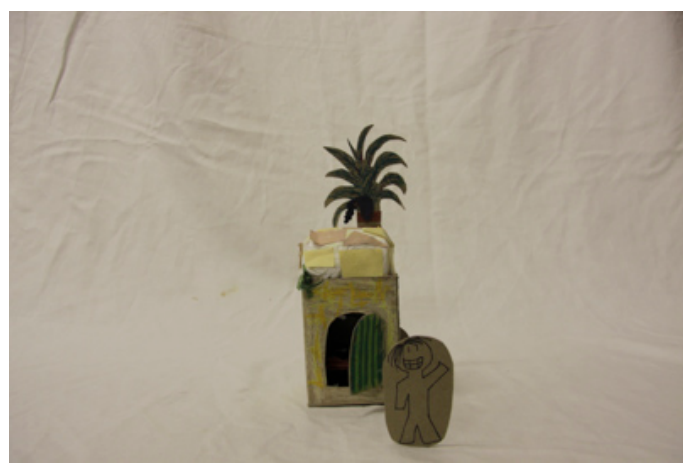

Plate 34

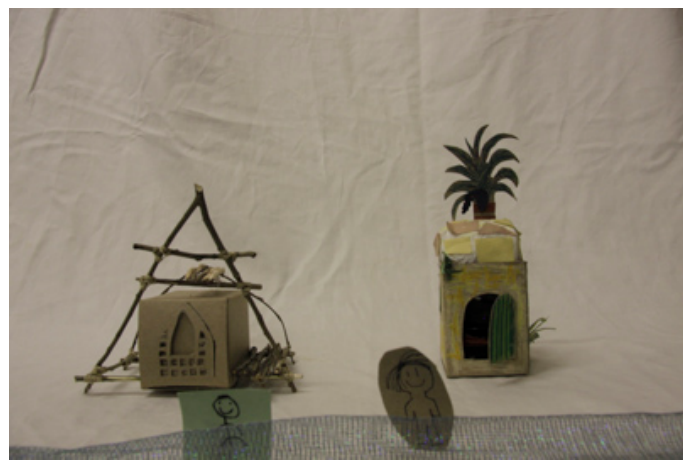

Plate 36

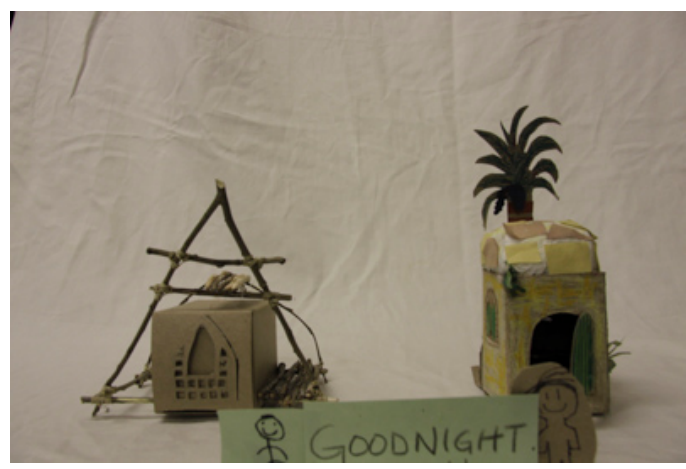

Plate 38

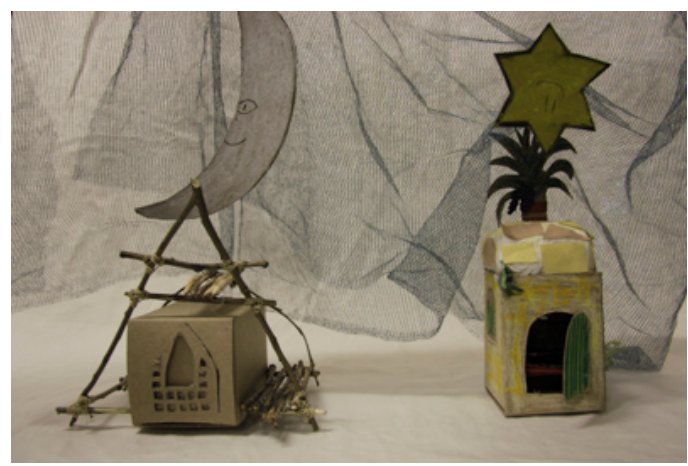

Plate 40

Plates 33-40 - Quennisha and Omar. 2012. Untitled stop-motion animation. 


\subsection{The Project}

In my experience, few, if any, standalone workshops exist in community arts practice, or socially engaged arts in general. A quick glance at the primary funding sources for this field namely, the Toronto and Ontario Arts councils and the Canada Council for the Arts - support this claim. Annual and semi-annual project-oriented grants are the norm with these, and many other, funding organizations. As such, most socially engaged arts workshops - and certainly socially engaged camera arts activities - seem to be coordinated within some broader form of project.

This typically leaves the project form to develop temporal, demographic, and financial boundaries: common examples include youth summer mural projects, week-long digital storytelling workshops, cooking circles with local mothers, community plays demanding weekly rehearsals, and so on. Projects have more general aesthetic and social goals than individual workshops might; indeed, funding is partly contingent on how such broader goals are explicitly set out in grant proposals.

In this analytical light, I would suggest that community arts organizations themselves often resemble the projects they conduct. In how they marshall resources (or have them disbursed to them seasonally or annually), coordinate activities like workshops, and plan for culminating events or performances, organizations are often subject to the demands of discrete projects, even while they try to maintain an organizational identity that stretches beyond such boundaries. This material reality poses serious concerns for organizational history and stability, what it takes to build a career in socially engaged and community arts, the kinds of commitments to community that can be claimed, and other matters of sustainability. These structural matters 
affect many socially engaged arts organizations, but particularly those with few resources beyond project funding to devote to organizational concerns like publicity, grant proposal development, archiving, and so on.

In an abstract sense, projects contribute to the contentious and alternative framing of an organization's aesthetic and political goals in a broader and deeper way than is possible through the particular pedagogical strategies found in workshops. Projects complement the otherwise emergent, experientially-oriented structure of workshops by providing at least a minimal structural integrity to a workshop's discrete goals. Additionally, projects provide a means for organizations to both conceptualize and materialize imaginative socially engaged pedagogies in engagements which are not strictly centered around workshops.

This is not to say that projects are inherently preferable to workshops because they claim to take a broader view of aesthetic and political engagement. The goals of artist-practitioners and artist-participants are always likely to diverge to a greater or lesser extent in any educational encounter, and a project's longer duration and broader scope inherently offers greater opportunities for such divergence. What is perhaps more crucial is whether such divergence is advantageous or not in achieving the goals of projects and their sponsoring organizations - that is, will a project strengthen an organization, its practitioners, and its participants, or will it merely be busy work for all? A provisional answer is that, as with workshops, socially engaged arts projects demand an overarching frame that bridges particular goals with those, more farreaching ambitions for social transformation - both in terms of individuals and their communities.

For example, in discussing his instructional experience leading a series of skill- and 235 
technique-focused photography workshops with youth at Regent Park Focus, Nick Kozak describes the potentially transformative effects a concurrent local photography competition seemed to have on participants who chose to enter. Kozak suggests that the external requirements and constraints of the competition (such as project guidelines and submission deadlines) seemed to have helped direct participants' energies, cultivating a passion and enthusiasm for photography from what he believed to be merely mild interest. Kozak acknowledges that such a competition is not necessarily the motivating factor in these participants' transformations, since there always tends to be one or two participants more eager than the others attending his workshops. Nevertheless, he believed that the structure of the project - its particular, concrete requirements and boundaries external to those inherent in his workshop - put his participants in a different relation to learning camera-based practice.

Kozak himself speaks of the experience as one his most "memorable" working in the field of socially engaged arts, suggesting (somewhat obviously by this point) that practitioner transformation is also a possible effect. In terms of practitioners and participants both, the example points to the variable nature of transformation as a result of project work in socially engaged arts. For some, for example, it seems that the intrinsic rewards of participating were sufficiently motivating and transformational - at least on a personal level. For others, it may have been the extrinsic rewards offered by the competition. Indeed, there may have been others for whom experience in the project led to transformation after the fact, indirectly from their experiences at the time. Critically speaking, the kind of change Kozak describes may not be transformation at all - neither in terms of the broader kinds of social transformation to which socially engaged arts aspires nor in terms of the experiences of all project participants. For some, this and other forms of project work may be completely unmemorable, utterly non- 
transformative.

It is difficult to enumerate the qualitative, experiential gains offered by this project. While it is clear that some participants achieved a degree of personal success - Kozak points to his participant's success in winning the competition, resulting in a new camera and subsequent freelance paid employment - it is nonetheless difficult to define the specific factors to which such success might be attributed. What role was played by Nick's presence, for example? Or by the incentives and parameters of the project? To what degree did the internal motivations of the artist-participants shape everything?

More generally, this episode raises concerns about the point at which a project such as this ceases to be socially engaged or community arts and becomes something else (such as corporate promotion or urban regeneration and development). The external motivations (as I said above, the contest offered a camera as an ostensible prize in exchange for a visual photo story) may have demanded distinct criteria from those inherent in Nick's workshop alone. One could legitimately ask, By what aesthetic criteria were these images made? Did such criteria change with respect to the project? Would they have changed in similar ways with a workshop experience absent of the project? Moreover, at what point do participants lose control over their images as their own expressions? At what point do such images become vehicles for other discursive agendas, however benign or complementary they might seem? To what extent can this project (or others) be considered exploitative? To what degree is it voluntary? And what roles do artist-practitioners play in mediating between the values of the organization with which they are working, and those of the artist-participants with whom they are engaging?

In short, while looking to the broader, more concrete goals or outcomes of project work 
has an important place in developing an imaginative socially engaged pedagogy, such considerations need to be balanced by the strengths and limitations of the project mode. In many cases it is more likely that intersubjective, community-based, or otherwise experiential factors are more compelling, particularly when the work promises to address the identity-politics of marginalized populations. Indeed, on a pragmatic level, a key determinant of participation is preexisting relationships: people attend because their friend, or neighbour, or family member is going. In the absence of individual or community buy-in (without knowing someone to go along with to a local workshop or event), external incentives in and of themselves are likely to be ineffective. This simple fact - that is, of the divergence of expectations between artistpractitioners and artist-participants - fundamentally impacts the effectiveness of project work in achieving predetermined goals. In order to develop an imaginative socially engaged pedagogy, project work needs to balance its pre-determined goals with an emergent, participant-centered approach. This often means its goals need to be continually refined or even, at times, rewritten altogether.

\section{Digital Story as Project Work}

Thus in the case of the digital story workshop I assisted with, the ostensible goals of skill development and digital media production - "you will complete a digital story" - were not nearly as important for participants as was knowing where the artist-practitioners were coming from - who they were, what their values were, and who they were working with. This is not to suggest that the politically and aesthetically alternative goal of producing digital stories was unimportant, but rather that it was not decisive to the actual engagement of the artist-participants in the project. Of greater importance was the commitment practitioners made to engaging participants on their own terms, and on their own turf. The particular shape they helped give the 
project, and indeed the particular parameters of the engagement as a project, helped frame this engagement.

Run by Jennifer Lafontaine and Emmy Pantin as part of the Journeys to Health project a broader, longer-term artists residency pilot project - the (short-term) digital story project workshops were scheduled with middle-school aged youth from a west end Toronto Community Housing complex during their March break. The youth were willing to participate during unseasonably mild weather and a rare break from mandatory schooling - digital storytelling requires a fair bit of planning, recording, and editing work that's best done indoors. This interest and commitment suggests that the youth did, on some level, value the material incentives of the program. For instance, this was a chance to play around with digital technology, to produce a lasting video record of their experience, and to participate in an exchange with youth from a native community north of Thunder Bay - uncommon experiences for these youth. Their willingness, however, must also be seen as deriving from their previous and on-going participation in a community health group; not only did they learn of the opportunity from this experience (in some ways they were recruited, at least informally, from their participation in this preexisting group), they were trusting enough with the program coordinator from Four Villages and with one another to welcome Lafontaine and Pantin (and myself) and complete the project. Moreover, there was significant enough concern that they were being misrepresented symbolically - either as a community or individually (or both), both at school and in the media that also contributed directly to their decisions to participate.

My point here is that the workshop form, working within a project structure, offers significant means within which an imaginative socially engaged pedagogy might be developed. 
The discrete boundaries of both along with the stated production outcomes of the digital story model offered a fairly clear picture to participants about expectations and goals. Nevertheless, it is the flexibility of the method Lafontaine and Pantin implement that is decisive. The specific conditions of implementation were dictated by local, emergent factors so that the specific practitioners and participants in the room helped reshape and exceed the predetermined plan.

This is not to say, however, that predetermined planning is impossible in socially engaged and community arts, but rather that the conditions of such planning need to take distinct factors into account. For example, referring mainly to community development and social service organizations, Lafontaine describes the methodological model of digital storytelling she, along with Pantin, have developed, first as a satellite for the California-based Center for Digital Storytelling, and subsequently as a component of a Toronto multi-service settlement organization:

There's not a lot of places out there that have media or community arts infused in what it does, so [our practice] gives [us] the opportunity to pilot things in different places, or help a particular project. If a group says 'We really want to do an awareness campaign about this issue, and we think that personal stories would help so that people can connect to the issue we're talking about.' There's lots of reasons why people want to incorporate digital storytelling into the organizational work that they want to do.

Lafontaine and Pantin have developed projects and delivered workshops across Canada with a wide range of local-level and national organizations. Although their model is fairly systematic and brought to participants in roughly the same way regardless of context, it is simultaneously a successful socially engaged art form in how it values so thoroughly emergent 
and experiential paradigms. It does this by engaging artist-participants - individually and cooperatively - and channeling the substantial narrative and technical skills of Lafontaine and Pantin as artist-practitioners into largely editorial roles in support of, rather than in control of, participants' project development.

The paired structural/experiential aspects of Lafontaine's and Pantin's methodology are precisely what is common, despite significant contextual differences, to the practices of other successful socially engaged arts organizations and projects. One common effect, despite differences between specific practices, is to allow artist-practitioners and artist-participants to voluntarily develop, amongst themselves as well as cooperatively with one another, alternatives to the kinds of mandatory relations they have with dominant social forces (such as with formal education, the media, private corporations, governmental service organizations, police or, especially in the case of practitioners, the art world). The material creation of such alternatives, and the contentious resistance to conventional practice to which such alternatives tacitly or explicitly refer, is directly related to the imaginative socially engaged pedagogy I am proposing here.

In a key sense, the goal of such project work is to develop autonomy. This is not without its contradictions, of course, since the emancipatory promise of autonomy may yield isolation rather than community, or mask the benefits of heteronomous relations to counter-hegemonic contentious and alternative cultural production.

As in other instances, an emergent approach to core organizational goals is often most appropriate in the development of projects that strive towards achieving such autonomy. For example, Adonis Huggins outlines the emergence of an unintended alternative in the form of a 
unique and opportunistic partnership between the organization he leads, Regent Park Focus, and several others:

Four years ago they [Focus' principal funder] cut the summer positions that we depended on. What that meant was we didn't have the support staff to supervise youth anymore. Through doing some workshops with other organizations, we did a workshop where [...][a neighbourhood affiliate organization] called us and said 'Hey, we want you do a workshop with our youth putting together a video.' A large number of youth came by: we supplied the project support staff, the coordination staff, and the equipment that we had, and they provided the staff supervision that we used to have. And we said 'Well, this worked!'

As Huggins says, shifting project parameters to account for an organizational deficit created a novel opportunity to partner with another organization. As he suggests, this model has since become an important pedagogical strategy:

For the last three years, rather than reach out to individual youth [...] the focus was connecting with [at least four distinct neighbourhood affiliates]. They would come to [Regent Park] Focus with ... kids in their summer program, then they'd come out to work a couple mornings a week, doing video production or radio production or music production. Really it was 'How could we use our resources together to support each other's work?' [Focus] didn't have the supervision staff where you could go out and do things, but their organizations did. We have the expertise.

Serendipitous as this novel interorganizational development is, it is impossible to ignore 
the circumstances that brought about the partnerships Huggins describes. Although the relationships seem beneficial - indeed, the partnerships that have been made are certainly with like-minded organizations, and are working with individual participants that may utilize both services - it is clearly the result of funding cuts that threaten the activities of Focus and likeminded organizations. Like others I interviewed, Huggins is quick to recognize the possible pressures this may impose upon organizations - for example, to normalize cost-cutting and accountability measures, as if such neoliberalization were simply an inevitable part of doing their substantive work. Later, Huggins shares his criticism of what he sees as a pressure to become not simply autonomous, but entrepreneurial: "I'm concerned it's a way that enables people to withdraw their funding support to community organizations in this, thinking 'Well, they'll get lean because they'll find ways to create social enterprise to fund the work that they want to do.'”

Lafontaine and Pantin also share concerns with entrepreneurial pressures increasingly put on socially engaged and community arts practices. This is crucial, because the digital storytelling practice they have adopted from the Berkeley model of digital storytelling of Joe Lambert (see Lambert 2012) essentially operates as an enterprise, using a fee-for-service model common to many US community arts practices. Since what Lafontaine and Pantin do is effectively what has been recently termed "social enterprise" (for example, see Kay 2006; Lewis and Swinney 2007; Galera and Borzaga 2009; Lasby et al. 2010), the concerns have more to do with the challenge of effectively supporting existing community development organizations with their unique pedagogical and production-based approach. In other words, Lafontaine and Pantin are concerned about the strengths and weaknesses of, on the one hand, playing a limited part in a multiplicity and diversity of communities, which offers them a broader reach as media practitioners to instigate unique alternative productions and, on the other hand, committing to a 
more intensive role within fewer communities, which would allow them distinct opportunities to refine their practices as socially engaged media artists. These concerns are directly related to the scope and duration of the project work that their professional relationships with organizational partners permit them to develop, and the material ways they are able to make viable careers out of such endeavours.

Importantly, the broader scope of the Four Villages youth digital storytelling workshop represents, for them, a means to address that concern; to "go deeper" with a community, as Pantin has put it (and perhaps even, I surmise, to resist the potential for projects to seem like selfcontained packages of socially engaged arts experience). Their work with Four Villages is part of a pilot project of the Ontario Arts Council that will eventually establish unique medium term artist residencies in health care (rather than the more common studio art or educational) settings, and explore the potential of such dedicated interventions in other fields of social practice. As Lafontaine describes of the experience:

It let us really spend a whole year there [Four Villages] and go into multiple programs and create multiple things, as opposed to a little project and then you're out. Then we were lucky enough that we got to continue it for a second year. That was the real - by the end of the first year we were like, 'Look at all the learnings we can pass back to you [Four Villages] for what needs to happen in new sectors like this!'

It is worth remembering that Lafontaine's and Pantin's experiences are both typical and atypical in relation to the experiences of other socially engaged artists and organizations. Funding in particular is a complicated creature: as Huggins implied above, its sudden withdrawal demands savvy to imagine alternatives, and social capital to successfully execute them. (This is, 
again, a decidedly entrepreneurial approach.) Couched within a larger, longer-term project, Lafontaine's and Pantin's experiences with Four Villages through the Journeys to Health project allowed them opportunities to work with a range of people from a variety of west end Toronto communities. Uncommonly, it also allowed them time and space to cultivate relationships with people - both participants from those communities, but also the community health care providers with whom those participants interact.

Lafontaine's and Pantin's practice is certainly atypical in that they have developed a multi-level project model that seems to work well for both artist-participants and themselves as artist-practitioners - a model that supports a combination of broad reach across communities and in-depth aesthetic creation within them, all done through short-term projects couched within a longer-ranged parent project. Project work is more commonly short- and medium-term in nature. Often, it takes the form of a "pilot project": a program of short or medium duration (usually 12 months or less) that offers no long term funding commitment to either the participant communities or the practitioners with whom they work. Even standard socially engaged arts funding seems to put pressure on artists and organizations - particularly new ones - to develop new and innovative projects; such emphasis on forward momentum rather than historical development seems concerning in terms of sustainability, both in terms of a predictability to how resources are managed and distributed, and in terms of an institutional memory that may guide future practitioners through unexpected organizational hurdles.

Thus in a very important sense, project funding often seems like pilot funding (although council grants have attempted to fund what they term research and development phases). One artist spoke of her concerns with the pilot grant her organization received. Although she 
acknowledges the support it provided - namely a "majority of salary and program expenses" she is concerned that subsequent, post-pilot recipients will likely receive only a fraction of that amount - indeed, if the program even continues at all: "Anybody who applies is going to get $\$ 10,000$. They'll never be able to do what we've done in the last two years on $\$ 10,000$."

Her concern is a broader one about financial support for socially engaged and community arts initiatives. She continues:

The funding is just not available. I have expressed some curiosity around core funding from arts organizations 'How would it help? What would it mean for us to be an arts organization?' In the end they only give you $10 \%$ of your annual operating budget. $10 \%$ of it. That's core funding?

Certainly talk about money was a common theme. While it never veered into the territory of asking participants to pay or to make art to sell, it did cross over into questions of how socially engaged arts processes - namely projects and workshops - could be made saleable. Of his organization's practice, for example, one artist muses about the financial impact of socially engaged arts:

I hate to bitch about money because everybody [does it] - it's the hue and cry of the nonprofit sector. And we're prepared to earn it; but it just seems like we work three times as hard - because we don't have a pure business agenda, and we don't have a pure arts agenda, and we don't have a pure youth agenda. Where do we fit?

The limits of project funding for community arts and media organizations impacts what socially engaged arts organizations can accomplish, both aesthetically and politically since they 
typically, as I have argued, finance only the immediate requirements of the project, and not the infrastructure that situates the project in the broader social, historical, and artistic context. The most resourceful of practitioners and organizations have developed sophisticated and integrated solutions that leverage existing resources to fulfill their mandate and expand their goals, and have developed significant strategies using the project as a frame for diverse goals, both organizational and pedagogical. As I suggested earlier, the question of the costs associated with such success remains an open one: Do the kinds of alternatives that have been created contribute to an imaginative socially engaged pedagogy that will support further alternative and contentious creation? Or does the kind of entrepreneurial approach demanded instead threaten to shortchange such imagining and envisioning in preference to leaner, more neoliberal organizational principles? Beyond organizations, what effects are felt by artist-practitioners and artistparticipants? Returning to Skott-Myhre, is it more toward subjectus or subjectum that such artists seem to be developing when arms-length grants dry up, and goal-oriented ones become more prevalent?

Certainly there is a great degree of cynicism across the field and, as with the similarly low-income fields of arts and community development practice, a great deal of burnout. Since many artist-practitioners are often mentors, both formally and informally, what this signals both for engaging communities in contentious and alternative politics and for the development of emerging socially engaged artists - when career prospects often appear to be uncertain, or at least unpredictable, and the likelihood of physical and emotional exhaustion seems high - is problematic at best.

At a workshop I attended with a number of community artists, one organized by a 
Toronto-area community arts umbrella organization, one of the moderators joked about the affective rewards of doing community arts. "Well, we certainly don't do it for the money!" she quipped to a knowing, but tired, laughter from the audience.

This notion of self-identity seemed simultaneously to signal both a selfless commitment to one's work as practitioner and also a self-deprecation resigned to that skill and expertise remaining undervalued and underpaid. While such a self-image is not ubiquitous to the field, it seems nevertheless dominant, and as such risks normalizing certain exploitative practices in the field. At the very least it threatens to make socially engaged and community arts a very unstable, unsustainable cluster of labour practices. At worst, it contributes to the normalization of a culture of precarity amidst, potentially, some the most marginalized members of Canadian society. The question of whether the significance of community arts and socially engaged arts interventions through project work is of material benefit to participants despite such possible risks to artistpractitioners is certainly a matter for further consideration.

\subsection{The Laboratory}

My point so far is that pedagogical models like workshops and projects are significant ways of organizing a kind of basic interface between and amongst artist-practitioners and artistparticipants. Additional larger scale projects can successfully coordinate several smaller ones (subprojects or workshop series), uniting even broader conceptual goals with more specific, immediately practical ones. Exhibitions and performances, as the ostensible culmination of both workshop activity and project work, are also important as pedagogical interventions. However, the pedagogical relationship between exhibition or performance and audience is fundamentally distinct from that which exists between and amongst artist-practitioners and artist-participants. 
These cumulative moments are perhaps better understood in their aesthetic and political dimensions, pedagogy being a not insignificant, but nevertheless typically minor, concern.

I would like to turn instead to what I will call the laboratory mode of socially engaged arts. Structurally similar to project work, a laboratory in artistic practice is a more experimental or autonomous aesthetic and pedagogical form, demanding a different relation between and amongst practitioners and participants. I would like to focus on the laboratory because it was implied or referred to by practitioners from several practices and was, in general, a dimension of practice people claimed they would like to develop further.

In all honesty, reference to the idea of the laboratory as an idealization of community arts organizational work caught me off guard. Although I was expecting a kind of informal discussion of emergent, participant-centered practice, I wasn't prepared for this concept, which I had previously understood - despite the ways it has become manifest at present - to be rooted in early modern and avant-garde art practice (for example, see Gough 2005). I spent some time in Chapter 2 trying to expand such modernist conceptions of laboratory beyond the purely formalist, positivist, and sociotechnical to suggest that the film and photo leagues that emerged during the 1920s and 1930s inaugurated the kinds of resource-sharing, inclusionary, and experimental practices we see today. There are obvious structural similarities between these kinds of historical and contemporary cultural laboratories, as well as key differences in aesthetic mission and sociopolitical organization surrounding their existence. For better or worse, the same kinds of formal, medium-specific experimentation and explicitly class-based politics are not as readily apparent in contemporary movements as they were in their more explicitly revolutionaryminded predecessors. This is a matter I attempted to point out in Chapter 2, and one I will return 
to in the conclusion. Nevertheless, the laboratory is a provocative attempt to actualize, or at least imply, the contentious and alternative politics inherent in the turn to socially engaged art practice, and an arguably more stable space within which to develop an imaginative socially engaged pedagogy as it evolves across spaces and situations and over time.

Adonis Huggins uses the term in his describing his ambitions for the future development of Regent Park Focus:

I would like to see more of the peers coming together - young people themselves coming together and taking more [ownership]. A lot of our stuff is guided through facilitators [we have] a facilitator approach. So having five youth come in and say 'Hey. We've gone through a project. We know how to use this equipment. We want to do a video of this.' $[\ldots]$

I'd like to see that happen - youth taking even more ownership of the program activities, and not just 'OK, I've learned that. I've put together my video - that's great.' More like a laboratory, right? I would want to see that.

In certain ways, the present context at Focus, developed over two and a half decades through grassroots coalition building - the result of "peers coming together" - suggests that Huggins' laboratory ideal already exists in key ways. By deploying the term, Huggins seems instead to suggest a desire to see a greater youth contingent participating in and, indeed, constituting organizational practice at Focus. To put it another way, while the space already is a laboratory in key respects, the on-going challenge is in getting practitioners and, importantly, participants to use it as such. Thus, rather than simply engaging with the media as it exists at 
Focus, Huggins' idea is far more political, demanding as it does greater agency and autonomy:

We certainly have a youth-driven approach to what we do. We try as much as possible to encourage them. It's really that they're hands on - being able to use those issues [that they're faced with daily] as a way of dialoguing. When they're doing radio [...] that they're dialoguing with decision-makers ... Through that dialogue, exchanges happen they're learning about each other's perspectives, [that] kind of thing. In terms of developing a radio show or a news show, that they're looking at what's on the news what's going on in the world around them.

Huggins suggests that certain supports exist to work against and challenge forms of discrimination from reproducing themselves in the otherwise open pedagogical context of the centre. "But," he claims, it's crucial

To also talk about anti-oppression and other issues in society, and challenge them around homophobia and really about identity, too. Being able to find their place within the context of 'I am producing this. Who is the "I"?' [That] kind of thing. Getting them to explore being a resident from a community within communities. Where they are, and trying to find strength and resources in that voice to be able to integrate that into their work.

It may be that the critical and self-reflexive piece Huggins refers to here is what he sees missing from realizing Focus as a laboratory. In the language I have used, perhaps alternative production and contentious practice necessary to imaginative socially engaged pedagogy are being constrained, leading to merely contained or "good" practices rather than transformative or 
transgressive ones. It is difficult to say. Nevertheless, the kinds of employment and participant experiences Focus has developed through it's approaches to learning and mentoring are noteworthy and influential. As Huggins summarizes,

Sometimes it really works well, sometimes it doesn't work well. Also, because we take a youth-model approach - if you look at our organization, a lot of people who work here are either young people themselves, or are residents who have been empowered to [take on] the positions that they have. It's not where we - and we do this too - it's not where we only employ professionals to do the work.

In terms of developing a laboratory practice, what Huggins referred to as the "youthmodel" bears further consideration. He seems to be talking about a system of learning and mentorship that encourages participants to gradually take on different roles within a socially engaged art practice. While occasionally this may take the shape of a formal instructor-pupil kind of relationship (for example, during workshop introductions to the technology and facilities at Focus), it far more often seems to occur as informal mentorship, or peer to near-peer learning encounters. In my time there as a participant observer, it seemed that this was a fairly hands-off approach, occurring in very informal, conversational ways in the computer lab, the studios, or while waiting for the elevator. Such conversational, ad hoc engagement is the heart of pedagogical relations in much of community arts, where the widespread paternalism and ethnocentrism common to mainstream society - from public schooling to the media, representative governance to the legal system (and even found in certain community arts projects) - is actively and practically resisted in preference to an emergent associative action. It is in the laboratory, I am arguing, that such a model can actively flourish not merely in resistance 
to or contention with normalized practice, but as a critical, alternative practice of its own.

This is not to say that a youth-model is not inherently unproblematic. Major issues exist across practices - particularly when ideas like "autonomy" and emergence are deployed uncritically, as well as when supporting mechanisms like documentation and assessment - which can help give shape to such fluid experiencing - are left underdeveloped. For the moment, let me highlight how difficult it is to imagine and establish the conditions within which a socially engaged arts practice might become a laboratory, materially and conceptually speaking.

Novak, for example, highlights a complex approach to pedagogy that echoes aspects of the "youth model" Huggins discussed:

We constantly encourage, right from our management, leadership, all the way through, [that] this is a learning initiative. We encourage experimentation and failure, and success (or whatever that is), and learn from all those things just to keep playing and keep trying. [...] Lots of playfulness, reflexivity, and a kind of reclaiming of error, in a good way. And a definite philosophy [that] who we are together is always going to be better than who we are alone. A lot of collaboration.

Like Focus, Sketch seems to emphasize a principally experiential pedagogy: one in which play and practical activity encounter the material, day-to-day context of participant's lives. Add to this a rather fluid organizational structure - where artist-participants help strongly determine their own roles within it, and the result is fairly unexpected and emergent. Novak seems keen to institutionalize this experimentation; or, rather, to return emergence to the fabric of organizational practice. She continues: 
I want Sketch to be a place where we're doing literally that: we're just sketching out all these options of living that we can play with and incubate. I think that the key strategists in that will be the young people that are living on the margins - that have developed an other-worldly perspective just by virtue of survival. [T]hey are entering into the conversation through a different door. I feel - I want them to be highlighted as teachers $[\ldots]$ to the rest of the community. I hope that Sketch could be seen as this sometimes. (My emphasis)

Like Huggins, or Barndt on propositional art, Novak adds her own uncertainty about the approach, "I don't know if we're doing this so well, so we have to figure out how to do this well. But," she continues, pointing to the cultural energy such unanticipated alternatives seem to make possible:

It's not just a social program that has arts attached to it. It is a real cultural development initiative that, just by virtue of it being present, is saying to the community 'Young people who are living on the margins have this huge social capital that is being missed. We've got to make this space available for them to recreate themselves. We've go to make it possible for them to build leadership to help us recreate ourselves.'

For Novak here, the laboratory model appears to signal a desire to extend art beyond aesthetic practice and engage with a broader social realm in order to secure a place for it as affective, experiential knowledge. Engagement in this sense is simultaneously with a distinct cohort of participants, but also ideally with those for whom art may represent entirely different forms, practices, and possibilities. For Novak as for a number of practitioners, such transformational possibilities seem most likely to become manifest in a single, well-crafted, and 
intentionally designed space. For those at MABELLEarts, such a space seems to be the small Mabelle Park at the centre of that community. For those at Focus, such a space seems to have led to the development of professional-quality media facilities: sound and recording studios, video editing suites, and even a television studio. For those at Sketch, such a space seems to have led to the planning and development of a multi-purpose studio and visual art production space. After sharing with me some architectural drawings of the space and recounting the kinds of deliberations that went into such extensive design efforts, Novak seemed to want to characterize the broader ambitions and long term scope of Sketch. "I'm interested in the intermingling of cultural expressions," she stated, reiterating her commitment to a broader understanding and valuing of cultural knowledge and experience:

I would love to see our new creative space, the hub, be so beautifully shared that there are cultural studies programs in the arts happening there. That's one of our strategic directions, is that we want to see a vibrantly diasporic, interactive environment where we are drawing from one another's cultural expression and wisdom.

It is, of course, impossible to know whether participants, or even other practitioners, share Novak's vision of what Sketch is and what it might become. Nevertheless, as Artistic Director, Novak no doubt experiences a significant degree of support for these expansive and inclusive views. Speaking more concretely of on-going work at Sketch, for example, she discusses a project that seems to fit into these broader organizational goals. "We have a newcomer project right now," Novak continues:

My excitement about the project is not just about [asking the question] 'How do you use the arts to feel more comfortable about integrating into society?' I would rather see it be 
like 'How is the artist in you - coming from another country and landing here - how is that benefitting or fitting into you being the author, recreating a whole new reality?' Because that is what's happening. This is the golden opportunity of immigration, the blending of new worlds so our children can become more inclusive, more globally aware [...] and build together [in a way] that's not economically driven.

To be clear, the consideration of space as a determinant of, or at least a significant factor in, the kind of experimental pedagogy being discussed is a component of a long-term project such as Focus or Sketch or MABELLEarts. Not all organizations and practitioners, indeed, very few, may be deeply embedded enough in socially engaged arts - either experientially or financially - to be in a position to develop similar approaches.

Nevertheless, a laboratory, experimental approach may be found in other practices. In Joshua Barndt's work, for example, the public spaces of a neighbourhood can become the experimental sites of community arts practice. In such a practice, specialized studio space is unnecessary. Of a multi-artist, street-art influenced youth mentorship project (see Goudge 2011), Barndt says:

We started doing these small garbage sculptures in spots that were being underused. It was really important that they were temporary because what we made was not that great. [...] We turned this weird horseshoe concrete thing that had been abandoned forever, [left] full of garbage, into a playground. It couldn't be a real playground, because it wasn't up to code. But it looked wonderful there. Within 20 minutes [of putting it up] there was like 20 kids playing there. It shows that something could be there - that the space could be used better. It's just a proposition - we're not actually building a 
playground - but it informs, I think, what could happen next. (My emphasis)

Addressing the possible roots and inspirations contributing to the development of such an ad hoc, emergent, or "propositional” practice Barndt adds:

I'm starting to reconsider the role [of] street-based practices in terms of autonomous actions, temporary actions, in the overall social transformation of space, or of people's understanding of that space. [Street art] is the biggest propositional research ground: you can quickly see what works and what doesn't. [...] And, since it's temporary, it's low risk. It's not like if a city department does that kind of thing, and it has to fit into this specific framework of having a longevity.

We take those small risks, which are propositions that then other people can build off of. It's the sort of organic research work that's happening, and it's generally being done by autonomous individuals.

The propositional nature of socially engaged arts informed by street art that Barndt mentions is certainly experimental, and suggests a radically distinct approach to imaginative socially engaged pedagogy relative to many of the others I spoke with. It seems to imply a practice distinct from, yet as effective as, the project work that structures other community arts endeavours, all while still compatible with the emergent tendencies of socially engaged arts.

As an aesthetic practice, it seems to echo a kind of Brechtian distanciation or v-effect (see Jameson 1998) where a propositional act "jolts" an otherwise apathetic viewer into response (or action) through a process of alienation with regards to habitual practices and routine experiences. However, this characterization doesn't seem entirely accurate. Barndt's work - both his 
curatorial practice at Whippersnapper, an artist-run gallery, and his own practice as a socially engaged artist - is less about alienating people than about engaging people in collaborative challenges that address the material conditions that seem to structure everyday life. In this sense, his propositions seem akin to enacting temporary alternatives.

Despite the strengths of such an idea - the energy of his actions are profoundly engaging, and provide an enviable model of rapid community engagement - the limited degree of sustainability of such actions and the impermanence of their products cannot be ignored, raising the possibility that such contention may actually be "contained" rather than "transgressive." For Barndt, it would seem, an approach to resolving this tension has been to embed these ephemeral processes in documentation; indeed, to conceive of documentation as a crucial aspect of the artistic process:

One thing that I love about photos is that you can document people. [...] The documentation always included people using those things. The playground that we made, kids playing on it. The shrine, people building - youth building it. That's real people! $[\ldots]$

That mural was called Make Your Mark on Paradise [...] We are contributing to the city, and this neighbourhood, and these youth. These are small actions, but they will have a psychological impact. All the small things people are doing to help shape that is important, and sort of beautiful.

Despite the differences in scale, Barndt's concern with more intimate actions echoes Novak's interest in broader-reaching transformation. Both are concerned with the ways socially 
engaged arts intervene in the very fabric of community and culture; moreover, in the radical reshaping of inherited practices - such as Barndt's appropriation of archival practices into emergent processes - innovative and transgressive opportunities for art to integrate with life, rather than to merely represent it, become possible.

As a pedagogical mode, the laboratory suggests a range of possibilities that are both compatible with and distinct from more typical socially engaged art workshops and projects. Deployed in the context of the values of such arts - such as process-oriented, participant-centric, practitioner-driven, contentious, alternative-envisioning - these general models of engagement can and often do work together to create both rich experiences and sophisticated art forms and events. 


\section{CONCLUSIONS: TOWARDS IMAGINATIVE SOCIALLY ENGAGED PEDAGOGIES}

The project of this dissertation is to explore what an imaginative, visionary, aesthetically

critical, politically active, and democratically cooperative camera arts - a socially engaged

camera arts - might look like in practice. Drawing on ethnographic methods to explore the work of several contemporary practitioners and organizations located in Toronto, I discovered that any such practice is difficult to characterize, since the use of cameras in socially engaged arts rests on an emergent, participant-driven, and contextually-bound framework of cultural production.

Making art in this context - whether with cameras or in some other medium - depends on highly variable cultural, organizational, pedagogical, and aesthetic factors, and the complex interplay between and amongst them.

In this dissertation, I traced out what I saw to be several key factors with some apparent commonalities amongst otherwise disparate practices. In particular, I discovered, first, that socially engaged arts are generally committed to an expansive and inclusive trajectory, one in which practices seem concerned to broaden and deepen the place of culture and art in contemporary communities (in whatever ways "community" gets defined). Secondly, I found that camera arts are being used to both represent the processes that such expansion entails and also, through their specific ontologies, to intervene in the context underlying such expansion. Thirdly, I found that the external and internal forces which help shape socially engaged arts and camera arts practices have, despite many differences, key organizational similarities that specific instances may mask or inflect in certain ways. I discovered, in short, that the images that a socially engaged camera arts develops are the result of a rich set of experiential practices that are often distinct from camera use in normative professional or mainstream popular practice. It is towards these conceptually sophisticated and experientially rich practices that artists - both those 
working in socially engaged arts and those working in critical photographic or filmic modes might continue to aspire.

This project took form as an exploration of socially engaged arts practices in Toronto, developing from an interest in better understanding the myriad different community arts practices being developed in and around the city, and it materialized through both participating in and speaking to people involved in those practices. Drawing principally on ethnographic methodologies, I developed a research project in which I acted as a participant observer and conducted open-ended, semi-structured interviews with the people I met at several community arts and community media practices across Toronto. I was extremely fortunate to be invited to volunteer at several Toronto-area practices in exchange for an opportunity to watch and observe - I am well aware that many sites face resource challenges that make accommodating such requests difficult, if not impossible. Most of my interviews are with practitioners from these sites; however, some are from people at practices with which I had no formal involvement.

I learned a great deal throughout the research process about matters both substantive and methodological. In the initial outreach or recruitment phases of my research, while many practitioners were quick to respond and eager to support my research, others proved more difficult to contact. I assumed that non-response was due to one or more of several key reasons: first, that practitioners are sometimes suspicious about academic research; secondly, that practitioners assign unsolicited requests low priority because of limited resources and multiple demands, many of which occupy a great deal of time in terms of their day-to-day organizational activities; and, thirdly, that practitioners are protective of their participants and communities and wary of potential exploitation - particularly by another white, male, university-associated 
researcher claiming an interest in a marginalized and racialized community.

While interviews and observations confirmed these assumptions, they also pointed out several additional realities. For instance, some practitioners may not have been suspicious of academic work so much as they are fundamentally disinterested in it; they may even see it as utterly disconnected from what they do (such an idea of "academic" may even include postsecondary fine arts or studio practice, and may reveal important distinctions about what is valuable to different groups or communities). Some practitioners may be wary of research that is seen to be prying into or categorizing their own practices. Such concern may relate to anxieties over self-preservation and over-exploitation in a demanding field, or to worries that complex ideas, practices, and relations might be misrepresented by third-party accounts, or missed altogether. Finally, it may simply be that, for some practitioners, face-to-face communications are preferred to email or even telephone, so much so that failing to connect is often a matter of potential practitioners checking their emails or their phone messages infrequently or assigning unsolicited emails a low priority. In short, while ethical factors may be present, pragmatic reasons fostered by resource limitations may often be the likeliest reason for non-responsiveness.

I also had several more substantive assumptions when I began this dissertation. During the course of my research and analysis, some of these have since been confirmed while others have been sharply challenged. In this brief conclusion, I will address three key themes that emerged from my research in relation to these assumptions. These conclusions are, first, that the deployment of camera practices in socially engaged arts hinges on the very specific attributes or particular qualities these media manifest in such practices (the medium specificity of what I am calling socially engaged camera arts). Secondly, that the development of socially engaged arts 
faces a productive but challenging tension between organizational sustainability and visionary practice. Thirdly, that socially engaged arts, in and through cameras and other means, elaborates an increasingly vital approach to culture as emergent and of common concern.

\section{Cameras and Socially Engaged Art}

In terms of the media specificity of cameras in socially engaged arts, I began my research with the assumption that, while many practices were innovative, most were rather conventional (indeed, some problematically so). Drawing on the complex, dualistic nature of photographic imagery (perhaps most comprehensively developed by Steve Edwards: for example, see Edwards

2006c; Edwards 2006b), I assumed - based on anecdotal experience - that many instances of still and moving imagery in socially engaged arts were likely to veer toward a documentary, matterof-fact rhetoric of photorealism, and shy away from more personally expressive, formally radical, socially critical, or culturally affective modes (characteristics which, I was prepared to point out, most successful social documentary already possess). The concern of my research was to explore how successful practices ensured a richness of form and to demonstrate how these supplemented and even drove a critical approach to content.

Upon beginning my fieldwork, I realized that this perceived tendency was not entirely the case and that a rather different - and, frankly, more interesting - set of challenges was present. In all the practices I visited, it was clear that photos and videos, as artistic products, were being made in meaningful, intentional ways. Some of these were aesthetically intriguing, others less so, but all held meaning in ways that exceeded mere aesthetic concerns. Indeed, meaningfulness was pivotal: as a barometer of practice, participant engagement would have crumbled and participants themselves would have abandoned the processes without it. However, such 
meaningfulness was not necessarily found in any images that were finally produced. More often than not, this source of engagement could be better located in the various encounters that led them to be there, and to remain.

What became quickly apparent to me was the primacy of process in the context of making: although the products of image making remained important, the kinds of on-going material and social encounters amongst practitioners and participants with their local community contexts seemed to be crucial. Thus while the duality of document and art remains important as an anchor to structure work done in photo-based communication, an exploration of the continuing and iterative negotiations that supported how such work gets done became a surprisingly crucial part of my research. This is because the forms of action shared between and amongst participants and practitioners through the individual and cooperative use of camera arts practices both engaged with and exceeded this duality. The images generated by Motherland, the videos developed through Journeys to Health, the Portraits of Silence wheatpastings, and so on: such concrete mediations between art and document demand novel ways of understanding, just as they required distinct strategies for their construction.

As I have argued throughout this dissertation, the peculiar status of photorealistic imagery is, in part, at the core of the continued popular appeal of camera practices. The duality of camera-derived imagery as simultaneously indexical and authored, as objective document and subjective expression, offers a diverse range of communicative and experiential possibilities to a great variety of image viewers (and makers). In addition, the proliferation of camera technologies (at least in this North American urban context) and near fully complete transition to digital means of image production and distribution has made these novel communicative and 
experiential possibilities accessible - although arguably not ubiquitous - to a new and expanding cohort of image producers in wholly unprecedented ways. When focused through the aesthetic and activist sensibilities of socially engaged artists, certain of these production practices offer emergent experiential possibilities distinct from those available through other means and artistic media.

In short, although I anticipated that the deployment of camera practices in socially engaged arts would help develop unique artistic and social innovations achievable only through such media, I was surprised by the complex and unprecedented ways cameras came to be incorporated into and, indeed, critically appropriated by many of these practices. (My discussion in Chapter 4 differentiating novel representations from novel practices using cameras was an attempt to highlight several nuanced ways this distinction between expression and action is made manifest.)

By the same token, I was a little shocked that many examples of such appropriation, from a disconcerting number of sites, seemed to me to be under-utilized in subsequent projects and practices. While some practitioners lamented the fact that such achievements were poorly archived (if at all - practitioners spoke variously of "piles of photographs," or "harddrives of files"), I was far less convinced about the blame some seemed to assign themselves or their organizations for such perceived lapses. Thus, rather than to perceive unarchived material as evidence of a lapse in practice, I instead chose to understand its presence as a sign that traditional archiving was not perceived to be of value, especially in terms of the on-going and iterative meaningfulness I have already discussed. As such, by looking to examples that expand upon the vernacular, visible, and performative realms of camera-based practice, I am not simply proposing 
a way to make sense of innovation in socially engaged camera arts, but I am proposing a theoretical frame that may be useful to on-going praxis in camera-based strategies of expansion. Such praxis may do well to critically and creatively appropriate conventional camera-based practices - such as archiving and exhibiting - but they might instead continue to adopt or expand on such practices, to appropriate them in ways that seem most practically necessary and conceptually meaningful.

\section{Organizational Challenges}

Organizationally, I was surprised by the specific ways that the diffuse field of socially engaged arts in Toronto is, and also fails to be, interconnected. I already had some sense of the factors that seemed most commonly to affect the extent of interorganizational engagement geographic proximity and distance, for example, or differences in organizational mission, resource disparities (particularly as they disproportionately impacted practices led by racialized practitioners), or even how much time an organization dedicated to reaching out to simpatico partners. However, I underestimated the particular ways in which funding and financing shaped the field and even contributed to the high degree of variability with which collaboration and cooperation occurred (or failed to occur) amongst like-minded organizations and practitioners.

To be clear, I found the relationship between intraorganizational funding challenges and the overall (interorganizational) health of the field to be highly variable: the two do not necessarily correlate. While it is very likely that relatively weak arts funding has contributed to the demise of many nascent organizations and deterred many potential practitioners from entering the field (particularly of, by, and for minority artists and marginalized communities),

socially engaged arts in Toronto nevertheless seems to continue to grow. As I have argued, this 
may be because other forms of funding and financing have been, and continue to be, found beyond traditional arts council grants, such as in other forms of governmental funding (which are usually more outcomes-based, less arms-length in nature), as well as in corporate donations (as grants or sponsorship) and even volunteerism (often as unpaid internships). I argued that these on-going transformations of funding and financing and resourcing - specifically, away from an arms-length, patronage model and toward one of increasingly quantifiable forms of accountability - play a crucial, if complex, role in affecting organizational autonomy.

The role of autonomy in socially engaged arts is, of course, complex and contradictory: emergent, participant-led practice is, in many ways, necessarily heteronomous. As such, it demands a cooperative, multivocal (and multi-visual or even multi-perceptual) approach in order to be effective and to maintain community engagement which may often be at odds with conventional notions of artistic autonomy. At the same time, such engagement demands a driving, even unifying vision, one which ultimately synthesizes and harmonizes disparate narrative and experiential voices - amplifying some, diminishing others - all while attempting to maintain organic relations with marginalized communities rather than mechanical affiliations with governmental or private (extraorganizational) interests. As I have argued, the most successful socially engaged arts practices seem to have developed sophisticated techniques to mitigate and even avoid the risks of normalization and homogenization that both artistic autonomy and extraorganizational heteronomy variously pose. Such practices accomplish this largely by cultivating experimental aesthetic and pedagogical spaces in which emergent, multidisciplinary processes can occur in reciprocal engagement with participants. At their best, such spaces variously instantiate a diffuse set of experiences for participants and curate uniquely participatory spaces for audiences, ultimately creating art that is transformative for all involved - 
not merely "contained" in McAdam, Tarrow, and Tilly's sense (or "good” in Ledwith's), but “transgressive" as well (as discussed in Chapter 6; see McAdam, Tarrow, and Tilly 2001; Ledwith 2011).

In this sense, there is no doubt in my mind that socially engaged arts and its affiliated practices are the avant-garde of contemporary artistic practice (Bishop 2006; Kester 2011). The radical and novel approaches they bring to form and practice are changing the field of art and even the fabric of our culture. Yet even so there remain significant concerns about the on-going success and sustainability inherent in such practices, in particular in the ways artistic labour gets organized. Individual practitioners, emerging from both artistic and activist backgrounds, and from ostensibly successful practices, often indicated a prevailing "labour of love" sentiment to normalize their overwork and relative poverty. Frequently, and with few exceptions, burnout and recovery were discussed as anticipated or already experienced, and underpayment and underemployment were portrayed as inevitable. Speaking of their practices, practitioners seemed to espouse a general resistance to commodification - of both products and performances and, in particular, of their participants and communities. Nevertheless, a certain contradictory entrepreneurialism regarding their own labour seemed apparent in the ways such topics were personalized (rather than perceived as effects of structural inequalities.

It seems possible that both this resistance to commodification and this self-sacrificing commitment represent an attempt to shield minority communities and possibly vulnerable participants from exploitation by third-party organizations. While for some participants this protectionist stance may be necessary, for others it may merely be patronizing - or worse. Certainly, the kinds of strategies many practitioners sought to develop in order to bring 
participants into greater positions of influence and decision-making within organizations may signal an attempt to remedy such diffuse forms of discrimination.

That said, the inconsistent development and, occasionally, outright absence of alternative organizational structures in such purportedly cooperative aesthetic practices as these signals a crucial challenge facing socially engaged arts. Visionary organizational practices like formalized mentorship programs, in-kind partnerships with simpatico community organizations, and participant-led governance are vanishingly rare and often narrow in their focus. Artist cooperatives and participant-practitioner cooperatives are virtually non-existent, except on the periphery of such movements (even still, with the exception of the West-end Food Co-op and perhaps several daycare co-operatives, structural alternatives seem largely separate from one another). Non-profits, incorporated and unincorporated, as well as charities are instead predominant in the field. This reality suggests an experimentalism of organization that fails to mirror the field's experimentalism of form. Developing concrete strategies for better engaging participants in experimental organizational governance is beyond the scope of this dissertation, but seems to me to be a crucial imperative for future research and practice.

\section{Strategies of Expansion}

Finally, I was surprised by the ways I found the emergent character of socially engaged arts being developed. Based on my prior experience with community arts and social activism, I expected, and to some degree found, a certain emphasis on community engagement that veered towards particular norms and assumptions. I expected to find an emphasis on youth development, for example, as well as on marginalized communities (and, for the most part, I did). I further expected to find a majority of these practices taking a pedestrian or instrumental 
approach to art-making as a cultural production practice in favour of community-building as a social justice initiative. That is, I expected most practices to be slightly innovative, but also featuring a largely dehistoricized, acritical, and/or deskilled cluster of aesthetic techniques which thinly veiled a more substantive sociopolitical project responding in weakly and instrumentally aesthetic ways to particular local concerns. (This was discussed in Chapter 3 , in part, as the “craft-approach" to socially engaged arts emerging from certain traditions in community development.)

While I did indeed find (mostly anecdotal) examples of such a goal-oriented approach, in my fieldwork I found more examples where a degree of complexity and nuance transformed simple formal techniques into critical and adaptive approaches that seemed careful to consider the component aspects of the term socially engaged arts. I argued for a conception of these practices as fundamentally emergent and guided by a repertoire of pedagogical action I called strategies of expansion. It seemed necessary to me to consider and categorize this repertoire of actions in the abstract because, while they are invariably connected to specific historical, geopolitical, and sociocultural contexts and material practices, their fundamentally emergent character precedes and antecedes historical contextualization. It is true that the framing questions I proposed to describe the strategies in general terms - namely, With whom else can art be done? In what other forms? and In what other spaces? - may be historically situated as pragmatic strategies for critically engaging particular, spatially-bounded, and temporally-defined immigrant and minority communities. Yet taken as imperatives that may apply to virtually any point in the history of modernity, and any context impacted by the permeating effects of global capital, such strategies might offer a theoretical frame and practical repertoire for a wide range of workers in arts and culture. As discussed in Chapter 4, the specificity of camera arts within this repertoire 
offers unique forms and processes by which such expansive action and intervention might be elaborated and accomplished.

Perhaps most crucially, however, the framing concepts of strategies of expansion represent my attempt to theorize the profoundly political character of the aesthetic action inherent in socially engaged arts, and to contribute in more pragmatic ways to the rich theoretical discussion of the role of art in radical democracy or as radical democratic practice. Such arts are neither mere craft nor propaganda, but are sophisticated interventions at the level of culture. (Certainly more might be said here about the interrelations between art, contention, discourse, experience, hegemony, and democratic practice, particularly in relation to the work of Mouffe and Laclau, but also perhaps the more recent critical thinking of Diana Boros into public art and American public life, of Judith Green into transformative politics of difference, of Mouffe into the agonistic and interventionist roles of public art, among others - on-going research I look forward to pursuing. See Boros 2012; Green 1999; Mouffe 2008; Mouffe 2001; Laclau and Mouffe 1985) The strategies used to enact such interventions are therefore fundamentally democratic, even if they fail to outwardly resemble formal, normative democratic practices or cohere with the bureaucratic workings of mainstream political institutions.

Indeed, perhaps this very resistance to resemblance is a strength. It may be that it is precisely this mercurial character of socially engaged arts - to be democratic while not acting like that which we nominally assume to be "democracy" - that makes socially engaged arts valuable in supporting a range of progressive social movements and envisioning novel trajectories for such movements. My attention to a particular set of strategies through the specific, relatively ubiquitous medium of cameras is an attempt to anchor, in a language that 
spans both the theoretical and the material, the myriad possibilities that the radical interventions of socially engaged arts have to offer.

\section{Moving Forward: Questions and Further Research}

My experience in researching and developing this dissertation has left me with many unanswered questions. Below are several areas where, it seems to me, further research is crucial.

The first relates to the specifically visual character of socially engaged art. If the goal of a socially engaged camera art is to use cameras critically rather than instrumentally, then how might this be accomplished? Given the many situational and cultural differences between and across practices, what must be developed emergently, by trial and error? By the same token, given underlying structural conditions (such as sociopolitical and socioeconomic contexts, systematic forms of discrimination, and so on) what could be developed with some degree of uniformity and regularity across and, importantly, with other organizational practices? In this dissertation I proposed that socially engaged camera arts may help continue socially engaged arts' project of cultural expansion through several distinct strategies: namely, by expanding the vernacular, expanding what's visible, or expanding the performative in relation to participants' lived experiences. I recognize, of course, that this assertion is quite abstract. What would doing any or all of these things concretely entail? Would it mean, for example, participants visiting museums or galleries to experience exemplary work to emulate and appropriate? Would it mean organizations engaging with academic forms and methodologies of visual research to deploy in their own communities? And what must be done to ensure engagement in a distinct perceptual sense such as the visual is accessible to and inclusive for participants - both in terms of cultural differences, but also in terms of physical abilities and limitations? 
A second relates to the increasingly central role of participants in organizing. If an organization's goal is to invite or actively recruit participants into roles as "community leaders" - mentors or even practitioners - how is that labour to be recognized? When and how should remuneration occur, if at all? In an impoverished field of practice, what kinds of activism and advocacy might be done to boost state support for minimum, liveable, or other wages? What, if any, ethical or professional standards might be adopted or developed to guide who gets paid in socially engaged arts, and when? Specific to socially engaged camera arts, what might be the risks and benefits of framing work with cameras as skills development or vocational training? What, in general, are the consequences on community and cooperative practice of individual remuneration?

A third relates to tackling the ethical issues of engaging participants in research projects. In my original project proposal, I had planned to selectively interview participants. As I entered different sites to begin my field work, it became clear that there were a number of ethical and practical concerns I had not properly considered, and so I abandoned this aspect of field work. While through participant observation I feel like I developed a small, limited degree of understanding of participant motivation, clearly there is far more understanding to be developed. What criteria are key to determining whether research encounters with participants are meaningful to both parties? What research techniques - participant observation, focus groups, interviews - are most appropriate to researching participants? How is consent, including media release, to be ethically negotiated through third-party involvement (for example, through translators, social workers, community activists, or other artists or practitioners)? 
Finally, and perhaps most importantly, a fourth concern relates to doing practice-based research with minority and marginalized communities. Certainly there are structural inequalities to be rectified, such as underrepresentation of visible minorities and women in academia and associated fields. Yet it seems to me that waiting for intrepid and visionary researchers to infiltrate and radically reshape the curricula and institutions of higher education is highly problematic, and that a more grassroots and cooperative approach to structural change might more quickly and effectively reconfigure the terrain of who counts as knowledgeable in society. Moreover, there are already exemplary practices in place that pose radical challenges to how knowledge is produced, such as the cooperative and collaborative popular education practices common to socially engaged arts. Such exemplars, in addition to balancing critical and creative practice, often elaborate an ethical and ecological framework that helps determine what knowledge is socially important. I argue that attending to and cultivating the autonomous development of these practices, and the communities of which they are a part (as many socially engaged arts and camera arts practices seem fundamentally keen on doing) is a crucial way of beginning to repair the cultural devastation caused by neoliberalism and its ideological predecessors. 


\section{APPENDIX: PROFILES}

\section{Artist-Practitioner Profiles}

Miriam Ahmed was an administrator with MABELLEarts, and helped coordinate the Ladies Cooking Circle, as well as supporting on-going programming, events, and day-to-day activities.

Joshua Barndt "is a professional community-based artist and curator with a specialization in mural making, documentary video" whose practice extends beyond Toronto. Locally, he has been affiliated with Whippersnapper Gallery, an artist-run centre committed to experimental and socially-engaged practice. In addition to developing work with Alexandra Park residents, he has also collaborated with Michael Burtt and Parkdale community members at Making Room, and has created a number of murals with youth across the city. (See http://www.joshuabarndt.com/bio/.)

Michael Burtt is Artistic Director of Making Room Community Arts, and is strongly affiliated with other Jumblies-related projects and organizations, particularly MABELLEarts. (See http://making-room.org/lead-artists-past-and-present/.)

soJin Chun is head of Education and Community Outreach at Gallery 44, and has coordinated the Gallery 44's OUTREACH program over the past several years, partnering with organizations like Beat the Street, $7^{\text {th }}$ Generation Image Makers, Regent Park Focus, and SKETCH. (See http://sojincita.com/sample-page/.)

Kim Katrin Milan (Crosby) "is a queer survivor, an award-winning multidisciplinary artist, activist, consultant, facilitator and educator." She is co-founder and executive director of The People Project, which works with spectrum LGBTTQQ2SIA youth and is "committed to 
individual and community empowerment through alternative education, art activism and collaboration.” (See http://kimkatrincrosby.squarespace.com/.)

Leah Houston is Artistic Director and co-founder of MABELLEarts, and has developed community arts projects locally (with Jumblies affiliates and Clay and Paper Theatre), nationally, and internationally. (See http://mabellearts.ca/staff-board/.)

Adonis Huggins is Executive Director of Regent Park Focus Youth Media Arts Centre, and has been with the organization - and working with the community in Regent Park to encourage critical and participatory media practices - since its inception.

Nick Kozak is a freelance photojournalist whose work has been featured in Torontoist, The Toronto Star, and Maclean's. He has volunteered at Regent Park Focus and SKETCH, leading documentary photography workshops with youth participants.

Jennifer Lafontaine is a photographer, popular educator, activist, and digital storyteller. She has worked with a number of social service organizations across the city in attempts to bring arts and community media into diverse and non-traditional spaces. Since 2008, she has collaborated with Emmy Pantin on a variety of digital storytelling projects. Both have done work with the Toronto Centre for Digital Storytelling and North York Community House, and are currently developing Community Story Strategies. (See http://www.communitystorystrategies.ca/about/.)

Lloyd MacKenzie is Executive Director of the Community Centre for Media Arts (CCMA) in Hamilton, which has developed a number of social enterprise projects to support local nonprofits and services for youth in particular. CCMA under MacKenzie's direction has developed 
specific initiatives like Photovoice.ca and Studio 3 (which contributed to the development of the Urban Arts Initiative.)

Phyllis Novak is Artistic Director and Founder of SKETCH, and has been intimately involved in the organization's transformation and transition to broader practices over the past 20 years.

Emmy Pantin is a community activist, organizer, and media producer. Since 2008 she has worked with Jennifer Lafontaine on a number of digital storytelling projects. (See http://www.communitystorystrategies.ca/about/.)

Mindy Stricke is a photographer and multi-disciplinary artist. Over several years, Stricke developed the Greetings from Motherland project, collaborating with mothers and caregivers in Toronto and Madison, Wisconsin, to complete several different works in that time. (See http://www.mindystricke.com/greetingsfrommotherland; http://www.mindystricke.com/about/.)

Sean Walmsley supported Nick Kozak as he facilitated the youth photography workshop at Regent Park Focus in 2012. Walmsley was a teacher candidate at York, completing a volunteer placement at Focus.

El Whidden is a sculptor, performance, and multi-disciplinary artist. She has been commissioned by MABELLEarts to facilitate photography workshops for community participants, and is currently collaborating with community artist Maggie Hutcheson on the Department of Public Memory project. (See http://www.elinorwhidden.com/.) 


\section{Organizational Site Profiles}

Department of Public Memory is a performative community arts practice that seeks to “remember Toronto's hidden infrastructure of public services." It is a collaboration between Maggie Hutcheson and El Whidden. I helped create some publicity photos for the DoPM. (See http://departmentofpublicmemory.com/about/.)

Greetings From Motherland was a multi-year, multi-site series of collaborative and interdisciplinary community arts projects relating to the realities of motherhood. Through a series of inclusive, non-professional workshops, different cohorts of practitioners and participants in Madison, Wisconsin, and Toronto collectively produced interactive works that sought to address a range of aesthetic, cultural, and political concerns related to being a mother. (See http://www.greetingsfrommotherland.com/about/.)

Journeys to Health was an Ontario Arts Council funded pilot project coordinated by Jennifer Lafontaine and Emmy Pantin with the Four Villages Community Health Centre. It consisted of two phases, ending in 2012, and was comprised of a number of projects coordinated with Four Villages' community partners, including digital stories, a knitted map, and a photo exhibit. (See https://digitaljourneys.wordpress.com/.)

MABELLEarts is a multi-disciplinary and site-specific community arts organization located in central Etobicoke. It works with nearby residents, some of whom live in Toronto Community Housing Corporation managed properties, to develop a small park at the heart of the neighbourhood - an on-going series of projects under the title A Park of Many Paths. MABELLE began in 2007 as Pigeon Creek Collective after a residency by Jumblies Theatre, and has developed a number of recurring events, including a winter production (A Light in 
Midwinter), and Eid and Iftar celebrations, among others. MABELLE continues to collaborate with Jumblies and its other offshoots, and receives support from this family of practitioners and participants in turn. MABELLE has also supported interns from local colleges and universities (including York University’s Community Arts Practice certificate program; CAP), and has participated in other regional, national, and international projects. (See http://mabellearts.ca/about-mabellearts/.)

Making Room is a multi-disciplinary and site-specific community arts organization in a longterm residency at Parkdale Arts and Recreation Centre (PARC) in west end Toronto. While Making Room has worked with a wide range of practitioners and participants, a significant number identify as psychiatric survivors. Making Room is also affiliated with the Jumblies family of community arts organizations, and shares resources with these organizations in turn. Making Room has strong associations with York University's CAP program, as well as grassroots organizations at PARC, in Parkdale, and beyond. (See http://making-room.org/aboutus/.)

Regent Park Focus Youth Media Arts Centre is multi-disciplinary community media organization supporting marginalized and minority youth development in broadcasting and digital arts. Since its inception in 1990, Focus has engaged participants in hands-on photographic, videographic, radio, and television arts practice, including skills training in current digital technologies. Focus maintains many connections with partnering community organizations, such as York University's Faculty of Education, Pathways to Education, and so on. (See http://www.regentparkfocus.com/content/aboutus.html.) 
SKETCH is a multi-disciplinary community arts organization that seeks to engage marginalized and street-involved youth through a range of social supports and cultural activities, framed by a radical and equitable approach to youth self-sufficiency. (See http://sketch.ca/mission-andvision/.) 


\section{REFERENCES}

Alvarado, Manuel, Edward Buscombe, and Richard Collins. 2001. Representation and Photography: a Screen Education Reader. Basingstoke: Palgrave Macmillan.

Apple, Michael W. 2000. Official Knowledge: Democratic Education in a Conservative Age. 2nd ed. New York: Routledge.

Apple, Michael W. 2004. Ideology and Curriculum. 3rd ed. New York: RoutledgeFalmer.

Arendt, Hannah. 1998. The Human Condition. 2nd ed. Chicago: University of Chicago Press.

Argyris, Chris, and Donald A Schön. 1978. Organizational Learning: a Theory of Action Perspective. Reading: Addison-Wesley.

ArtBridges - ToileDesArtes. 2015. "ArtBridges - ToileDesArtes.” ArtBridges / ToileDesArts. Toronto. http://artbridges.ca/community/community_map.

Bailey, Carol A. 2008. "Public Ethnography." In Handbook of Emergent Methods, edited by Sharlene Nagy Hesse-Biber and Patricia Leavy, 265-81. Handbook of Emergent Methods. New York: The Guilford Press.

Barndt, Deborah. 1980. Education and Social Change: a Photographic Study of Peru. Kendall/Hunt Publishing Company.

Barndt, Deborah. 1991. To Change This House: Popular Education Under the Sandinistas. Toronto: Between the Lines.

Barndt, Deborah, ed. 2011. ;Viva!: Community Arts and Popular Education in the Americas. Toronto: Between the Lines.

Barndt, Deborah, Ferne Cristall, and Dian Marino. 1982. Getting There: Producing Photostories with Immigrant Women. Toronto: Between the Lines.

Barthes, Roland. 1972. Mythologies. Translated by Annette Lavers. New York: Noonday Press.

Bauman, Zygmunt. 2001. Community: Seeking Safety in an Insecure World. Cambridge: Polity.

Beeby, Dean. 2014. "CRA Denies Agency Audits Target Charities with Anti-Government Political Leanings." The National Post, August 3, Politics edition.

http://news.nationalpost.com/news/canada/cra-denies-agency-audits-target-charities-withanti-government-political-leanings.

Bell, Robyn. 2012. “An Event to Be Remembered.” Parkdale Activity and Recreation Centre. Toronto. http://parc.on.ca/an-event-to-be-remembered/.

Berland, Jody. 2000. "Nationalism and the Modernist Legacy: Dialogues with Innis." In Capital Culture: a Reader on Modernist Legacies, State Institutions, and the Value(S) of Art, edited by Jody Berland and Shelley Hornstein, 14-38. Montréal and Kingston: McGill-Queen's University Press.

Berland, Jody. 2007. "The Politics of the Exasperated." ESC: English Studies in Canada 33 (3): 24-30.

Berman, Russell, David Pan, and Paul Piccone. 1990. "The Society of the Spectacle 20 Years 
Later: a Discussion.” Telos 86: 81-102.

Bezencenet, Stevie, and Philip Corrigan, eds. 1986. Photographic Practices: Towards a Different Image. London: Comedia.

Bicket, Douglas, and Lori A Packer. 2004. “An Early 'Denial of Ekphrasis': Controversy Over the Breakout of the Visual in the Jazz Age Tabloids and the New York Times." Visual Communication 3 (3): 360-79.

Bishop, Claire. 2006. "The Social Turn: Collaboration and Its Discontents.” Artforum 44 (6): $178-83$.

Bishop, Claire. 2012. Artificial Hells: Participatory Art and the Politics of Spectatorship. London: Verso.

Bolton, Richard, ed. 1992. Culture Wars: Documents From the Recent Controversies in the Arts. New York: New Press.

Borland, Katherine. 2007. "Decolonizing Approaches to Feminist Research: the Case of Feminist Ethnography." In Handbook of Feminist Research: Theory and Praxis, edited by Sharlene Nagy Hesse-Biber, 621-27. Thousand Oaks: SAGE.

Boros, Diana. 2012. Creative Rebellion for the Twenty-First Century: the Importance of Public and Interactive Art to Political Life in America. New York: Palgrave Macmillan.

Bourriaud, Nicolas. 2002. Relational Aesthetics. Translated by Simon Pleasance and Fronza Woods. Dijon: Les presses du réel.

Braden, Su. 1978. Artists and People. London: Routledge \& Kegan Paul.

Braden, Su. 1983. Committing Photography. London: Pluto Press.

Bratich, Jack Z, Jeremy Packer, and Cameron McCarthy. 2003. "Governing the Present." In Foucault, Cultural Studies, and Governmentality, edited by Jack Z Bratich, Jeremy Packer, and Cameron McCarthy, 3-21. Foucault, Cultural Studies, and Governmentality. Albany: State University of New York Press.

Brayer, Elizabeth. 1996. George Eastman: a Biography. Baltimore: John Hopkins University Press.

Bromley, Roger. 2010. "Storying Community: Re-Imagining Regional Identities Through Public Cultural Activity." European Journal of Cultural Studies 13 (1): 9-25. doi:10.1177/1367549409352546.

Brown, Leslie, and Susan Strega, eds. 2005. Research as Resistance: Critical, Indigenous, \& Anti-Oppressive Approaches. Toronto: Canadian Scholars Press.

Burnham, Linda Frye, Steven Durland, and Maryo Gard Ewell. 2004. The CAN Report: the State of the Field of Community Cultural Development: Something New Emerges. Saxapahaw: Art in the Public Interest.

Caplan, Gerald. 2014. “As CRA Audits Charities, There's a Scandal Within a Scandal.” The Globe and Mail, November 14, Politics edition.

http://www .theglobeandmail.com/news/politics/as-cra-audits-charities-theres-a-scandalwithin-a-scandal/article21599291/. 
Chalfen, Richard. 1987. Snapshot Versions of Life. Bowling Green, Ohio: Bowling Green State University Popular Press.

Charlton, Margo, Deborah Barndt, Katherine Dennis, and Rosemary Donegan. 2013. Transforming Communities Through the Arts: a Study of Three Toronto Neighbourhoods. Toronto: Toronto Arts Foundation. http://torontoartsresearch.org/.

Charney, Leo, and Vanessa R Schwartz, eds. 1995. Cinema and the Invention of Modern Life. Berkeley: University of California Press.

Community Arts Ontario Board of Directors. 2012. "News: Community Arts Ontario Suspends Operations." ArtBridges / ToileDesArts. http://artbridges.wordpress.com/2012/10/22/news-community-arts-ontario-suspendsoperations/.

Condé, Carole, Karl Beveridge, and Bruce Barber. 2008. Condé and Beveridge: Class Works. Edited by Bruce Barber. Halifax, NS: The Press of the Nova Scotia College of Art and Design.

Crehan, Kate. 2011. Community Art: an Anthropological Perspective. Oxford: Berg.

Crenshaw, Kimberlé Williams. 1991. "Mapping the Margins: Intersectionality, Identity Politics, and Violence Against Women of Color." Stanford Law Review 43 (6). Stanford Law Review: 1241-99.

Cruikshank, Barbara. 1999. The Will to Empower: Democratic Citizens and Other Subjects. Ithaca: Cornell University Press.

Cummings, Milton C, Jr, and J Mark Davidson Schuster, eds. 1989. Who's to Pay for the Arts? New York: ACA Books.

Curtis, Edward S. 2007. The North American Indian: the Complete Portfolios. Köln; New York: Taschen.

Curtis, Edward S Brown Joseph Epes. 1972. The North American Indians: a Selection of Photographs by Edward S. Curtis. New York: [Aperture].

Day, Gail. 2010. Dialectical Passions: Negation in Postwar Art Theory. New York: Columbia University Press.

Debord, Guy. 2006. Society of the Spectacle. Translated by Ken Knabb. London: Rebel Press.

Dennett, Terry, and Jo Spence, eds. 1979. Photography/Politics: One. London: Photography Workshop.

Denning, Michael. 2011. The Cultural Front: the Laboring of American Culture in the Twentieth Century. Updated. New York: Verso.

Dewdney, Andrew. 2011. “That Was Then, This Is Now: the Legacy of Ten:8." Photographies 4 (2). Taylor \& Francis : 261-64. doi:10.1080/17540763.2011.598734.

Edwards, Steve. 1996. "Photography, Allegory, and Labor.” Art Journal 55 (2): 38-44.

Edwards, Steve. 2006a. The Making of English Photography: Allegories. University Park: Pennsylvania State University Press. 
Edwards, Steve. 2006b. "Introduction: Photography, Writing, Resentment." In The Making of English Photography: Allegories, 1-18. The Making of English Photography: Allegories. University Park: Pennsylvania State University Press.

Edwards, Steve. 2006c. Photography: a Very Short Introduction. Oxford: Oxford University Press.

Edwards, Steve. 2012. Martha Rosler: the Bowery in Two Inadequate Descriptive Systems. Cambridge: MIT Press.

Evans, Jessica, ed. 1997. The Camerawork Essays: Context and Meaning in Photography. London: Rivers Oram Press.

Ewald, Wendy. 2002. I Wanna Take Me a Picture: Teaching Photography and Writing to Children. Boston: Beacon Press.

Finkelpearl, Tom. 2013. What We Made: Conversations on Art and Social Cooperation. Durham: Duke University Press.

Forbes, Duncan. 2011. “The Worker Photography Movement in Britain, 1936-1939.” In The Worker Photography Movement (1926-1939), edited by Museo Reina Sofia, 206-17. Madrid: TF Editores.

Ford, Colin, and Karl Steinorth, eds. 1988. You Press the Button We Do the Rest: the Birth of Snapshot Photography. London: Dirk Nishen in association with the National Museum of Photography Film and Television.

Ford-Smith, Honor, and Suzanne Methot. 2001. No Frame Around It: Process and Outcome of the a Space Community Art Biennale. Edited by Melanie Fernandez. Toronto: A Space Gallery.

Freund, Gisèle. 1980. Photography \& Society. Boston: David R. Godine.

Galera, Giulia, and Carlo Borzaga. 2009. "Social Enterprise: an International Overview of Its Conceptual Evolution and Legal Implementation.” Social Enterprise Journal 5 (3): 210-28. doi:10.1108/17508610911004313.

Gallery 44. 2014. "History I Gallery 44." Gallery 44 Centre for Contemporary Photography. Toronto. https://gallery44.org/history.

Gauntlett, David. 2011. Making Is Connecting: the Social Meaning of Creativity From DIY and Knitting to Youtube and Web 2.0. London: Polity.

Goldbard, Arlene. 2003. "When (Art) Worlds Collide: Institutionalizing the Alternatives." In Alternative Art New York, 1965-1985, edited by Julie Ault, 183-200. Minneapolis: University of Minnesota Press.

Goldbard, Arlene. 2006. New Creative Community: the Art of Cultural Development. New Village Press.

Goldin, Nan. 1986. The Ballad of Sexual Dependency. New York: Aperture.

Goudge, Amy. 2011. “Take Me with You: Street Art Mentorship.” Neighbourhood Arts Network. Toronto. https://neighbourhoodarts.wordpress.com/2011/08/09/takemewithyou/. 
Gough, Maria. 2005. The Artist as Producer: Russian Constructivism in Revolution. Berkeley: University of California Press.

Graves, James Bau. 2005. Cultural Democracy: the Arts, Community, and the Public Purpose. Urbana: University of Illinois Press.

Green, Judith M. 1999. Deep Democracy: Community, Diversity, and Transformation. Lanham: Rowman \& Littlefield Publishers.

Hannavy, John, ed. 2008. Encyclopedia of Nineteenth Century Photography. New York: Routledge.

Heath, David. 2000. A Dialogue with Solitude. Toronto: Lumiere Press.

Helguera, Pablo. 2011. Education for Socially Engaged Art: a Materials and Techniques Handbook. New York: Jorge Pinto Books.

Hickey-Moody, Anna. 2013. Youth, Arts, and Education: Reassembling Subjectivity Through Affect. London: Routledge.

Holland, Patricia, Jo Spence, and Simon Watney, eds. 1986. Photography/Politics: Two. London: Comedia.

Jackson, Shannon. 2011. Social Works: Performing Art, Supporting Publics. New York: Routledge.

Jameson, Fredric. 1998. Brecht and Method. London: Verso.

Jay, Martin. 1994. Downcast Eyes. Berkeley: University of California Press.

Kay, Alan. 2006. "Social Capital, the Social Economy and Community Development." Community Development Journal 41 (2): 160-73. doi:10.1093/cdj/bsi045.

Kelly, Owen. 1984. Community, Art and the State: Storming the Citadels. London: Comedia.

Kester, Grant H. 2011. The One and the Many: Contemporary Collaborative Art in a Global Context. Durham: Duke University Press.

Klein, Mason, and Catherine Evans. 2011. The Radical Camera: New York's Photo League, 1936-1951. New Haven: Yale University Press.

Knowles, Malcolm S, Elwood F Holton III, and Richard A Swanson. 2005. The Adult Learner. 6 ed. Amsterdam: Elsevier.

Koven, Seth. 1997. “Dr. Barnardo's “Artistic Fictions”.” Radical History Review 1997 (69): 645. doi:10.1215/01636545-1997-69-6.

Laclau, Ernesto, and Chantal Mouffe. 1985. Hegemony and Socialist Strategy: Towards a Radical Democratic Politics. London: Verso.

Lambert, Joe. 2009. Digital Storytelling. 3rd ed. Berkeley: Digital Diner Press.

Lambert, Joe. 2012. Digital Storytelling: Capturing Lives, Creating Community. 4 ed. New York: Routledge.

Lasby, David M, Michael H Hall, R Mark Ventry, and Denyse Guy. 2010. "A Portrait of the Ontario Social Economy." In Researching the Social Economy, edited by Laurie Mook, Jack 
Quarter, and Sherida Ryan, 25-62. Toronto: University of Toronto Press.

Latour, Bruno. 2005. Reassembling the Social: an Introduction to Actor-Network-Theory. Oxford: Oxford University Press.

Ledwith, Margaret. 2011. Community Development: a Critical Approach. 2nd ed. Bristol: Policy Press.

Levinthal, David. 1996. Small Wonder: Worlds in a Box. Washington, D. C.: National Museum of American Art, Smithsonian Institute.

Levinthal, David. 1997. David Levinthal, Work From 1975-1996. New York: International Center of Photography.

Lewis, Mike, and Dan Swinney. 2007. "Social Economy \& Solidarity Economy." Making Waves 18 (4): 9-15.

Lincoln, Yvonna S, and Egon G. Guba. 1985. Naturalistic Inquiry. Beverly Hills: SAGE Publications.

Lindlof, Thomas R., and Bryan C. Taylor. 2011. Qualitative Communication Research Methods. Los Angeles: SAGE Publishers.

Louis, Skye, and Leah Burns. 2012. Arts \& Equity Toolkit. Toronto: Neighbourhood Arts Network.

MABELLEarts. 2015. “About.” MABELLEarts. Toronto. http://mabellearts.ca/aboutmabellearts/.

Mayworks Festival of Working People and the Arts. 2012. "About." Mayworks Festival of Working People and the Arts. Toronto. http://mayworks.ca/about/.

McAdam, Doug, Sidney Tarrow, and Charles Tilly. 2001. Dynamics of Contention. Cambridge: Cambridge University Press.

McLean, Heather E. 2014. "Cracks in the Creative City: the Contradictions of Community Arts Practice.” International Journal of Urban and Regional Research, October. doi:10.1111/1468-2427.12168.

McQuire, Scott. 1998. Visions of Modernity. London: SAGE.

Mikkonen, Juha, and Dennis Raphael. 2010. Social Determinants of Health: the Canadian Facts. Toronto: York University School of Health Policy and Management. http://www.thecanadianfacts.org/The_Canadian_Facts.pdf.

Mouffe, Chantal. 2001. "Democracy - Radical and Plural." Centre for the Study of Democracy Bulletin 9 (1): 10-13.

Mouffe, Chantal. 2008. "Art and Democracy." Open, no. 14: 6-13. http://www.skor.nl/_files/Files/OPEN14_P6-15(1).pdf.

Museo Reina Sofia, ed. 2011. The Worker Photography Movement (1926-1939). Madrid: TF Editores.

Native Indian/Inuit Photographers' Association. 1996. "History.” Native Indian/Inuit Photographers' Association (NIIPA). Hamilton. 
http://web.archive.org/web/20031123124650/http://creative-spirit.com/history1.htm.

Ontario Arts Council / Conseil des arts de l'Ontario. 2013. "List of Grant Recipients: Community and Multidisciplinary Arts Organizations." Ontario Arts Council / Conseil Des Arts De l'Ontario. Toronto.

http://www .arts.on .ca/Page5224.aspx ?DateTime=635004576000000000\&PageMode=View .

Osman, Colin, and David Englander. 1981. "The British Worker.” Edited by Colin Osman. Creative Camera, no. 197/198: 93-124.

Plummer, Ken. 1999. “The 'Ethnographic Society' at Century's End: Clarifying the Role of Public Ethnography.” Journal of Contemporary Ethnography 28 (6): 641-49.

Polletta, Francesca. 2001. “"This Is What Democracy Looks Like' a Conversation with Direct Action Network Activists David Graeber, Brooke Lehman, Jose Lugo, and Jeremy Varon." Social Politics. http://www.socsci.uci.edu/ polletta/Articles\%20and\%20Book\%20Chapters_files/This_is_w hat_demo_looks_like.pdf.

Polletta, Francesca. 2002. Freedom Is an Endless Meeting: Democracy in American Social Movements. Chicago: University of Chicago Press.

Polletta, Francesca. 2006. It Was Like a Fever: Storytelling in Protest and Politics. Chicago: University of Chicago Press.

Ribalta, Jorge. 2008. “Introduction.” In Public Photographic Spaces, 11-26. Public Photographic Spaces. Barcelona: Museu d'Art Contemporani.

Ribalta, Jorge. 2011. "Introduction.” In The Worker Photography Movement (1926-1939), edited by Museo Reina Sofia, 12-22. Madrid: TF Editores.

Roberts, John. 1998. The Art of Interruption: Realism, Photography and the Everyday. Manchester: Manchester University Press.

Roberts, John. 2008. “The Amateur's Retort.” In Amateurs, edited by Grace Kook-Anderson and Claire Fitzsimmons, 15-24. Amateurs. San Francisco: CCA Wattis Institute for Contemporary Arts.

Rosenblum, Walter, and Colin Osman. 1983. "Walter Rosenblum.” Edited by Colin Osman. Creative Camera, no. 223/224: 1019-21.

Rosler, Martha. 2004. "In, Around, and Afterthoughts (on Documentary Photography).” In Decoys and Disruptions: Selected Writings, 1975-2001, 151-206. Cambridge: MIT Press.

Ruby, Jay. 2000a. "Speaking for, Speaking About, Speaking with, or Speaking Alongside." In Picturing Culture: Explorations of Film and Anthropology, 195-219. Chicago: University of Chicago Press.

Ruby, Jay. 2000b. Picturing Culture: Explorations of Film \& Anthropology. Chicago: University of Chicago Press.

Sekula, Allan. 1981. “The Traffic in Photographs.” Art Journal 41 (1): 15. doi:10.2307/776511.

Shiff, Richard. 1989. "Phototropism (Figuring the Proper)." Studies in the History of Art 20: 161-79. 
Sholette, Gregory. 2011. Dark Matter: Art and Politics in the Age of Enterprise Culture. London: Pluto Press.

Skott-Myhre, Hans Arthur. 2008. Youth and Subculture as Creative Force: Creating New Spaces for Radical Youth Work. Toronto: University of Toronto Press.

Smith, Linda Tuhiwai. 1999. Decolonizing Methodologies: Research and Indigenous Peoples. London: Zed Books.

Sobchack, Vivian. 2004. "The Scene of the Screen: Envisioning Photographic, Cinematic, and Electronic 'Presence'." In Carnal Thoughts: Embodiment and Moving Image Culture. Berkeley: University of California Press.

Sochor, Zenovia A. 1988. Revolution and Culture: the Bogdanov-Lenin Controversy. Ithaca: Cornell University Press.

Stanley, Liz, and Sue Wise. 1993. Breaking Out Again: Feminist Ontology and Epistemology. London: Routledge.

Stricke, Mindy. 2010. “A Day in the Gardens.” Greetings From Motherland. Madison. http://www.greetingsfrommotherland.com/2010/08/a-day-in-the-gardens/.

Stricke, Mindy. 2013. "Hear, Hear." Greetings From Motherland. Toronto. http://www.greetingsfrommotherland.com/2013/10/hear-hear/.

Taylor, Diana. 2003. The Archive and the Repertoire: Performing Cultural Memory in the Americas. Durham: Duke University Press.

The VIVA! Project, ed. 2009. Jumblies Theatre/York University the "Bridge of One Hair" Project (Toronto, Canada). Vol. 11. Toronto: The VIVA! Project. https://vimeo.com/2040238.

Thompson, Nato. 2011. "Socially Engaged Contemporary Art." Animating Democracy. Americans for the Arts. http://animatingdemocracy.org/webfm_send/50.

Tilly, Charles. 1977. "Getting It Together in Burgundy, 1675-1975." Theory and Society 4 (4). Springer: 479-504.

Tilly, Charles. 2008. Contentious Performances. Cambridge: Cambridge University Press.

Toronto Arts Council. 2013. “2013 Grant Allocations.” Toronto Arts Council. Toronto. http://www.torontoartscouncil.org/content/download/3703/18197/file/2013\%20allocations\% 20list.pdf.

Trend, David. 1992a. Cultural Pedagogy: Art/Education/Politics. New York: Bergin \& Garvey.

Trend, David. 1992b. "Living in the Material World: Institutions and Economies." In Cultural Pedagogy: Art/Education/Politics, 31-49. New York: Bergin \& Garvey.

Tresch, John. 2007. "The Daguerreotype's First Frame." Studies in History and Philosophy of Science Part A 38 (2). Elsevier: 445-76.

Tsinhnahjinnie, Hulleah J. 2003. "When Is a Photograph Worth a Thousand Words?.” In Photography's Other Histories, edited by Christopher Pinney, 40-52. Durham: Duke University Press. 
Tucker, Anne. 1983. “The Photo League.” Edited by Colin Osman. Creative Camera, no. 223/224: 1013-17.

Tucker, Anne. 2011. "Modernism and the Left: Paul Strand and the Workers Film and Photo Movement." In The Worker Photography Movement (1926-1939), edited by Museo Reina Sofia, 322-33. Madrid: TF Editores.

Tuer, Dot. 2005a. "Parables of Community and Culture for a New World (Order)." In Mining the Media Archive: Essays on Art, Technology, and Cultural Resistance, 143-58. Mining the Media Archive: Essays on Art, Technology, and Cultural Resistance. Toronto: YYZ Books.

Tuer, Dot. 2005b. "Is It Still Privileged Art? the Politics of Class and Collaboration in the Art Practice of Carole Condé and Karl Beveridge." In Mining the Media Archive: Essays on Art, Technology, and Cultural Resistance, 109-25. Mining the Media Archive: Essays on Art, Technology, and Cultural Resistance. Toronto: YYZ Books.

Van Gelder, Hilde, and Jan Baetens. 2010. "Introduction: a Note on Critical Realism Today." In Critical Realism in Contemporary Art: Around Allan Sekula's Photography, edited by Jan Baetens and Hilde Van Gelder, 6-10. Leuven: Leuven University Press.

van Maanen, Hans. 2009. How to Study Art Worlds: on the Societal Functioning of Aesthetic Values. Amsterdam: Amsterdam University Press.

Vaughan, Genevieve, ed. 2007. Women and the Gift Economy. Toronto: Inanna Publications and Education Inc.

Wang, Caroline. 1999. "Photovoice: a Participatory Research Strategy Applied to Women's Health.” Journal of Women's Health 8 (2): 185-92.

Wang, Caroline, and Mary Ann Burris. 1997. "Photovoice: Concept, Methodology, and Use for Participatory Needs Assessment.” Health Education \& Behavior 24 (3): 369-87. doi:10.1177/109019819702400309.

Wang, Caroline, and Yanique A Redwood-Jones. 2001. "Photovoice Ethics: Perspectives From Flint Photovoice." Health Education \& Behavior 28 (5): 560-72.

Wang, Caroline, Susan Morrel-Samuels, Peter M. Hutchison, Lee Bell, and Robert M. Pestronk. 2004. "Flint Photovoice: Community Building Among Youths, Adults, and Policymakers." American Journal of Public Health 94 (6): 911-13.

Wang, Caroline, Wu Kun Yi, Zhan Wen Tao, and Carolyn Ellis. 1998. "Photovoice as a Participatory Health Promotion Strategy." Health Promotion International 13 (1): 75-86.

Whippersnapper Gallery. 2015. “About.” Whippersnapper Gallery. Toronto. http://whippersnapper.ca/about.html.

Wilson, Nance, Stefan Dasho, Anna C Martin, Nina Wallerstein, Caroline C Wang, and Meredith Minkler. 2007. "Engaging Young Adolescents in Social Action Through Photovoice." The Journal of Early Adolescence 27 (2): 241-61. doi:10.1177/0272431606294834.

Winogrand, Garry. 2004. The Animals. Edited by John Szarkowski. 2nd ed. New York: The Museum of Modern Art. 
Wolf, Erika. 2011. "The Soviet Union: From Worker to Proletarian Photography.” In The Worker Photography Movement (1926-1939), edited by Museo Reina Sofia, 32-46. Madrid: TF Editores.

Worth, Sol. 1981. Studying Visual Communication. Edited by Larry Gross. Philadelphia: University of Pennsylvania Press.

Worth, Sol, and John Adair. 1997. Through Navajo Eyes: an Exploration in Film Communication and Anthropology. Edited by Richard Chalfen. Albuquerque: University of New Mexico Press.

2013. "The Pathways Model.” Pathways to Education. Toronto. Accessed November 5. http://pathwaystoeducation.ca/about-us/pathways-model.

2013. "Department of Public Memory." Departmentofpublicmemory.com. Toronto. Accessed November 12. http://departmentofpublicmemory.com/. 